Hamburg University of Applied Sciences Universitat Politécnica de València

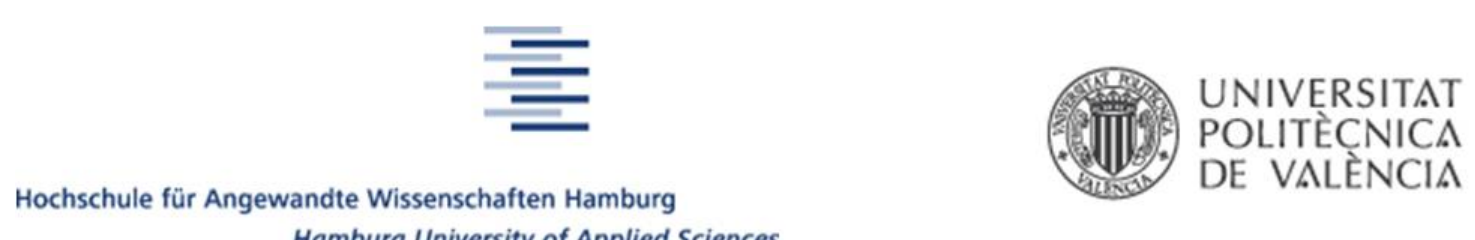

Hamburg University of Applied Sciences

Doctoral Thesis

\title{
Pattern recognition applied to chart analysis. Evidence from intraday international stock markets
}

Author:

Karolina MichniUK
Directors:

Prof. Dr. Francisco Guijarro MARTínez

Prof. Dr. Roberto E. Cervelló Royo

Supervisor:

Prof. Dr. Thomas Pfahler

A thesis submitted in fulfilment of the requirements

for the degree of Doctor of Philosophy

November 2017 


\section{Declaration of Authorship}

I, Karolina Michniuk, declare that this thesis titled, 'Pattern recognition applied to chart analysis. Evidence from intraday international stock markets' and the work presented in it are my own. I confirm that:

- This work was done predominately by myself with help from others where annotated while in candidature for a research degree at these Universities.

- Where any part of this thesis has previously been submitted for a degree or any other qualification at these Universities or any other institution, this has been clearly stated.

- Where I have consulted the published work of others, this is always clearly attributed.

- Where I have quoted from the work of others, the source is always given. With the exception of such quotations, this thesis is entirely my own work.

- I have acknowledged all main sources of help.

- Where the thesis is based on work done jointly with others, I have made clear exactly what was done by others and what I have contributed myself.

Signed:

Date: 
"A journey of a thousand miles begins with a single step."

Lao Tzu 
Hamburg University of Applied Sciences - Universitat Politécnica de València

\section{Abstract}

Faculty of Economics and Public Management

Doctor of Philosophy

\section{Pattern recognition applied to chart analysis. Evidence from intraday international stock markets}

by Karolina Michniuk

Technical analysis as a sophisticated form of forecasting technique has a varying popularity in the academic and business world. In the past, users were sceptical about technical trading rules and their performance. This is substantiated by the acceptance of the Efficient Market Hypothesis and mixed empirical findings about technical analysis in widely cited studies.

The flag pattern is seen as one of the most significant spread chart patterns amongst stock market charting analysts. The present research validates a trading rule based on the further development of flag pattern recognition. The research question concentrates on whether technical analysis applying the flag pattern can outperform international stock markets indices and prove the inefficiency of these markets. The markets observed are represented by the corresponding indices DAX (Germany), DJIA (United States) and IBEX (Spain).

The design of the trading rule presents several changes with respect to previous academic works: The wide sample used when considering intraday data, together with the configuration of some of the variables and the consideration of risk, concludes that the trading rule provides greater positive risk-adjusted returns than the buy-and-hold strategy which is used as a benchmark. The reported positive results strengthen the robustness of the conclusions reached by other researchers. 


\section{Resumen}

El análisis técnico es una forma sofisticada de técnica de predicción cuya popularidad ha ido variando en el mundo académico y de los negocios. En el pasado, los usuarios eran bastante escépticos respecto de las reglas técnicas de trading y su performance. Todo esto, se encuentra sustentado por la aceptación de la hipótesis del mercado eficiente y descubrimientos empíricos mixtos sobre el análisis técnico, que se mencionan en un número amplio de estudios.

El patrón bandera es visto como uno de los patrones gráficos más significativo y difundido entre los analistas técnicos de mercado. El presente estudio valida una regla de trading basada en el desarrollo futuro del reconocimiento gráfico del patrón bandera. La pregunta de investigación se centra en si el análisis técnico basado en el patrón bandera puede batir los índices internacionales de mercado y probar, de esta manera, la ineficiencia de dichos mercados. Los mercados observados son representados por los correspondientes índices DAX (Alemania), DJIA (Estados Unidos) e IBEX (España).

El diseño de la regla de trading presenta varios cambios y novedades con respecto a trabajos académicos previos. La amplia muestra usada al considerar los datos intradía, junto con la configuración de algunas variables y la consideración del riesgo, confirman que la regla de trading proporciona mejores, y más ajustadas al riesgo, rentabilidades positivas que la estrategia de buy-and-hold que se utiliza como referencia. Los resultados positivos corroboran la robustez de las conclusiones a las que también se llegan en otros trabajos. 


\section{Resum}

L'anàlisi tècnica és una forma sofisticada de tècnica de predicció, la popularitat de la qual ha anat variant al món acadèmic i dels negocis. En el passat, els usuaris eren bastant escèptics respecte de les regles tècniques de trading i la seva performance. Tot això, es troba sustentat per l'acceptació de la hipòtesi del mercat eficient i descobriments empírics mixts sobre l'anàlisi tècnica, que s'esmenten en un nombre ampli d'estudis.

El patró bandera és vist com un dels patrons gràfics més significatiu i difós entre els analistes tècnics de mercat. El present estudi valida una regla de trading basada en el desenvolupament futur del reconeixement gràfic del patró bandera. La pregunta de recerca se centra en si l'anàlisi tècnica basada en el patró bandera pot batre els índexs internacionals de mercat i provar, d'aquesta manera, la ineficiència d'aquests mercats. Els mercats observats són representats pels corresponents índexs DAX (Alemanya), *DJIA (Estats Units) i IBEX (Espanya).

El disseny de la regla de trading presenta diversos canvis i novetats pel que fa a treballs acadèmics previs. L'àmplia mostra usada en considerar les dades intradia, juntament amb la configuració d'algunes variables i la consideració del risc, confirmen que la regla de trading proporciona millors, i més ajustades al risc, rendibilitats positives que l'estratègia de buy-and-hold que s'utilitza com a referència. Els resultats positius corroboren la robustesa de les conclusions a les quals també s'arriben en altres treballs. 


\section{Acknowledgements}

I would like to express my special appreciation and thanks to my advisers Prof. Dr. Francisco Guijarro Martínez (UPV, València), Prof. Dr. Roberto E. Cervelló Royo (UPV, València) and Prof. Dr. Thomas Pfahler (HAW, Hamburg), you have been tremendous mentors for me. I would like to thank you for encouraging my research and for allowing me to grow as a research scientist. Your advice on both research as well as on my career have been priceless.

A special thanks to Prof. Dr. Thomas Pfahler and the monthly meetings which strongly improved the quality of my thesis and gave me a lot of inspiration and ideas. I would also like to special gratitude Prof. Dr. Francisco Guijarro Martínez and Prof. Dr. Roberto E. Cervelló Royo for all the meetings in València. These meetings were all enjoyable moments, especially your brilliant comments and suggestions.

A special thanks also to my family. Words cannot express how grateful I am to my parents for all of the sacrifices that they have made on my behalf. I would like to express my special thanks to father who has always encouraged this project and, unfortunately, is unable to enjoy these moments. Thank you for supporting me to strive towards my goal.

Last but not least, I would like to thank all of my friends who supported me and believed in me. Without your mental support this project would have been much harder to realize. 


\section{Contents}

Declaration of Authorship i

Abstract

Acknowledgements vi

List of Figures $\quad$ ix

List of Tables $\quad x$

Abbreviations $\quad$ xi

1 Introduction 1

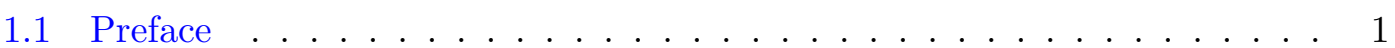

1.2 Research motivation . . . . . . . . . . . . . . . . . . 2

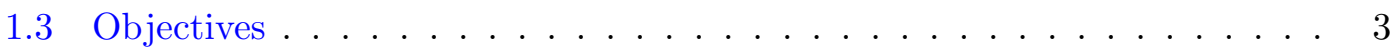

1.4 Structure of the research project . . . . . . . . . . . . . . 4

2 Theory and practice of technical analysis $\quad 6$

2.1 Technical analysis and the idea behind . . . . . . . . . . . . 6

2.1.1 Definition of technical analysis . . . . . . . . . . . . 6

2.1 .2 Technical vs. fundamental analysis . . . . . . . . . . . . 8

2.2 The Efficient Market Hypothesis . . . . . . . . . . . . . . . . . . . . . . . . . . . . . . .

2.3 Implementation of technical analysis . . . . . . . . . . . . . . . . 10

2.3.1 Technical trading rules . . . . . . . . . . . . . . . . . . 10

2.3 .2 Candlesticks . . . . . . . . . . . . . . . . . . 12

2.3 .3 The flag pattern . . . . . . . . . . . . . . . . . . . . . 14

2.4 Theoretical classification of the topic . . . . . . . . . . . . 15

2.5 Practitioner use of technical analysis: evidence from history . . . . . . . . 16

3 Literature review $\quad 18$

3.1 Classification methods of literature . . . . . . . . . . . . . . . . 18

3.2 Analysis of empirical literature . . . . . . . . . . . . . . . . . 21

3.2 .1 Pattern Recognition Studies . . . . . . . . . . . . . . . . . 21

3.2.1.1 Studies applying general chart patterns . . . . . . . . 21 
3.2.1.2 Studies applying the bull flag pattern . . . . . . . 23

3.2.1.3 Excursion: Late history of general pattern recognition . . 25

3.2 .2 Other studies . . . . . . . . . . . . . . . 26

3.2.2.1 Non-linear studies . . . . . . . . . . . . . . 26

3.2.2.2 Model-based Bootstrap studies . . . . . . . . . . . . 27

3.2.2.3 Standard Studies . . . . . . . . . . . . . . . . . . 31

3.2.2.4 Reality Check Studies . . . . . . . . . . . . . . . . . . 34

3.2.2.5 Studies without classification . . . . . . . . . . . 34

3.2 .3 Stock market anomaly studies . . . . . . . . . . . . . . . . . . . . . . . . . . 35

3.3 Initial situation for practical work . . . . . . . . . . . . . . . 39

4 Implementation of pattern recognition to chart analysis 44

4.1 Status Quo . . . . . . . . . . . . . . . . . . 44

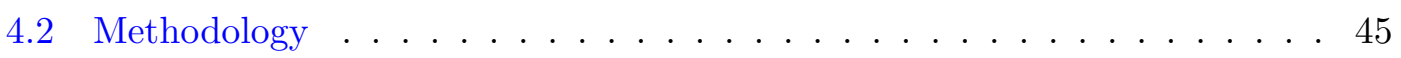

4.3 Explanation of the algorithm applied . . . . . . . . . . . . 51

4.4 Country information . . . . . . . . . . . . . . . . . 57

4.4 Germany . . . . . . . . . . . . . . . . . 57

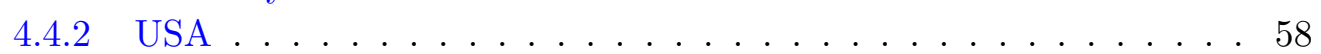

4.4 .3 Spain . . . . . . . . . . . . . . . . . . 59

4.4 .4 Final overview . . . . . . . . . . . . . . 60

4.5 Analysis of international stock markets . . . . . . . . . . . . . 61

4.5.1 Germany $(\mathrm{DAX}) \ldots \ldots \ldots \ldots 1$

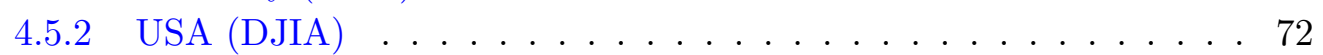

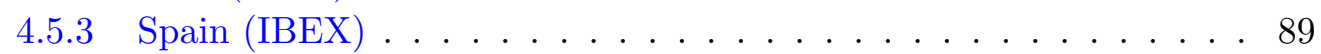

4.6 Analysis results . . . . . . . . . . . . . . . . . . . 96

4.6 .1 Germany $(\mathrm{DAX}) \ldots \ldots \ldots \ldots 6$

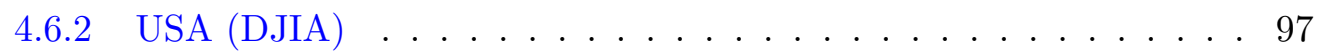

4.6 .3 Spain $(\mathrm{IBEX}) \ldots \ldots \ldots \ldots$. . . . . . . . . . . . . . . . . . . .

$\begin{array}{llr}5 & \text { Conclusions } & 99\end{array}$

$\begin{array}{ll}\text { A Technical analysis studies divided by categories } & 103\end{array}$

$\begin{array}{ll}\text { B Market anomaly studies } & 121\end{array}$

$\begin{array}{lr}\text { Bibliography } & 130\end{array}$ 


\section{List of Figures}

1.1 Structure of the research project $\ldots \ldots \ldots \ldots \ldots$

2.1 Illustration of a Japanese candlestick in rising and falling markets . . . . . 12

2.2 Representation of a stock price chart showing the bull flag stock pattern

(Leigh et al., 2008) . . . . . . . . . . . . . . . . . . . . 14

2.3 Theoretical classification of the topic . . . . . . . . . . . . 16

3.1 Literature tree of technical trading studies, 2004-2014 . . . . . . . . . 40

3.2 Literature tree of market anomaly studies, 2004-2014 . . . . . . . . . . . 42

4.1 Bull flag template (Leigh et al., 2002c) _ . . . . . . . . . . . . . . 46

4.2 Calculation process of the fit function . . . . . . . . . . 47

4.3 Examples of a bull flag template . . . . . . . . . . . . . . . . . . . . . . . . . . . . 49

4.4 Grid of weights proposed to identify a bull flag pattern . . . . . . . . . . . 49

4.5 Extract from the program code in RStudio . . . . . . . . . . . . . . . 51

4.6 Processes performed by the algorithm . . . . . . . . . . . . . 52

4.7 Extracted data file for the DAX . . . . . . . . . . . . . . . 53

4.8 Causal link between grid of weights and stop loss levels . . . . . . . . . 54

4.9 Hit Ratio: Relation between profits and losses . . . . . . . . . . . . . . . . . 55

4.10 Calculation example of the Hit Ratio . . . . . . . . . . . . . . . . 56

4.11 Japanese Candlesticks figure for the German Stock Index DAX from 12:00 a.m. to 5:15 p.m. on April 2, 2013 at time intervals of 15 minutes . . . 63

4.12 Comparison of the return curves between the obtained with one of the trading rule configurations and the obtained with the buy-and-hold strategy 71

4.13 Price series of futures over the DJIA index from 5:00 p.m. to 10:00 p.m. on June 16, 2003 at time intervals of 15 minutes . . . . . . . . . . . 74

4.14 Total return curves for five different configurations of the trading rule . . 82

4.15 Candlestick Chart of the Spanish Ibex-35, from 10:00 a.m. on August 31, 2011 until 4:15 p.m. on the same day at time intervals of 15 minutes . . . 90 


\section{List of Tables}

3.1 Number of technical trading studies by results, 2004-2014 . . . . . . . . . 40

3.2 Number of technical trading studies by analysed markets, 2004-2014 . . . 41

4.1 Overview: Demographic information of Germany, the USA and Spain . . 60

4.2 Overview: Economic information of Germany, the USA and Spain . . . . 60

4.3 Correlation between DAX, DJIA and IBEX, weekly data from January 4,2010 to November 23, 2015 . . . . . . . . . . . . . . 61

4.4 Correlation between DAX, DJIA and IBEX, daily data from January 2, 2015 to November 27, 2015 . . . . . . . . . . . . . 61

4.5 Historic lows and highs for the DAX, 2000-2015 . . . . . . . . . . . 62

4.6 Trading rule results over the DAX Index, intraday data at time intervals of 15 minutes . . . . . . . . . . . . . . . . . . 6 65

4.7 Historic lows and highs for the DJIA, 2000-2015 . . . . . . . . . . . 72

4.8 Trading rule results over the DJIA index for the whole period . . . . . . 76

4.9 Correlation matrix . . . . . . . . . . . . . . . . 83

4.10 Results of the trading rule over the DJIA index for 3 non-overlapped

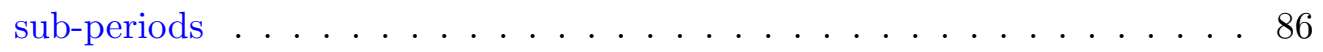

4.11 Historic lows and highs for the Ibex-35, 2000-2015 . . . . . . . . . . . 89

4.12 Results of the investment strategy on data at time intervals of 15 minutes from the Spanish Ibex-35 . . . . . . . . . . . . . . . . . . . 92

4.13 Results of the investment strategy on hourly data of the Spanish Ibex-35 . 94

A.1 General Chart Pattern Studies, 2004-2014 . . . . . . . . . . . . . . . . . 104

A.2 Bull Flag Pattern Studies, 2002-2014 . . . . . . . . . . . . . . 107

A.3 Non-linear Studies, 2004-2014 . . . . . . . . . . . . . . . . . . 111

A.4 Model-based Bootstrap Studies, 2004-2014 . . . . . . . . . . . . . . 113

A.5 Standard Studies, 2004-2014 . . . . . . . . . . . . . . . . . . 116

A.6 Reality Check Studies, 2004-2014 . . . . . . . . . . . . . . . . . 118

A.7 Studies without classification, 2004-2014 . . . . . . . . . . . 119

B.1 Market anomaly studies, 2004-2014 . . . . . . . . . . . . . . . 122 


\section{Abbreviations}

$\begin{array}{ll}\text { ATM } & \text { at-the-money } \\ \text { AR } & \text { Average of the returns } \\ \text { bp } & \text { basis point(s) } \\ \text { BUX } & \text { Budapest Stock Exchange } \\ \text { BSE } & \text { Bombay Stock Exchange } \\ \text { CAC } & \text { Cotation Assistée en Continu } \\ \text { CBOE } & \text { Chicago Board of Options Exchange } \\ \text { CMA } & \text { Capital Market Authority } \\ \text { CSE } & \text { Colombo Stock Exchange } \\ \text { CTA } & \text { Commodity Trading Advisors } \\ \text { DAX } & \text { German Stock Index } \\ \text { DJIA } & \text { Dow Jones Industrial Average } \\ \text { DM } & \text { Deutsche Mark } \\ \text { EMH } & \text { Efficient Market Hypothesis } \\ \text { eRRTS } & \text { Expanded real-time rule-based trading system } \\ \text { ETF } & \text { Exchange traded funds } \\ \text { EUR } & \text { Euro } \\ \text { FL } & \text { Filter rule } \\ \text { FTSE } & \text { Financial Times Stock Exchange } \\ \text { GARCH } & \text { Generalized Autoregressive Conditional Heteroscedasticity } \\ \text { GDP } & \text { Gross domestic product } \\ \text { HKEX } & \text { Hong Kong Stock Exchange } \\ \text { HOSE } & \text { Ho Chi Minh Stock Exchange } \\ \text { HR } & \text { Hit Ratio } \\ \text { HPQ } & \text { Hewlett-Packard } \\ \end{array}$


IBEX 35 Iberia Index 35

IBM International Business Machines Corporation

ICA Independent component analysis

INTC Intel Corporation

LM Lagrange Multiplier

MA Moving average rule

MACD Moving average convergence-divergence

MD Maximum Drawdown

ML Maximal losses

MR Maximal possible returns

MSCI Morgan Stanley Capital Index

MSFT Microsoft Corporation

N No

NASDAQ Nasdaq Composite Index

NegOps Negative operations

NYSE New York Stock Exchange

OLS Ordinary least squares

Ops Operations

ORCL Oracle Corporation

PosOps Positive operations

PX Prague Stock Exchange Index

R Price range

RSI Relative strength index

SL Stop loss

SPA Superior predictive ability

S\&P500 Standard \&Poor's 500

SSE Shanghai Stock Exchange

SVR Support vector regression

t time

TA Technical analysis

Thr Threshold fit value

TP Take profit

TR Total return 
TSE Tokyo Stock Exchange

TWI Taiwan Weighted Index

USA United States of America

U.S. United States

VAR Value at Risk

VN Vietnam Stock Market

WIG Warsaw Stock Exchange

$\mathbf{Y}$

Yes 
Dedicated to my father, †October 7, 2010. 


\section{Chapter 1}

\section{Introduction}

\section{$1.1 \quad$ Preface}

The history of stock markets began in the late 1700s in New York City. In those days, there was no clear structure how trading occurs. Usually morning and afternoon sessions took place (Hafer and Hein, 2007). In the time before computers were invented, stocks and commodities were traded by investors on intuition. Over the years, more investors showed up on the markets and consequently the processes on stock markets have changed. Finally, the volume of investing and trading on stock markets grew. As a result, the investors' interest was aroused in the methods and tools of increasing profitability and minimizing risk within their investments (Lawrence, 1997). This development was encouraged by the globalization of the economy and, especially in the wake of the global financial crisis (Esmalifalak et al., 2015). Nowadays there even exist studies about the role social media plays in stock movement predition (Nguyen et al., 2015).

Financial markets are complex systems influenced by several economical, political and psychological factors (Chourmouziadis and Chatzoglou, 2016). Dealing with the creation and exchange of financial assets, nowadays financial markets are integrated throughout the world (Chandra, 2008). In the context of investment approaches for stock markets, the concept of technical analysis is to prevail (Murphy, 1999). The most important tools of analysts are the so-called charts; consequently technical analysis is also known under the designation "charting" (Lo et al., 2000). Basically, charts graphically depict historical price trends. The main focus builds the analysis of past market developments to gain buying and selling signals (Scholl, 2014).

Technical analysis as a sophisticated form of forecasting technique and the detection of charts are popular instruments that are accepted and appreciated by stockbrokers as 
serious analytical alternatives. Their job refers to pure time series analysis by studying historical price movements up to the present aiming to predict the further price development (Jobmann, 2008).

Nevertheless, technical analysis nowadays joins different popularity in the academic and business world. On the one hand, this is reasoned in the acceptance of the Efficient Market Hypothesis (EMH), on the other hand, negative empirical findings transpired in widely cited studies about technical analysis on international stock markets (Park and Irwin, 2004).

Critics imply that if markets were efficient then all the approaches and tools that technical analysis offers are useless. The EMH states that stock market prices develop in accordance with the real economic conditions. This means that on efficient markets, price relevant new information will directly influence the price formation (Ang et al., 2011). The strictest version of the EMH suggests that insider information are already reflected in the price trend. In the long run, profits could not be generated based on this information or by means of a chart analysis. Consequently, if all information is already priced in the asset prices, efficient markets would make profits on financial markets impossible since it would be consistently impossible to beat the market. Thus, additional profits would not be realisable based on any available set of information (Murphy, 1999).

Nonetheless, analytical approaches show in practical terms that profits on financial markets are a reality. Several publications have proven the inefficiency of stock markets in the past. At this stage the EMH is questioned and a more detailed analysis is required.

\subsection{Research motivation}

As a committed investor into stocks of the German Stock Index (DAX) my interest in stock markets was already aroused many years ago. Based on a lack of deeper analytical knowledge, my investments into certain DAX stocks were mostly driven by intuition. I observed the development of return charts within a day and within the last couple of days, weeks and months. In addition to that, I read the latest news about the companies in my shortlist to get an orientation about their profitability and their possible performance potential. In fact, this approach shows some parallels to technical analysis when analysing the charts itself and fundamental analysis when considering additional information regarding a certain company. Finally, I tried to buy when the return curve went down and sell on higher levels. At the beginning of my investor's career this plan worked out very well. Even though I became a successful intraday-trader to this time, finally I ended up losing a lot of money on the German stock market. A main reason 
was not being a rational investor: I sold my entire portfolio in panic when the stock markets rapidly went down. In the end this seemed to be a good solution since the prices went down even more. But years later I regret my decision since my portfolio would have almost doubled until now. This was the moment when I felt the need to understand more about useful approaches of investing into stock markets and maybe even compensate for the loss one day.

This dissertation project gave me the chance to concentrate on international stock markets and the development of adequate investment strategies. Instead of investing on intuition, I wanted to learn more about the complex approaches which are used in the academic and business world when deciding for or against a certain investment strategy. A major focus for my thesis was the correct timing of selling and buying stocks. I wanted to understand how professional investors use several approaches to increase profitability and reduce risk within their investments and develop an own method for making profitable investment decisions.

\subsection{Objectives}

The present research builds on empirical findings of previous research following the objective to verify that technical analysis applying flag pattern is a profitable forecasting method for different international stock markets. In this context, the analyses aims to prove that the analysed international stock markets are not efficient. This objective will be predominately achieved using quantitative research, supplemented by a qualitative literature review underlining how technical analysis approaches contribute to prove the inefficiency of financial markets.

The academic research and teaching offers different methods of how to implement technical analysis. In the variety of methods, the present research project pays special attention to the flag pattern, answering the question whether selected international stock markets are efficient or not. For the sake of completeness, general chart pattern recognition and other methods not applying chart analysis will be considered likewise. To maintain the overall focus on the flag pattern, general chart patterns and other methods will be subject of discussion within the literature review only. In this context, market anomalies will be also investigated with the objective to prove that markets are inefficient.

In the course of qualitative investigations, previous technical analysis studies are in the focus of examination. This theory-driven part should create an overview of today's reputation of technical trading strategies pointing out whether technical trading rules are able to outperform a chosen benchmark and prove the inefficiency of financial markets 
in this way. In this sense, a research gap will be identified which is to be closed within the practical part of the research.

The practical part will be implemented by quantitative research. The research gap detected in the scope of literature review shall by closed by adapting initially implemented flag pattern analyses in a more appropriate way to the financial markets' environment. Thus, in the foreground of analysis is the further development and optimization of existing pattern recognition methods applying the flag pattern. In this context, returns provided by trading rules based on pattern recognition are subject to deeper discussion. Some relevant changes compared to previous studies will be realized in a way that the results, analysed as a whole, validate the flag pattern in a more consistent and robust way. All these steps shall contribute to negate the research question that the analysed international stock markets are efficient.

\subsection{Structure of the research project}

The present research project consists of five chapters and follows the structure displayed in figure 1.1:

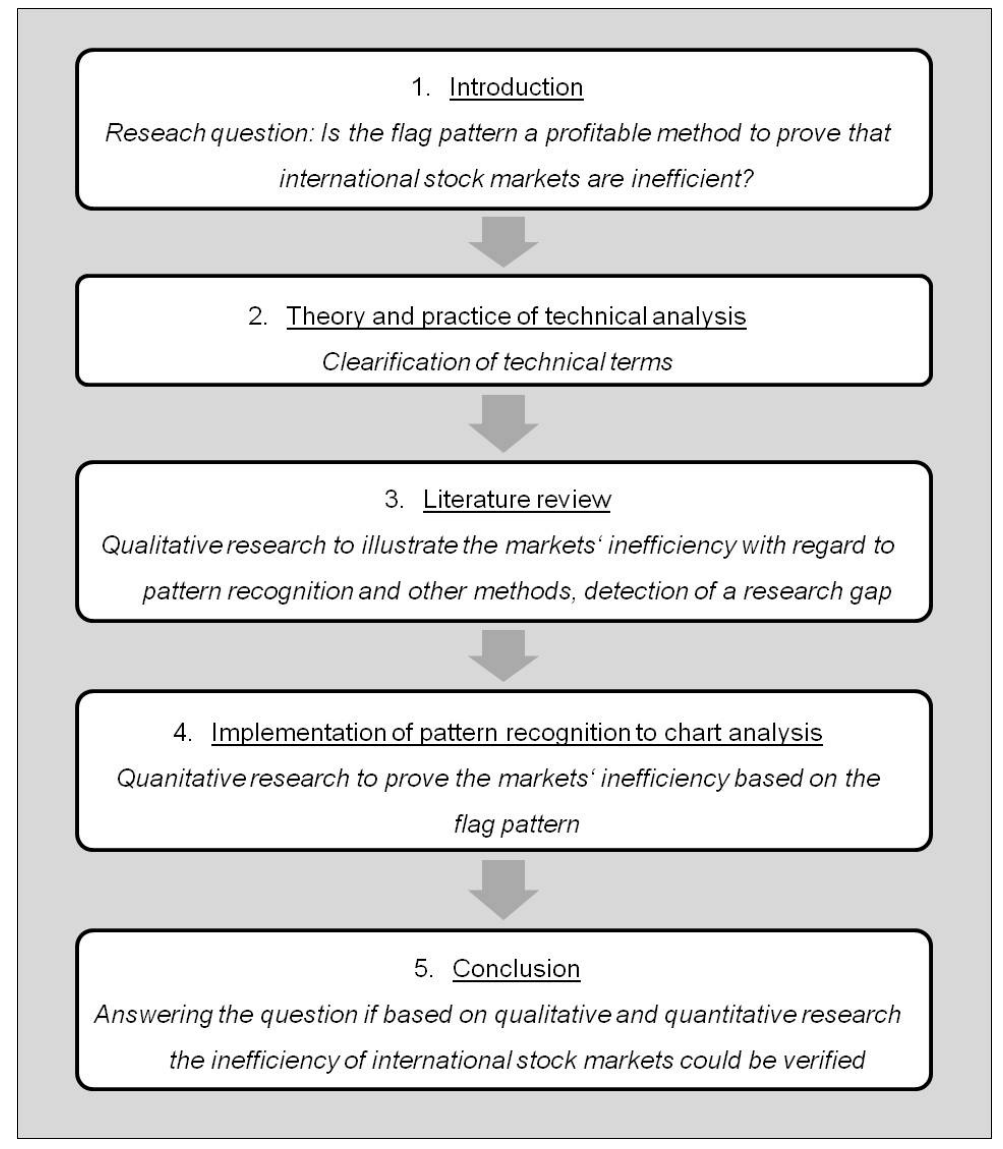

FiguRE 1.1: Structure of the research project 
After a short introduction into the topic in the first chapter, the research motivation and objectives will be presented. Further, the research question will be introduced.

The second chapter serves as theoretical background section to gain a general understanding of the topic and related areas. Here technical terms related with the topic will be explained briefly. Further, a small insight into technical analysis in practical terms will be given.

In the third chapter a literature review will be conducted. Technical analysis studies published between 2004 and 2014 will be examined with regard to the profitability of technical trading rules. The literature is selected according to its' contribution to prove whether the observed financial markets are efficient or not. For standardization purpose of results, the information found will be evaluated following a previous defined structure. The segmentation of literature occurs according to pattern recognition studies and other studies not applying pattern recognition. Additionally, studies covering market anomalies will be evaluated with regard to the statement whether markets are efficient. Finally, in this chapter a research gap is pointed out which builds the initial point of the practical part of the thesis.

The fourth chapter is determined by quantitative research. The research gap found in flag pattern studies is in the scope of analysis and is to be closed. Therefore a fit function between the price window to be evaluated and the weight matrix will be built. Moreover, a new definition of the weight matrix used for pattern recognition will be introduced where the allocation of weights is implemented in a more appropriate way. The validation process occurs in a dynamic way. This means that the strategy will be performed with a trading rule with the use of different configurations (i.e. different thresholds for stop loss (SL) and take profit (TP), different fit values) and also for different cycles (uptrend, downtrend). The use of intraday data serves evaluating the trading rule over a larger sample than ever done in previous research projects. Together with the return analysis, the practical part completes with a risk evaluation, examining if the trading rule based on the flag pattern provides greater risk-adjusted returns than the ones provided by the buy-and-hold strategy which is applied as a benchmark.

The fifth chapter summarizes the main findings focusing the research question. The results will be validated with regard to their contribution whether international stock markets are efficient or not. Further, this chapter gives an outlook for future research. 


\section{Chapter 2}

\section{Theory and practice of technical analysis}

\subsection{Technical analysis and the idea behind}

\subsubsection{Definition of technical analysis}

Technical analysis involves a financial topic with large tradition among investors and speculators in general (Edwards et al., 2012). In the 1970s, technical analysis was already wide spread and applied as instrument for investment decision making (Goodmann, 1979). Later professionals used technical analysis instruments for short-term decisions (Taylor and Allen, 1992; Dormeier, 2011).

Technical analysis can be summarized as the study of the action of the market itself. This science records price histories and tries to deduct from that pictured history the probable future trend (Edwards et al., 2012). In this context, technical analysis comprises a group of indicators, oscillators and chart patterns whose goal is to predict the financial asset's price movements from the historical information of prices, volume and/or open interests by (almost) exclusively analysing time series of past returns (Schabacker, 2005).

Technical analysis applies a variety of forecasting techniques as chart analysis, cycle analysis and computerized technical trade systems (Park and Irwin, 2004; Jobmann, 2008). Markets analysed are not only stock markets but also commodities or foreign exchange markets (Menkhoff and Schlumberger, 1995).

The idea behind technical analysis is that prices move in trends and that all relevant company data are already included in the share price. Thus, there is no need to collect data separately as in the case of the fundamental analysis (Murphy, 1999). Pring, a 
leading technical analyst, confirms: "The technical approach to investment is essentially a reflection of the idea that prices move in trends that are determined by the changing attitudes of investors toward a variety of economic, monetary, political, and psychological forces. The art of technical analysis [...] is to identify a trend reversal at a relatively early stage and ride on that trend until the weight of the evidence shows or proves that the trend has reversed" (Pring, 2002). Pring underlines within his definition that prices follow a trend and understanding and using this trend is essential for profitable investment decisions.

Shynkevich states that "technical analysis explores time-series predictability of returns, which is different from cross-sectional predictability, and it is typically used by financial market participants to predict price movement for short forecasting horizons" (Shynkevich, 2012c). It is noteworthy that Shynkevich points out that technical analysis is applicable for short term horizons and investment returns are the explicit subject of investigation.

Park and Irwin (2004) believe that "technical analysis is an important factor in determining price movement at shorter time horizons up to 6 months" (Park and Irwin, 2004). Within this definition the short term predictability is underlined again, as done by Shynkevich, and limited to a period of a maximum of 6 months.

Yamamoto states that "technical analysis involves the use of historical market data, such as price, volume, and other observables, to predict future returns in financial assets" (Yamamoto, 2012). In contrast to the previous definitions, Yamamoto does not mention the forecast horizon but underlines that historical data as price, volume, and other observables are used for future predictions. He generalises the subject of investigation to financial assets.

Further, Shynkevich states that "technical analysis encompasses a large set of techniques designed to predict future prices using historical data on price and other related observables" (Shynkevich, 2012c). This definition is close to Yamamoto's definition.

Marshall et al. (2008) follow the above direction in defining technical analysis describing technical analysis as "the use of past price movements to predict future price movements" (Marshall et al., 2008). A similar definition is offered by Leight and Purvis (2008) stating that "technical analysis uses the past dynamics of price and volume to predict future stock price" (Leigh and Purvis, 2008). Leight and Purvis give a limitation on stock markets within their definition of technical analysis.

To summarize, several definitions for technical analysis exist in the financial world. Some minor things are laid out differently but it is clear that all authors have a common understanding of technical analysis. 


\subsubsection{Technical vs. fundamental analysis}

When searching for the key word "technical analysis" in the internet search engine Google (Deutschland), 74,700,000 urls are found compared to only 16,400,000 urls for "fundamental analysis". ${ }^{1}$ This serves as good indicator for the wide acceptance and adoption of technical analysis by practitioners.

Financial market analysts can be classified as technicians or fundamentals. Consequently, the forecast based on the economic performance of a company can be distinguished from a forecast based on the last known market data. The first one is called fundamental analysis, while the second one describes technical analysis (Schwager, 2013).

Fundamental analysis deals with the selection of appropriate investment products influenced by demand and supply leading to rising, falling or constant prices (Murphy, 1999; Priermeier, 2006). In this sense, fundamental analysis examines firstly the macroeconomic changes in supply and demand (Börsenlexikon, 2015). This analysis takes into account fundamental data of a company such as profit, cash flow, cost structure, profitability, future prospects and shares of different companies in the same industry (Heese and Riedel, 2015). Based on the determined indicators, fundamental analysis compares evaluated investment alternatives (Molzahn, 2012).

Bulkowski (2013) understands fundamental analysis as a tool for what is expected in long term, while technical analysis serves for short-term decisions. Nevertheless, both tools are useful for profitable investments decisions but fundamental analysis supports the decision when selecting companies to buy and hold (Bulkowski, 2013).

In contrast to fundamental analysis, technical analysis aims to determine the right timing of investment decisions finding out the cheapest to buy and sell points in time and predicting the share's price performance or at least it's probability. Both, fundamental and technical analysis, rank among the "two main frameworks [...] while none of them is absolutely superior to the other" (Jasemi et al., 2011).

Since the present research project is focused on technical analysis, fundamental analysis will not be examined any further. At this point, reference is made to previous research.

\footnotetext{
${ }^{1}$ Both searches were conducted on December 4, 2015.
} 


\subsection{The Efficient Market Hypothesis}

The history of the Efficient Market Hypothesis (EMH) dates back to more than 100 years ago when Bachelier (1990) modelled the first stochastic process now called Brownian motion $^{2}$. His doctoral thesis is historically the first paper to use advanced mathematics in the study of finance applying the Brownian motion to evaluate stock options (Bachelier, 1990).

Bachelier suspected that stock prices follow a Brownian motion which means that stock prices are unpredictable (Kurth, 2011). Later, Kendall and Hill (1953) further developed Bachelier's idea and came to the conclusion that stock prices follow a random walk and thus cannot be predicted (Kendall and Hill, 1953). Samuelson (1965) confirmed these findings (Samuelson, 1965).

As suggested already, technical analysis has not always enjoyed a good reputation in the academic literature, mainly reasoned in its contradiction of the fundamental EMH. To understand the EMH it is essential to have a closer look at the definition of efficient markets first. Efficient markets are defined by "prices instantly reflect[ing] all available information:

- in the absence of transaction costs;

- at given costless information; and

- for homogeneous expectations" (Leigh et al., 2008).

For practical purposes, in large, modern stock markets these assumptions are regarded as fulfilled and all investors act rational (McNeel, 2005).

In his pioneering work, Fama developed the EMH assuming that the price always "fully reflects" all available information in a proper and complete way (Fama, 1970). Prices follow a random walk so past price and volume information seem to be worthless to predict future market prices. Therefore, making profits by trading on a basis of an information set is impossible since efficient markets rapidly adjust to new information (Leigh et al., 2004; Lee et al., 2009).

Consequently, the EMH can be tested by considering net profits and the risk of trading strategies based on a given information set (Jensen, 1978).

\footnotetext{
${ }^{2}$ Brownian motion describes a time continuous stochastic process which follows a normal distribution and has independent increments.
} 
According to the EMH, three forms of efficiency are known (Jensen, 1978):

\section{- Weak form of efficiency}

Information immediately reflected in price contains the past price history of the market (public information). Thus, profits could be made based on additional information which is not available to the public. This "implies that exceptions and counter-examples to the weak form also apply to the strong and semi-strong forms" (Leigh et al., 2004; Reilly and Brown, 2011). Basically, this leads to the conclusion that no relationship between past and future price exists, and price changes are independent (Lee et al., 2009).

\section{- Semi-strong form of efficiency}

Not only information found in the record of past prices, but also all public information is available and priced in the market prices. Making profits is only possible for investors who possess private information. This information can be used for profitable investment decisions (Chandra, 2008).

\section{- Strong form of efficiency}

This theory includes both the weak and the semi-strong form since public and private information as well as past price history are given. This means that all known and available information is already priced in the market price. In other words, no further profits can be made and investors are wasting their time.

Later research has not only helped to evaluate the return of different strategies based on the technical analysis, but also to question the same fundamentals of the EMH (Peters, 1994; Miller et al., 2009; Harding, 2014).

Further, negative empirical findings in several early and widely cited studies of technical analysis in the stock market are present. This also affects the reputation of technical analysis negatively.

\subsection{Implementation of technical analysis}

\subsubsection{Technical trading rules}

Nowadays technical trading occurs via technical trading systems (Carver, 2015). A trading system is a system of rules which defines the point of purchase and sale of financial assets on stock markets. As stated by Charlebois and Sapp "[a] trading rule is a systematic method for determining when to hold (0), go long $(+1)$, or go short $(-1)$ the 
asset" (Charlebois and Sapp, 2007). Thus, the trading rule generates automatic signals when to make an investment and therefore it is the heart of any trading system.

In the past several early studies have proven the efficiency of technical trading rules: Dooley and Shafer (1983) applied a simple filter rule on daily foreign exchange rates while Sweeney (1986) worked with a comparable method analysing the the German mark (Dooley and Shafer, 1983; Sweeney, 1986). Schulmeister (1987) and Taylor and Allen (1992) are also studies which support the profitability of technical trading rules tested on foreign exchange markets in earlier periods (Schulmeister, 1987; Taylor and Allen, 1992).

In one of his publications Shynkevich copes with technical trading rules as components of technical trading systems in detail. He differentiates technical trading rules by fixed or variable-length holding periods.

While a variable-length rule describes the situation when "a trader keeps an open position following a buy or sell signal until the opposite trading signal emerges", the fixedlength rule is defined by a situation where "the holding period following a signal has a fixed length and a signal occurring during the holding period is ignored" (Shynkevich, 2012c).

Further, Shynkevich describes "a variation of a trading rule [which] can impose one of two commonly applied filters to weed out presumably weak signals. One of such filters represents a fixed percentage band: a buy (sell) signal emerges if the signal-generating indicator is above (below) the pre-specified threshold by a fixed percentage. The second filter is in the form of a time delay option: it requires the signal to remain valid for a pre-specified number of days before the respective position is ultimately taken. Only one filter is imposed at a given time and a combination of the fixed-length holding period and a filter permits a neutral position" (Shynkevich, 2012c).

As illustrated, technical trading rules can be either simple or complex (Kaufman, 2013). Depending on the objective, researchers decide for or against a certain kind of trading rule. Comprehensively, trading rules serve to approximate investors' behaviour since all investors want the same two things: buying for the lowest possible price aiming to sell for the highest possible (Jankovsky, 2011). This behaviour is tried to be reflected within trading rules including thresholds since every natural investor has an individual pain threshold with regard to buying or selling an asset (Baker and Ricciardi, 2014; Copur, 2015).

Finally, another essential aspect is that trading rules make it possible to test the efficient market hypothesis (Acar and Satchell, 2002) and hence the profitability of the trading strategy itself (Ruppert, 2013). 


\subsubsection{Candlesticks}

Stock prices are solely determined by supply and demand. If the demand for buying a stock exceeds the actual supply a company offers, the price for the stock will most likely go up and, a lower demand than a needed supply will most likely lower the stock's price (North and Caes, 2011).

The financial practice offers a variety of possibilities how to graphically depict the price development of financial assets (Fontanills and Gentile, 2002). When analysing time series the analyst has the choice whether to analyse opening or closing prices, lowest or highest prices, or average prices, or the body of candlesticks. Considering candlestick bodies means including more information about the price's evolution into the analysis (Caginalp and Laurent, 1998; Barak et al., 2015).

Even though Japanese rice merchants already applied candlesticks in the 17th century, the Western countries became familiar with candlesticks not until the early 1990s (Daeubner, 2005). This was mainly reasoned in it's poor comprehensibility and translation problems. Later on several analysts analysed candlesticks in detail and made them open to a broad audience (Groffig, 2001).

Figure 2.1 illustrates two types of candlesticks (rising and falling markets) and concretes the price information included in it, defined for a line chart:

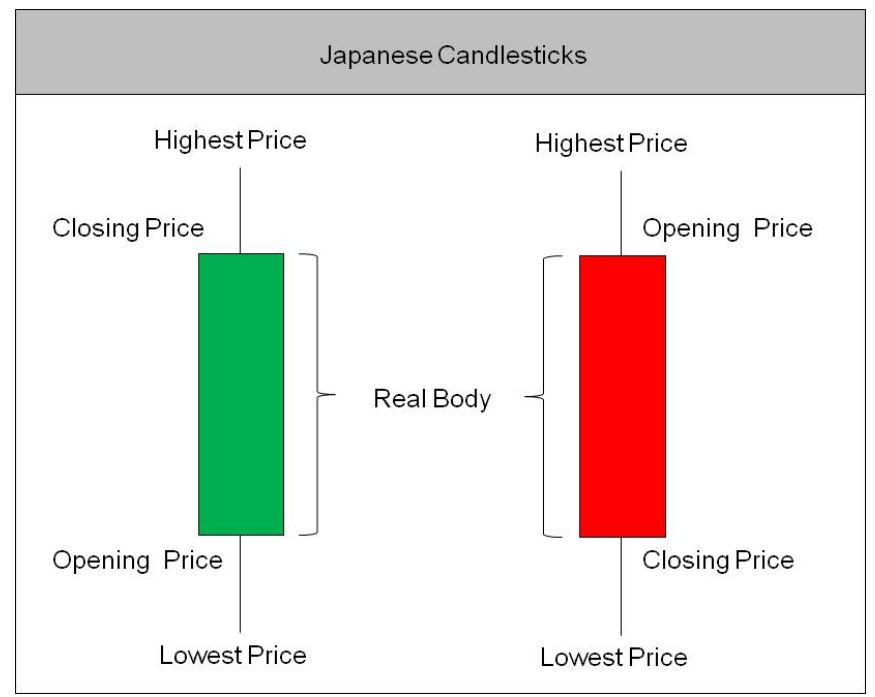

FIGURE 2.1: Illustration of a Japanese candlestick in rising and falling markets

It can be seen in figure 2.1 that besides opening and closing price information, the information about the lowest and highest price of a certain period is also displayed. On days with rising prices the opening price is expressed through the candle's ground, while the upper edge of the candle illustrates the closing price. On days when prices fall, it is opposite (Daeubner, 2005). 
While the candlestick's body edges express the opening and closing price, the wicks at each end stand for the highest and lowest price which was reached within the considered period (Fischer and Fischer, 2003). The duration of a candle stick depends on the requirements the analyst has and can last from one second to a year (Schulz, 2013).

The use of the Japanese candlesticks in charting analysis has become widespread; in fact, currently most of the trading platforms work with this kind of representation. Depending on whether the opening or closing price is higher and thus, whether the prices have risen or fallen, the candle stick body has a different color. Black and white or red and green are popular color pairs to illustrate an up- or downward trend: In a rising market the candlestick body is often white or green, while for days with falling rates black or red is used (Horton, 2009).

Caginalp and Laurent (1998) describe the advantages of using of candlesticks as follows:

- "The definitions tend to be more precise than in the longer patterns.

- The time intervals are fixed, facilitating statistical tests.

- The method has been in use for many years so that it confronts directly the issue of whether a simple method will self-destruct in a short time due to overuse" (Caginalp and Laurent, 1998).

Further advantages can be summarized as:

- Candlesticks and their unique structure are easy to understand what makes them a convincing and easily managed trading technique (Fischer and Fischer, 2003).

- Candlesticks indicate an earlier market change as bars or other illustrations. Thus, candlesticks optimize the timing of any investment decision.

- Finally, the perspective of candlesticks opens further information for analysis purpose (Nison, 2015).

Besides the advantages mentioned above, a quick visual observation and the comprehensive statements included in candlesticks, the candlestick theory also has disadvantages. Some traders see a disadvantage that a clear identification of the opening and closing price compared to the bar charts with entry and exit is not always given although the candlestick is clearly defined by the body. Another disadvantage may arise from the significant amount of misinterpretations of the candlesticks that have occurred by analysts in the past. Further, a long term chart appears more complicated when displaying it as a candlestick chart since individual candles can not be clearly identified (Horton, 2009). 
In practical terms, other price representations exist. Not only Japanese candlesticks but also bar charts, line charts etc. are applied to illustrate price movements. Nevertheless, the present doctoral thesis does not apply any other price representation. For further information, reference is made to existing literature (Kamich, 2009).

\subsubsection{The flag pattern}

"A line that is in fluctuation over a period will represent a struggle between buyers and sellers. The result is a pattern that, in its completed form, can resemble recognized shapes [...]. On this basis it is named and categorized" (Davidson, 2011).

Chart analysis offers a variety of patterns to work with. Wedges, bottoms, triangles, channels and flags are only some of them which are applied by professionals in practical terms (Jiler, 2003; Bulkowski, 2011).

The focus of the present research project is the flag pattern. Flags are "easy to spot, very profitable and sport excellent risk/reward characteristics" (Robbins, 2012). Depending on whether prices on markets are rising or falling, there are two types of flags: In an uptrend the bull flag forms after a drop in price while in a downtrend a bear flag appears and is virtually a mirror of a bull flag (Furgang, 2010; Tarr, 2014).

Generally, in instructional articles and books about technical analysis an occurrence of a flag, a strong type of stock chart pattern, is illustrated as done in figure 2.2:

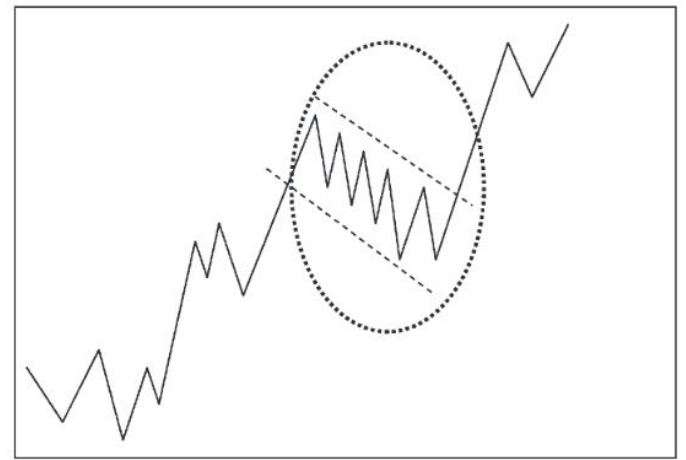

Figure 2.2: Representation of a stock price chart showing the bull flag stock pattern (Leigh et al., 2008)

For identifying a flag a strong up- or downward move in the first place is required. This is the entire basis for the flag pattern (Knight, 2011).

A bull flag pattern can be interpreted as a "strong upward price trend being interrupted by a period during which investors "consolidate their gains" before a strong positive bullish breakout occurs and the upward price trend resumes. After the bullish breakout, the price is expected to continue in the upward direction" (Leigh et al., 2008). 
In Downes and Goodman a more general definition of the shape of the flag pattern can be found: "Technical chart pattern resembling a flag shaped like a parallelogram with masts on either side, showing a consolidation within a trend. It results from price fluctuations within a narrow range, both preceded and followed by sharp rises or declines" (Downes and Goodman, 1998). Therefore, it is a situation in which price suffers an abrupt movement, up or down according to the bull flag or bear flag pattern, respectively; after this movement, price will stabilize inside a range during a determined period of time, until it again suffers a strong movement in the same direction as the initial one.

The general implications of flag patterns are the same on long and short term. But the investor should be cautious that a pattern which seems to be a flag on the longterm could be "a reversal pattern rather than a consolidation for another move ahead" (Kamich, 2009). Nonetheless, flags are short-term trading patterns. Markets are moving fast and flag patterns are the shortest of duration. Typically they occupy two to seven days of trading activity (Robbins, 2012). The longest period of a flag is just a few weeks (Knight, 2011).

\subsection{Theoretical classification of the topic}

In principle, the chosen approach for this work belongs to the area of financial analysis. Generally spoken, financial analysis deals with the "selection, evaluation, and interpretation of financial data and other pertinent information to assist in evaluating the operating performance and financial condition of a company" (Drake and Fabozzi, 2012).

Financial analysis aims to optimize profit and efficiency while reducing risk. In case of problems a contemporary identification of corresponding problem areas is essential and corrective action needed (Shim and Siegel, 2007).

Within the last decades the methods of financial analysis made progress. While in the 50 s and 60 s the analysis of a stock's intrinsic value applying fundamental analysis was wide spread, in the 70s investors used computer-based approaches of technical analysis. Later on the behavioural finance approach was detected as innovative method of financial analysis (Holtfort, 2013).

Following Rehkugler's and Poddig's definition, financial analysis basically deals with the allocation of (meaningful) guidelines for action of inference to a set of states in situations (Rehkugler and Poddig, 1994). 
In the context of the present research project, a possible guideline for action could be to buy, hold or sell an asset. The selection of a corresponding action would directly depend on situations on financial markets defined by the states of certain economic variables such as interest rates, orders, etc:

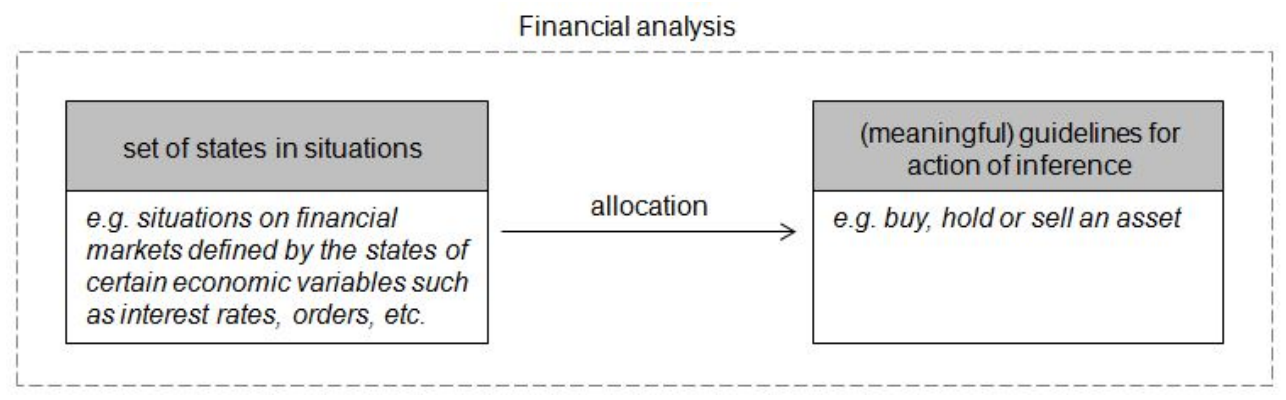

Figure 2.3: Theoretical classification of the topic

According to the method applied in the present research project, recognizing a flag pattern would describe the set of state in situations. Depending on whether a bullish or bearish flag is identified, the guideline for action of inference would be to buy or sell the asset at previously defined take profit (TP) or stop loss (SL) levels. Since identifying a flag pattern does not occur daily and an occurrence probability of about once a month is more likely, the need of a huge data base is indispensable.

Chapter 3.1 copes in detail how different methods in the area of technical analysis can be categorized. Further, information about the bull flag template and the method applied will be given in detail.

\subsection{Practitioner use of technical analysis: evidence from history}

After analysing the history and the actual meaning of financial analysis, at this stage of research the question arises whether technical analysis is only a tool of academic research or if technical analysis is accepted and adopted by practitioners (Dormeier, 2011). This section serves as an indication how technical analysis was seen so far in practical terms in the past.

Taylor and Allen (1992) conducted surveys of firms dealing with foreign exchange trading. Within their results the authors show that more than $90 \%$ of firms which were interviewed use some form of technical analysis, at least in determining their short-term investment strategies in the foreign exchange markets. Their work gives evidence that technical analysis supports investment decision making in firms as well and is not just accepted by academics (Taylor and Allen, 1992). 
Lui and Mole (1998) conducted a survey in Hong Kong, publishing their results in 1998, stating that technical analysis is almost twice as important as fundamental analysis for short term investments. Thus, technical analysis is associated positively in short term decision making of companies located in Hong Kong (Lui and Mole, 1998).

Cheung and Chinn (2001) published their survey of U.S.-based foreign exchange traders in 2001. When asked what their trading practices were, the most popular answer (with almost $30 \%$ of respondents) was "technical analysis". As illustrated, technical analysis joins a good reputation in the U.S. foreign exchange market as well (Cheung and Chinn, 2001).

Park and Irwin resulted in 2004 that "technical analysis has been widely used by market participants in futures markets and foreign exchange markets, and that about $30 \%$ to $40 \%$ of practitioners" use technical analysis for short term forecasts. Park and Irwin's work also contributes in a positive way to the acceptance of technical analysis, in futures and foreign exchange markets likewise (Park and Irwin, 2004).

To summarize, these few contributions illustrate that technical analysis is not just an instrument of the academic world but serves also as a practical tool in the business world. It is important to mention that the authors underline the short term predictability covered by technical analysis and pay attention to different markets. 


\section{Chapter 3}

\section{Literature review}

\subsection{Classification methods of literature}

When the level of investing in stocks and other financial assets grew, tools and methods for optimizing investment strategies awoke the interest of investors. Automatically, the amount of published scientific papers covering this topic rose. Classifying empirical literature by different methods has overview character and contributes to pointing out the corresponding research gap.

This section deals with possibilities of how to classify or cluster literature about technical analysis in a plausible way. After a theoretical analysis, the most adequate classification will be implemented on the researched literature to give the literature review a corresponding structure. The chapter closes by demonstrating the research gap which serves as the starting point for the practical part of the present research project.

Lawrence (1997) categorized the available methods into technical analysis, fundamental analysis, traditional methods of times series prediction, chaos theory and computational techniques:

- Technical analysis is a forecasting method to predict price movements using past prices, volume and/or open interest (Park and Irwin, 2004). Technical analysis assumes that prices move in trends and history repeats which serves to determine future stock prices by examining past prices. $90 \%$ of the major stock traders use this approach.

- Fundamental analysis focuses on a company's performance and profitability to predict future stock prices. In this context the intrinsic value of shares is determined which serves as a criterion to compare different companies. 
- Traditional methods of times series prediction include univariate or multivariate types of time series forecasting. The analysis of past data is projected to estimate future data using one or more variables within non-linear functions.

- Chaos theory combines a deterministic and a random process modelling nonlinear dynamic systems as stock markets. Chaos theory contradicts the EMH since it assumes that stock markets are not simply random but chaotic.

- Computational techniques include a broad range from charting programs to sophisticated expert systems. Expert systems incorporate trading rules and can be used for example in combination with neural networks.

Lawrence underlines that all these approaches have advantages and disadvantages. Nevertheless all of them follow the common goal which is to predict future market movements from past information (Lawrence, 1997).

Later, Park and Irwin conducted an intense examination of technical analysis studies and categorized empirical literature which they published (Park and Irwin, 2007):

\section{- Early studies (1960-1987)}

Technical trading systems as filters, stop-loss orders, moving averages, channels and relative strength are analysed within early studies. Their main limitations are a small number of considered trading systems on the one hand, and not conducting statistical tests of significance on technical trading returns on the other hand. As stated by the authors, early studies indicate that technical trading strategies are profitable in foreign exchange markets and futures markets but not in stock markets.

- Modern studies (1988-present)

Modern studies aim to improve aspects which were originally criticized within the early studies. Thus, modern studies represent an advancement of early studies in terms of testing procedures. There are still considerable differences with regard to treatment of transaction costs, risk parameter optimization, out-of-sample tests, statistical tests and data snooping.

As stated by Park and Irwin, modern studies indicate that technical trading strategies consistently generated economic profits in various speculative markets at least until the early 1990s. Their analysis covers 95 modern studies. Of these studies, 56 obtained 
positive results, 20 studies delivered negative and 19 studies mixed results (Park and Irwin, 2007).

By having a closer look at modern studies, Park and Irwin differentiate seven groups of modern studies based on differences in the testing procedure: chart patterns, standard, model-based bootstrap, reality check, (genetic programming) ${ }^{1}$, non-linear, and others (Park and Irwin, 2007):

- Chart pattern studies refer to studies that develop and apply algorithms for chart patterns. Jain et al. (2000) pointed out that pattern recognition is to be understood as the study about how machines can observe the environment, learn to distinguish patterns of interest from their background, and make sound and reasonable decisions about the categories of the patterns (Jain et al., 2000).

- Standard studies consider transaction costs and risk within the testing procedures. Further, trading systems using optimized trading rules are applied (parameter optimization). To adapt to actual traders' behaviour as well as partially addressing data snooping problems, a specific performance criterion and out-ofsample tests are conducted (Jensen, 1967; Taylor, 1986).

Parameter-optimization and out-of-sample verification describe the major improvements over early studies since they are closer to investors' behaviour and may partially address data snooping problems (Park and Irwin, 2004).

- Model-based bootstrap studies typically focus on analysing part or all of the trading rules (Brock et al., 1992). In general, model-based bootstrap studies conduct statistical tests for trading returns using the model-based bootstrap approach to test statistical significance of trading profits (Park and Irwin, 2004).

- Reality check indicates studies that attempt to solve data snooping problems using White's bootstrap reality check methodology. It is applied on data snooping bias associated with an in-sample search for profitable trading rules (Park and Irwin, 2007).

- Non-linear studies indicate studies that apply non-linear methods (e.g. feedforward neural networks or nearest neighbour regressions) to recognize patterns in prices or estimate the profitability of technical trading rules.

\footnotetext{
${ }^{1}$ Genetic programming is not in the research scope.
} 
- The category "other studies" covers all studies which do not fit into any of the previous categories.

Zapranis and Tsinaslanidis (2012) use another classification method of technical analysis tools: "firstly into technical indicators, such as relative strength index (RSI), moving average convergence-divergence (MACD) and moving average crossovers, and secondly into charting patterns such as head-and shoulders, cup-with-handle, saucers, and flags" (Zapranis and Tsinaslanidis, 2012).

Inspired by the previously introduced classification methods of scientific literature, the present research categorizes modern studies of the past decade until present into two main groups: pattern recognition studies (differentiating studies covering general patterns and flag patterns) and other studies. The considered studies will be grouped based on differences in their testing procedure. Additionally, studies about market anomalies will be evaluated regarding their contribution to reject the EMH.

The later history is generally not in the research scope. Special attention will be paid to pattern recognition studies, so as an exception, the later history of these studies is also considered within this section. Further, three flag pattern studies publicised in 2002 will also be considered. In all other cases, reference is made to the intense research already done in the past.

\subsection{Analysis of empirical literature}

\subsubsection{Pattern Recognition Studies}

\subsubsection{Studies applying general chart patterns}

One of the first studies in the area of technical analysis was written in the 18th century, after the Japanese developed a candlestick charting technique. In the West, this technique was not introduced until the 1970s (Nison, 1991).

Charlebois and Sapp (2007) analysed the largest financial market in the world - the foreign exchange market. Inspired by studies done before 1995, where the weak-form market efficiency was rejected, the authors concentrate on options, and more specifically open interest on options on the U.S.\$/DM exchange market from 1988 to 1999. Charlebois and Sapp apply commonly used strategies based on historical spot exchange rates (past prices) as a benchmark. They come to the conclusion that the "foreign exchange market, and especially the series of U.S.\$/DM, does not appear to be as efficient 
as the theory would suggest, not so much because of historical spot rates but rather because of another source of information, the option market". Finally, their results show that overall the strategies using information from at-the-money (ATM) options outperformed every other series. Thus, "technical analysts would benefit from incorporating the differential in open interest for ATM options into their strategies". The robustness of results was strengthened by out-of-sample tests (Charlebois and Sapp, 2007).

In 2009, Horton published his examination about the profitability of stars, crows, and doji on stock markets. Even though he examines 349 stocks of the S\&P500 in 1992, he comes to the conclusion that the analysed candlestick charting methods are not suitable for trading individual stocks and finds only little value in the use of candlesticks. His examination supports the weak form of the EMH implying "that past price information for a stock is of no value in predicting future movements of the stock's returns". Horton shows that investment decisions based on stars, crows and doji are not recommended and therefore is of no value in trading individual stocks. Nevertheless, it is worth mentioning that Horton's study only covers the investigation of four of the bull market signals and four of the bear market signals, analysing a short period in 1992 (Horton, 2009).

In 2009, Wang and Chan analysed tech stocks traded in the U.S., including Microsoft (MSFT), IBM, Intel (INTC), Oracle (ORCL), DELL, APPLE (AAPL) and HewlettPackard (HPQ). They apply a template grid concentrating on two kinds of charting patterns, rounding top and saucer, and pay special attention to explain how to format weight values of the template grid. The sample period covers daily returns in the time from the date the stock is listed in the stock exchange to September 24, 2007. Transaction costs are considered with $1 \%$. Further, the authors implement two different trading rules by capturing price reversal trends. While trading rule A serves to find numerous filter rules with stable profits using NASDAQ index data, trading rule B represents a further employment of these filter rules to examine the profit potential for the tech stocks with the largest market cap in the U.S. Within their results, Wang and Chan illustrate that trading rule $\mathrm{B}$ exactly predicts the stock price movements and thus, generates higher returns than buying every day over the sample period (Wang and Chan, 2009).

Zapranis and Tsinaslanidis (2012) analysed a novel rule-based mechanism for the identification of rounding bottoms pattern using the same U.S. tech stocks as done by Wang and Chan (2009): MSFT, IBM, INTC, ORCL, DELL, AAPL and HPQ. The sample period is also the same but the authors do not consider transaction costs. To ensure that statistical significance of positive excess returns is taken into account, "the comparison between the mean market return and the mean trading rule return is managed by a two-sample, one-tailed, unequal variance (heteroscedastic) Students t-test". Overall the 
authors received positive results for short term horizons. "The rule-based mechanism proposed in [their] study can be seen as an expert system in order to test the predictive power of technical analysis and thus test the weak-form efficiency of various financial markets". The authors do not apply a template matching technique as done by Wang and Chan in 2009 (Zapranis and Tsinaslanidis, 2012).

Finally, three of four presented studies proved market inefficiency and showed positive results. Only one study gained negative results.

\subsubsection{Studies applying the bull flag pattern}

The bull flag pattern is in the focus of the present research. At this point, five studies working with the bull flag template will be introduced regardless of their publication date. All of the studies obtained positive results.

Leigh, Modani et al. (2002), Leigh, Paz et al. (2002), Leigh, Purvis et al. (2002) and Wang and Chan (2007) implemented a variation of the bull flag stock chart using a template matching technique based on pattern recognition (Leigh et al., 2002c; Leigh et al., 2002b; Leigh et al., 2002a; Wang and Chan, 2007).

Leigh, Modani et al. (2002) and Leigh, Paz et al. (2002) illustrated that bull flag patterns generate positive excess returns (before transaction costs) for the NYSE Composite Index over a buy-and-hold strategy (Leigh et al., 2002c; Leigh et al., 2002b).

Leigh, Paz et al. (2002) test the bull flag charting heuristic for trading the NYSE Composite Index for 4,817 trading days in a test period from 1980 to 1999 applying various time horizons. They implement a 10x10 grid with weights ranging from -2 to +4 . Statistical results fail to confirm the null hypothesis that the markets are efficient respectively to the weak form of the EMH. The results are supplied for a long time period. Parameter optimization and out-of-sample tests are conducted and data snooping problems addressed. This publication supports the statement that the analysed stock market is inefficient (Leigh et al., 2002b).

Leigh, Purvis et al. (2002) conduct four experiments combining pattern recognition, neural network, and genetic algorithm techniques to forecast price changes for the NYSE Composite Index. The first experiment focuses on recognizing the flag pattern and underlies the same methodology as applied by Leigh, Paz et al. (2002). The authors use a 10x10 grid with weights ranging from -2.5 to +1.0 in the cells for the period from January 1, 1981 to December 31, 1996. Within their experiments Leigh, Purvis et al. detect the decision support potential of the new soft computing tools, the application of multiple tools and the power in multiple classifier systems. The results of their work 
support the effectiveness of the technical analysis approach through use of the bull flag price and volume pattern heuristics. Thus, their publication is also seen as a positive contribution to prove the inefficiency of financial markets (Leigh et al., 2002a).

Leigh, Modani et al. (2004) examined daily data of the NYSE Composite Index applying a variation of the bull flag stock charting heuristic. The authors used a template matching technique from pattern recognition covering the period from January 28, 1981 to September, 15, 1999 (4,697 trading days). The authors use a 10x10 grid with weights ranging from -2 to +4 . Further, they use a 120 -trading-day history of price and volume to forecast price movement at horizons from 20 to 100 trading days and work with fit values applying conditional trading rules ("filter rules"). Such a trading rule could be for example: "If the fit value for a trading day exceeds a set value AND the price change during the period of the window has been positive (negative), then buy on that trading day, hold for some number of days, and then sell". The authors obtained positive results pointing out that the method applied has some forecasting power. Nevertheless, Leigh, Modani et al. indicate that future research is needed to strengthen the results (Leigh et al., 2004).

Leigh, Modani et al. (2004) compared the returns of the trading rule with the benchmarks (buy-and-hold or random-selection trading strategy) and obtained positive results, especially for longer forecast horizons. Due to increasingly moot transaction costs thanks to costfree 401(k) transfers and extremely low fixed cost trades reasoned in negotiated commission rates since 1975, the authors do not consider transaction costs within their analysis. Risk adjustment when working with the NYSE Composite Index, a broadbased market average, is seen as unnecessary by the authors and the "beta coefficient" of the index (the portfolio) is defined as 1 (systematic risk). To validate the results, Leigh, Modani et al. apply a two-sample, one-tailed, unequal variance (heteroscedastic) Student's t-test and several back-tests within different periods (Leigh et al., 2004).

Another study about pattern recognition which obtained positive results is Wang and Chan's (2007). Wang and Chan analysed the potential profit of bull flag technical trading rules for the NASDAQ Composite Index and the Taiwan Weighted Index (TWI). The authors find out that bull flag technical trading rules using a template matching technique are more profitable than buying every day for the study period. The study period covers daily returns in the time from 1985 to 2004 for the NASDAQ and from 1971 to 2004 for the TWI. All technical trading rules correctly predict the direction of changes in the NASDAQ and TWI. Thus, this study supports the inefficiency of financial markets since additional profits were realisable (Wang and Chan, 2007). 


\subsubsection{Excursion: Late history of general pattern recognition}

The main scope of research is set on publications of the last decade. Studies published before are defined as later history. Since pattern recognition is generally the main strategy used in the present research project, and studies about pattern recognition applied to chart analysis were already conducted long time before, this section serves as an overview to what has been done previously on pattern recognition.

Caginalp and Laurent (1998) conduct a study about S\&P500 stocks from 1992 to 1996. By performing a statistical test of the predictive capability of candlestick patterns, the authors find out that candlestick reversal patterns generate substantial profits in stock markets compared to a buy-and-hold strategy. In 1998, their publication was the first scientific test which provided strong evidence in favour of any trading rule or pattern on a large unrestricted scale. Out-of-sample tests support the strong predictive power of this approach proving that financial markets are inefficient (Caginalp and Laurent, 1998).

Another example for a rigorous study of chart pattern is Chang and Osler's (1999). Chang and Osler analyse six foreign exchange markets using daily spot rates evaluating the performance of head-and-shoulders patterns from 1973 to 1994. The authors program an algorithm for head-and-shoulders identification and implement a buy-and-hold strategy. The study shows that simple technical trading rules generate substantially higher returns than the head-and-shoulders rules in case of all six foreign exchange rates (Chang and Osler, 1999).

Lo et al. (2000) test the usefulness of ten chart patterns on a large number of NYSE/AMEX and NASDAQ stocks from 1962 to 1996. Applying smoothing techniques such as non-parametric kernel regression, their methods suggest that technical analysis can be improved by using automated algorithms. Further the authors detected that traditional patterns such as head-and-shoulders and rectangles do not have to be optimal. Lo et al. obtain positive results and conclude that technical analysis can add value to the investment process (Lo et al., 2000).

Negative results with regard to the profitability of pattern recognition were obtained by Curcio et al. (1997), Guillaume (2000) and Lucke (2003). Their main focus was set on foreign exchange markets. 


\subsubsection{Other studies}

\subsubsection{Non-linear studies}

In 2004, Lam published his examination of 16 financial statement variables (financial data of $364 \mathrm{~S} \& \mathrm{P}$ companies) and 11 macroeconomic variables covering the time from 1985 to 1995. Lam compared the performance of neural networks (specifically, the backpropagation algorithm) with the average return from the top one-third returns in the market (maximum benchmark) and with the overall market average return (minimum benchmark). In this matter, he approximates perfect information whilst using a highly diversified market. The statistical significance of mean differences is considered by applying paired t-tests, while neural networks are trained with a rule extraction technique of how to implement symbolic classification rules (Lam, 2004).

Lam considered single or multiple-year financial statement data. He determined that the ability of neural networks to integrate fundamental and technical analysis outperforms the minimum benchmark. This indicates the forecast ability of neural networks on a highly diversified investment strategy. Nevertheless, the results do not outperform the maximum benchmark. Thus, these findings are categorized as mixed results (Lam, 2004).

Kamo and Dagli (2009) investigated two hybrid stock market forecasting models. With the first model the authors implement a committee machine with simple generalized regression neural networks experts and a gating network. The model contains Japanese candlestick patterns' features in the gating network as a key element of mediation. The second model differs from the first in the way that a similar committee machine has a hybrid type gating network being controlled by fuzzy logic. Thus, the second model applies fuzzy logic to recognize the candlestick patterns and stock market conditions. Kamo and Dagli use stock market data obtained from Hewlett-Packard, Bank of America, Ford, DuPont, and Yahoo for the period from 2001 to 2007. They illustrate within their results that fuzzy logic improves forecasting results whilst also being able to define candlestick patterns. The authors give further advice for future research within their study, such as a recommended adjustment of types of membership functions and numbers of membership functions (Kamo and Dagli, 2009).

Yang et al. (2010) presented a study about analysing 18 international stock index ETFs from 1996-2006 for developed markets and from 1999 to 2006 for emerging markets. The authors obtain mixed results since they find evidence on predictability for six of 18 ETFs. They apply data-snooping bias using Whites Reality Check and conduct out-of-sample tests (Yang et al., 2010). 
Jasemi et al. (2011) applied a non-linear method using feed-forward neural network and the technical analysis of Japanese Candlestick. Using two approaches (raw data-based and signal-based with fifteen and twenty-four variables), they analysed daily data of General Motors stocks in NYSE from 2000 to 2004 and obtain positive results. The first approach performs even better than the second one (Jasemi et al., 2011).

Besides positive evidential studies, some authors also point out critical aspects of nonlinear studies:

Lam (2004) underlined that hybrid analytical tools are critical for decision support systems to deliver results. Nevertheless, his examination shows positive evidence that next generation support systems perform well by combining fundamental and technical analysis in the same model (Lam, 2004).

Jasemi et al. (2011) criticized data snooping. The authors showed that including candlestick charting within the examination makes technical trading rules more robust towards data snooping than other technical trading rules (Jasemi et al., 2011).

To summarize, feed-forward neural networks or nearest neighbour regressions describe non-linear methods. By recognizing patterns in prices, non-linear methods give information about the profitability of technical trading rules. The present research covers four non-linear studies obtaining positive and mixed results. Two studies analysing stock markets from 2000 to 2007 show positive evidence on the profitability of technical analysis. Two further studies with mixed results also support the statement that technical trading rules on stock markets are profitable but only a part of the sample used proves evidence.

Overall the studies in this category at least partially support the profitability of technical trading rules on different stock markets covering the time from 1985 to 2007. This is an indication for the inefficiency of financial markets since otherwise additional profits would not be realisable.

\subsubsection{Model-based Bootstrap studies}

In 2004, Kidd and Brorsen came to the conclusion that technical trading returns have been lower after 1990 than before. They apply several bootstrap tests, as for example testing the significance of a change in statistics related to daily returns, close-to-open changes, breakaway gaps, and serial correlation. The analysis examines managed futures funds on 17 commodities and Commodity Trading Advisors (CTA) on daily basis from 1975 to 2001. 
Due to a decrease in price volatility and an increase in the kurtosis of price changes occurring on closed markets, Kidd and Brorsen rather explain the reduced technical trading profitability with a structural change in prices and possibly with a reduced autocorrelation. Thus, changes in the overall economy have a negative impact on the profitability of technical trading. Further, the authors presume that more volatile prices would increase the returns to technical trading (Kidd and Brorsen, 2004).

Another noteworthy examination is Marshall et al.'s (2006) who did the first robust study of candlestick charting, the oldest known form of technical analysis. The difference to other studies is that Marshall et al. use an extension of the bootstrap methodology to generate random open, high, low and close prices for the time from 1992 to 2002. Their results show that the DJIA is an informationally efficient stock market: Candlestick trading strategies do not outperform the market and thus have no forecasting power. Further, Marshall et al. do not consider risk-adjusted returns, transaction costs or economic significance because there is no statistical significance. The examination of 35 stocks shows that candlestick technical analysis has no value for a majority of DJIA stocks (Marshall et al., 2006).

Another examination of Marshall et al. (2008) focuses on intraday returns of the U.S. equity market and differs from previous research with respect to the applied time horizon. In general, analysts consider long term horizons, while Marshall et al. apply 815 minutes intervals over the trading day. They conclude that none of the 7,846 technical trading rules tested are profitable in comparison to long term technical trading rules. The technical trading rules tested are from the five major rules families: Filter, Moving Average, Support and Resistance, Channel Breakout, and On-Balance Volume Rules. The authors find no evidence that the trading rules generate statistically significant profits after consideration of data snooping bias. If considering transaction and market impact costs, the authors assume an even worse performance of these rules (Marshall et al., 2008).

Critical aspects of model-based bootstrapping were underlined by the following publications:

Brock et al.'s (1992) work is considered among the first ones to find empirical evidence in favour of technical analysis. The authors designed and evaluated different trading rules based on the moving averages oscillator and the range break-out, basic elements of the technical analysis used by most investors and speculators. They compared the results obtained with these strategies with the ones generated by several econometric models and, by means of the bootstrapping methodology, they concluded that the strategies based on technical analysis provided better returns than the econometric models. This 
work generated great controversy and it served as a basis for other researchers to introduce and to validate new trading rules, which provide mixed results depending on the analysed financial asset and the period of time considered in the sample (Brock et al., 1992).

On the other hand, Sullivan et al. (1999) found mixed results for the approach of Brock et al. (1992): They conclude that these results are positive for in-sample data but negative when out-of-sample data is considered (Sullivan et al., 1999). Moreover, Bajgrowicz and Scaillet (2012) showed that the performance of technical analysis is offset by the introduction of low transaction costs (Bajgrowicz and Scaillet, 2012). Their results call into question the economic value of technical trading rules.

The first model-based bootstrap method was applied by Brook et al. in 1992 which is seen as the most influential work on technical trading rules in this category of studies. Brook et al. analysed the DJIA from 1897 to 1986 by applying two technical trading systems: A moving average oscillator and a trading range break-out (resistance and support levels). It can be noted that Brook et al. report only gross returns of each trading rule without adjustment for transaction costs. These results are not sufficient to underline the forecasting ability of technical trading rules (Brock et al., 1992). Since transaction costs accrue, a correct presentation requires the consideration of transaction costs. Besides this, the strongly consistent and positive results of their examination prove the forecasting ability of technical trading rules.

As shown by Marshall et al. (2008) the profitability of technical trading rules decreases when data snooping problems and transaction costs are taken into consideration. It is important that these aspects are incorporated into studies since they reflect vital aspects of analyses. Once the performance of rules are dependent upon whether transaction costs or data snooping problems are considered, the profitability of technical trading rules is very much questioned (Marshall et al., 2008).

Another noteworthy aspect criticising model-based bootstrapping is that changes in the overall economy, as for example a structural change in prices, influence the profitability of technical trading negatively (Kidd and Brorsen, 2004).

Further, data snooping problems present an important critical aspect of model-based bootstrap studies and were already handled in many other technical analysis studies. Marshall et al. (2006) understood testing the technique of candlestick technical analysis using DJIA component stock data as an out-of-sample test since it was developed for an entirely different purpose, namely forecasting rice markets. As stated by the authors using "a stock data set which is able to be traded in its own right overcomes the criticism that technical analysis profits documented on non-traded indices are purely hypothetical. 
Individual stock data also overcomes any bias introduced by non-synchronous trading within an index" (Marshall et al., 2006).

Model-based bootstrap studies apply statistical tests to test statistical significance of trading profits. The present research covers three model-based bootstrap studies published between 2004 and 2014. The studies refer to a sample period from 1975 to 2003 and obtain positive and negative results: One commodities market's study shows positive results while two studies analysing stock and equity markets archived negative results with regard to the predictive ability of technical trading rules. All studies conduct statistical tests but do not consider transaction costs.

Kidd and Brorsen (2004) obtained positive results within their examination. The authors figure out that changes in the overall economy have an influence on the profitability of technical analysis. This means that more volatile prices would possibly increase returns to technical trading (Kidd and Brorsen, 2004).

Both examinations of Marshall et al. show negative evidence on the profitability of technical trading rules. Candlestick technical analysis does not show any prediction ability for a majority of DJIA stocks covering years from 1992 to 2002 (Marshall et al., 2006). Yet their examination of intraday returns does not show evidence that trading rules are profitable in the U.S. equity market after considering data snooping bias. Transaction and market impact costs are not considered but assumed to cause an even worse performance of these rules (Marshall et al., 2008).

To summarize, the studies analysed in this category show that bootstrapping studies in general do not confirm that technical trading rules are profitable. Only one study with positive results underlines the coherency between changes in the overall economy and the profitability of technical trading rules. Thus, bootstrapping studies confirm that markets are efficient and are not suitable to contradict the EMH. 


\subsubsection{Standard Studies}

Shynkevich applies several filter rules (FL) and moving average rules (MA) to the Dow Jones World Index and Dow Jones Global Titans 50 Index for the sample period from 1992 to 2010. Buy-and-hold or risk-free benchmark returns are used for benchmark purpose.

The author applies several adjustments within his examination:

1. The impact of non-synchronous prices in the reported closing index levels is adjusted since otherwise spurious autocorrelations in returns could be caused.

2. Data snooping bias is taken into account since reaching superior in-sample performance is always connected to searching through a large number of possible trading strategies, and

3. Transaction costs are considered within the analysis since they reduce any profits from active trading.

Shynkevich examination confirms short term market efficiency in the global equity market but does not produce short term profits by applying technical analysis to global industry equity portfolios. The author employs several performance measures to incorporate the risk properties of returns and works with the Jarque-Bera portmanteau test and the Lilliefors test (Shynkevich, 2012a).

Another study of Shynkevich in the same year deals with the U.S. equity market from 1995 to 2010 focusing on the technology industry and small cap sector portfolios applying 12,937 multiple models. In both examinations, Shynkevich considers transaction costs, first one-way with five basis points, then with ten basis points until there is no portfolio left for which the null hypothesis can be rejected at the $10 \%$ level of significance. Risk features are not considered within the analysis. Further, the author applies White's Reality Check and Hansen's Superior Predictive Ability (SPA) (Hansen, 2005). In dependence of the sample period tested, Shynkevich obtains mixed results: In the first half of the sample period technical trading rules are profitable for several tech industries and a few small cap sector portfolios. Shynkevich adjusts for data snooping bias but does not apply any transaction costs. In the second half of the sample period, technical analysis did not outperform the buy-and-hold approach for any portfolio tested. The authors summarizes that applying technical analysis to small cap sector portfolios seems to be more successful than in comparison to technology industry indices (Shynkevich, $2012 b)$. 
The third examination Shynkevich published in his 2012 analyses the short term predictability of returns on small versus large stocks and growth versus value stocks from 1969 to 2009. By analysing 12,000 trading rules to investigate the short-term predictability of portfolio returns, the author also obtains mixed results: Portfolios of small stocks and value stocks generate positive results for active trading strategies "since returns on value portfolios exhibit more predictability than returns on growth portfolios and returns on portfolios of large stocks appear to be less predictive than returns on portfolios of small stocks." During the 2000s the author observes that predictability decreases and reasons this with the popularization of exchange-traded funds and the introduction of quote decimalization on the exchanges (Shynkevich, 2012c).

Yamamoto (2012) analysed intraday return series on the Japanese stock market (Nikkei 225 ) from 2005 to 2007. He applied technical trading rules that utilize information regarding the order-flow imbalance and the order-book imbalance. By analysing 5,081 technical trading strategies for 207 individual stocks listed on the Nikkei 225, he obtained mixed results. Positive results are achieved for more than half of the Nikkei 225-listed stocks with regard to their short term return predictability, however none of the analysed technical trading strategies outperforms the buy-and-hold strategy. As stated by Yamamoto, information on past prices and on demand/supply imbalances in the order book are not related to superior technical trading profitability. The author applies White's Reality Check bootstrap procedure and Hansen's SPA test to validate the results and reduce data-snooping problems which avoid rules that are found by pure chance (Yamamoto, 2012).

A negative aspect of the standard approach arises with regard to transaction costs. The fact that transaction costs accrue and therefore should be considered within conducted analyses is also a main critical aspect within standard studies. As Shynkevich illustrates, trading rules for portfolios with small to moderate one-way transaction costs (5 to $20 \mathrm{bp}$ ) generate statistically significant profits but once a higher level of transaction cost is applied only two portfolios in the sample of Shynkevich's analysis are profitable (Shynkevich, 2012c). The fact that technical analysis' profitability is eroded by transaction costs was already detected by Alexander, and Fama and Blume a long time ago (Alexander, 1964; Fama and Blume, 1966). Thus, it can be concluded that the impact of transaction costs on the profitability of standard studies is essential while the correct estimation of transaction costs is still challenging.

Another critical aspect was discovered by Shynkevich and refers to the sample period observed. The same analysis was done by Shynkevich for two different sample periods, coming up with different results with regard to the profitability on technical trading rules (Shynkevich, 2012b). 
Testing procedures of standard studies incorporate transaction costs and risk adjustments. Further, optimized trading rules, also known as parameter optimization, are applied and data snooping problems, are taken into account in the form of out-of-sample tests.

The present research analyses four standard studies covering the time from 1969 to 2010. All studies concentrate on stock markets, with most taking transactions costs and conduct statistical tests into consideration. The chosen benchmark in all studies is the buy-and-hold strategy. The overall results show that three studies obtained mixed while one study shows negative results.

The mixed results illustrate that active trading strategies perform well for small stocks and value stocks but are less profitable in case of large stocks. Further it is mentioned that the main reasons for the lack of predictability are exchange-traded funds and the introduction of quote decimalization on the exchanges (Shynkevich, 2012c).

Another study of Shynkevich confirms that trading strategies are profitable for several tech industries and a few small cap sector portfolios within the first half of sample period observed. Once the analysis is repeated to the second half of the testing-period, the buyand-hold approach is not outperformed. This is an indication that supports the EMH (Shynkevich, 2012b).

Additionally, Yamamoto finds evidence for short term return predictability for more than half of the Nikkei 225-listed stocks. Nevertheless, all analysed trading strategies fail to outperform the buy-and-hold strategy and indicate that markets are efficient since no extra profits are realizable (Yamamoto, 2012).

One study obtains negative results since short term market efficiency in the global equity market is supported, however, no short term profits by applying technical analysis to global industry equity portfolios can be achieved (Shynkevich, 2012a).

To summarize, the analysed standard studies published between 2004 and 2014 show mixed to negative results with regard to the profitability on technical trading strategies. Previous studies have shown that the forecasting probability of technical analysis can be improved by conducting parameter optimization, out-of-sample-testing and addressing data snooping problems. Thus, the inefficiency of markets can only be partially proved. 


\subsubsection{Reality Check Studies}

Hsu et al. (2010) examined growth and emerging market indices and their exchange traded funds (ETFs). The authors apply an extension of Hansen's SPA test to a stepwise SPA test that can identify predictive models without potential data snooping bias (Hsu et al., 2010). Romano and Wolf's stepwise reality check test is used as a benchmark (Romano and Wolf, 2005). The authors work with one-way transaction costs of $0.05 \%$ on each trade for all market indices and ETFs. Overall Hsu et al. obtained positive results for market indices and concluded that technical trading rules are profitable on considered markets, in both growth and emerging markets, even though the introduction of ETFs lowers their profitability (Hsu et al., 2010).

Based on Hsu et al.'s statement, reality check is criticized for the decreasing predictive power of trading rules since the introduction of ETFs. The reality check approach quantifies data snooping problems directly by testing the performance of several rules. In the present research Hsu et al.'s examination is the only study in this category. Hsu et al. obtain positive results with regard to the profitability of technical analysis on U.S. growth and emerging markets from 1996 to 2003. Transaction costs are considered and statistical tests conducted within the analysis (Hsu et al., 2010).

To summarize, the present research only considers one reality check study. Therefore the positive analysis results and the indication for inefficient markets should not be overstated.

\subsubsection{Studies without classification}

Leigh and Purvis (2008) conducted a long term study that cannot be assigned to any of the categories above. Analysing daily volume and return values for the DJIA and S\&P500, the authors conclude that implementing the trading heuristic "buy on volume spike" is effective. The examination covers a very long period, particularly the years from 1934 to 2005 for the DJIA and 1954 to 2005 for the S\&P500. Leigh and Purvis use two methods: Within the basic method all parameter value settings are reported and optimization is only conducted for the 1,000 day length of the history period. The extended method applies some optimization of the size of the correlation sets and the correlation threshold value. In conclusion the authors state: "The trading heuristic "buy when one-day share volume spikes" is demonstrated to be effective for simulated trading with long time series market data for major stock indices". Leigh and Purvis validate their results by applying back-tests or simulating trading (Leigh and Purvis, 2008). 
Sevastjanov and Dymova (2009) see the financial performance of a company as essential and analyse the relationship between a company's success reflected directly on stock markets and the financial indices for the year 2004. To meet this objective, the three most popular aggregating modes, weighted sum, multiplicative and min operator, were used. They conclude "that a proper choice of method for the local criteria aggregation plays a key role in the success of stock selection irrespective of used approach to the local criteria ranking" (Sevastjanov and Dymova, 2009).

Leigh and Purvis (2008) underlined in their examination that "the methods should be considered for inclusion as elements of any market trading decision support system, although of themselves as limited opportunistic heuristics they do not constitute a complete investment strategy". In other words, this approach should not be used as a sole instrument for investment decision making but instead as a supplement (Leigh and Purvis, 2008).

Two of the overall analysed studies fall into the last category named "studies without classification" since they do not fulfil the criteria of any category listed before.

Both examined studies obtain positive results by analysing stock markets that supports the existence of inefficient markets. The study of Leigh and Purvis which covers a very long sample period is noteworthy in this context.

In general, "studies without classification" show innovative ways how researchers tackle the challenge of proper investment decision making. There is no reason why studies which do not conform to any of the listed categories above should not be profitable on the markets.

\subsubsection{Stock market anomaly studies}

This section analyses studies with regard to stock market anomalies. "The evidence of equity market anomalies contradicts the prediction of the EMH, at least in its weak form, because the predictable movements in asset prices provide investors with opportunities to generate abnormal returns. In addition, stock market anomalies may result from an inefficient flow of information in financial markets, which is a violation of an underlying assumption of the EMH". One classical effect is called Monday effect which states that "asset returns are lower or negative on Mondays relative to other days of the week" (Aly et al., 2004).

Aly et al. (2004) analysed the day-of-the-week effects in the Egyptian Stock Market. The authors state that "before April 1998 stock trading in Egypt took place from Monday to Thursday, and also occasionally on certain Fridays and Sundays, resulting in an irregular 
pattern of four-day, five-day and six-day trading weeks". Aly et al. focused on daily closing values for the major Egyptian stock market index, the CMA Index for the period from April 26, 1998 to June 6, 2001 and made sure that only consistent four-day trading weeks are considered. Even though the authors obtained positive results concluding that stock market returns are consistent with the weak form of market efficiency, they advise interpreting these results with caution since the Egyptian stock market has only a limited number of stocks that are actively traded. Nevertheless, the authors did not detect any evidence for any daily seasonal patterns in the Egyptian stock market since the positive returns weren't significantly different from returns of the rest of the week. Overall, Aly et al. contribute to prove market inefficiency in a positive way but did not find any evidence for the Monday effect (Aly et al., 2004).

Cho et al. (2006) analysed stock indices including large caps and small caps as well as UK and Japanese indices. The authors covered different periods from 1970 to 2004 and defined the Monday effect based on the stochastic dominance criterion because in their opinion it is a stronger criterion than those based on comparing means. Cho et al. state that "the results using stochastic dominance criteria confirm earlier findings of a Monday effect for many series over the full sample. This effect has weakened for some large cap series like the DJIA and the S\&P500 post 1987, but remains strong for more broadly based indices". Nevertheless, the authors advise that it is not clear if the results conclude market inefficiency or a bad model of market equilibrium since statistical significance requires quite a large sample size (Cho et al., 2006).

Mazal (2009) worked with an extended dummy variable approach based on a factor model and applied it to returns of 30 stocks traded at the German Stock Exchange, whilst also applying a dummy variable approach to returns of 28 world indices. The period covered was from from January 1, 2006 to December 31, 2008. In the scope of his analysis are the Monday effect and the September effect. Within his simulation he confirms "that the day of the week effect started disappearing in the second half of 1990s". His simulated portfolio beats the buy-and-hold-strategy which serves as a benchmark. This violates the EMH and gives positive evidence for the existence of inefficient markets (Mazal, 2009).

Singhal and Bahure (2009) analysed the weekend effect of returns in the Indian stock market. The authors examined daily returns for the three major operational indices in India: BSE Sensex, BSE 200 and the S\&P Nifty. The period covered was from April 2003 to April 2008. The authors calculate t-statistics and perform the one tailed t-test. Their results conclude that "there is conclusive evidence of the existence of weekend effect in India" which raises questions about market efficiency (Singhal and Bahure, 2009). 
Liu and Li (2010) examined day of the week effects based on daily closing prices of the Top 50 Australian Stocks starting from January 2001 (for most companies) to June 2010. Their results show that in the case of 15 companies the largest mean weekday returns occurred on Monday, and in case of another 15 companies the lowest mean weekday returns occurred on Friday. To summarize, the obtained results are mixed across companies and industries regarding the weekday effects (Liu and Li, 2010).

Ho et al. (2011) analysed weekly data of 20 tourism firms of the Taiwan Security Exchange from 2001 to 2009. The authors did not find any evidence for the Monday effect but detected a reverse Monday effect in the U.S. market after 1990. Nevertheless, they indicate that "positive returns on the last weekly trading day (especially when it is a Friday) is one of the factors to result in positive Monday returns". Thus, "institutional holdings tend to purchase stocks on Monday after positive Friday returns". The methods applied are descriptive statistics, regression analyses, t-tests and robustness tests. All in one, the study does not contribute to support the EMH (Ho et al., 2011).

Cohen (2012) analysed the day of the week effect based on daily closing values of the FTSE 100 index from the London Stock Exchange from December 28, 1987 until December 31, 2011. The author used the $\operatorname{GARCH}(1,1)$ model to determine the strength of the day of the week effect. Afterwards he calculated the recursive and rolling least squares. Cohen found positive evidence for the day of the week effect and could prove that it disappeared from the London Stock Exchange during 1993 (Cohen, 2012).

Loc (2012) examined the day of the week effect in stock returns and volatility for the Vietnamese Ho Chi Minh Stock Exchange (HOSE) from March 1, 2002 to March 1, 2011. Applying OLS and GARCH $(1,1)$ regression models the author finds positive evidence for the day of the week. The author states that "a negative effect is observed for Tuesday while a positive effect occurs on Friday. Moreover, the highest volatility occurs on Thursday, and the lowest volatility is observed on Monday." Further, Loc summarizes that his results "fail to reject the hypothesis of day of the week effect on stock-market volatility for the HOSE" what is an indication that inefficiencies were identified for the observed market (Loc, 2012).

Nghiem et al. (2012) focused their examination on developed and emerging markets applying regression models from March 2002 to May 2008. With regard to developed markets the U.S. (S\&P500 composite), Japan (Nikko composite), the UK (all FTSE shares), France (Paris CAC 40), Hong Kong (DJTM Hong Kong) and Singapore (DJTM Singapore) are analysed. The analysis of emerging markets includes Malaysia (DJTM Malaysia) and Vietnam (VN-Index). Additionally, the MSCI World Index was also considered within their study. The authors find highly mixed results that may support the EMH "since evidence of daily anomalies seems to be inconsistent and difficult to 
explain in terms of economics". To check the robustness of the conclusions the authors recommend a more intense research on this topic (Nghiem et al., 2012).

Patel et al. (2012) analysed daily closing prices of Asian indices, namely of India (Bombay Stock Exchange), Hong Kong (Hong Kong Stock Exchange), Japan (Tokyo Stock Exchange) and China (Shanghai Stock Exchange). The period covered lasts from January 1, 2000 to March 21, 2011 and is divided into three sub-periods. To neutralize the returns the authors work with logarithm transformed stock price indices. Patel et al. obtain negative results stating that the Monday was a day of high volatility in the Asian markets. Thus, no day of the week effect could be proven in any of the three subperiods. According the EMH, the authors state that "the market is said to be weak form of efficient if no day or no month outperform or underperform. In other words, there should not be a specific day or month which can predict the price momentum." Since this is not the case, the publication of Patel et al. contributes to prove that analysed markets are efficient (Patel et al., 2012).

Rogriguez (2012) concentrated his analysis on Latin America's stock markets (Argentina, Brazil, Chile, Colombia, Mexico, and Peru), covering the period from 1993 to 2007. Rogriguez applied three different analyses, including GARCH models for the returns and volatility of daily returns. In many cases the author found significant evidence for a Monday Effect, where returns were lower than expected, or a Friday Effect, where returns were higher than expected. This publication supports the hypothesis that markets are inefficient (Rodriguez, 2012).

Stavárek and Heryán (2012) resulted within their GARCH analysis that the day of the week effect is not typical for the Central European stock markets. Considered markets were the Prague Stock Exchange Index (PX), the Budapest Stock Exchange Index (BUX) and the Warsaw Stock Exchange Index (WIG). Six sub-periods lasting from April 2006 to March 2012 were analysed. The authors could also prove for the time of the financial crisis that day of the week effects did not occur. Thus, these markets were efficient to that time (Stavárek and Heryán, 2012).

Panait et al. (2013) analysed five Romanian official exchange indices and for one MSCI Barra country index from May, 2007 to March, 2013. The authors worked with the GARCH-M model. Finally, the results are negative with respect to existing day of the week effects for all analysed indices. Thus, this publication does not confront the EMH since the analysed markets were efficient during the observed period (Panait et al., 2013).

Osazevbaru and Oboreh (2014) focused their analysis on the Nigerian stock market. The methods applied were the OLS test and the GARCH model. The authors found positive 
evidence for the Monday effect and for inefficient markets in Nigeria from January, 1995 to December, 2009 (Osazevbaru and Oboreh, 2014).

Deyshappriya (2014) conducted an analysis of daily and monthly data of the Colombo Stock Exchange (CSE) from 2004 to 2013. The methods applied were OLS and the GARCH $(1,1)$ model. His results can be summarized as follows: He detected a negative Monday effect and positive effects for all other days during the war period. A positive volatility effect on Monday and the negative volatility effect on Friday were found for both war period and the entire sample period. Futher, Deyshappriya states that the "positive January effects are common for all sample periods, the negative December effects cannot be identified for post war periods". Finally the author concludes that these "seasonality patterns limit the validity of Efficient Market Hypothesis in the context of Colombo Stock Exchange". This is an indication that analysed markets were not efficient in the considered period (Deyshappriya, 2014).

To summarize, the analysis deals with 15 studies covering market anomalies on international stock markets. Eight studies obtained positive results while three studies show mixed results and four negative. In total the tendency is positive. Thus, the examined market anomaly studies contribute in a positive way to prove the existence of market inefficiencies and to contradict the EMH.

\subsection{Initial situation for practical work}

Chart pattern studies examine the forecasting probability of visual chart patterns commonly used by technical analysis. In the academic literature, different markets are analysed with regard to patterns, e.g. stock markets and foreign exchange markets. Besides varying markets to be analysed, the profitability of patterns strongly depends on the methodology worked with, sample periods tested and patterns applied (Park and Irwin, 2007).

Within the above stated sections, technical trading analysis' published between 2004 and 2014 were grouped into categories and evaluated with regard to the profitability of technical trading rules. 23 studies were examined for this period and fill all of the implemented categories. Six pattern studies were additionally examined focusing on the later history. Further, a closer look at studies covering market anomalies is taken. In this context, another 15 studies were considered.

In the following the results of analysed studies will be displayed. 
Figure 3.1 illustrates the examined studies - except market anomaly studies - with regard to their contribution whether the study obtained positive, negative or mixed results:

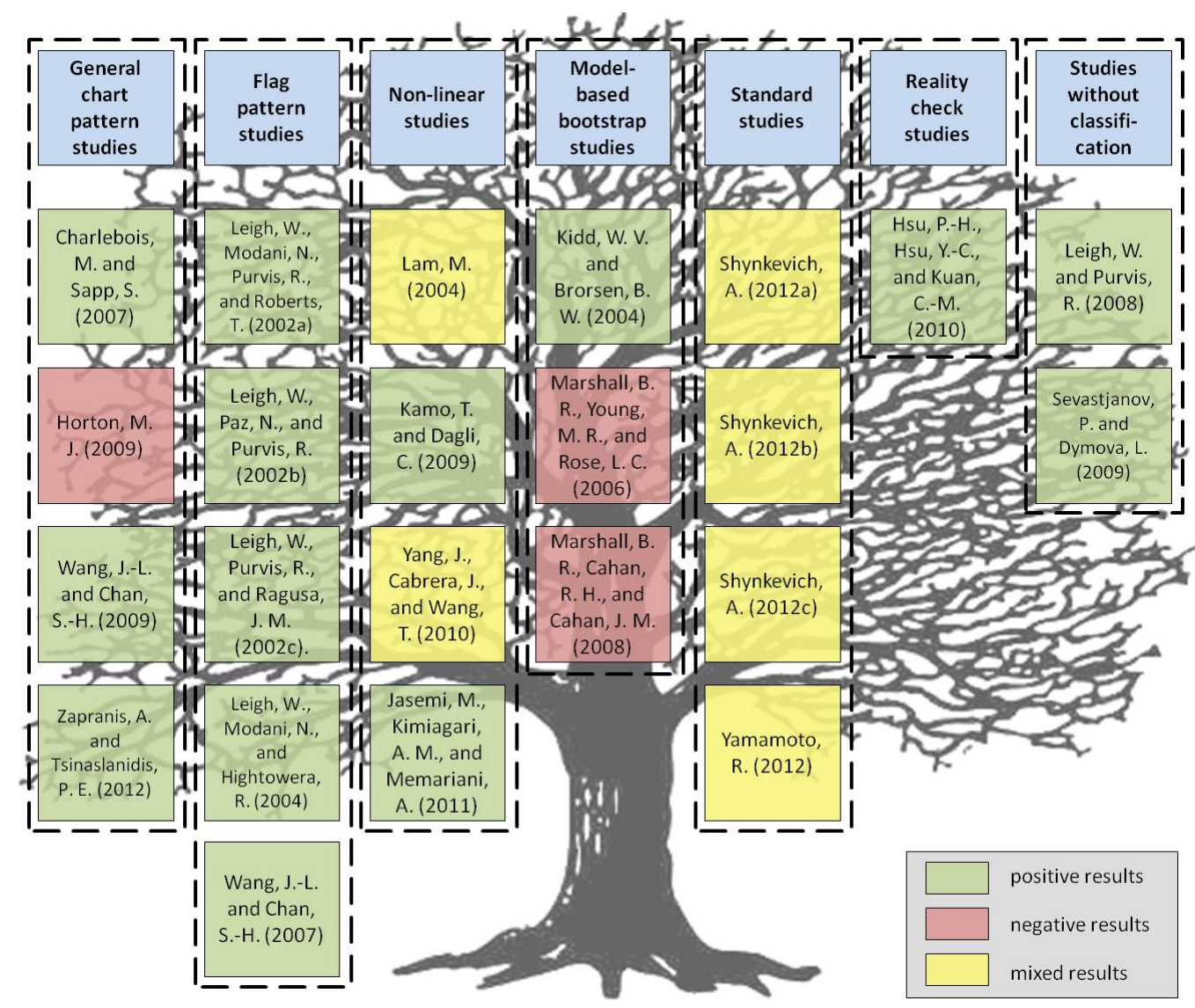

FiguRE 3.1: Literature tree of technical trading studies, 2004-2014

A first view allows the statement that the majority of technical trading studies conducted between 2004 and 2014 obtained positive results. There were also studies with mixed and negative findings but their share is relatively small as quantified in table 3.1:

TABLE 3.1: Number of technical trading studies by results, 2004-2014

\begin{tabular}{llllll} 
Category of studies & Positive & Negative & Mixed & Total & $\begin{array}{l}\text { Relative } \\
\text { frequency } \\
(\%)\end{array}$ \\
& & & & & 17.4 \\
\hline Chart pattern (general) & 3 & 1 & 0 & 4 & 21.7 \\
Chart pattern (flag) & 5 & 0 & 0 & 5 & 17.4 \\
Non-linear & 3 & 0 & 1 & 4 & 13.0 \\
Model-based bootstrap & 1 & 2 & 0 & 3 & 17.4 \\
Standard & 0 & 0 & 4 & 4 & 4.3 \\
Reality check & 1 & 0 & 0 & 1 & 8.7 \\
Without classification & 2 & 0 & 0 & 2 & 100.0 \\
& & & & & \\
Total & 15 & 3 & 5 & 23 & 100.0 \\
Total (\%) & 65.2 & 13.0 & 21.7 & &
\end{tabular}


Table 3.1 illustrates the results of the present research with respect to the profitability of technical trading analysis. Most studies obtain positive, some negative and some mixed results. As illustrated, the profitability of technical trading analysis can be confirmed by the present research. $65.2 \%$ of the examined studies obtain positive results while $21.7 \%$ of studies show mixed results. Of note, chart pattern studies show that eight from nine studies were profitable.

In a next step the markets observed are analysed. Table 3.2 serves as overview of the studies taken into account for the literature review divided by analysed markets:

TABLE 3.2: Number of technical trading studies by analysed markets, 2004-2014

\begin{tabular}{llllll} 
Category of studies & $\begin{array}{l}\text { Stock } \\
\text { markets }\end{array}$ & $\begin{array}{l}\text { Foreign } \\
\text { exchange } \\
\text { markets }\end{array}$ & $\begin{array}{l}\text { Futures } \\
\text { markets }\end{array}$ & Total & $\begin{array}{l}\text { Relative } \\
\text { frequency } \\
(\%)\end{array}$ \\
\hline Chart pattern (general) & 3 & 1 & 0 & 4 & 17.4 \\
Chart pattern (flag) & 5 & 0 & 0 & 5 & 21.7 \\
Non-linear & 4 & 0 & 0 & 4 & 17.4 \\
Model-based bootstrap & 2 & 0 & 1 & 3 & 13.0 \\
Standard & 4 & 0 & 0 & 4 & 17.4 \\
Reality check & 1 & 0 & 0 & 1 & 4.3 \\
Without classification & 2 & 0 & 0 & 2 & 8.7 \\
& & & & & \\
Total & 21 & 1 & 1 & 23 & 100.0 \\
Total (\%) & 91.3 & 4.3 & 4.3 & 100.0 & \\
\hline
\end{tabular}

As presented in table 3.2, the majority of studies examined stock markets, with 21 of 23 studies applying different approaches that fell into this category. Further, it is noteworthy that $39.1 \%$ of studies are chart pattern studies, which form the focus of the present research.

Besides technical trading studies, studies dealing with market anomalies were considered in the scope of the present research. Market anomalies are also an indication for the inefficiency of markets and therefore they were additionally considered.

For this reason, in the next step, a closer look at the results of market anomaly studies is taken. 
In this context, the figure 3.2 serves as illustration to display the results of market anomaly studies:

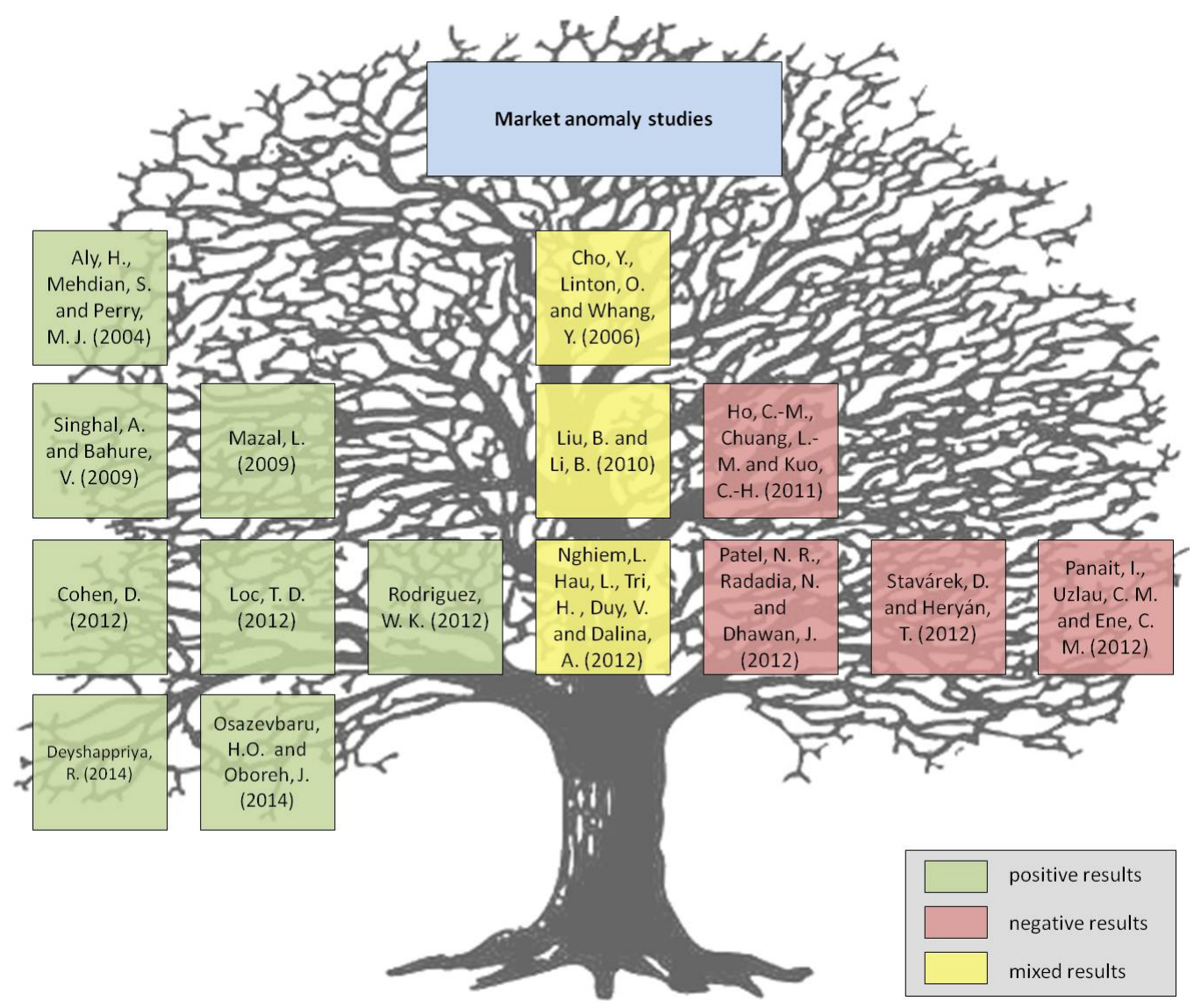

FIGURE 3.2: Literature tree of market anomaly studies, 2004-2014

The majority of the 15 analysed studies gained positive results since eight studies (53.3\%) confirm the inefficiency of considered markets and thus the profitability of technical analysis. While three studies $(20.0 \%)$ show mixed results, four studies $(26.7 \%)$ result in negative findings. All of these studies evaluated stock markets.

To summarize, the present research confirms the profitability of technical trading rules on different markets. It is worth mentioning that results strongly depend on markets considered, sample period tested and methods applied. Nevertheless the overall analysis allows the positive statement, that based on the considered studies, the profitability of technical trading rules and therefore the inefficiency of financial markets can be confirmed.

The majority of studies analysed above show a positive trend with regard to the forecasting power of technical analysis approaches. The present research examines different pattern studies, where only one obtains negative and eight show positive results focusing on the last decade. Examined pattern studies cover the time from 1962 to 2007. Transaction costs within these studies are handled differently: Wang and Chan consider 
transaction costs in the amount of $1 \%$, while the other authors don't apply transaction costs at all.

The considered studies covering market anomalies also support the profitability of technical analysis since only four studies obtain negative results. Thus, more than half of the studies prove the inefficiency of analysed international stock markets.

When applying the flag pattern, several configurations within the method have to be taken into consideration by practitioners. Nevertheless, with regard to several aspects a research gap could be identified:

- A commonality between all chart pattern studies, that have so far been analysed, is that daily returns are used for research. One general pattern study analyses intraday data. In this context the question arises which return to chose (opening, closing, highest, lowest). Some studies work with candlesticks to include the development of prices within a trading day (Marshall et al., 2006; Horton, 2009). The present research goes one step further and analyses intraday data applying candlesticks. This ensures that a trading day is displayed in a high degree of detail.

- When implementing the flag pattern approach, researchers build a 10x10 grid matrix allocating weights into the cells. So far, the idea of the weight allocation is to construct a consolidation phase which is followed by a break out. Following the definition of Downes and Goodman a more accurate reflection would be achieved by assuming the break out first and the consolidation afterwards (Downes and Goodman, 1998). In the present research, this is put into practice by allocating the weights in a different way than done in previous research.

- Further, in previous research a lack of dynamic approach can be observed. Therefore the idea is to implement stop loss and take profit thresholds. In this way the whole approach is IF-THEN rule related which is closer to investor's behaviour.

- The last aspect which is subject to further development is the consideration of risk. In the past the approach was often not risk-adjusted. Mostly it was reasoned in using a broad-based market average which made the adjustment for risk of individual securities unnecessary (Leigh et al., 2004). Some authors conducted out-of-sample-tests (Charlebois and Sapp, 2007). The present research intends considering the risk component by using the maximum drawdown. 


\section{Chapter 4}

\section{Implementation of pattern recognition to chart analysis}

\subsection{Status Quo}

Chart pattern recognition is one of the methods that has attracted attention of researchers. Despite being at an early stage of chart analysis, speculators already consider patterns within their decision making processes. Its use has spread due to the generalization of IT-trading applications. By means of algorithms, IT-trading applications are able to recognize figures like head-and-shoulders, tops and bottoms, triangles, wedges, saucers and gaps, etc. (Bulkowski, 2014).

Among the first attempts in addressing pattern recognition and the potential use of patterns for the elaboration of trading rules (in an un-automated way), the work by Levy is noteworthy. Levi analysed different NYSE securities and a total of 32 patterns (Levy, 1971). Later, Lo et al. examined the performance of ten chart patterns for the prediction of U.S. securities. They conclude that some rules provide positive returns in a consistent way (Lo et al., 2000).

Taking into account the patterns most analysed by researchers, the flag pattern is the focus of the current research. Recent research has reported significant and consistent returns for different configurations of the flag pattern and it's parameters (Leigh et al., 2002b).

The practical part of the present research focuses on how to implement pattern recognition to chart analysis. German, American and Spanish stock markets - represented by the corresponding indices DAX, DJIA and Ibex-35 - will be examined in the following sections to validate the profitability of chart analysis, or the flag pattern itself in detail. 
First of all, a description of the methodology applied occurs. The methodology is to a great extent the same for all countries; it only differs in means of data frequency in the case of one analysis and or in means of analysing additionally non-overlapping sub-periods in the case of another analysis.

Since the method is implemented through an algorithm, a deeper insight will be given into the processes performed by the algorithm.

Further, country information focusing on every relevant country is presented to get an overview of the analysed countries from a demographic and economic perspective as well as making a statement in which way comparability is given. In the end, the most important information will be displayed in tables which serve as final overview divided by demographic and economic information.

Then, the analysis will be implemented on the three above mentioned indices. A closer look at previous research in the area of bull flag pattern recognition resulted in a high potential of further development. In the scope of further development is the improvement and optimization of the approach to gain a more robust and profitable analysis tool for predicting return curves on international stock markets. This is what the analysis section deals with in detail.

In the end of the chapter, the corresponding results are illustrated. Here the central question, whether the analyses could contribute to prove the international stock markets' inefficiency, will be finally answered.

\subsection{Methodology}

This section serves as an overview of the methodology applied to all indices of the markets concerned. Leigh, Modani et al., Leigh, Paz et al. and Leigh, Purvis et al. are among the first works to introduce the recognition of this kind of chart pattern (Leigh et al., 2002a; Leigh et al., 2002b; Leigh et al., 2002c). For this purpose, they built a fit function between the price window they tried to evaluate and the weight matrix like the one showed in figure 4.1: 


\begin{tabular}{|c|c|c|c|c|c|c|c|c|c|}
\hline .5 & 0 & -1 & -1 & -1 & -1 & -1 & -1 & -1 & 0 \\
\hline $\mathbf{1}$ & .5 & 0 & -.5 & -1 & -1 & -1 & -1 & -.5 & 0 \\
\hline $\mathbf{1}$ & $\mathbf{1}$ & .5 & 0 & -.5 & -.5 & -.5 & -.5 & 0 & .5 \\
\hline .5 & $\mathbf{1}$ & $\mathbf{1}$ & .5 & 0 & -.5 & -.5 & -.5 & 0 & $\mathbf{1}$ \\
\hline 0 & .5 & $\mathbf{1}$ & $\mathbf{1}$ & .5 & 0 & 0 & 0 & .5 & $\mathbf{1}$ \\
\hline 0 & 0 & .5 & $\mathbf{1}$ & $\mathbf{1}$ & .5 & 0 & 0 & $\mathbf{1}$ & $\mathbf{1}$ \\
\hline-.5 & 0 & 0 & .5 & $\mathbf{1}$ & $\mathbf{1}$ & .5 & .5 & $\mathbf{1}$ & $\mathbf{1}$ \\
\hline-.5 & -1 & 0 & 0 & .5 & $\mathbf{1}$ & $\mathbf{1}$ & $\mathbf{1}$ & $\mathbf{1}$ & 0 \\
\hline-1 & -1 & -1 & -.5 & 0 & .5 & $\mathbf{1}$ & $\mathbf{1}$ & 0 & -2 \\
\hline-1 & -1 & -1 & -1 & -1 & 0 & .5 & .5 & -2 & -2.5 \\
\hline
\end{tabular}

Figure 4.1: Bull flag template (Leigh et al., 2002c)

The first seven columns of the weight matrix in figure 4.1 correspond to the consolidation process pointed out by Downes and Goodman, while the last three columns indicate the sharp increase of the price (breakout). ${ }^{1}$

The fit function is defined as a measure of the matching between the template which represents the pattern and the price values in a window of $p$ negotiation periods (weeks, days, 4 hours, 15 minutes, etc.). The greater the value reached by the fit function, the greater the confidence when identifying a flag pattern. The fit function Fit $t_{k}$ over the period $k$ considers a price window composed by $p$ negotiation periods (in the case of figure $4.1 p=10$ ) finishing the day $k-1$.

First of all, a template of 10x10 dimension is built for the values of the index, where each column is identified with each one of the $p$ periods of the price window, and the rows mark out the maximum and minimum reached by the index during those $p$ periods. This template calculates the values $I_{i t}$, where the subindex $t$ corresponds to each one of the $p$ periods of the price window, and the subindex $i$ corresponds to the price rank of the index. The prices of the index are ordered from largest to smallest for those $p$ periods, dividing them in 10 portions or rows with the same size.

For example, if the index had reached a maximum of 1,000 points and a minimum of 900 points during this period, then 10 rows with a size of 10 points each row would be obtained. If for the period $t$ the price of the index positions over the row $i$, then $I_{i t}=$ 1 ; and in other case, $I_{i t}=0$.

With this process a template of 100 cells $(10 \mathrm{x} 10)$ can be built, from which 10 will have a value of 1 and 90 will have a value of 0 . Moreover, each column of the template can only contain a cell with value 1 ; in such a way that those cells point out the area in which the price closed for each one of the 10 negotiation periods.

\footnotetext{
${ }^{1}$ The bear/decreasing version will be obtained as a reflection of the matrix over the horizontal axis.
} 
The final step of the calculation process of the fit function is to multiply the previous template with the template of figure 4.1:

$$
F_{i t}=\sum_{t=k-10}^{k-1} \sum_{i=1}^{10}\left(I_{i t} * J_{i t}\right)
$$

where $J_{i t}$ corresponds to the value of the cell of the row $i$ and the column $t$ of the template of figure 4.1 .

Figure 4.2 contains an example of how to calculate the value of the fit function for a determined price window. The matrix near the top left corner corresponds to the grid of figure $4.1\left(I_{i t}\right)$ :

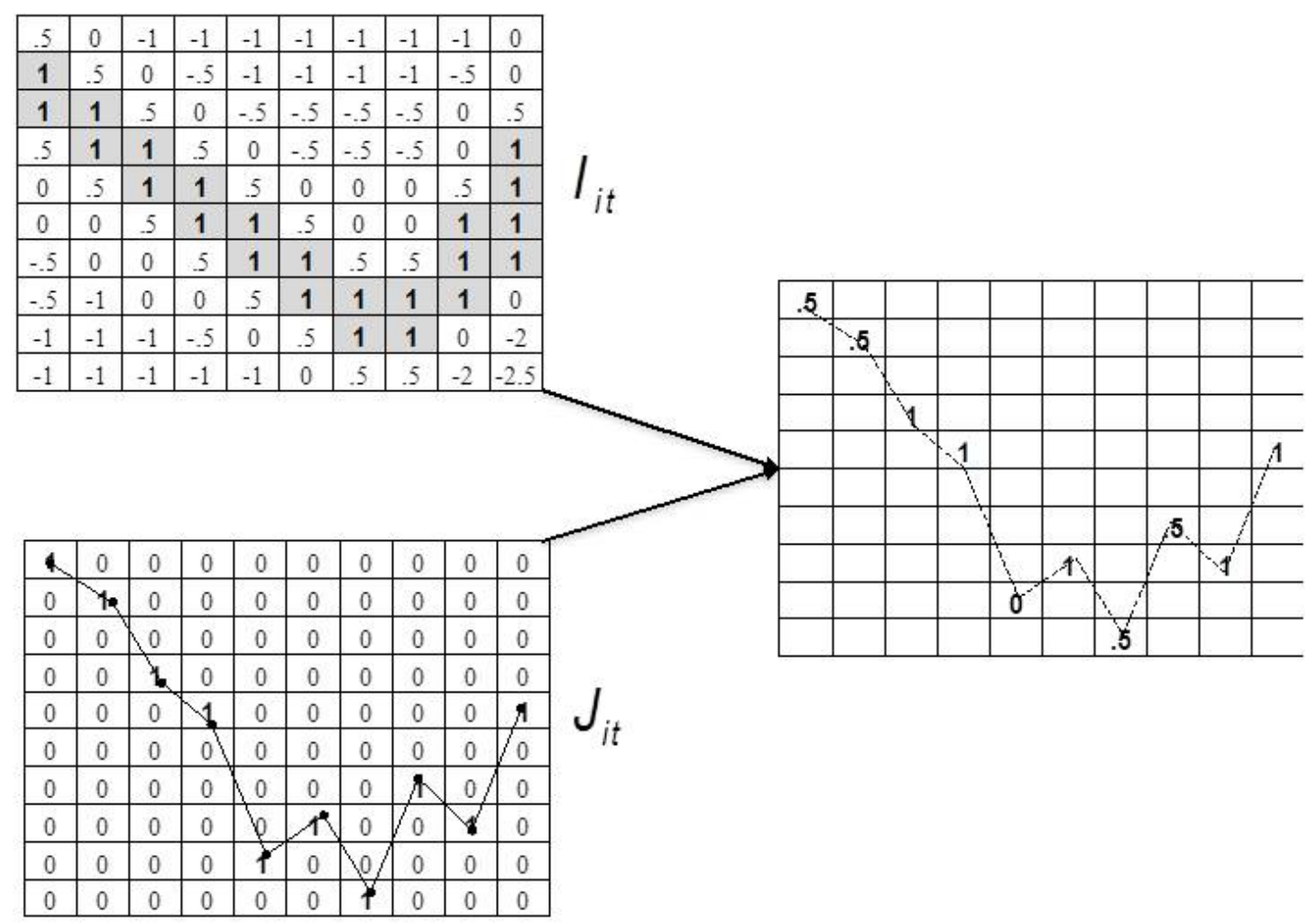

FiguRe 4.2: Calculation process of the fit function

In the bottom left corner the price evolution during a window of ten days is represented. The cells, in which the price has closed, have a value of 1 , and the remaining cells have a value of 0 . The result is the matrix $J_{i t}$. Finally, the matrix at the right of the figure is obtained by multiplying cell by cell each one of the two previous matrices, which allows to estimate a value of $0.5+0.5+1+1+0+1+0.5+0.5+1+1=7$.

If the price positions in some of the cells labelled with value 1 , the fit function will increase in one unit. If the price passes through one of the cells labelled with value 0 , the fit function will not change it's value; and if the price cell passes through cells labelled with a negative value, the fit function will decrease in the value marked by the 
cell. In this way, those price values have tried to be identified as flag patterns which follow a similar evolution to the one delimited by the cells labelled with value 1 . The ideal value of the fit function is 10 . The price can only visit one cell at a time. The maximum possible fitting between the price and the flag pattern is the one defined by Leigh, Purvis et al. (Leigh et al., 2002c).

From the template defined in figure 4.1, the authors find positive evidence in favour of the trading rule designed over the flag pattern. The obtained results were statistically significant and, therefore, "fail to confirm the null hypothesis that the markets are efficient" (weak form of EMH) (Leigh et al., 2002b). Although transaction costs were not considered, results show a return two times greater than the one obtained by the buy-and-hold strategy.

Despite the positive results reported in these works, Wang and Chan highlight a weakness in the template of figure 4.1. Due to the price distribution, it is possible that some price windows will be considered as flags, when actually they are not. With this in mind, the authors provide some examples in order to evidence this possibility. They introduce a new weight matrix in which the number of cells labelled with 1 is reduced considerably; in this way, it is possible to reduce the number of cells that the price should pass through in order to recognize the figure as flag pattern (Wang and Chan, 2007).

When analysing both indices, NASDAQ and TWI, Wang and Chan conclude that based on the flag pattern all analysed trading rules rightly predict the direction change in the price of both indices, more significantly for the index TWI. The authors justify the greater prediction power of the TWI index by the greater maturity of the NASDAQ market. Similar conclusions were reached when analysing specific securities in the U.S. market like Microsoft, Apple, Oracle or Dell (Wang and Chan, 2009).

In order to increase the robustness of the conclusions reached by these authors, the present work includes a series of relevant changes which will be introduced in the following sections.

The first essential change of the present research project implements a new weight matrix. The new definition of the weight matrix will allow the identification of the flag pattern in a more accurate way, hence amending the inconveniences pointed out by Wang and Chan (2007).

Figure 4.3 presents two window prices which, considering the grid of weights of Leigh, Purvis et al.'s bull flag template, provide the same total fitting value of 6.5. While in the first case (figure 4.3.a) it can be assumed that the price window corresponds to a bull flag pattern, in the second case (figure 4.3.b) the price goes down without confirming a following breakout and the shape deviates far from a bull flag pattern. One 
solution might be to increase the threshold of the total fitting value but in this case, price windows that will fit the pattern, would be discarded (figure 4.3.a).

\begin{tabular}{|c|c|c|c|c|c|c|c|c|c}
\hline .5 & 0 & -1 & -1 & -1 & -1 & -1 & -1 & -1 & 0 \\
\hline $\mathbf{1}$ & .5 & 0 & -.5 & -1 & -1 & -1 & -1 & -.5 & 0 \\
\hline $\mathbf{1}$ & $\mathbf{1}$ & .5 & 0 & -.5 & -.5 & -.5 & -.5 & 0 & .5 \\
\hline .5 & $\mathbf{1}$ & $\mathbf{1}$ & .5 & 0 & -.5 & -.5 & -.5 & 0 & $\mathbf{1}$ \\
\hline 0 & .5 & $\mathbf{1}$ & $\mathbf{1}$ & .5 & 0 & 0 & 0 & .5 & $\mathbf{1}$ \\
\hline 0 & 0 & .5 & $\mathbf{1}$ & $\mathbf{1}$ & .5 & 0 & 0 & $\mathbf{1}$ & $\mathbf{1}$ \\
\hline-.5 & 0 & 0 & .5 & $\mathbf{1}$ & $\mathbf{1}$ & .5 & .5 & $\mathbf{1}$ & $\mathbf{1}$ \\
\hline-.5 & -1 & 0 & 0 & .5 & $\mathbf{1}$ & $\mathbf{1}$ & $\mathbf{1}$ & $\mathbf{1}$ & 0 \\
\hline-1 & -1 & -1 & -.5 & 0 & .5 & $\mathbf{1}$ & $\mathbf{1}$ & 0 & -2 \\
\hline-1 & -1 & -1 & -1 & -1 & 0 & .5 & .5 & -2 & -2.5 \\
\hline
\end{tabular}

a

\begin{tabular}{|c|c|c|c|c|c|c|c|c|c}
\hline .5 & 0 & -1 & -1 & -1 & -1 & -1 & -1 & -1 & 0 \\
\hline $\mathbf{1}$ & .5 & 0 & -.5 & -1 & -1 & -1 & -1 & -.5 & 0 \\
\hline $\mathbf{1}$ & $\mathbf{1}$ & .5 & 0 & -.5 & -.5 & -.5 & -.5 & 0 & .5 \\
\hline .5 & $\mathbf{1}$ & $\mathbf{1}$ & .5 & 0 & -.5 & -.5 & -.5 & 0 & $\mathbf{1}$ \\
\hline 0 & .5 & $\mathbf{1}$ & $\mathbf{1}$ & .5 & 0 & 0 & 0 & .5 & $\mathbf{1}$ \\
\hline 0 & 0 & .5 & $\mathbf{1}$ & $\mathbf{1}$ & .5 & 0 & 0 & $\mathbf{1}$ & $\mathbf{1}$ \\
\hline-.5 & 0 & 0 & .5 & $\mathbf{1}$ & $\mathbf{1}$ & .5 & .5 & $\mathbf{1}$ & $\mathbf{1}$ \\
\hline-.5 & -1 & 0 & 0 & .5 & $\mathbf{1}$ & $\mathbf{1}$ & $\mathbf{1}$ & $\mathbf{1}$ & 0 \\
\hline-1 & -1 & -1 & -.5 & 0 & .5 & $\mathbf{1}$ & $\mathbf{1}$ & 0 & -2 \\
\hline-1 & -1 & -1 & -1 & -1 & 0 & .5 & .5 & -2 & -2.5 \\
\hline
\end{tabular}

b

Figure 4.3: Examples of a bull flag template

The grey cells indicate that the price has fallen. In (a) there is a price window that can fit a bull flag pattern. Summing the values of the dark cells, a total fitting value of 6.5 results. In (b) there is a price window whose total fitting value is also 6.5; however, it should not be considered a bull flag pattern.

This section tries to mitigate this inconvenience by making an alternative choice of weights. After having already defined the way in which the flag patterns are identified, the following step will consist in defining the trading system. According to Park and Irwin a technical trading system consists of a set of trading rules that generate trading signals according to various parameter values. In order to implement a trading system, it is necessary to determine the starting moment of the buying (selling) operation of an asset, and the conditions required to close the operation (Park and Irwin, 2007).

Figure 4.4 illustrates the proposed grid of weights:

\begin{tabular}{|l|l|l|l|l|l|l|l|l|l}
\hline $\mathbf{0}$ & $\mathbf{0}$ & $\mathbf{0}$ & $\mathbf{0}$ & $\mathbf{0}$ & $\mathbf{0}$ & $\mathbf{0}$ & $\mathbf{0}$ & $\mathbf{0}$ & $\mathbf{0}$ \\
\hline $\mathbf{0}$ & $\mathbf{0}$ & $\mathbf{0}$ & $\mathbf{0}$ & $\mathbf{0}$ & $\mathbf{0}$ & $\mathbf{0}$ & $\mathbf{0}$ & $\mathbf{0}$ & $\mathbf{0}$ \\
\hline $\mathbf{0}$ & $\mathbf{0}$ & $\mathbf{0}$ & $\mathbf{0}$ & $\mathbf{0}$ & $\mathbf{0}$ & $\mathbf{0}$ & $\mathbf{0}$ & $\mathbf{0}$ & $\mathbf{0}$ \\
\hline $\mathbf{0}$ & $\mathbf{0}$ & $\mathbf{0}$ & $\mathbf{0}$ & -1 & -1 & -1 & -1 & -1 & -1 \\
\hline $\mathbf{0}$ & $\mathbf{0}$ & $\mathbf{0}$ & -1 & -2 & -2 & -2 & -2 & -2 & -2 \\
\hline $\mathbf{0}$ & $\mathbf{0}$ & -1 & -3 & -3 & -3 & -3 & -3 & -3 & -3 \\
\hline $\mathbf{0}$ & -1 & -3 & -5 & -5 & -5 & -5 & -5 & -5 & -5 \\
\hline $\mathbf{0}$ & -1 & -5 & -5 & -5 & -5 & -5 & -5 & -5 & -5 \\
\hline $\mathbf{0}$ & -1 & -5 & -5 & -5 & -5 & -5 & -5 & -5 & -5 \\
\hline $\mathbf{5}$ & -1 & -5 & -5 & -5 & -5 & -5 & -5 & -5 & -5 \\
\hline
\end{tabular}

FIGURE 4.4: Grid of weights proposed to identify a bull flag pattern

The first difference with respect to the matrix in figure 4.1 can be found in the shape of the bull flag pattern. While Leigh, Modani et al. (2002), Leigh, Paz et al. (2002), Leigh, Purvis et al. (2002) and Wang and Chan (2007, 2009) use the consolidation and breakout version, the present work applies the breakout and consolidation version. This approach is more related to Downes and Goodman's definition of a flag. According to 
their definition, the breakout and consolidation movement should be followed by another breakout movement; and this last movement is the one used in order to define the trading rule (Downes and Goodman, 1998).

The second difference lies in the range of weights and in the distribution of the weights around the matrix. It is important to point out that the weight configuration is a key point of the methodology applied. Only one cell is labelled with a positive weight, the one located at the left bottom corner containing the value 5 . In order to obtain a positive fit value for a price window, the price should necessarily start from this cell. Cells labelled with a value of 0 indicate areas in which the price can move without negatively affecting the recognition of the flag pattern, while the cells with negative weight indicate areas which the price should not pass through if they try to assimilate the window to a flag pattern. Consequently, the more negative the value of a cell is, the greater the difference is with respect to the flag pattern.

The proposed weight distribution is related to the logic IF-THEN rule. This is done for approaching investors behaviour. An example serves as illustration of this matter: If deciding that those price windows whose fitting value is greater or equal to 4 are the only ones to be considered as flags, then the following conditions must take place:

1. Price should fall in the cell labelled with 5;

2. Price should visit one cell with negative weight at the most.

These two conditions strictly limit the cells in which the price can fall, thus at least eight of the ten price columns must fall in the cells labelled with 0. If both conditions are fulfilled (IF) then the price window is considered as bull flag pattern (THEN).

Logically, the minimum fit function value that a window should have, in order to be considered as flag pattern, depends on the analyst. A very demanding threshold will reduce the number of identified flags, restricting the statistical significance of the results. Conversely, choosing a more permissive threshold would not accurately define the shape in figure 4.4 .

The matching between the historical prices and the grid of weights represent another important difference with respect to other works. Instead of working with closing prices the present research applies the body of the candlesticks. This implies that a candlestick can fall in more than one cell per column and, therefore, the fitting function will not be found by only adding the value of the ten cells, since it could include a greater number. The candlesticks body variation is adopted instead of the simpler closing price in order to include more information about the price evolution. The total range of the candlestick 
(the high and low difference) was not used since these extremes represent price levels which have already been reached after the opening and rejected before the closing.

Further, instead of working with daily data only, the present research project applies intraday data in two different frequency intervals. The main time interval applied is 15 minutes, whilst one analysis also adopts an hourly interval. This leads to a very large data base which was worked with.

Another important change with respect to works previously cited is the use of stop loss SL and take profit TP variables. Teixeira and Oliveira (2010) have already used these kind of thresholds within their study (Teixeira and de Oliveira, 2010). The use of these two variables will limit both - the loss (SL) and the profit (TP) of each one of the operations. In this way, the closing of the operations can be done in a dynamic way, instead of keeping them open during a fixed period of time (Leigh et al., 2002c; Leigh et al., 2002b; Leigh et al., 2002a; Wang and Chan, 2007; Wang and Chan, 2009).

\subsection{Explanation of the algorithm applied}

The method described in the previous section is implemented by an algorithm. The program worked with is called RStudio. R statistical language is applied with the aim of gathering data and analysing it (Gandrud, 2015).

The following figure 4.5 shows an extract from the program code applied:

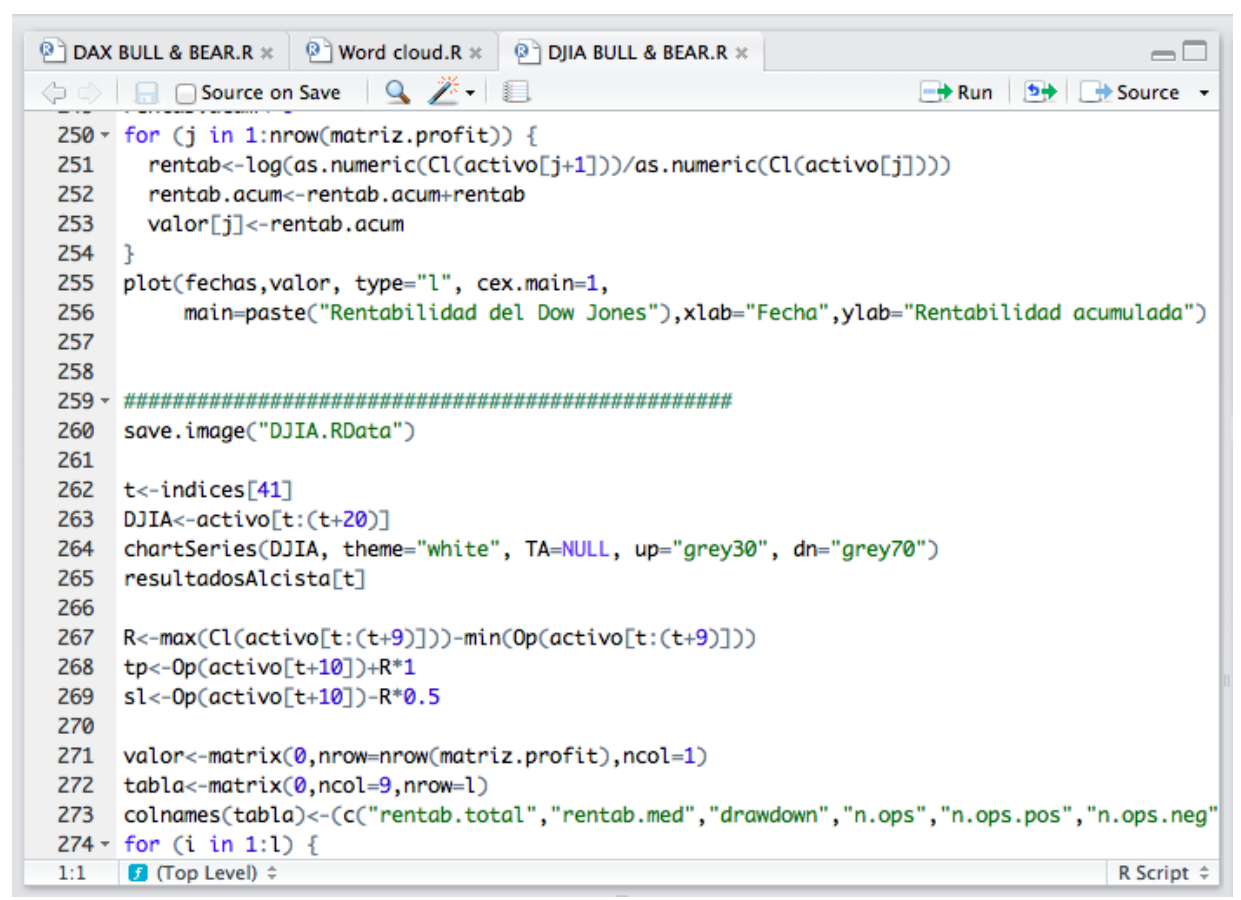

FIGURE 4.5: Extract from the program code in RStudio 
The objective of this section is to give a functional overview of the different processes executed by the algorithm. It is not aimed to show the complete program code itself since only the causal relation of processes is in the limelight.

The whole process can be summarized into eight steps which are displayed in the following figure 4.6 :

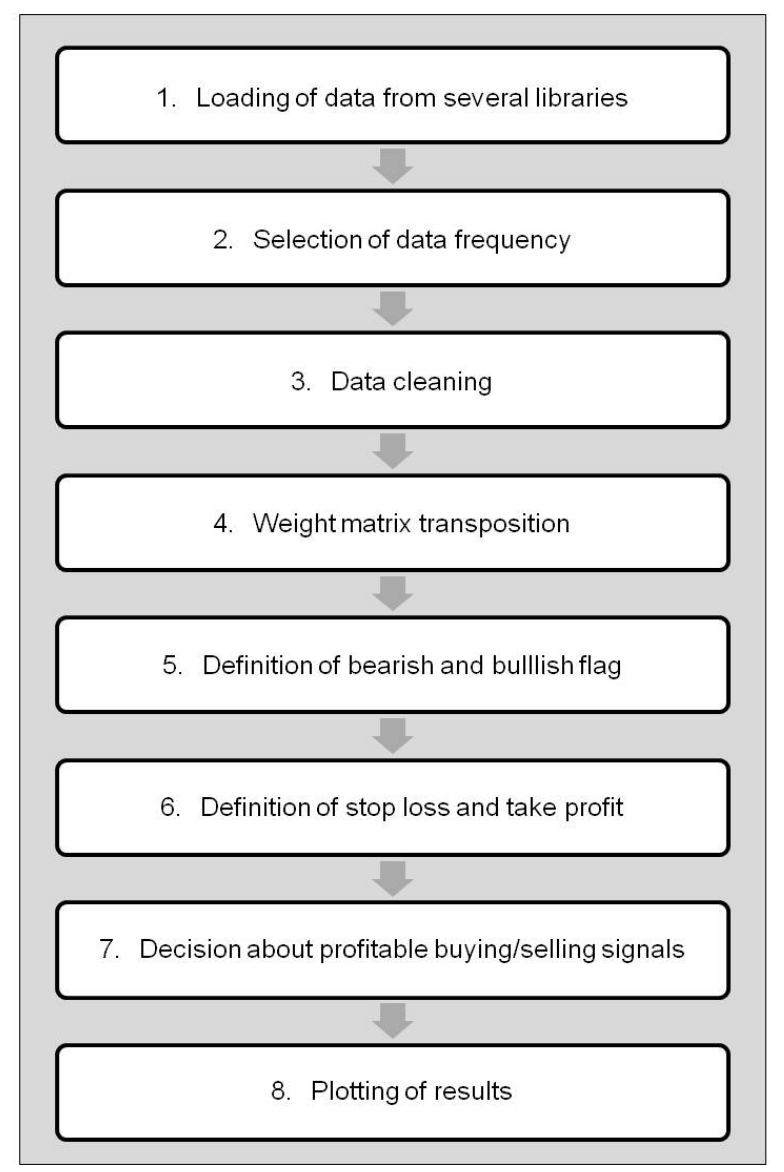

Figure 4.6: Processes performed by the algorithm

\section{PROCESS 1}

For starting the process and the work itself, in the first step, the data has to be loaded from different libraries. Each library (e.g. fImport which enables data import from Yahoo Finance) has a different function, thus, loading the complete data sets is required.

\section{PROCESS 2}

In the second process, the frequency of the analysed data is determined. In the majority of performed analyses, the data is analysed at time intervals of 15 minutes. In case of a single analysis, the frequency is selected to be an hourly interval. Thus, if changing the frequency of data, this is the only section in the program code where a minor adaptation 
has to be made. The result of this step is a csv.file containing a huge amount of rows in a table with information about date, time, the stock's price (open, high, low and close) and volume for the selected time frequency as illustrated exemplary for the DAX in the figure 4.7 below:

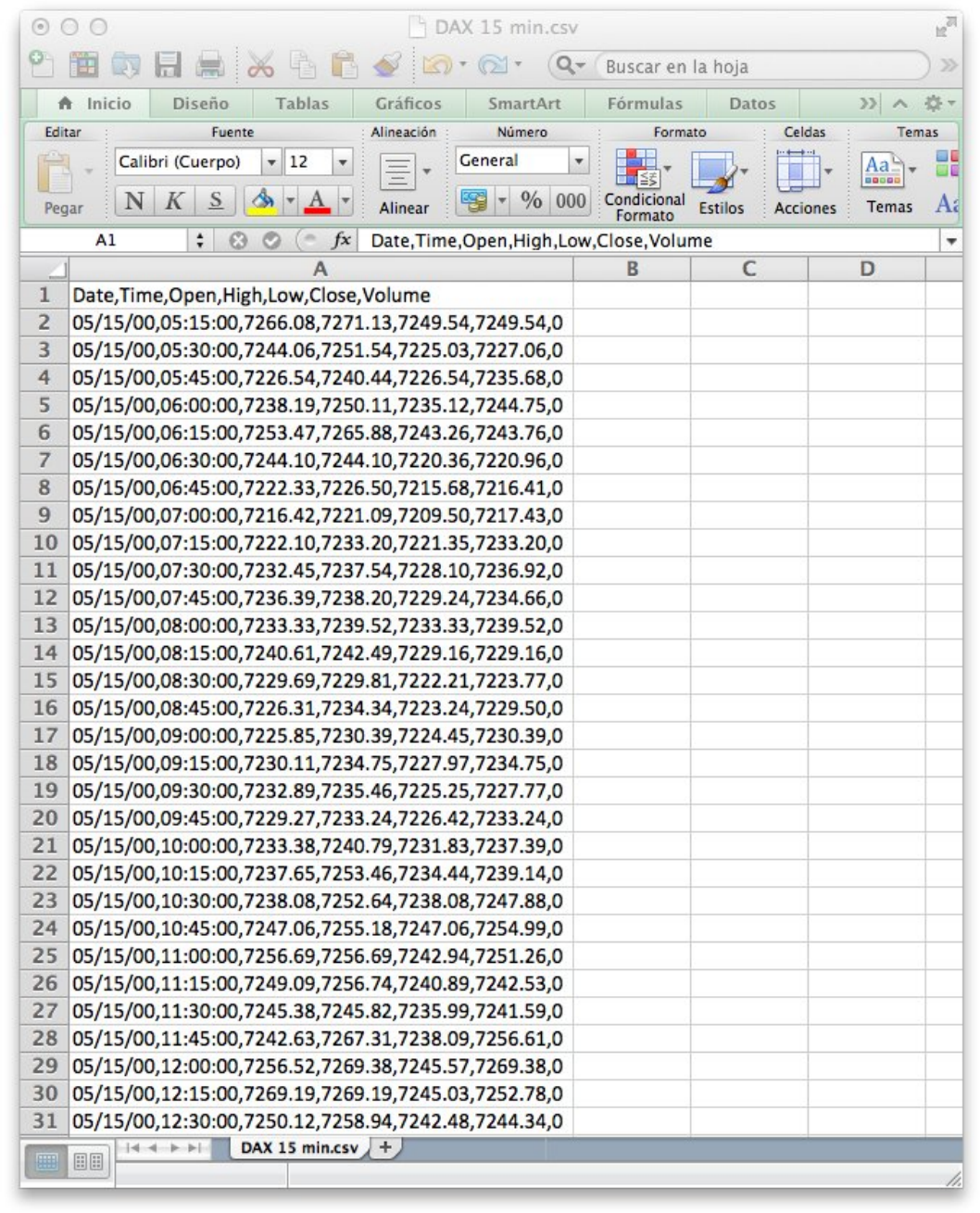

Figure 4.7: Extracted data file for the DAX

\section{PROCESS 3}

In the third process, the data is "cleaned" and made applicable for future steps. Unfortunately, the extracted data file contains information for seven weekdays but the financial markets' operating hours are from Monday to Friday only. As as result, the libraries provide data for Saturdays and Sundays which is equal to the previous Friday's data. Thus, price information for every Friday is included three times in the data set. Therefore "cleaning" the data means eliminating all the Saturday's and Sunday's information for the selected index. The result is a reduced data file containing the index's correct Monday to Friday price information at time intervals of 15 minutes. 


\section{PROCESS 4}

The forth process of the algorithm deals with the weight matrix which defines the flag (see figure 4.4). To be able to work with the matrix, the algorithm transposes the matrix at this stage.

\section{PROCESS 5}

The fifth process deals with the definition of the bearish and bullish flag. This step answers the question how to identify a flag.

\section{PROCESS 6}

The sixth process defines the SL and TP values to enable buying the bullish flag and selling the bearish flag. This process is called "loop" since several configurations of fit value, SL and TP thresholds are tested here. The results will be displayed i.a. in tables 4.6, 4.8 and 4.12 .

The values for the SL level are derived directly from the matrix. As already illustrated, the matrix consists of ten rows and ten columns with a total of 100 cells. For the determination of SL thresholds the horizontal perspective, namely the rows, are essential.

The first three rows of the weight matrix only contain cells labelled with value 0 . Therefore the line underneath the third row can be understood as support line since, starting from the top of the grid, in the first $30 \%$ of rows the values of 0 would not affect the bull flag recognition. Thus, a SL of 0.3 would correspond to this support line as illustrated in the following figure 4.8 :

\begin{tabular}{|c|c|c|c|c|c|c|c|c|c|c|c|}
\hline \multirow{10}{*}{ support line } & 0 & 0 & 0 & 0 & 0 & 0 & 0 & 0 & 0 & 0 & \multirow{3}{*}{$\begin{array}{l}\leftarrow S L=0.2 \\
\leftarrow S L=0.3\end{array}$} \\
\hline & 0 & 0 & 0 & 0 & 0 & 0 & 0 & 0 & 0 & 0 & \\
\hline & 0 & 0 & 0 & 0 & 0 & 0 & 0 & 0 & 0 & 0 & \\
\hline & 0 & 0 & 0 & 0 & -1 & -1 & -1 & -1 & -1 & -1 & $\leftarrow S 1=0.4$ \\
\hline & 0 & 0 & 0 & -1 & -2 & -2 & -2 & -2 & -2 & -2 & \\
\hline & 0 & 0 & -1 & -3 & -3 & -3 & -3 & -3 & -3 & -3 & \\
\hline & 0 & -1 & -3 & -5 & -5 & -5 & -5 & -5 & -5 & -5 & \\
\hline & 0 & -1 & -5 & -5 & -5 & -5 & -5 & -5 & -5 & -5 & \\
\hline & 0 & -1 & -5 & -5 & -5 & -5 & -5 & -5 & -5 & -5 & \\
\hline & 5 & -1 & -5 & -5 & -5 & -5 & -5 & -5 & -5 & -5 & 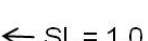 \\
\hline
\end{tabular}

FigURE 4.8: Causal link between grid of weights and stop loss levels

A value of 0.2 as SL threshold would be a row above the support line while a row underneath the support line would correspond to a SL value of 0.4. If the second to ninth 
candlesticks are completely located in the area above the support line, the likelihood of identifying a flag pattern is not affected due to the values of 0 .

The determination of corresponding take profit values more or less follow the same logic and is less complex when determining the adequate value: In accordance with technical trading rules, the TP value has to be at least 1 or $100 \%$. In case of all analyses other values (e.g. up to 2 or 3 ) were applied as TP to check the robustness of the strategy.

In case of the analysis for the DAX, the loop for all configurations of SL, TP and threshold contain more than 200 constellations to check the robustness of the strategy. For both, the bearish and the bullish flag, the strategy and the corresponding configurations are repeated.

\section{PROCESS 7}

In the seventh process the decision whether a buying or selling signal is profitable or not is made. In general, there are more signals which lead to losses than signals which lead to profits. If the SL value is set to be 0.2 , for example, than the maximum possible loss is limited to $20 \%$. Profits would not be designated as maximum accepted or limited but a TP of e.g. 1 or $100 \%$ could be determined as displayed in figure 4.9:

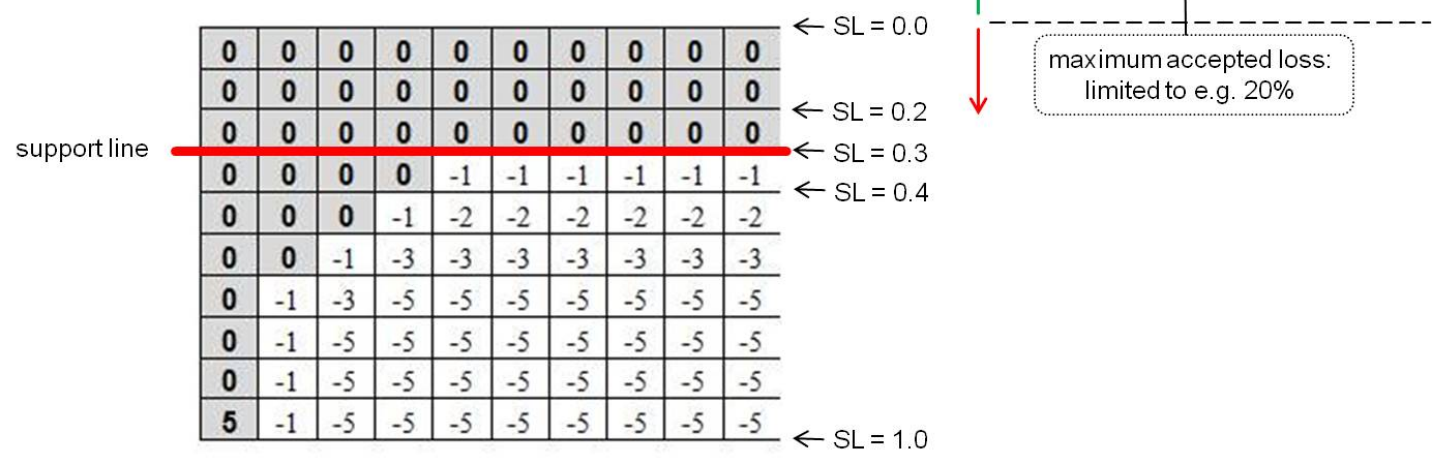

Figure 4.9: Hit Ratio: Relation between profits and losses

The hit ratio (HR) defines the relation between profits and losses and gives information about the percentage of profitable trades. 
The following calculation example serves as an illustration of how to calculate the minimum HR, assuming a transaction which consists of a total of six trades. Further, it is assumed that only one trade of these six trades was profitable and the remaining five trades were not profitable. The SL threshold is set to 0.4 and the TP equals to 2 .

In the first step, the profit for the profitable trade is subject to calculation. In the case of one profitable trade the profit would equal 2, which corresponds to the TP value. After determining the profit for the profitable trade, the second step deals with calculating the losses for the unprofitable trades. Thus, the remaining five negative trades would also have a loss of 2. This is reasoned in the SL value of 0.4 which is accepted for each one of the five negative trades. Thus, the profit of 2 and the loss of 2 would balance and lead in total to 0 .

The following figure 4.10 illustrates the calculation:

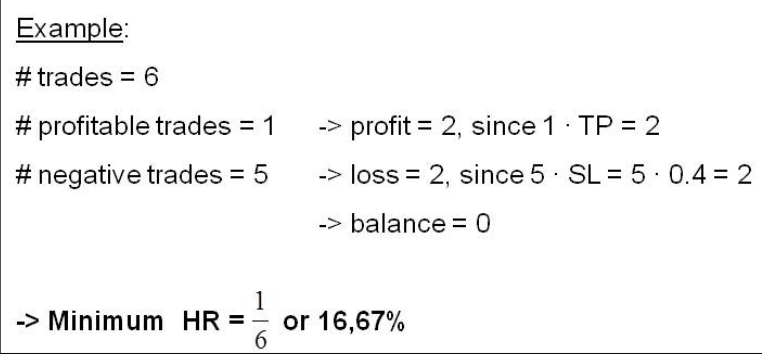

\begin{tabular}{|l|l|l|l|l|l|l|l|l|l|}
\hline $\mathbf{0}$ & $\mathbf{0}$ & $\mathbf{0}$ & $\mathbf{0}$ & $\mathbf{0}$ & $\mathbf{0}$ & $\mathbf{0}$ & $\mathbf{0}$ & $\mathbf{0}$ & $\mathbf{0}$ \\
\hline $\mathbf{0}$ & $\mathbf{0}$ & $\mathbf{0}$ & $\mathbf{0}$ & $\mathbf{0}$ & $\mathbf{0}$ & $\mathbf{0}$ & $\mathbf{0}$ & $\mathbf{0}$ & $\mathbf{0}$ \\
\hline $\mathbf{0}$ & $\mathbf{0}$ & $\mathbf{0}$ & $\mathbf{0}$ & $\mathbf{0}$ & $\mathbf{0}$ & $\mathbf{0}$ & $\mathbf{0}$ & $\mathbf{0}$ & $\mathbf{0}$ \\
\hline $\mathbf{0}$ & $\mathbf{0}$ & $\mathbf{0}$ & $\mathbf{0}$ & -1 & -1 & -1 & -1 & -1 & -1 \\
\hline $\mathbf{0}$ & $\mathbf{0}$ & $\mathbf{0}$ & -1 & -2 & -2 & -2 & -2 & -2 & -2 \\
\hline $\mathbf{0}$ & $\mathbf{0}$ & -1 & -3 & -3 & -3 & -3 & -3 & -3 & -3 \\
\hline $\mathbf{0}$ & -1 & -3 & -5 & -5 & -5 & -5 & -5 & -5 & -5 \\
\hline $\mathbf{0}$ & -1 & -5 & -5 & -5 & -5 & -5 & -5 & -5 & -5 \\
\hline $\mathbf{0}$ & -1 & -5 & -5 & -5 & -5 & -5 & -5 & -5 & -5 \\
\hline $\mathbf{5}$ & -1 & -5 & -5 & -5 & -5 & -5 & -5 & -5 & -5 \\
\hline
\end{tabular}

Figure 4.10: Calculation example of the Hit Ratio

In conclusion, to pursue a profitable strategy the HR must be higher than $\frac{1}{6}$ or $16.67 \%$. Considering 100 trades a minimum of 17 profitable trades are needed to pursue a successful strategy. 


\section{PROCESS 8}

The eighth process describes the visualisation and illustration of results in tables and figures. Tables and figures, as included in the present research project, are realized with the plot function of the algorithm.

Eventually, there could exist a ninth step which would include repeating the whole process for non-overlapping sub-periods.

\subsection{Country information}

\subsubsection{Germany}

The first country which is analysed is Germany. Germany with its capital in Berlin is a federal state in central Europe and a member state of the EU and the Euro zone. As the most populous country after Russia, Germany is one of the leading industrial powers and one of the biggest exporting nations (Lexas Information Network, 2015a).

After Germany's defeat in World War II, in 1945 the country was divided into two states. The Western state formed the Federal Republic which was affiliated with democratic, Western powers and subsequently had a free market economy, whereas the Eastern state became the Democratic Republic and was a part of the Soviet Bloc and it's corresponding communist market. The collapse of the Soviet bloc in 1989 cleared the way for the reunification of Germany in 1990. Since 1990, the Federal Republic is made up of 16 states (Lexas Information Network, 2015a).

Germany's population in 2011 was 80.2 million inhabitants, of which 3.5 million live in Berlin. $7.7 \%$ of the German inhabitants are foreigners. Germany covers a total area of $357,050 \mathrm{~km}^{2}$ (Auswärtiges Amt, 2015b). This equates to a population density of 230 inhabitants per $\mathrm{km}^{2} .88,91 \%$ of Germany's inhabitants live in urban areas. The average age is 42.6 years. Germany records a light positive annual population growth of $0.02 \%$. The average life expectancy is 78.8 years for males and 83.4 years for females (2013) (Welt-in-Zahlen.de, 2015b).

Currently, Germany's economy is characterized by an unusually high level of unemployment, particularly in Eastern Germany, and by relatively low economic growth rates which are mainly due to stagnant domestic demand (Lexas Information Network, 2015a). The unemployment rate equals to $5.3 \%$ (2013) while economic growth makes only $1.50 \%$ per year (2014). The gross domestic product (GPD) is 3.8 billion USD (2014), which is $1.60 \%$ higher than in the previous year and corresponds to a GPD per person of 47,590 
USD (Auswärtiges Amt, 2015b). $0.90 \%$ of the GDP is earned by agriculture, $30.70 \%$ by industry and $68.40 \%$ by services (2013). The annual inflation rate compared to the previous year (2014) is $0.80 \%$ and the national debt corresponds to $74.5 \%$ of the GDP (2014) (Welt-in-Zahlen.de, 2015b).

Since the present $\mathrm{PhD}$ project grew from a cooperation between two universities located in Germany and Spain, along with having a stable economy, Germany was a logical selection for analysis in this thesis.

\subsubsection{USA}

The second country which is subject to analysis is the USA. The United States emerged in 1776 with the declaration of independence of the British colonies in America and rapidly won influence by strong industrialization and massive immigration from Europe in the 19th century. After overcoming the totalitarian fascism (during World War II) and communism (during the Cold War), the USA were the only remaining superpower at the end of the 20th century. Through their hegemony the USA shaped world events. Until today, the consumerist embossed American way of life has great influence on world cultures (Lexas Information Network, 2015c). Currently, the United States of America (USA) count 50 states and the Federal District of Columbia. The capital of the USA is Washington, D.C.

Actually, the USA has 320 million inhabitants (March 2015) of which approximately 39 million are African Americans, approximately 50.5 million Americans have a Latin American origin, 14.7 million are Asian Americans and about 3 million are of Indian origin. 658,000 inhabitants live in Washington, D.C. The USA covers a total area of $9,857,306 \mathrm{~km}^{2}$ (about 25 times the size of Germany) with a population density of 33 people per $\mathrm{km}^{2}$. Roughly $82 \%$ of the population lives in urban areas (Auswärtiges Amt, 2015c).

The average age is 36.5 years (Welt-in-Zahlen.de, 2015a). The USA has a slight positive annual population growth of $0.7 \%$. While the average male life expectancy is 76.5 years, the female life expectancy is 81.3 years (2013) (Statistisches Bundesamt, 2015a).

The economy of the USA can be described as follows: The gross domestic product (GPD) makes in total 17.74 billion USD (2014), which corresponds to a GPD per person of 55,438 USD (Auswärtiges Amt, 2015c). 1.3\% of the GDP is earned by agriculture, $21.0 \%$ by industry and $77.7 \%$ by services (2012). The annual inflation is $1.50 \%$ (2013) and the national debt corresponds to $101.53 \%$ (2014) of the GDP. The unemployment 
rate is $7.40 \%$ (2013) while economic growth makes 2.20\% (2013) per year (Statistisches Bundesamt, 2015a).

Throughout the last decade, the U.S. has experienced some interesting economic developments, such as the real estate bust and the financial crisis, whilst still maintaining its superpower status. Therefore the U.S. has been included into the present analysis.

\subsubsection{Spain}

The third country considered within the analysis is Spain. In the late 19th century Spain (officially the Kingdom of Spain) lost many of its colonies to America by wars of independence. In 1936 to the time of the Spanish Civil War, the career of the dictator Franco began in Spain. Today, the country has no more colonies. The democracy was officially introduced in 1978.

Today's form of government is called Parliamentary hereditary monarchy; the king of Spain is Felipe VI. Spain is located in South Western Europe and occupies most of the Iberian Peninsula. The capital is Madrid (Lexas Information Network, 2015b).

46.7 million people live in Spain, whereof 3.16 inhabitants reside in Madrid (2014). 13\% of Spain's population are foreigners. Spain covers a total area of 505,990 $\mathrm{km}^{2}$, with a population density of 81 people per $\mathrm{km}^{2} .76 .5 \%$ of the Spanish population lives in urban areas. The average age in Spain is 40.1 years while the average life expectancy is 85.57 years for females and 76.74 years for males. The annual population growth is about 0.65\% (Lexas Information Network, 2015b).

Spain has an economic growth of $1.4 \%$ and an inflation rate of $0.27 \%$ (2014) (Statistisches Bundesamt, 2015b). In 2013, Spain generated a GDP of 1,393 billion USD which equals to a GDP per person of 29,863 USD. $3.80 \%$ of the GDP is earned by agriculture, $30.10 \%$ by industry and $66.10 \%$ by services. The national debts makes $97.6 \%$ of the GDP (2014). The unemployment rate is $23.7 \%$ (2014) (Auswärtiges Amt, 2015a).

As previously explained, the present $\mathrm{PhD}$ project is being undertaken in conjunction with two universities, one of which is located in Spain, hence the inclusion of Spain in the present analysis. 


\subsubsection{Final overview}

The three countries presented form the focus for the present analysis. To gain a better overview about the key facts of each country, this section will briefly summarize the demographic and economic information of each country. In the end, a correlation matrix will be displayed.

The following table 4.1 summarizes and compares the demographic information of each country:

TABle 4.1: Overview: Demographic information of Germany, the USA and Spain

\begin{tabular}{llllll} 
Country & $\begin{array}{l}\text { population } \\
\text { (million) }\end{array}$ & $\varnothing$ age & $\begin{array}{l}\varnothing \text { life expectancy } \\
(\mathrm{m})\end{array}$ & $\begin{array}{l}\varnothing \text { life expectancy } \\
(\mathrm{f})\end{array}$ & $\begin{array}{l}\text { population } \\
\text { growth }\end{array}$ \\
\hline Germany & 80.2 & 42.6 & 78.8 & 83.4 & $0.02 \%$ \\
USA & 320 & 36.5 & 76.5 & 81.3 & $0.7 \%$ \\
Spain & 46,7 & 40.1 & 76.7 & 85.6 & $0.65 \%$ \\
\hline
\end{tabular}

It can be seen that the demographic aspects of each country with regard to average age and life expectancies are comparable. This is an indication that the medical care in all countries is on a comparable level. With by far the largest area of the three analysed countries, it's no surprise that the U.S. also has the largest population. The annual population growth in the USA and in Spain is nearly on the same level while in Germany it is nearly non-existent.

The following table 4.2 summarizes and compares the economic information of each country:

TABLE 4.2: Overview: Economic information of Germany, the USA and Spain

\begin{tabular}{lllllll} 
Country & $\begin{array}{l}\text { GDP } \\
\text { (billion } \\
\text { USD) }\end{array}$ & $\begin{array}{l}\text { GDP per } \\
\text { person } \\
\text { (USD) }\end{array}$ & $\begin{array}{l}\text { Unemployment } \\
\text { rate }\end{array}$ & $\begin{array}{l}\text { Economic } \\
\text { growth }\end{array}$ & $\begin{array}{l}\text { Inflation } \\
\text { rate }\end{array}$ & $\begin{array}{l}\text { National } \\
\text { debt }\end{array}$ \\
\hline Germany & 3.8 & 47,590 & $5.30 \%$ & $1.50 \%$ & $0.80 \%$ & $74.5 \%$ \\
USA & 17.74 & 55,438 & $7.40 \%$ & $2.20 \%$ & $1.50 \%$ & $101.53 \%$ \\
Spain & 1,393 & 29,863 & $23.7 \%$ & $1.40 \%$ & $0.27 \%$ & $97.6 \%$ \\
\hline
\end{tabular}

As illustrated, the USA gain the highest GDP per person of all three countries, followed by Germany and Spain. The unemployment rate in Spain is the highest of all, while Germany has the lowest. With regard to the economic growth all three countries are on a comparable level. The inflation rate in Spain is the lowest, followed by Germany and the USA. While the national debt in \% of the GDP is the highest in USA and Spain, Germany shows a much lower national debt. 
In summarising, all three countries show some varying differences, however, they are all in some way comparable with regard to economic and demographic aspects.

The correlation between returns of DAX, DJIA and IBEX should help to understand that they are positively correlated, but the correlation is not 1 . So the strategy will be applied over markets that are far from being perfectly correlated, as displayed in the following tables 4.3 and 4.4 :

TABLE 4.3: Correlation between DAX, DJIA and IBEX, weekly data from January 4, 2010 to November 23, 2015

\begin{tabular}{|l|r|r|r|}
\hline & DAX & DJIA & IBEX \\
\hline DAX & 1.00 & 0.76 & 0,75 \\
DJIA & 0.76 & 1.00 & 0.64 \\
IBEX & 0.75 & 0.64 & 1.00 \\
\hline
\end{tabular}

TABLE 4.4: Correlation between DAX, DJIA and IBEX, daily data from January 2, 2015 to November 27,2015

\begin{tabular}{|l|r|r|r|}
\hline & DAX & DJIA & IBEX \\
\hline DAX & 1.00 & 0.53 & 0,83 \\
DJIA & 0.53 & 1.00 & 0.52 \\
IBEX & 0.83 & 0.52 & 1.00 \\
\hline
\end{tabular}

The correlation was calculated for the open, high, low and end price on daily and on weekly basis. Finally an average was calculated of the four correlation coefficients and used to display it on weekly and daily basis within the present analysis. The tables show a strong positive correlation between the three indices since the correlation coefficient for both periods is above 0.5 (Cohen, 1988).

\subsection{Analysis of international stock markets}

\subsubsection{Germany (DAX)}

The German stock market is the first analysed market within the present doctoral thesis. The stock market is not a single place but more a network of different and connected markets where stocks are bought and sold (Zuravicky, 2005). The chosen index for the following analysis is the DAX (German Stock Index).

The DAX is a stock index first published on July 1, 1988 and includes the 30 largest and most actively traded German stocks (blue chips). Currently, more than $80 \%$ of capital stock of domestic listed companies is represented by the DAX. Thus, the DAX is 
one of the most influential markets in the European Stock Market (finanzen.net GmbH, 2015a).

The following table 4.5 provides an overview of the DAX's development within the last 15 years (finanzen.net GmbH, 2015a):

TABLE 4.5: Historic lows and highs for the DAX, 2000-2015

\begin{tabular}{rrrrrr} 
Year & Annual start & Annual end & Annual low & Annual high & $\%$ \\
\hline 2015 & $9,764.73$ & - & $9,469.66$ & $12,374.73$ & 19.99 \\
2014 & $9,400.04$ & $9,805.55$ & $8,571.95$ & $10,087.12$ & 4.31 \\
2013 & $7,778.78$ & $9,552.16$ & $7,459.96$ & $9,589.39$ & 22.80 \\
2012 & $6,075.52$ & $7,655.88$ & $5,969.40$ & $7,672.10$ & 26.01 \\
2011 & $6,989.74$ & $5,898.35$ & $5,072.33$ & $7,527.64$ & -15.61 \\
2010 & $5,975.52$ & $6,914.19$ & $5,476.47$ & $7,077.99$ & 15.71 \\
2009 & $4,973.07$ & $6,002.29$ & $3,666.41$ & $6,010.92$ & 20.70 \\
2008 & $8,045.97$ & $4,810.20$ & $4,127.41$ & $8,045.97$ & -40.22 \\
2007 & $6,614.73$ & $8,010.89$ & $6,495.85$ & $8,101.89$ & 21.11 \\
2006 & $5,410.24$ & $6,617.85$ & $5,298.62$ & $6,617.85$ & 22.32 \\
2005 & $4,260.92$ & $5,446.79$ & $4,160.26$ & $5,464.00$ & 27.83 \\
2004 & $3,969.04$ & $4,254.38$ & $3,643.08$ & $4,270.56$ & 7.19 \\
2003 & $2,898.68$ & $3,957.93$ & $2,203.97$ & $3,957.93$ & 36.54 \\
2002 & $5,155.26$ & $2,838.87$ & $2,593.26$ & $5,453.95$ & -44.93 \\
2001 & $6,431.14$ & $5,110.22$ & $3,792.86$ & $6,788.57$ & -20.54 \\
2000 & $6,961.72$ & $6,376.10$ & $6,210.81$ & $8,069.98$ & -8.41 \\
\hline
\end{tabular}

It can be observed that the DAX has recovered from the financial crisis in 2008/2009 long ago. The current high is the highest within the last 15 years. After weak years in 2003, 2004, 2005 and 2009, since 2012 the DAX records positive growth.

The trading rule can be fully characterized by combining pattern recognition with the use of SL and TP.

In this case, the matching between the grid of weights of figure 4.4 and the 10 first candlesticks' window shows how all the candlestick bodies locate themselves over cells labelled with value 0 , except the first one which locates over the cell with value 5 . Therefore, the fit function will take the maximum possible value 5 , which indicates that the price window will perfectly fit the flag pattern defined.

Once the bull flag pattern has been identified, the buying price will take place at 7,892 points (the opening of the candle number 11). When fixing the SL and the TP the following was considered:

- Their value is not constant, but proportional to the price range $\mathrm{R}$ observed in the pattern. Thus, if the flag had been developed over a narrow range of prices, then 
the SL and the TP will be small. In the case the flag was developed over a wide range of prices, the SL and the TP would be relatively big.

- The TP value will always be greater than the SL value. Thus, investors make sure that the return obtained with the operation will always be higher than the risk assumed. It is reasonable to think that an investor will only carry out an operation if the risk assumed does not exceed the profit expected from the operation.

Figure 4.11 contains an example for intraday data of the German Stock Index DAX:

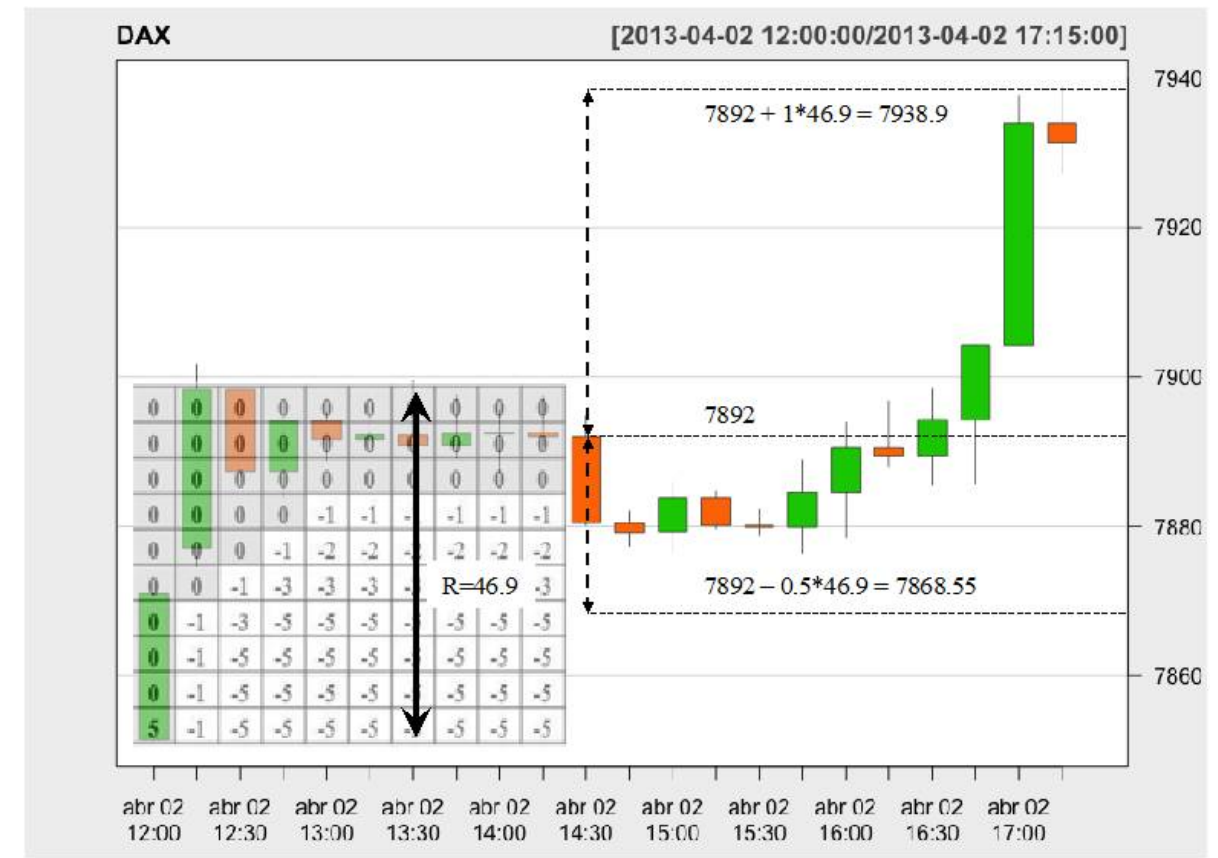

Figure 4.11: Japanese Candlesticks figure for the German Stock Index DAX from 12:00 a.m. to 5:15 p.m. on April 2, 2013 at time intervals of 15 minutes

Identification of a bull flag which corresponds to the first 10 candlesticks of the period, with fit value $=5$. The price range during the flag is $\mathrm{R}=46.9$. The stop loss (SL) is calculated as the difference between the opening price of the same candlestick minus 0.5 times $\mathrm{R}(7,868.55)$, and the take profit (TP) as the same opening price plus one time $\mathrm{R}$ $(7,938.9)$. The operation closes at 5:15 p.m. when the price reaches the TP level.

Taking into account these two assumptions for the operation shown in figure 4.4, the results show a price range $\mathrm{R}=46.9$ points, a $\mathrm{TP}=7,892+1^{*} 46.9=7,938.9$ and a $\mathrm{SL}$ $=7,892-0.5^{*} 46.9=7868.55$. Therefore, the expected profit for this operation will be twice the maximum loss disposing to assume.

The trading rule based on the flag pattern has been applied to intraday data of the German Stock Index DAX. The use of intraday data allows for the increase of the sample size in a very significant way in comparison to daily data. Furthermore, by increasing the sample size it is not necessary to consider historical data delayed in time in order to count with a sample size that is insignificant. The use of very old historical data can lead 
to a contradiction already remarked in the literature: to validate an investment strategy based on technology which, by that time, was not available to investors (Sullivan et al., 1999; Timmermann and Granger, 2004).

The data used for the study is extracted at time intervals of 15 minutes, and covers the period from May 15, 2000 to October 4, 2013. The sample is comprised by 127,480 Japanese candlesticks and seems to be the greatest sample which has ever been used for the analysis of a trading rule. In order to improve the robustness of the results the following was configured:

1. the fit function threshold which will allows the identification of the flag patterns,

2. the stop loss value according to the price range $\mathrm{R}$, and

3. the take profit value according to the price range $\mathrm{R}$.

The trading rule has been implemented over the following values:

$$
\begin{gathered}
\text { threshold fit value } \in\{1,2,3,4,5\} \\
S L \in\{0.2,0.4,0.6,0.8\} \\
T P \in\{1.0,1.2,1.4,1.6,1.8,2.0,2.2,2.4,2.6,2.8,3.0\}
\end{gathered}
$$

where the SL and the TP values are defined by multiples of the range $\mathrm{R}$.

The combination of these three parameters gives a total of 220 different configurations from the trading rule. For each one of them the total number of operations, the total return and the maximum drawdown were found.

The drawdown allows measuring the risk of the trading rule. Since the returns of this kind of strategy do not follow a normal distribution, it will not be possible to use the statistical t (Leigh et al., 2002a).

The drawdown $D_{t}$ at time $t$ is defined as the fall in the total return (TR) curve from the previous maximum in $s, s<t$. For example, if at time $s$ the return curve reaches a new maximum of $T R_{s}=60 \%$, and after several operations the total return drops in $t$ until $T R_{t}=45 \%$, then the drawdown at time $t$ would be $15 \%$.

$$
\begin{gathered}
D_{t}=\max _{s<t} T R_{s}-T R_{t} \\
M D=\max _{t} D_{t}
\end{gathered}
$$


The maximum drawdown corresponds to the maximum loss experienced during all the period, keeping some similitude with the value at risk (VAR).

Table 4.6 shows the results provided by the application of the trading rule for the 220 analysed configurations. As illustrated, 208 of the 220 configurations provide positive returns, which equates to $94.5 \%$. If considering the risk, in 189 configurations $(85.9 \%)$ the return exceeds the maximum drawdown; therefore, in all cases the investor would have obtained a favourable risk-adjusted return, since the final return is greater than the maximum loss experienced during the whole period.

TABLE 4.6: Trading rule results over the DAX Index, intraday data at time intervals of 15 minutes

127,480 Japanese candlesticks analysed from May 15, 2000 to October 4, 2013. $\mathrm{SL}=$ Stop Loss (times R); TP = Take Profit (times R); TR = Total Return; $\mathrm{MD}=$ Maximum Drawdown; $\mathrm{TR}>\mathrm{MD}=$ is TR greater than MD? Yes/No

\begin{tabular}{|c|c|c|c|c|}
\hline SL & TP & TR & $\mathrm{MD}$ & $\mathrm{TR}>\mathrm{MD}$ \\
\hline \multirow{11}{*}{0.8} & 3.0 & -0.785 & 0.922 & $\mathrm{~N}$ \\
\hline & 2.8 & -0.534 & 0.743 & $\mathrm{~N}$ \\
\hline & 2.6 & -0.502 & 0.789 & $\mathrm{~N}$ \\
\hline & 2.4 & -0.379 & 0.695 & $\mathrm{~N}$ \\
\hline & 2.2 & -0.298 & 0.660 & $\mathrm{~N}$ \\
\hline & 2.0 & -0.391 & 0.694 & $\mathrm{~N}$ \\
\hline & 1.8 & -0.298 & 0.596 & $\mathrm{~N}$ \\
\hline & 1.6 & -0.412 & 0.652 & $\mathrm{~N}$ \\
\hline & 1.4 & -0.129 & 0.477 & $\mathrm{~N}$ \\
\hline & 1.2 & -0.158 & 0.451 & $\mathrm{~N}$ \\
\hline & 1.0 & -0.167 & 0.411 & $\mathrm{~N}$ \\
\hline \multirow{11}{*}{0.6} & 3.0 & -0.048 & 0.537 & $\mathrm{~N}$ \\
\hline & 2.8 & 0.163 & 0.376 & $\mathrm{~N}$ \\
\hline & 2.6 & 0.262 & 0.413 & $\mathrm{~N}$ \\
\hline & 2.4 & 0.316 & 0.382 & $\mathrm{~N}$ \\
\hline & 2.2 & 0.350 & 0.379 & $\mathrm{~N}$ \\
\hline & 2.0 & 0.280 & 0.328 & $\mathrm{~N}$ \\
\hline & 1.8 & 0.423 & 0.239 & $\mathrm{Y}$ \\
\hline & 1.6 & 0.271 & 0.231 & $\mathrm{Y}$ \\
\hline & 1.4 & 0.393 & 0.206 & $\mathrm{Y}$ \\
\hline & 1.2 & 0.326 & 0.198 & $\mathrm{Y}$ \\
\hline & 1.0 & 0.223 & 0.243 & $\mathrm{~N}$ \\
\hline
\end{tabular}

\begin{tabular}{|c|c|c|c|c|}
\hline SL & TP & TR & $\mathrm{MD}$ & $\mathrm{TR}>\mathrm{MD}$ \\
\hline \multirow{11}{*}{0.4} & 3.0 & 0.144 & 0.430 & $\mathrm{~N}$ \\
\hline & 2.8 & 0.371 & 0.280 & $\mathrm{Y}$ \\
\hline & 2.6 & 0.515 & 0.279 & $\mathrm{Y}$ \\
\hline & 2.4 & 0.497 & 0.276 & $\mathrm{Y}$ \\
\hline & 2.2 & 0.546 & 0.262 & $\mathrm{Y}$ \\
\hline & 2.0 & 0.403 & 0.219 & $\mathrm{Y}$ \\
\hline & 1.8 & 0.572 & 0.193 & $\mathrm{Y}$ \\
\hline & 1.6 & 0.462 & 0.219 & $Y$ \\
\hline & 1.4 & 0.606 & 0.151 & $\mathrm{Y}$ \\
\hline & 1.2 & 0.448 & 0.164 & $\mathrm{Y}$ \\
\hline & 1.0 & 0.367 & 0.131 & $Y$ \\
\hline \multirow{11}{*}{0.2} & 3.0 & 0.446 & 0.235 & $\mathrm{Y}$ \\
\hline & 2.8 & 0.510 & 0.206 & $\mathrm{Y}$ \\
\hline & 2.6 & 0.535 & 0.222 & $Y$ \\
\hline & 2.4 & 0.541 & 0.186 & $\mathrm{Y}$ \\
\hline & 2.2 & 0.615 & 0.151 & $\mathrm{Y}$ \\
\hline & 2.0 & 0.512 & 0.124 & $\mathrm{Y}$ \\
\hline & 1.8 & 0.630 & 0.125 & Y \\
\hline & 1.6 & 0.550 & 0.138 & $\mathrm{Y}$ \\
\hline & 1.4 & 0.659 & 0.116 & $\mathrm{Y}$ \\
\hline & 1.2 & 0.597 & 0.106 & $\mathrm{Y}$ \\
\hline & 1.0 & 0.543 & 0.087 & $\mathrm{Y}$ \\
\hline
\end{tabular}

Panel a.) Threshold for the fit value $=5$, Number of operations $=625$ 


\begin{tabular}{|c|c|c|c|c|}
\hline SL & TP & TR & MD & TR $>$ MD \\
\hline \multirow{5}{*}{} & 3.0 & 0.350 & 1.026 & $\mathrm{~N}$ \\
\hline 2.8 & 0.620 & 0.858 & $\mathrm{~N}$ \\
\hline 2.6 & 0.631 & 0.902 & $\mathrm{~N}$ \\
\hline 2.4 & 0.785 & 0.739 & $\mathrm{Y}$ \\
\cline { 2 - 5 } 0.2 .2 & 0.866 & 0.608 & $\mathrm{Y}$ \\
\cline { 2 - 5 } & 2.0 & 0.639 & 0.545 & $\mathrm{Y}$ \\
\hline 1.8 & 0.576 & 0.623 & $\mathrm{~N}$ \\
\hline 1.6 & 0.304 & 0.649 & $\mathrm{~N}$ \\
\hline 1.4 & 0.554 & 0.498 & $\mathrm{Y}$ \\
\hline 1.2 & 0.382 & 0.438 & $\mathrm{~N}$ \\
\hline 1.0 & 0.301 & 0.361 & $\mathrm{~N}$ \\
\hline \multirow{6}{*}{3.0} & 1.211 & 0.579 & $\mathrm{Y}$ \\
\hline 2.8 & 1.356 & 0.419 & $\mathrm{Y}$ \\
\hline 2.6 & 1.430 & 0.389 & $\mathrm{Y}$ \\
\hline 2.4 & 1.545 & 0.362 & $\mathrm{Y}$ \\
\hline 2.2 & 1.573 & 0.370 & $\mathrm{Y}$ \\
\hline 2.0 & 1.406 & 0.377 & $\mathrm{Y}$ \\
\hline 1.8 & 1.444 & 0.385 & $\mathrm{Y}$ \\
\hline 1.6 & 1.213 & 0.393 & $\mathrm{Y}$ \\
\hline 1.4 & 1.346 & 0.298 & $\mathrm{Y}$ \\
\hline 1.2 & 1.124 & 0.311 & $\mathrm{Y}$ \\
\hline 1.0 & 0.926 & 0.278 & $\mathrm{Y}$ \\
\hline
\end{tabular}

\begin{tabular}{|c|c|c|c|c|}
\hline SL & TP & TR & $\mathrm{MD}$ & $\mathrm{TR}>\mathrm{MD}$ \\
\hline \multirow{11}{*}{0.4} & 3.0 & 1.422 & 0.459 & $\mathrm{Y}$ \\
\hline & 2.8 & 1.644 & 0.320 & $\mathrm{Y}$ \\
\hline & 2.6 & 1.744 & 0.342 & $\mathrm{Y}$ \\
\hline & 2.4 & 1.776 & 0.242 & $\mathrm{Y}$ \\
\hline & 2.2 & 1.801 & 0.271 & $\mathrm{Y}$ \\
\hline & 2.0 & 1.529 & 0.281 & $\mathrm{Y}$ \\
\hline & 1.8 & 1.622 & 0.308 & $\mathrm{Y}$ \\
\hline & 1.6 & 1.483 & 0.296 & $\mathrm{Y}$ \\
\hline & 1.4 & 1.652 & 0.193 & $\mathrm{Y}$ \\
\hline & 1.2 & 1.328 & 0.215 & $\mathrm{Y}$ \\
\hline & 1.0 & 1.252 & 0.164 & $\mathrm{Y}$ \\
\hline \multirow{11}{*}{0.2} & 3.0 & 1.748 & 0.229 & $\mathrm{Y}$ \\
\hline & 2.8 & 1.774 & 0.186 & $\mathrm{Y}$ \\
\hline & 2.6 & 1.676 & 0.192 & $\mathrm{Y}$ \\
\hline & 2.4 & 1.684 & 0.210 & $\mathrm{Y}$ \\
\hline & 2.2 & 1.713 & 0.140 & $\mathrm{Y}$ \\
\hline & 2.0 & 1.540 & 0.143 & $\mathrm{Y}$ \\
\hline & 1.8 & 1.619 & 0.147 & $\mathrm{Y}$ \\
\hline & 1.6 & 1.582 & 0.151 & $\mathrm{Y}$ \\
\hline & 1.4 & 1.666 & 0.167 & $\mathrm{Y}$ \\
\hline & 1.2 & 1.466 & 0.150 & $\mathrm{Y}$ \\
\hline & 1.0 & 1.360 & 0.138 & $\mathrm{Y}$ \\
\hline
\end{tabular}

Panel b.) Threshold for the fit value $=4$, Number of operations $=1,122$ 


\begin{tabular}{|c|c|c|c|c|}
\hline SL & TP & TR & MD & TR > MD \\
\hline \multirow{5}{*}{} & 3.0 & 1.044 & 1.209 & $\mathrm{~N}$ \\
\hline 2.8 & 1.296 & 1.137 & $\mathrm{Y}$ \\
\hline 2.6 & 1.217 & 1.187 & $\mathrm{Y}$ \\
\hline 2.4 & 1.104 & 1.116 & $\mathrm{~N}$ \\
\hline 2.2 & 1.106 & 1.009 & $\mathrm{Y}$ \\
\hline \multirow{5}{*}{0.8 .0} & 0.925 & 0.959 & $\mathrm{~N}$ \\
\hline 1.8 & 0.848 & 1.008 & $\mathrm{~N}$ \\
\hline 1.6 & 0.826 & 0.990 & $\mathrm{~N}$ \\
\hline 1.4 & 1.163 & 0.476 & $\mathrm{Y}$ \\
\hline 1.2 & 0.653 & 0.548 & $\mathrm{Y}$ \\
\hline 1.0 & 0.575 & 0.408 & $\mathrm{Y}$ \\
\hline \multirow{5}{*}{3.0} & 2.182 & 0.749 & $\mathrm{Y}$ \\
\hline 2.8 & 2.341 & 0.588 & $\mathrm{Y}$ \\
\hline 2.6 & 2.329 & 0.596 & $\mathrm{Y}$ \\
\hline 2.4 & 2.222 & 0.603 & $\mathrm{Y}$ \\
\hline 2.2 & 2.129 & 0.611 & $\mathrm{Y}$ \\
\hline \multirow{4}{*}{0.6} & 1.970 & 0.619 & $\mathrm{Y}$ \\
\hline & 1.8 & 2.029 & 0.626 & $\mathrm{Y}$ \\
\hline 1.6 & 1.685 & 0.634 & $\mathrm{Y}$ \\
\hline 1.4 & 1.946 & 0.354 & $\mathrm{Y}$ \\
\hline 1.2 & 1.369 & 0.383 & $\mathrm{Y}$ \\
\hline 1.0 & 1.175 & 0.279 & $\mathrm{Y}$ \\
\hline
\end{tabular}

\begin{tabular}{|c|c|c|c|c|}
\hline SL & TP & TR & $\mathrm{MD}$ & $\mathrm{TR}>\mathrm{MD}$ \\
\hline \multirow{11}{*}{0.4} & 3.0 & 2.683 & 0.551 & $\mathrm{Y}$ \\
\hline & 2.8 & 2.901 & 0.375 & $\mathrm{Y}$ \\
\hline & 2.6 & 2.933 & 0.382 & $\mathrm{Y}$ \\
\hline & 2.4 & 2.730 & 0.378 & $\mathrm{Y}$ \\
\hline & 2.2 & 2.685 & 0.385 & $\mathrm{Y}$ \\
\hline & 2.0 & 2.312 & 0.393 & $\mathrm{Y}$ \\
\hline & 1.8 & 2.456 & 0.401 & $\mathrm{Y}$ \\
\hline & 1.6 & 2.235 & 0.409 & $\mathrm{Y}$ \\
\hline & 1.4 & 2.511 & 0.237 & $\mathrm{Y}$ \\
\hline & 1.2 & 1.894 & 0.248 & $\mathrm{Y}$ \\
\hline & 1.0 & 1.810 & 0.204 & $\mathrm{Y}$ \\
\hline \multirow{11}{*}{0.2} & 3.0 & 2.836 & 0.262 & $\mathrm{Y}$ \\
\hline & 2.8 & 2.767 & 0.222 & $\mathrm{Y}$ \\
\hline & 2.6 & 2.650 & 0.225 & $\mathrm{Y}$ \\
\hline & 2.4 & 2.540 & 0.192 & $\mathrm{Y}$ \\
\hline & 2.2 & 2.505 & 0.192 & $\mathrm{Y}$ \\
\hline & 2.0 & 2.233 & 0.192 & $\mathrm{Y}$ \\
\hline & 1.8 & 2.368 & 0.192 & $\mathrm{Y}$ \\
\hline & 1.6 & 2.228 & 0.192 & $\mathrm{Y}$ \\
\hline & 1.4 & 2.323 & 0.192 & $\mathrm{Y}$ \\
\hline & 1.2 & 1.950 & 0.192 & $\mathrm{Y}$ \\
\hline & 1.0 & 1.904 & 0.192 & $\mathrm{Y}$ \\
\hline
\end{tabular}

Panel c.) Threshold for the fit value $=3$, Number of operations $=1,802$ 


\begin{tabular}{|c|c|c|c|c|}
\hline SL & TP & TR & $\mathrm{MD}$ & $\mathrm{TR}>\mathrm{MD}$ \\
\hline \multirow{11}{*}{0.8} & 3.0 & 2.571 & 0.878 & $\mathrm{Y}$ \\
\hline & 2.8 & 3.015 & 0.689 & $\mathrm{Y}$ \\
\hline & 2.6 & 2.984 & 0.691 & $\mathrm{Y}$ \\
\hline & 2.4 & 2.664 & 0.739 & $\mathrm{Y}$ \\
\hline & 2.2 & 2.658 & 0.731 & $\mathrm{Y}$ \\
\hline & 2.0 & 2.207 & 0.800 & $\mathrm{Y}$ \\
\hline & 1.8 & 1.964 & 0.876 & $\mathrm{Y}$ \\
\hline & 1.6 & 1.852 & 0.951 & $\mathrm{Y}$ \\
\hline & 1.4 & 1.861 & 0.490 & $\mathrm{Y}$ \\
\hline & 1.2 & 1.201 & 0.497 & $\mathrm{Y}$ \\
\hline & 1.0 & 1.042 & 0.365 & $\mathrm{Y}$ \\
\hline \multirow{11}{*}{0.6} & 3.0 & 3.551 & 0.643 & $\mathrm{Y}$ \\
\hline & 2.8 & 3.935 & 0.500 & $\mathrm{Y}$ \\
\hline & 2.6 & 3.969 & 0.508 & $\mathrm{Y}$ \\
\hline & 2.4 & 3.705 & 0.509 & $\mathrm{Y}$ \\
\hline & 2.2 & 3.616 & 0.529 & $\mathrm{Y}$ \\
\hline & 2.0 & 3.268 & 0.549 & $\mathrm{Y}$ \\
\hline & 1.8 & 3.161 & 0.569 & $\mathrm{Y}$ \\
\hline & 1.6 & 2.776 & 0.589 & $\mathrm{Y}$ \\
\hline & 1.4 & 2.787 & 0.397 & $\mathrm{Y}$ \\
\hline & 1.2 & 2.092 & 0.415 & $\mathrm{Y}$ \\
\hline & 1.0 & 1.852 & 0.328 & $\mathrm{Y}$ \\
\hline
\end{tabular}

\begin{tabular}{|c|c|c|c|c|}
\hline SL & TP & TR & $\mathrm{MD}$ & $\mathrm{TR}>\mathrm{MD}$ \\
\hline \multirow{11}{*}{0.4} & 3.0 & 4.066 & 0.426 & $\mathrm{Y}$ \\
\hline & 2.8 & 4.496 & 0.376 & $\mathrm{Y}$ \\
\hline & 2.6 & 4.612 & 0.330 & $\mathrm{Y}$ \\
\hline & 2.4 & 4.219 & 0.302 & $\mathrm{Y}$ \\
\hline & 2.2 & 4.159 & 0.306 & $\mathrm{Y}$ \\
\hline & 2.0 & 3.668 & 0.327 & $\mathrm{Y}$ \\
\hline & 1.8 & 3.696 & 0.327 & $\mathrm{Y}$ \\
\hline & 1.6 & 3.480 & 0.347 & $\mathrm{Y}$ \\
\hline & 1.4 & 3.521 & 0.248 & $\mathrm{Y}$ \\
\hline & 1.2 & 2.805 & 0.266 & $\mathrm{Y}$ \\
\hline & 1.0 & 2.567 & 0.228 & $\mathrm{Y}$ \\
\hline \multirow{11}{*}{0.2} & 3.0 & 4.194 & 0.223 & $\mathrm{Y}$ \\
\hline & 2.8 & 4.234 & 0.250 & $\mathrm{Y}$ \\
\hline & 2.6 & 4.007 & 0.262 & $\mathrm{Y}$ \\
\hline & 2.4 & 3.796 & 0.183 & $\mathrm{Y}$ \\
\hline & 2.2 & 3.804 & 0.206 & $\mathrm{Y}$ \\
\hline & 2.0 & 3.467 & 0.199 & $\mathrm{Y}$ \\
\hline & 1.8 & 3.540 & 0.141 & $\mathrm{Y}$ \\
\hline & 1.6 & 3.430 & 0.147 & $\mathrm{Y}$ \\
\hline & 1.4 & 3.354 & 0.153 & $\mathrm{Y}$ \\
\hline & 1.2 & 2.916 & 0.158 & $\mathrm{Y}$ \\
\hline & 1.0 & 2.646 & 0.164 & $\mathrm{Y}$ \\
\hline
\end{tabular}

Panel d.) Threshold for the fit value $=2$, Number of operations $=2,383$ 


\begin{tabular}{|c|c|c|c|c|}
\hline SL & TP & TR & $\mathrm{MD}$ & $\mathrm{TR}>\mathrm{MD}$ \\
\hline \multirow{11}{*}{0.8} & 3.0 & 2.074 & 0.982 & $\mathrm{Y}$ \\
\hline & 2.8 & 2.474 & 0.800 & $\mathrm{Y}$ \\
\hline & 2.6 & 2.339 & 0.788 & $\mathrm{Y}$ \\
\hline & 2.4 & 1.964 & 0.845 & $\mathrm{Y}$ \\
\hline & 2.2 & 2.220 & 0.928 & $\mathrm{Y}$ \\
\hline & 2.0 & 1.874 & 1.066 & $\mathrm{Y}$ \\
\hline & 1.8 & 1.590 & 1.146 & $\mathrm{Y}$ \\
\hline & 1.6 & 1.461 & 1.216 & $\mathrm{Y}$ \\
\hline & 1.4 & 1.821 & 0.601 & $\mathrm{Y}$ \\
\hline & 1.2 & 1.187 & 0.626 & $\mathrm{Y}$ \\
\hline & 1.0 & 0.990 & 0.508 & $\mathrm{Y}$ \\
\hline \multirow{11}{*}{0.6} & 3.0 & 3.255 & 0.750 & $\mathrm{Y}$ \\
\hline & 2.8 & 3.636 & 0.574 & $\mathrm{Y}$ \\
\hline & 2.6 & 3.591 & 0.621 & $\mathrm{Y}$ \\
\hline & 2.4 & 3.330 & 0.609 & $\mathrm{Y}$ \\
\hline & 2.2 & 3.372 & 0.633 & $\mathrm{Y}$ \\
\hline & 2.0 & 3.180 & 0.656 & $\mathrm{Y}$ \\
\hline & 1.8 & 3.043 & 0.701 & $\mathrm{Y}$ \\
\hline & 1.6 & 2.673 & 0.761 & $\mathrm{Y}$ \\
\hline & 1.4 & 2.932 & 0.387 & $\mathrm{Y}$ \\
\hline & 1.2 & 2.185 & 0.463 & $\mathrm{Y}$ \\
\hline & 1.0 & 1.866 & 0.345 & $\mathrm{Y}$ \\
\hline
\end{tabular}

\begin{tabular}{|c|c|c|c|c|}
\hline SL & TP & TR & $\mathrm{MD}$ & $\mathrm{TR}>\mathrm{MD}$ \\
\hline \multirow{11}{*}{0.4} & 3.0 & 4.251 & 0.479 & $\mathrm{Y}$ \\
\hline & 2.8 & 4.655 & 0.445 & $\mathrm{Y}$ \\
\hline & 2.6 & 4.802 & 0.407 & $\mathrm{Y}$ \\
\hline & 2.4 & 4.297 & 0.409 & $\mathrm{Y}$ \\
\hline & 2.2 & 4.333 & 0.367 & $\mathrm{Y}$ \\
\hline & 2.0 & 3.986 & 0.373 & $\mathrm{Y}$ \\
\hline & 1.8 & 3.993 & 0.390 & $\mathrm{Y}$ \\
\hline & 1.6 & 3.800 & 0.413 & $\mathrm{Y}$ \\
\hline & 1.4 & 4.080 & 0.230 & $\mathrm{Y}$ \\
\hline & 1.2 & 3.266 & 0.256 & $\mathrm{Y}$ \\
\hline & 1.0 & 2.911 & 0.220 & $\mathrm{Y}$ \\
\hline \multirow{11}{*}{0.2} & 3.0 & 4.933 & 0.200 & $\mathrm{Y}$ \\
\hline & 2.8 & 4.850 & 0.228 & $\mathrm{Y}$ \\
\hline & 2.6 & 4.609 & 0.240 & $\mathrm{Y}$ \\
\hline & 2.4 & 4.296 & 0.202 & $\mathrm{Y}$ \\
\hline & 2.2 & 4.336 & 0.172 & $\mathrm{Y}$ \\
\hline & 2.0 & 4.086 & 0.168 & $\mathrm{Y}$ \\
\hline & 1.8 & 4.110 & 0.174 & Y \\
\hline & 1.6 & 3.995 & 0.179 & $\mathrm{Y}$ \\
\hline & 1.4 & 4.024 & 0.121 & $\mathrm{Y}$ \\
\hline & 1.2 & 3.553 & 0.129 & $\mathrm{Y}$ \\
\hline & 1.0 & 3.185 & 0.140 & $\mathrm{Y}$ \\
\hline
\end{tabular}

Panel e.) Threshold for the fit value $=1$, Number of operations $=3,053$ 
If analysing these results in greater detail, configurations can be found which have a more favourable risk/profit-ratio than the average. For example, if excluding the configurations with greater SL (0.8 times $\mathrm{R}$ ), then the trading rule will offer positive results in 164 of the 165 configurations (99.4\%), while in 157 of them the return will surpass the maximum experimented drawdown $(95.2 \%)$.

These percentages will improve even more when restricting the SL value. The explanation can be found in the weight matrix structure showed in figure 4.4. The value of 0.3 times $\mathrm{R}$ would be acting in support of the price, since the possibility that a price window might be considered as flag decreases as the price falls down to the first rows of the matrix. Therefore, the support of 0.3 acts as a good indicator in order to predict if the price will continue in the same direction marked by the first breakout of the flag or if, by contrast, once it breaks the support, the price changes its direction and the operation eventually will finish with losses.

As an example figure 4.12 compares the return curves of one of the configurations with the one obtained by the buy-and-hold strategy over the DAX index which serves as a benchmark. ${ }^{2}$ The trading rule results referred to are the ones obtained with the parameters $\mathrm{Thr}=2, \mathrm{SL}=0.2 * \mathrm{R}$ and $\mathrm{TP}=2 * \mathrm{R}$. The total return is $346.7 \%$, with a maximum drawdown of only $19.9 \%$; therefore the investor obtains a very favourable risk/profit relation. In comparison to the benchmark, the DAX only provided a return of $9.9 \%$ bearing a maximum drawdown of $119.6 \%$.

\footnotetext{
${ }^{2}$ The trading rule has been programmed by means of the statistical software RStudio, and some of it's bundles, specially developed in order to handle stock market data.
} 


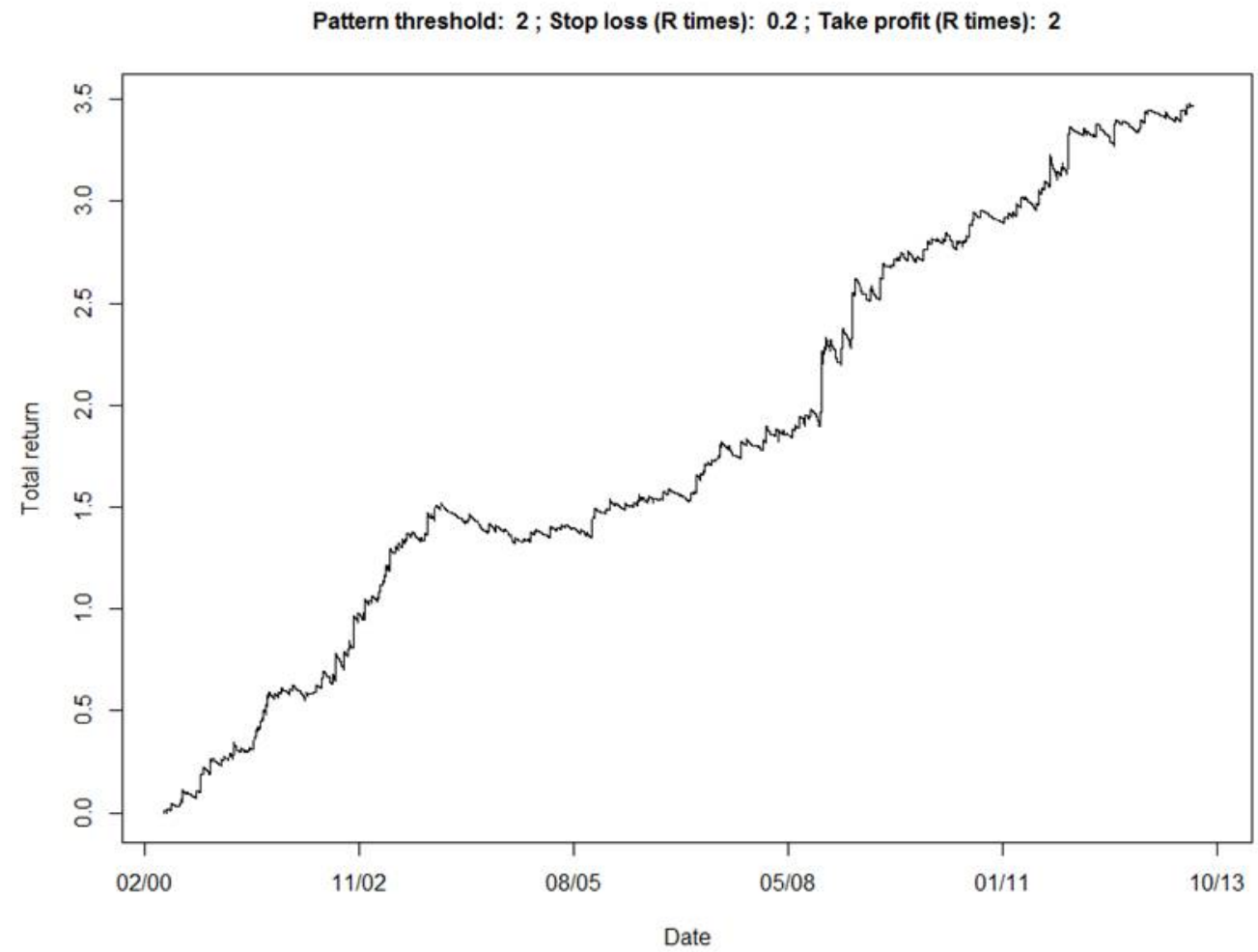

Panel a.) Return curve for the trading rule with specifications: $\mathrm{Thr}=2, \mathrm{SL}=0.2^{*} \mathrm{R}$, $\mathrm{TP}=2^{*} \mathrm{R}$

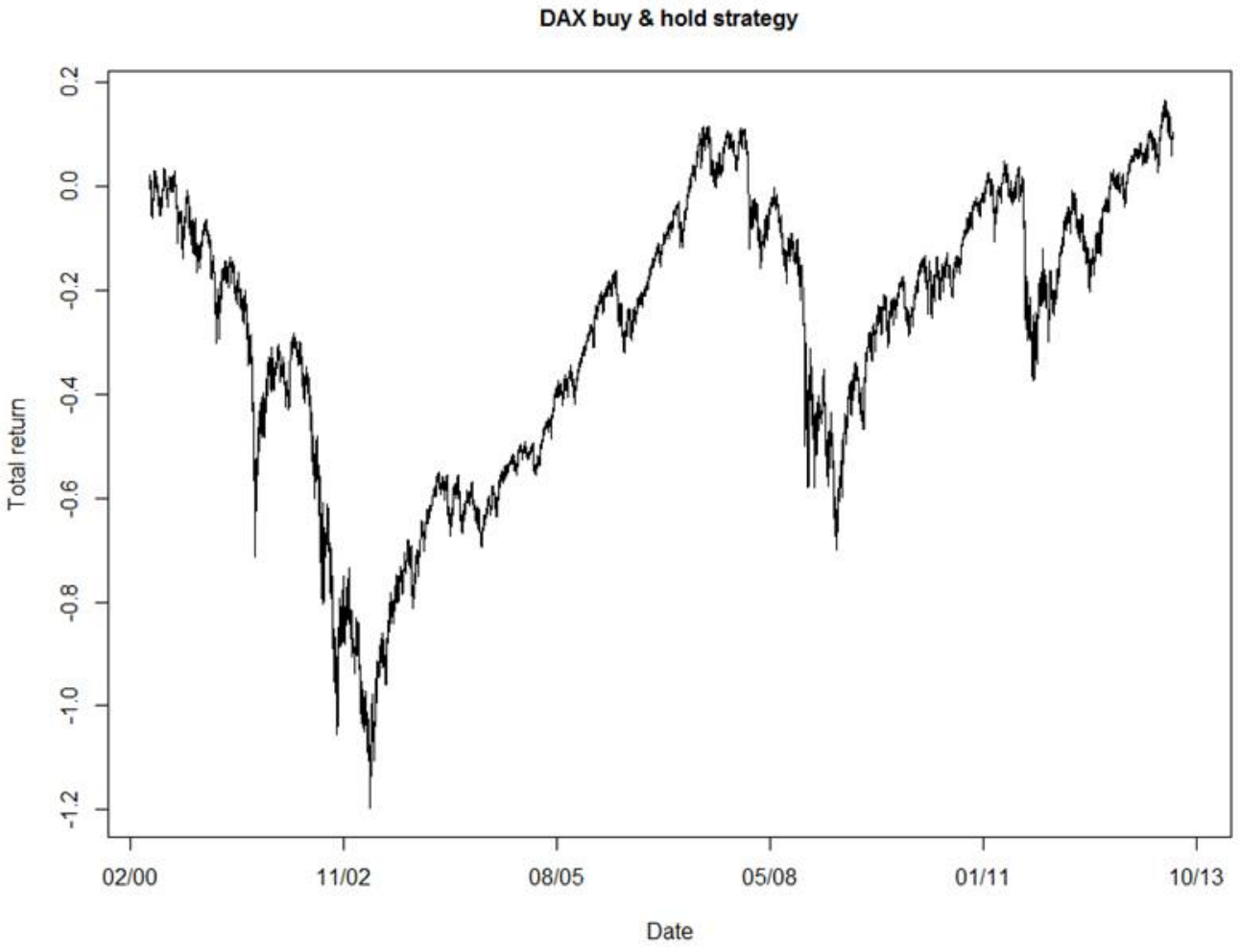

Panel b) Return curve for the buy-and-hold strategy over the DAX index

Figure 4.12: Comparison of the return curves between the obtained with one of the trading rule configurations and the obtained with the buy-and-hold strategy 


\subsubsection{USA (DJIA)}

This section focuses on the analysis of the American stock market applying the trading rule over intraday data of the Dow Jones Industrial Average (DJIA). ${ }^{3}$ Invented by Charles Dow in 1896, the DJIA is a price-weighted average of 30 actively traded blue chip stocks, primarily industrials, traded on the New York Stock Exchange and the NASDAQ (finanzen.net GmbH, 2015b; Productive Publications, 2012).

The following table 4.7 provides an overview of the DJIA's development within the last 15 years (finanzen.net GmbH, 2015b):

TABLE 4.7: Historic lows and highs for the DJIA, 2000-2015

\begin{tabular}{rrrrrr} 
Year & Annual start & Annual end & Annual low & Annual high & $\%$ \\
\hline 2015 & $17,832.99$ & - & $17,164.95$ & $18,312.39$ & 1.22 \\
2014 & $16,441.35$ & $17,823.07$ & $15,372.80$ & $18,053.71$ & 8.40 \\
2013 & $13,412.55$ & $16,576.66$ & $13,328.85$ & $16,576.66$ & 23.59 \\
2012 & $12,397.38$ & $13,104.14$ & $12,101.46$ & $13,610.15$ & 5.70 \\
2011 & $11,670.75$ & $12,217.56$ & $10,655.30$ & $12,810.54$ & 4.69 \\
2010 & $10,430.69$ & $11,577.51$ & $9,689.21$ & $11,585.38$ & 10.99 \\
2009 & $9,034.69$ & $10,548.51$ & $6,547.05$ & $10,548.51$ & 16.76 \\
2008 & $13,043.96$ & $8,776.39$ & $7,552.29$ & $13,058.20$ & -32.72 \\
2007 & $12,474.52$ & $13,264.82$ & $12,050.41$ & $14,164.53$ & 6.34 \\
2006 & $10,847.41$ & $12,463.15$ & $10,667.39$ & $12,510.57$ & 14.90 \\
2005 & $10,729.43$ & $10,717.50$ & $10,012.36$ & $10,940.55$ & -0.11 \\
2004 & $10,409.85$ & $10,783.01$ & $9,749.99$ & $10,854.54$ & 3.58 \\
2003 & $8,607.52$ & $10,453.92$ & $7,524.06$ & $10,453.92$ & 21.45 \\
2002 & $10,073.40$ & $8,341.63$ & $7,286.27$ & $10,635.25$ & -17.19 \\
2001 & $10,646.15$ & $10,021.57$ & $8,235.81$ & $11,337.92$ & -5.87 \\
2000 & $11,357.51$ & $10,787.99$ & $9,796.03$ & $11,722.98$ & -5.01 \\
\hline
\end{tabular}

Table 4.7 illustrates that the DJIA is on a current high compared to the last 15 years. The years 2002/2003 are characterized by a negative growth. The financial crisis in 2008/2009 also resulted in a strong negative growth which could be compensated within the last years. After the financial crisis the index recorded a positive growth until now.

Once the proper matching is obtained from the comparison between the price window and the grid of weights, the buying or selling operation is started depending on the bull or bear flag. Therefore, if the matching takes place for the price window between $t$ and $t+9$, the operation will start with the opening price in $t+10$.

In order to evaluate the return of the operation, the exit point should be defined. Most of the literature considers a holding period of $d$ candlesticks. The value $d$ will change

\footnotetext{
${ }^{3}$ Parts of this analysis were already published in scientific journals. (Martínez et al., 2014; Martínez et al., 2015).
} 
according to different authors: $d=6$ in Lee and Jo (1999), $d=20$ in Leigh, Purvis et al. (2002) and $d=100$ in Leigh, Modani et al. (2002). In order to increase the solidity of results and mitigate the data snooping effect, some authors propose to consider a group of values for $d$ instead of an only one:

- $d \in\{10,20,40,80\}$ in Leigh, Paz et al. (2004),

- $d \in\{20,40,60,80,100\}$ in Leigh et al. (2004) and in Wang and Chan (2007), and

- $d \in\{20,40,60,80,100,120,160,200,240\}$ in Wang and Chan (2009).

An interesting alternative won't be statically fixing a determined value or group of values, but instead adopting a dynamic process in which operations will close depending on the evolution of the price, and not on the time. Teixeira and Oliveira (2010) propose the use of a variation often used by traders: to put a SL and a TP in each operation, which will limit both the loss and the profit of each one of the operations. Once a position is initiated, the SL will mark the price level at which the maximum supported loss will be reached, thus if prices reach the SL then the operation will close assuming that loss. In the same way, the TP will mark the price level at which the expected profit or target of the operation should be taken, thus when the price reaches this level the operation will close and provide the corresponding profit.

Figure 4.13 contains an illustrative example for 15 minutes candlesticks over the DJIA futures, from 5:00 p.m. to 10:00 p.m. on June 16, 2003. This image shows a) a bull flag identification and b) the SL and the TP depending on the price range $\mathrm{R}$. In this case, the matching among the ten first candlesticks and the grid of weights provides a fitting value of 5 , the maximum possible value. A SL is set by 0.5 and a TP by 1 over the price range $\mathrm{R}=48$. Since the opening price of the 11 th candlestick is 9,249 , the $\mathrm{SL}$ will be at the level $9,249-0.5^{*} 48=9,225$ and the TP will be at the level $9,249+1^{*} 48=9,297$. The 9:45 p.m. candlestick reaches the take profit, thus the full operation will provide a positive result of 48 points.

According to the trading rule introduced in the previous sections, the future of one of the most internationally well known indexes, the DJIA, was chosen. In order to get a historical series wide enough to allow to infer significant results and to mitigate the data snooping effect, time intervals of 15 minutes were selected during the period from May 22, 2000 to November 29, 2013. During this period, there have been bullish, bearish and lateral market stages. The total number of candlesticks amounts to 91,307.

Most authors use daily data, which 1) limits the number of observations and 2) demands taking a very delayed historical price series in order to reach a representative number 


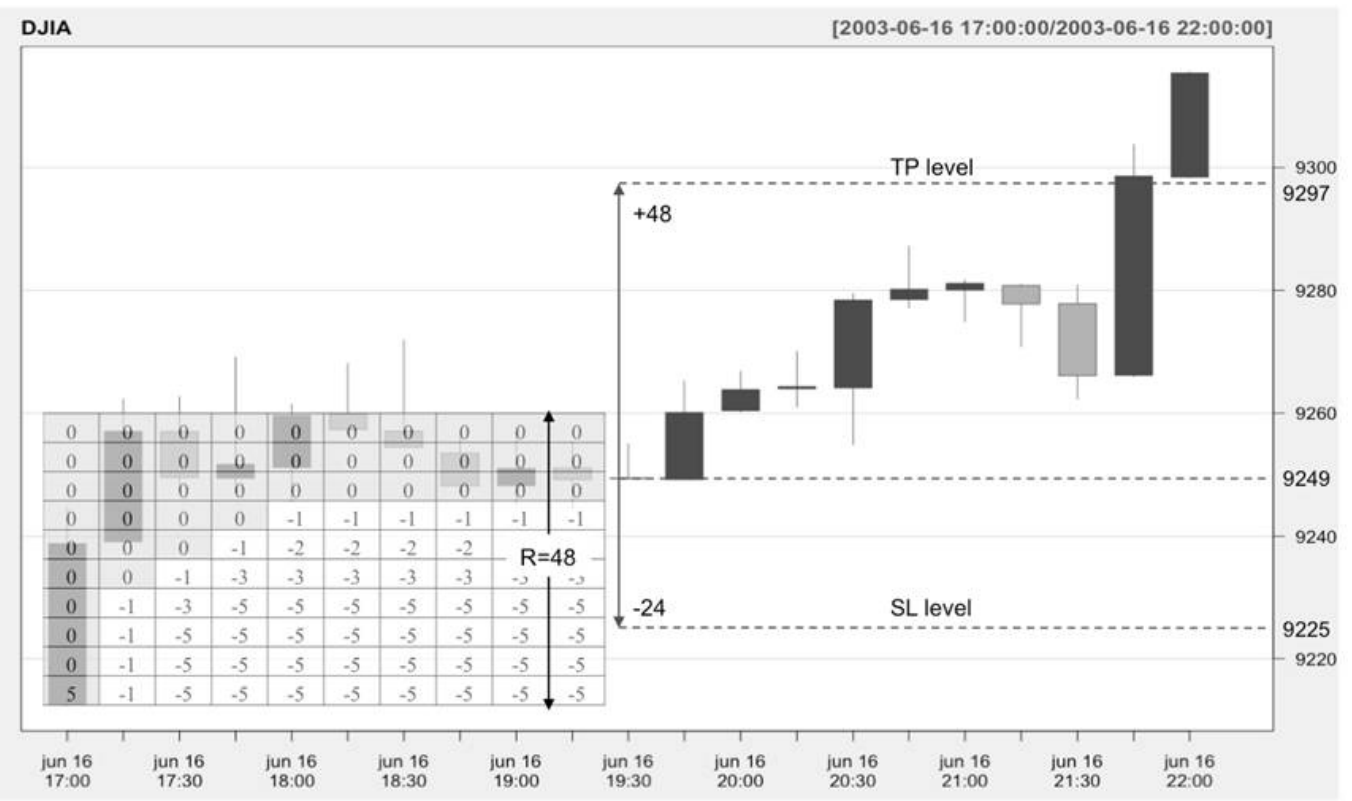

Figure 4.13: Price series of futures over the DJIA index from 5:00 p.m. to 10:00 p.m. on June 16, 2003 at time intervals of 15 minutes

Identification of a bull flag which corresponds to the ten first candlesticks of the period, and fitting value of 5 . The price range during the flag is $\mathrm{R}=48$. The $\mathrm{SL}$ is calculated as the difference between the opening price of candlestick number 11 minus 0.5 times $\mathrm{R}$, and the $\mathrm{TP}$ as the same opening price plus one time R. The operation closes at the 9:45 p.m. candlestick when the price reaches the TP.

of observations. The use of previous historical data with respect to the current moment can presume a problem when trying to validate a trading rule: "Suppose that some technical trading rules can be found that unambiguously outperform the benchmark over the sample period, but that these are based on technology (e.g. neural networks) that only became available after the end of the sample. Since the technique used was not available to investors during the sample period, it is unlikely that such evidence would contradict weak-form market efficiency" (Sullivan et al., 1999). In this line of argument, Timmermann and Granger question the use of strategies designed over the historical data in the short term, since once the more recent information is included the price strategy stops being successful (Timmermann and Granger, 2004).

The use of intraday data does not affect the price pattern identification, due to the fractality which underlies the stock market data. Elder, one of the most reputed traders, states "if you remove price and time markings from a chart, you won't be able to tell whether it is weekly, daily, or intraday. Markets are fractal" (Elder, 2002). Also Bollinger, who introduced the Bollinger bands, defends the existence of fractality at financial markets: "It turns out that fractal patterns are very common. For example, take a long-term W-bottom. When examined closely, the $\mathrm{W}$ may turn out to have intermediate-term W-bottoms embedded in its footings" (Bollinger, 2002). 
Given a price range R, the multiples considered in order to fix the SL and the TP have been:

$$
\begin{gathered}
S L \in\{0.2,0.4,0.6,0.8\} \\
T P \in\{1.0,1.2,1.4,1.6,1.8,2.0\}
\end{gathered}
$$

The combination of these values will work with 24 different SL and TP configurations.

The threshold fitting value is also a configurable parameter:

$$
\text { Threshold fitting value } \in\{2,3,4,5\}
$$

Therefore, the total number of configurations amounts to 96 . For each one of them, the total number of operations, the number of successful operations, the number of failed operations, the hit ratio, the total return, the average of the returns and the maximum drawdown were calculated. Table 4.8 summarizes the results. 
TABLE 4.8: Trading rule results over the DJIA index for the whole period

Thr $=$ Threshold fitting value; $\#$ Ops $=$ Number of operations; $\mathrm{SL}=(\mathrm{R}$ times $)$ Stop

Loss; $\mathrm{TP}=(\mathrm{R}$ times $)$ Take Profit; \#PosOps = Number of positive operations; \#NegOps $=$ Number of negative operations; HR = Hit ratio (\#PosOps / \#NegOps);

$\mathrm{TR}=$ Total Return; $\mathrm{AR}=$ Average of the returns; $\mathrm{MD}=$ Maximum Drawdown; $\mathrm{TR}>\mathrm{MD}=$ is $\mathrm{TR}$ greater than $\mathrm{MD}$ ?

\begin{tabular}{|c|c|c|c|c|c|c|c|c|c|}
\hline $\begin{array}{c}\text { Thr } \\
\text { (\#Ops) }\end{array}$ & SL & TP & \#PosOps & \#NegPos & HR & TR & AR & $\mathrm{MD}$ & $\mathrm{TR}>\mathrm{MD}$ \\
\hline \multirow{24}{*}{$\begin{array}{c}5 \\
(483)\end{array}$} & \multirow{6}{*}{0.8} & 2.0 & 137 & 346 & 0.284 & 0.810 & 0.0017 & 0.301 & $\mathrm{~T}$ \\
\hline & & 1.8 & 150 & 333 & 0.311 & 0.806 & 0.0017 & 0.243 & $\mathrm{~T}$ \\
\hline & & 1.6 & 161 & 322 & 0.333 & 0.636 & 0.0013 & 0.237 & $\mathrm{~T}$ \\
\hline & & 1.4 & 177 & 306 & 0.366 & 0.718 & 0.0015 & 0.241 & $\mathrm{~T}$ \\
\hline & & 1.2 & 194 & 289 & 0.402 & 0.644 & 0.0013 & 0.171 & $\mathrm{~T}$ \\
\hline & & 1.0 & 208 & 275 & 0.431 & 0.401 & 0.0008 & 0.232 & $\mathrm{~T}$ \\
\hline & \multirow[t]{6}{*}{0.6} & 2.0 & 116 & 367 & 0.240 & 0.776 & 0.0016 & 0.233 & $\mathrm{~T}$ \\
\hline & & 1.8 & 129 & 354 & 0.267 & 0.883 & 0.0018 & 0.191 & $\mathrm{~T}$ \\
\hline & & 1.6 & 138 & 345 & 0.286 & 0.701 & 0.0015 & 0.174 & $\mathrm{~T}$ \\
\hline & & 1.4 & 153 & 330 & 0.317 & 0.777 & 0.0016 & 0.134 & $\mathrm{~T}$ \\
\hline & & 1.2 & 168 & 315 & 0.348 & 0.693 & 0.0014 & 0.126 & $\mathrm{~T}$ \\
\hline & & 1.0 & 183 & 300 & 0.379 & 0.523 & 0.0011 & 0.126 & $\mathrm{~T}$ \\
\hline & \multirow[t]{6}{*}{0.4} & 2.0 & 87 & 396 & 0.180 & 0.481 & 0.0010 & 0.203 & $\mathrm{~T}$ \\
\hline & & 1.8 & 98 & 385 & 0.203 & 0.603 & 0.0012 & 0.149 & $\mathrm{~T}$ \\
\hline & & 1.6 & 103 & 380 & 0.213 & 0.431 & 0.0009 & 0.147 & $\mathrm{~T}$ \\
\hline & & 1.4 & 114 & 369 & 0.236 & 0.544 & 0.0011 & 0.112 & $\mathrm{~T}$ \\
\hline & & 1.2 & 126 & 357 & 0.261 & 0.436 & 0.0009 & 0.116 & $\mathrm{~T}$ \\
\hline & & 1.0 & 138 & 345 & 0.286 & 0.341 & 0.0007 & 0.086 & $\mathrm{~T}$ \\
\hline & \multirow[t]{6}{*}{0.2} & 2.0 & 58 & 425 & 0.120 & 0.614 & 0.0013 & 0.118 & $\mathrm{~T}$ \\
\hline & & 1.8 & 65 & 418 & 0.135 & 0.686 & 0.0014 & 0.076 & $\mathrm{~T}$ \\
\hline & & 1.6 & 71 & 412 & 0.147 & 0.605 & 0.0013 & 0.086 & $\mathrm{~T}$ \\
\hline & & 1.4 & 80 & 403 & 0.166 & 0.722 & 0.0015 & 0.070 & $\mathrm{~T}$ \\
\hline & & 1.2 & 84 & 399 & 0.174 & 0.558 & 0.0012 & 0.074 & $\mathrm{~T}$ \\
\hline & & 1.0 & 93 & 390 & 0.193 & 0.496 & 0.0010 & 0.069 & $\mathrm{~T}$ \\
\hline
\end{tabular}

Panel a) Threshold for the fit value $=5$, Number of operations $=483$ 


\begin{tabular}{|c|c|c|c|c|c|c|c|c|c|}
\hline $\begin{array}{c}\text { Thr } \\
\text { (\#Ops) }\end{array}$ & SL & TP & \#PosOps & \#NegPos & $\mathrm{HR}$ & TR & AR & $\mathrm{MD}$ & $\mathrm{TR}>\mathrm{MD}$ \\
\hline \multirow{24}{*}{$\begin{array}{c}4 \\
(739)\end{array}$} & \multirow[t]{6}{*}{0.8} & 2.0 & 211 & 528 & 0.286 & 0.812 & 0.0011 & 0.376 & $\mathrm{~T}$ \\
\hline & & 1.8 & 231 & 508 & 0.313 & 0.847 & 0.0011 & 0.296 & $\mathrm{~T}$ \\
\hline & & 1.6 & 250 & 489 & 0.338 & 0.821 & 0.0011 & 0.281 & $\mathrm{~T}$ \\
\hline & & 1.4 & 269 & 470 & 0.364 & 0.790 & 0.0011 & 0.267 & $\mathrm{~T}$ \\
\hline & & 1.2 & 295 & 444 & 0.399 & 0.722 & 0.0010 & 0.275 & $\mathrm{~T}$ \\
\hline & & 1.0 & 314 & 425 & 0.425 & 0.379 & 0.0005 & 0.306 & $\mathrm{~T}$ \\
\hline & \multirow[t]{6}{*}{0.6} & 2.0 & 183 & 556 & 0.248 & 0.981 & 0.0013 & 0.244 & $\mathrm{~T}$ \\
\hline & & 1.8 & 201 & 538 & 0.272 & 1.055 & 0.0014 & 0.191 & $\mathrm{~T}$ \\
\hline & & 1.6 & 215 & 524 & 0.291 & 0.966 & 0.0013 & 0.186 & $\mathrm{~T}$ \\
\hline & & 1.4 & 233 & 506 & 0.315 & 0.944 & 0.0013 & 0.171 & $\mathrm{~T}$ \\
\hline & & 1.2 & 257 & 482 & 0.348 & 0.868 & 0.0012 & 0.166 & $\mathrm{~T}$ \\
\hline & & 1.0 & 274 & 465 & 0.371 & 0.553 & 0.0007 & 0.172 & $\mathrm{~T}$ \\
\hline & \multirow[t]{6}{*}{0.4} & 2.0 & 143 & 596 & 0.194 & 0.882 & 0.0012 & 0.201 & $\mathrm{~T}$ \\
\hline & & 1.8 & 158 & 581 & 0.214 & 0.963 & 0.0013 & 0.152 & $\mathrm{~T}$ \\
\hline & & 1.6 & 167 & 572 & 0.226 & 0.839 & 0.0011 & 0.145 & $\mathrm{~T}$ \\
\hline & & 1.4 & 182 & 557 & 0.246 & 0.873 & 0.0012 & 0.121 & $\mathrm{~T}$ \\
\hline & & 1.2 & 200 & 539 & 0.271 & 0.728 & 0.0010 & 0.137 & $\mathrm{~T}$ \\
\hline & & 1.0 & 215 & 524 & 0.291 & 0.525 & 0.0007 & 0.124 & $\mathrm{~T}$ \\
\hline & \multirow[t]{6}{*}{0.2} & 2.0 & 98 & 641 & 0.133 & 1.077 & 0.0015 & 0.104 & $\mathrm{~T}$ \\
\hline & & 1.8 & 107 & 632 & 0.145 & 1.093 & 0.0015 & 0.094 & $\mathrm{~T}$ \\
\hline & & 1.6 & 118 & 621 & 0.160 & 1.084 & 0.0015 & 0.096 & $\mathrm{~T}$ \\
\hline & & 1.4 & 129 & 610 & 0.175 & 1.126 & 0.0015 & 0.071 & $\mathrm{~T}$ \\
\hline & & 1.2 & 138 & 601 & 0.187 & 0.931 & 0.0013 & 0.085 & $\mathrm{~T}$ \\
\hline & & 1.0 & 151 & 588 & 0.204 & 0.808 & 0.0011 & 0.084 & $\mathrm{~T}$ \\
\hline
\end{tabular}

Panel b) Threshold for the fit value $=4$, Number of operations $=739$ 


\begin{tabular}{|c|c|c|c|c|c|c|c|c|c|}
\hline $\begin{array}{c}\text { Thr } \\
\text { (\#Ops) }\end{array}$ & SL & TP & \#PosOps & \#NegPos & $\mathrm{HR}$ & TR & $\mathrm{AR}$ & $\mathrm{MD}$ & $\mathrm{TR}>\mathrm{MD}$ \\
\hline \multirow{24}{*}{$\begin{array}{c}3 \\
(1.077)\end{array}$} & \multirow[t]{6}{*}{0.8} & 2.0 & 301 & 776 & 0.279 & 0.698 & 0.0006 & 0.417 & $\mathrm{~T}$ \\
\hline & & 1.8 & 322 & 755 & 0.299 & 0.590 & 0.0005 & 0.375 & $\mathrm{~T}$ \\
\hline & & 1.6 & 350 & 727 & 0.325 & 0.750 & 0.0007 & 0.356 & $\mathrm{~T}$ \\
\hline & & 1.4 & 379 & 698 & 0.352 & 0.795 & 0.0007 & 0.345 & $\mathrm{~T}$ \\
\hline & & 1.2 & 415 & 662 & 0.385 & 0.719 & 0.0007 & 0.340 & $\mathrm{~T}$ \\
\hline & & 1.0 & 445 & 632 & 0.413 & 0.288 & 0.0003 & 0.384 & $F$ \\
\hline & \multirow[t]{6}{*}{0.6} & 2.0 & 263 & 814 & 0.244 & 1.113 & 0.0010 & 0.274 & $\mathrm{~T}$ \\
\hline & & 1.8 & 281 & 796 & 0.261 & 1.029 & 0.0010 & 0.230 & $\mathrm{~T}$ \\
\hline & & 1.6 & 301 & 776 & 0.279 & 1.054 & 0.0010 & 0.233 & $\mathrm{~T}$ \\
\hline & & 1.4 & 329 & 748 & 0.305 & 1.108 & 0.0010 & 0.229 & $\mathrm{~T}$ \\
\hline & & 1.2 & 362 & 715 & 0.336 & 1.027 & 0.0010 & 0.222 & $\mathrm{~T}$ \\
\hline & & 1.0 & 391 & 686 & 0.363 & 0.642 & 0.0006 & 0.192 & $\mathrm{~T}$ \\
\hline & \multirow[t]{6}{*}{0.4} & 2.0 & 210 & 867 & 0.195 & 1.161 & 0.0011 & 0.185 & $\mathrm{~T}$ \\
\hline & & 1.8 & 227 & 850 & 0.211 & 1.134 & 0.0011 & 0.162 & $\mathrm{~T}$ \\
\hline & & 1.6 & 241 & 836 & 0.224 & 1.051 & 0.0010 & 0.162 & $\mathrm{~T}$ \\
\hline & & 1.4 & 266 & 811 & 0.247 & 1.118 & 0.0010 & 0.166 & $\mathrm{~T}$ \\
\hline & & 1.2 & 289 & 788 & 0.268 & 0.937 & 0.0009 & 0.161 & $\mathrm{~T}$ \\
\hline & & 1.0 & 314 & 763 & 0.292 & 0.666 & 0.0006 & 0.149 & $\mathrm{~T}$ \\
\hline & \multirow[t]{6}{*}{0.2} & 2.0 & 143 & 934 & 0.133 & 1.430 & 0.0013 & 0.093 & $\mathrm{~T}$ \\
\hline & & 1.8 & 154 & 923 & 0.143 & 1.373 & 0.0013 & 0.093 & $\mathrm{~T}$ \\
\hline & & 1.6 & 169 & 908 & 0.157 & 1.409 & 0.0013 & 0.077 & $\mathrm{~T}$ \\
\hline & & 1.4 & 188 & 889 & 0.175 & 1.480 & 0.0014 & 0.067 & $\mathrm{~T}$ \\
\hline & & 1.2 & 202 & 875 & 0.188 & 1.256 & 0.0012 & 0.075 & $\mathrm{~T}$ \\
\hline & & 1.0 & 222 & 855 & 0.206 & 1.071 & 0.0010 & 0.089 & $\mathrm{~T}$ \\
\hline
\end{tabular}

Panel c) Threshold for the fit value $=3$, Number of operations $=1,077$ 


\begin{tabular}{|c|c|c|c|c|c|c|c|c|c|}
\hline $\begin{array}{c}\text { Thr } \\
\text { (\#Ops) }\end{array}$ & $\mathrm{SL}$ & TP & \#PosOps & \#NegPos & $\mathrm{HR}$ & TR & $\mathrm{AR}$ & $\mathrm{MD}$ & $\mathrm{TR}>\mathrm{MD}$ \\
\hline \multirow{24}{*}{$\begin{array}{c}2 \\
(1.402)\end{array}$} & \multirow[t]{6}{*}{0.8} & 2.0 & 400 & 1002 & 0.285 & 0.952 & 0.0007 & 0.479 & $\mathrm{~T}$ \\
\hline & & 1.8 & 428 & 974 & 0.305 & 0.842 & 0.0006 & 0.476 & $\mathrm{~T}$ \\
\hline & & 1.6 & 464 & 938 & 0.331 & 0.944 & 0.0007 & 0.449 & $\mathrm{~T}$ \\
\hline & & 1.4 & 501 & 901 & 0.357 & 1.056 & 0.0008 & 0.493 & $\mathrm{~T}$ \\
\hline & & 1.2 & 548 & 854 & 0.391 & 1.079 & 0.0008 & 0.405 & $\mathrm{~T}$ \\
\hline & & 1.0 & 594 & 808 & 0.424 & 0.613 & 0.0004 & 0.416 & $\mathrm{~T}$ \\
\hline & \multirow[t]{6}{*}{0.6} & 2.0 & 348 & 1054 & 0.248 & 1.357 & 0.0010 & 0.316 & $\mathrm{~T}$ \\
\hline & & 1.8 & 369 & 1033 & 0.263 & 1.165 & 0.0008 & 0.323 & $\mathrm{~T}$ \\
\hline & & 1.6 & 397 & 1005 & 0.283 & 1.162 & 0.0008 & 0.311 & $\mathrm{~T}$ \\
\hline & & 1.4 & 432 & 970 & 0.308 & 1.281 & 0.0009 & 0.306 & $\mathrm{~T}$ \\
\hline & & 1.2 & 476 & 926 & 0.340 & 1.342 & 0.0010 & 0.260 & $\mathrm{~T}$ \\
\hline & & 1.0 & 519 & 883 & 0.370 & 0.934 & 0.0007 & 0.213 & $\mathrm{~T}$ \\
\hline & \multirow[t]{6}{*}{0.4} & 2.0 & 279 & 1123 & 0.199 & 1.498 & 0.0011 & 0.215 & $\mathrm{~T}$ \\
\hline & & 1.8 & 299 & 1103 & 0.213 & 1.388 & 0.0010 & 0.219 & $\mathrm{~T}$ \\
\hline & & 1.6 & 322 & 1080 & 0.230 & 1.303 & 0.0009 & 0.206 & $\mathrm{~T}$ \\
\hline & & 1.4 & 354 & 1048 & 0.252 & 1.440 & 0.0010 & 0.192 & $\mathrm{~T}$ \\
\hline & & 1.2 & 390 & 1012 & 0.278 & 1.424 & 0.0010 & 0.153 & $\mathrm{~T}$ \\
\hline & & 1.0 & 428 & 974 & 0.305 & 1.078 & 0.0008 & 0.135 & $\mathrm{~T}$ \\
\hline & \multirow[t]{6}{*}{0.2} & 2.0 & 186 & 1216 & 0.133 & 1.802 & 0.0013 & 0.115 & $\mathrm{~T}$ \\
\hline & & 1.8 & 200 & 1202 & 0.143 & 1.703 & 0.0012 & 0.126 & $\mathrm{~T}$ \\
\hline & & 1.6 & 221 & 1181 & 0.158 & 1.723 & 0.0012 & 0.112 & $\mathrm{~T}$ \\
\hline & & 1.4 & 245 & 1157 & 0.175 & 1.752 & 0.0012 & 0.087 & $\mathrm{~T}$ \\
\hline & & 1.2 & 265 & 1137 & 0.189 & 1.523 & 0.0011 & 0.078 & $\mathrm{~T}$ \\
\hline & & 1.0 & 292 & 1110 & 0.208 & 1.267 & 0.0009 & 0.081 & $\mathrm{~T}$ \\
\hline
\end{tabular}

Panel d) Threshold for the fit value $=2$, Number of operations $=1,402$ 
As expected, the number of operations is inversely proportional to the threshold fitting value (Thr). In the most selective case $\mathrm{Thr}=5$, only 483 flag patterns were identified, which makes $0.53 \%$ of the total sample. In the case $\mathrm{Thr}=2$, the number of identified patterns is 1,402 ; that equates to $1.54 \%$ of the sample. Although these seem to be insignificant percentages, it should be highlighted that the flag is one pattern among a multitude of technical figures that can appear on the charts. When considering all the technical figures, the percentage would increase considerably. However, it is reasonable to think that the market does not offer investment opportunities in a permanent way, instead these will present from time to time and they will usually be linked to relevant news or information.

By analysing the trading rule performance it's proven that the total return (TR), total sum of the operation returns, is positive in the 96 cases; the same thing happens with the average of returns (AR). The maximum return of $180.2 \%$ is obtained by the configuration $\mathrm{Thr}=2, \mathrm{SL}=0.2$ and $\mathrm{TP}=2$. In the worst case scenario, a total return of $28.8 \%$ is obtained, by combining $\mathrm{Thr}=3, \mathrm{SL}=0.8$ and $\mathrm{TP}=1$. For this configuration, the worst average return of $0.18 \%$ was obtained by the combination $\mathrm{Thr}=5, \mathrm{SL}=0.6$ and $\mathrm{TP}=1.8$.

When comparing to the benchmark, the DJIA, and for the considered period, an average return of 0.0000042 is obtained. Therefore, all the configurations have provided a higher average return than the DJIA index.

Viewing the results, it can be concluded that the trading rule gets more positive and higher results than the benchmark. The only requirement that an investor should consider would be that the transaction costs should not exceed the obtained average of returns for the different configurations of Table 4.8 .

The percentage of successful operations is always lower than the percentage of failed operations $(\mathrm{HR}<50 \%)$. This is in accordance with the imposed restriction that TP should be greater than SL. However, as what has already been commented on, the total return and the average of returns are positive in all cases. Figure 4.14 shows the total return curves for different configurations of the trading rule; moreover, all the considered threshold levels have been included. 
Pattern threshold: 50 ; Stop loss (R times): 0.2 ; Take profit (R times): 1.4

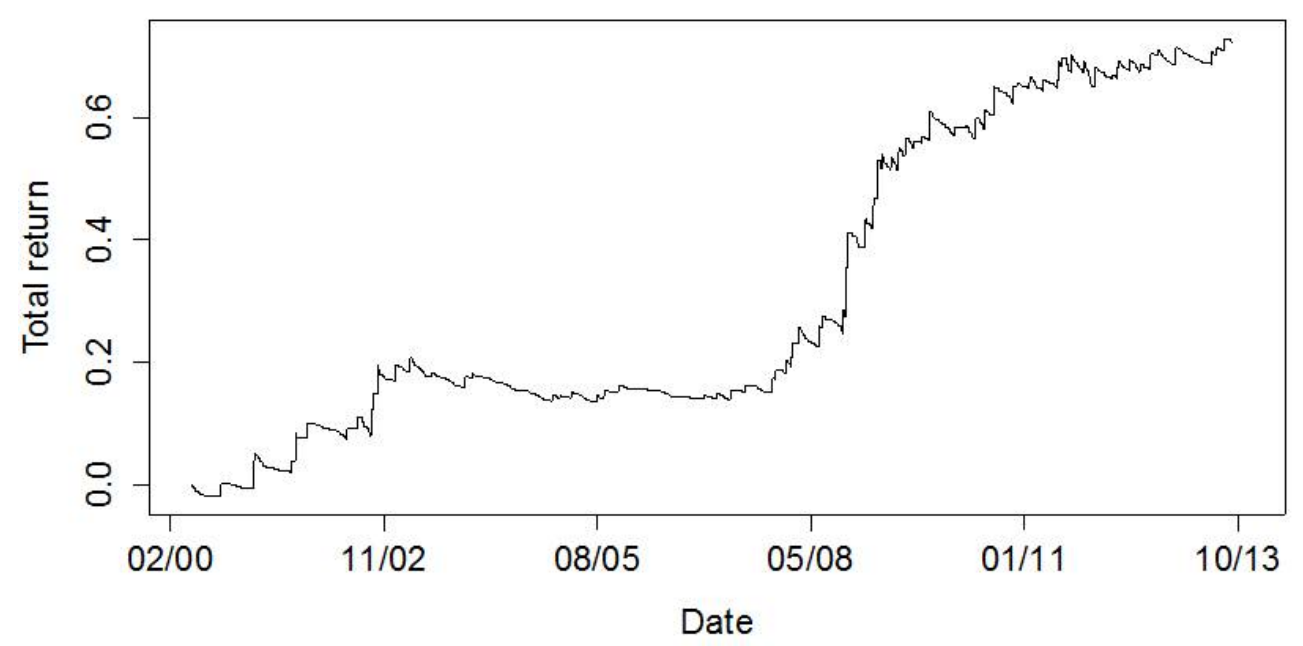

Pattern threshold: 40 ; Stop loss (R times): 0.2 ; Take profit (R times): 1.4

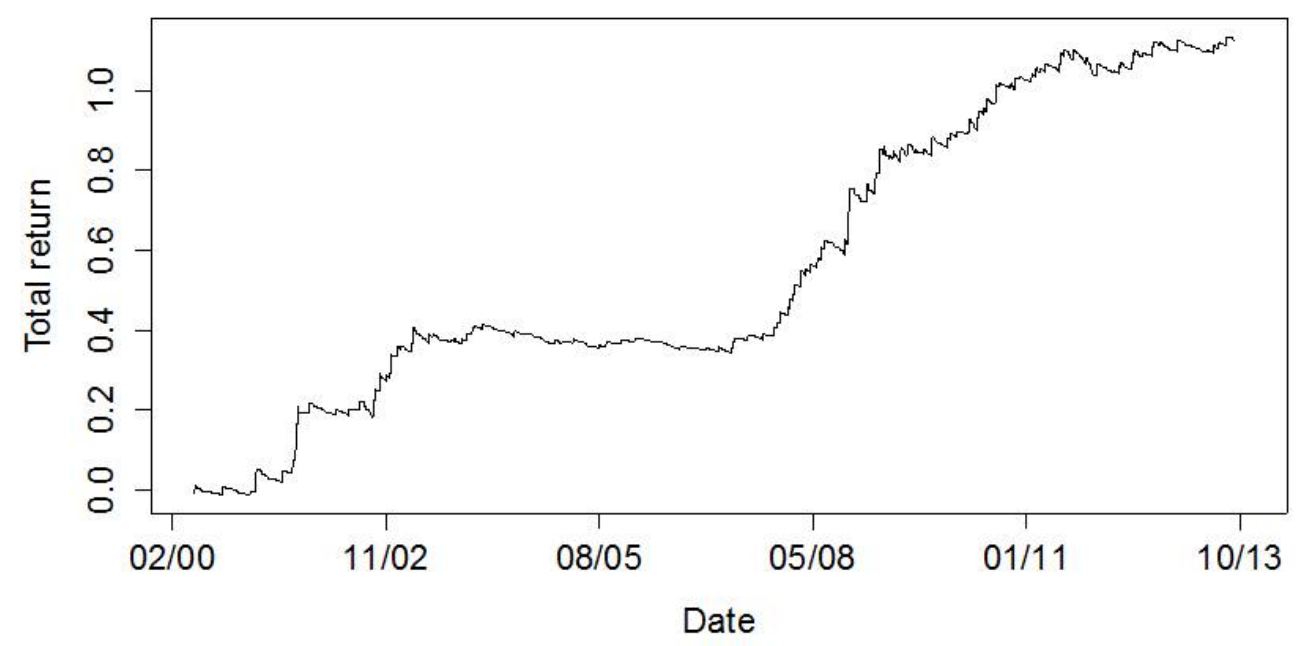

Pattern threshold: 30 ; Stop loss (R times): 0.4 ; Take profit (R times): 1.8

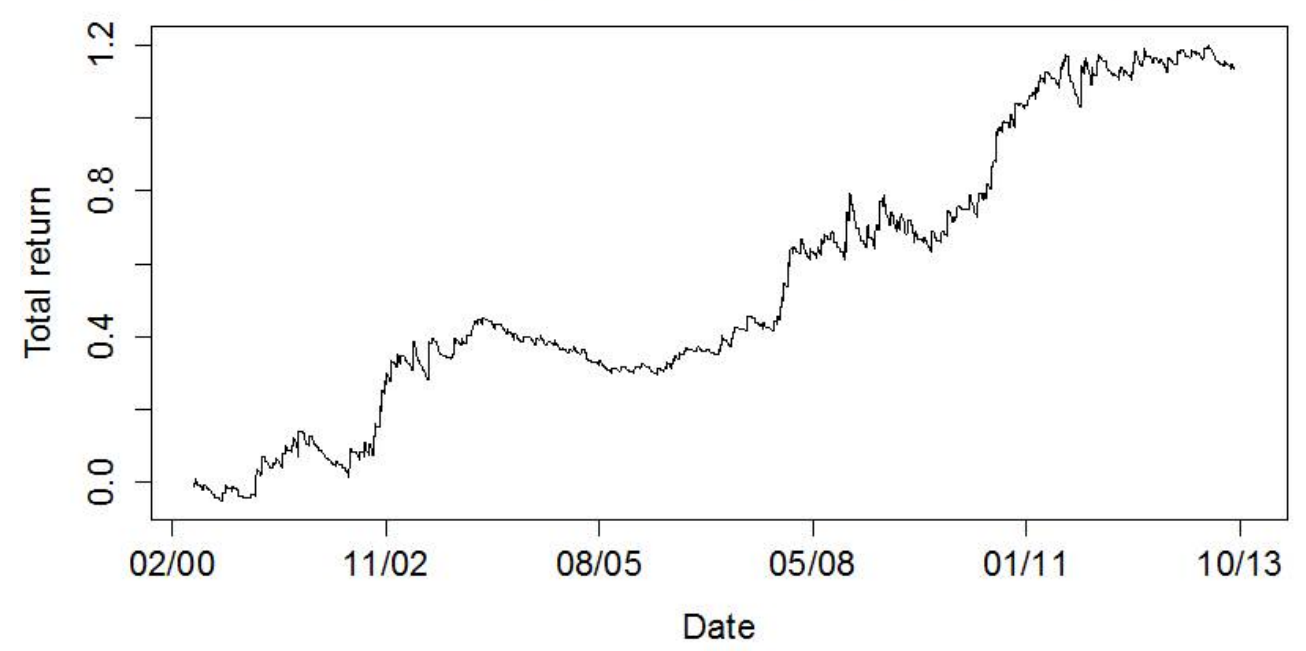


Pattern threshold: 20 ; Stop loss (R times): 0.4 ; Take profit (R times): 2

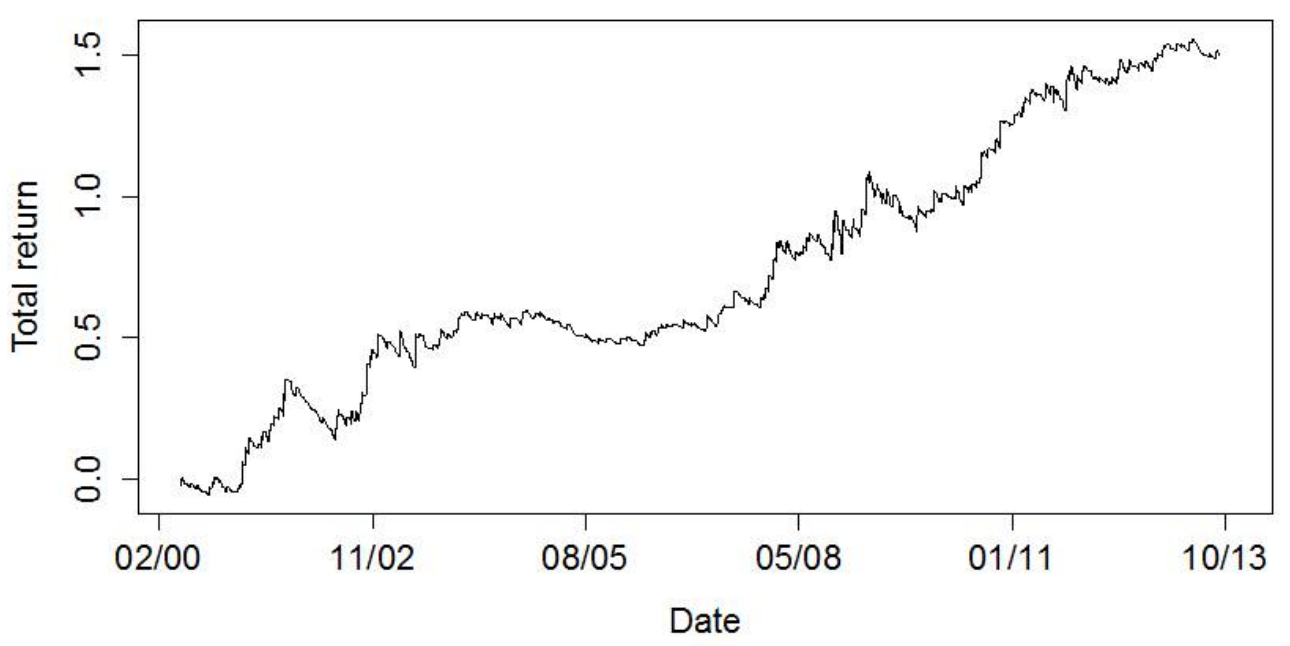

Pattern threshold: 20 ; Stop loss (R times): 0.2 ; Take profit (R times): 2

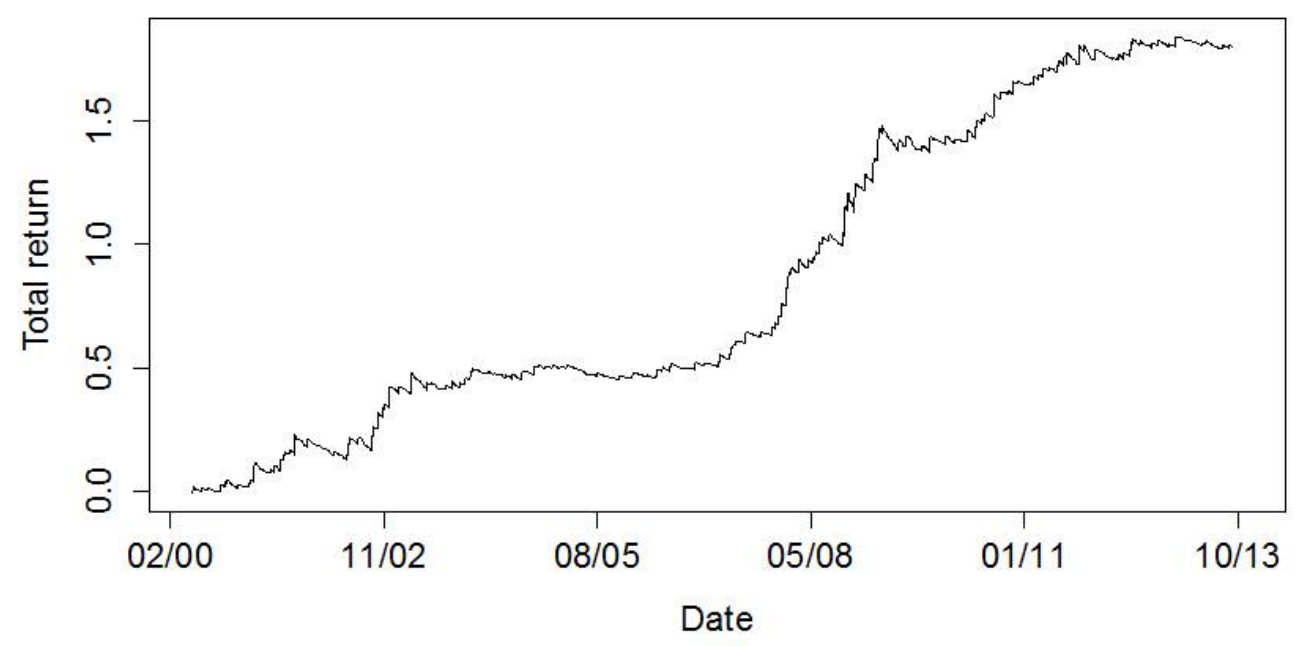

FiguRE 4.14: Total return curves for five different configurations of the trading rule

Besides the return, the risk for each of the configurations was estimated. The non normality of the trading rule returns impedes the application of the statistical $t$ (Leigh et al., 2004) and the estimation of the mean return intervals. In the present study, the non-normality of the returns is even higher than in other works, due to the levels of stop loss and take profit which were chosen. The restriction that the first one must be lower than the second one signifies that the returns follow a clearly asymmetric distribution, as we can infer from the hit ratio in Table 4.8.

The non-normality of returns results in looking for an alternative which could help to measure the risk of the strategy: the maximum drawdown (MD). 
The maximum drawdown corresponds with the maximum loss experienced during the entire period, keeping certain similarity with the value at risk (VAR). For instance, considering the configuration with the greatest total return of $180.2 \%$, a maximum drawdown of $11.5 \%$ was estimated. This value indicates that, having started the trading rule at the worst moment, the maximum loss capable to support would be $11.5 \%$. In the last column of table 4.8 it's noted that the total return is greater than the maximum drawdown in 95 of the total 96 configurations. Therefore, the use of this trading rule would have guaranteed a greater profit than the risk supported in a $98.96 \%$ of total configurations.

In order to compare with the DJIA, its drawdown was $78.42 \%$ and the total return was $37.53 \%$ during the whole period. Therefore, the risk-adjusted return of the trading rule is better than the risk-adjusted return of the DJIA.

The relation between the trading rule performance and the parameters of its configuration has also been applied as displayed in the following table 4.9:

TABLE 4.9: Correlation matrix

$(* *) 1 \%$ level of significance; $\left(^{*}\right) 5 \%$ level of significance

\begin{tabular}{|l|c|c|c|c|c|c|c|c|c|}
\hline & Thr. & SL & TP & \#Ops & \#PosOps & \#NegOps & TR & AR & MD \\
\hline Thr. & 1.00 & & & & & & & & \\
\hline SL & 0.00 & 1.00 & & & & & & & \\
\hline TP & 0.00 & 0.00 & 1.00 & & & & & & \\
\hline \#Ops & -1.00 & 0.00 & 0.00 & 1.00 & & & & & \\
& $(* *)$ & & & & & & & & \\
\hline \#PosOps & -0.77 & 0.52 & -0.29 & 0.77 & 1.00 & & & & \\
& $(* *)$ & $(* *)$ & $(* *)$ & $(* *)$ & & & & & \\
\hline \#NegOps & -0.95 & -0.24 & 0.13 & 0.96 & 0.55 & 1.00 & & & \\
& $(* *)$ & $(*)$ & & $(* *)$ & $(* *)$ & & & & \\
\hline TR & -0.70 & -0.39 & 0.29 & 0.69 & 0.18 & 0.82 & 1.00 & & \\
& $(* *)$ & $(* *)$ & $(* *)$ & $(* *)$ & & $(* *)$ & & & \\
\hline MR & 0.50 & -0.35 & 0.39 & -0.50 & -0.72 & -0.32 & 0.23 & 1.00 & \\
& $(* *)$ & $(* *)$ & $(* *)$ & $(* *)$ & $(* *)$ & $(* *)$ & $(*)$ & & \\
\hline MD & -0.35 & 0.85 & 0.20 & 0.35 & 0.69 & 0.14 & -0.16 & -0.52 & 1.00 \\
& $(* *)$ & $(* *)$ & & $(* *)$ & $(* *)$ & & & $(* *)$ & \\
\hline
\end{tabular}

It is worth noting the correlation between the threshold and both the variables total return and the average of returns. The total return is negatively related to the threshold level $(-0.70)$, while the average of returns per operation is positively related (0.50). It means there is a positive relation between the return of the operations and the similarity which exists between the price window and the flag pattern. Therefore, the more recognizable and clearer the pattern of a flag is, the greater the return of the trading rule. The negative relation between the threshold and the total return is explained by the greater number of operations for low threshold values. In fact, the correlation between the threshold and the total return after removing the effect of the number of operations 
is not statistically significant, with a coefficient value of -0.08 and a $p$-value of 0.42 . It is also interesting to check how both the total return and the average of returns are negatively related to the SL and positively related to the TP. This confirms the level's choice of TP, which are greater than the SL when defining an investment strategy.

With respect to the risk, the maximum drawdown is negatively related to the average of returns (-0.52). This would contradict the fundamentals of financial markets: return and risk are positively related. In order to contrast this hypothesis and once having removed the effect of the number of operations, the correlation coefficient and the $p$ value found were 0.01 and 0.90 respectively. Therefore, the number of operations will explain the relation between the average of returns and the maximum drawdown.

To summarize, a greater level of threshold will involve a greater average of returns, without assuming a greater risk. That is to say, the flag pattern provides a positive and significant risk-adjusted return.

In the next step an analysis of non-overlapped periods is conducted. Brock et al. state that the data snooping problem can be mitigated by:

1. using a very long data series,

2. reporting results from all trading rules, and

3. providing results across various non-overlapping sub-periods.

In the present work and thanks to intraday data, very long historical data series are used. A trading rule has been configured in order to analyse it's behaviour over different and plausible configurations. Therefore, only the use of several non-overlapping sub-periods remains (Brock et al., 1992).

This section presents the results of applying the trading rule over three non-overlapping sub-periods; all of them are of the same size with nearly 31,500 15-minutes candlesticks. The first sub-period lasts from May 22, 2000 to November 26, 2004; the second subperiod lasts from November 26, 2004 to February 27, 2007; and the third sub-period lasts from February 27, 2007 to November 29, 2013. The aim is to check if the behaviour of the trading rule for each one of the sub-periods is similar to the one observed for the whole sample.

Once again, for this purpose the 96 configurations of the trading rule over the three sub-periods are applied (results are presented in table 4.10). With the aim of reducing the length of the study, the information about the total return, the average of returns and the maximum drawdown are the only ones presented. 
It's noted that the results of the total return are positive in all cases for sub-period 1. Moreover, in most of the configurations the maximum drawdown is lower than the total return for the whole sub-period. Sub-period 2 has a very similar behaviour to sub-period 1. Results for the total return are positive, and the maximum drawdown exceeds the total return in only a few cases.

The results for sub-period 3 are more complex. The total return is negative for 12 configurations, and 34 configurations provide a maximum drawdown which is greater than the total return.

Therefore, it can be concluded that two of three sub-periods perform in a similar way to the entire sample, whereas the third sub-period presents negative returns in some cases and risks greater than the return.

Furthermore, the lower the values of the SL, the better the performance of the trading rule. When this parameter takes a value of 0.2 the total return is positive for all subperiods and the rest of the parameter values, whilst the total return is greater than the maximum drawdown. A similar conclusion is reached when taking a value of 0.4 ; all the total returns are positive and only in some cases are the risks greater than the return. These results are consistent with the correlations showed in table 4.9, where it's confirmed that low levels of stop loss favored a greater return and a lower level of drawdown. Furthermore, table 4.9 proves that the greater correlation coefficient in absolute value relates to the SL and the MD. 
TABLE 4.10: Results of the trading rule over the DJIA index for 3 non-overlapped sub-periods

First sub-period: From May 22, 2000 to November 26, 2004. Second sub-period:

November 26, 2004 to February 27, 2007. Third sub-period: February 27, 2007 to November 29, 2013. Thr $=$ Threshold fit value; $\mathrm{SL}=(\mathrm{R}$ times $)$ Stop Loss; $\mathrm{TP}=(\mathrm{R}$ times) Take Profit; $\mathrm{TR}=$ Total Return; AR = Average of Returns; $\mathrm{MD}=$ Maximum Drawdown (negative TR in bold; bold MD indicates a maximum drawdown which is greater than the total return)

\begin{tabular}{|c|c|c|c|c|c|c|c|c|c|c|c|}
\hline & & & \multicolumn{3}{|c|}{ Sub-period 1} & \multicolumn{3}{|c|}{ Sub-period 2} & \multicolumn{3}{|c|}{ Sub-period 3} \\
\hline Thr. & SL & TP & TR & $\mathrm{AR}$ & $\mathrm{MD}$ & TR & $\mathrm{AR}$ & $\mathrm{MD}$ & TR & $\mathrm{AR}$ & $\mathrm{MD}$ \\
\hline \multirow[t]{24}{*}{5} & \multirow[t]{6}{*}{0.8} & 2.0 & 0.463 & 0.0041 & 0.135 & 0.203 & 0.0015 & 0.184 & 0.089 & 0.0004 & 0.264 \\
\hline & & 1.8 & 0.421 & 0.0037 & 0.119 & 0.215 & 0.0016 & 0.158 & 0.201 & 0.0009 & 0.159 \\
\hline & & 1.6 & 0.398 & 0.0035 & 0.081 & 0.101 & 0.0008 & 0.209 & 0.171 & 0.0008 & 0.158 \\
\hline & & 1.4 & 0.404 & 0.0036 & 0.062 & 0.240 & 0.0018 & 0.135 & 0.113 & 0.0005 & 0.216 \\
\hline & & 1.2 & 0.338 & 0.0030 & 0.059 & 0.233 & 0.0018 & 0.131 & 0.117 & 0.0005 & 0.171 \\
\hline & & 1.0 & 0.309 & 0.0027 & 0.052 & 0.153 & 0.0012 & 0.111 & -0.014 & -0.0001 & 0.230 \\
\hline & \multirow[t]{6}{*}{0.6} & 2.0 & 0.450 & 0.0040 & 0.154 & 0.191 & 0.0014 & 0.130 & 0.057 & 0.0003 & 0.143 \\
\hline & & 1.8 & 0.416 & 0.0037 & 0.144 & 0.314 & 0.0023 & 0.095 & 0.158 & 0.0007 & 0.089 \\
\hline & & 1.6 & 0.370 & 0.0033 & 0.121 & 0.209 & 0.0016 & 0.103 & 0.131 & 0.0006 & 0.105 \\
\hline & & 1.4 & 0.381 & 0.0034 & 0.093 & 0.313 & 0.0023 & 0.095 & 0.096 & 0.0004 & 0.113 \\
\hline & & 1.2 & 0.325 & 0.0029 & 0.089 & 0.296 & 0.0022 & 0.080 & 0.089 & 0.0004 & 0.099 \\
\hline & & 1.0 & 0.300 & 0.0027 & 0.056 & 0.219 & 0.0016 & 0.092 & 0.023 & 0.0001 & 0.126 \\
\hline & \multirow[t]{6}{*}{0.4} & 2.0 & 0.256 & 0.0023 & 0.130 & 0.107 & 0.0008 & 0.108 & 0.145 & 0.0006 & 0.115 \\
\hline & & 1.8 & 0.228 & 0.0020 & 0.108 & 0.172 & 0.0013 & 0.065 & 0.231 & 0.0010 & 0.091 \\
\hline & & 1.6 & 0.178 & 0.0016 & 0.093 & 0.092 & 0.0007 & 0.065 & 0.188 & 0.0008 & 0.091 \\
\hline & & 1.4 & 0.204 & 0.0018 & 0.064 & 0.165 & 0.0012 & 0.073 & 0.202 & 0.0009 & 0.059 \\
\hline & & 1.2 & 0.178 & 0.0016 & 0.060 & 0.102 & 0.0008 & 0.065 & 0.184 & 0.0008 & 0.059 \\
\hline & & 1.0 & 0.179 & 0.0016 & 0.037 & 0.109 & 0.0008 & 0.069 & 0.082 & 0.0004 & 0.082 \\
\hline & \multirow[t]{6}{*}{0.2} & 2.0 & 0.140 & 0.0012 & 0.091 & 0.348 & 0.0026 & 0.054 & 0.136 & 0.0006 & 0.085 \\
\hline & & 1.8 & 0.138 & 0.0012 & 0.066 & 0.394 & 0.0029 & 0.032 & 0.165 & 0.0007 & 0.075 \\
\hline & & 1.6 & 0.119 & 0.0011 & 0.070 & 0.320 & 0.0024 & 0.032 & 0.178 & 0.0008 & 0.078 \\
\hline & & 1.4 & 0.149 & 0.0013 & 0.060 & 0.380 & 0.0028 & 0.032 & 0.206 & 0.0009 & 0.053 \\
\hline & & 1.2 & 0.122 & 0.0011 & 0.056 & 0.308 & 0.0023 & 0.032 & 0.141 & 0.0006 & 0.056 \\
\hline & & 1.0 & 0.092 & 0.0008 & 0.054 & 0.291 & 0.0022 & 0.032 & 0.127 & 0.0006 & 0.066 \\
\hline
\end{tabular}




\begin{tabular}{|c|c|c|c|c|c|c|c|c|c|c|c|}
\hline & & & \multicolumn{3}{|c|}{ Sub-period 1} & \multicolumn{3}{|c|}{ Sub-period 2} & \multicolumn{3}{|c|}{ Sub-period 3} \\
\hline Thr. & SL & TP & TR & $\mathrm{AR}$ & $\mathrm{MD}$ & TR & $\mathrm{AR}$ & $\mathrm{MD}$ & TR & $\mathrm{AR}$ & $\mathrm{MD}$ \\
\hline \multirow[t]{24}{*}{4} & \multirow[t]{6}{*}{0.8} & 2.0 & 0.460 & 0.0023 & 0.134 & 0.180 & 0.0009 & 0.248 & 0.145 & 0.0005 & 0.197 \\
\hline & & 1.8 & 0.463 & 0.0023 & 0.101 & 0.204 & 0.0010 & 0.206 & 0.228 & 0.0008 & 0.153 \\
\hline & & 1.6 & 0.582 & 0.0029 & 0.075 & 0.096 & 0.0005 & 0.221 & 0.150 & 0.0005 & 0.153 \\
\hline & & 1.4 & 0.531 & 0.0027 & 0.068 & 0.216 & 0.0011 & 0.208 & 0.044 & 0.0001 & 0.213 \\
\hline & & 1.2 & 0.425 & 0.0021 & 0.081 & 0.275 & 0.0014 & 0.216 & 0.042 & 0.0001 & 0.135 \\
\hline & & 1.0 & 0.362 & 0.0018 & 0.083 & 0.166 & 0.0008 & 0.206 & -0.120 & -0.0004 & 0.232 \\
\hline & \multirow[t]{6}{*}{0.6} & 2.0 & 0.546 & 0.0028 & 0.105 & 0.199 & 0.0010 & 0.166 & 0.193 & 0.0006 & 0.124 \\
\hline & & 1.8 & 0.484 & 0.0024 & 0.107 & 0.336 & 0.0017 & 0.130 & 0.265 & 0.0009 & 0.115 \\
\hline & & 1.6 & 0.536 & 0.0027 & 0.097 & 0.237 & 0.0012 & 0.135 & 0.192 & 0.0006 & 0.120 \\
\hline & & 1.4 & 0.500 & 0.0025 & 0.092 & 0.325 & 0.0016 & 0.120 & 0.111 & 0.0004 & 0.108 \\
\hline & & 1.2 & 0.412 & 0.0021 & 0.081 & 0.368 & 0.0018 & 0.135 & 0.095 & 0.0003 & 0.091 \\
\hline & & 1.0 & 0.333 & 0.0017 & 0.059 & 0.264 & 0.0013 & 0.128 & -0.021 & -0.0001 & 0.138 \\
\hline & \multirow[t]{6}{*}{0.4} & 2.0 & 0.474 & 0.0024 & 0.085 & 0.186 & 0.0009 & 0.140 & 0.257 & 0.0008 & 0.120 \\
\hline & & 1.8 & 0.416 & 0.0021 & 0.072 & 0.263 & 0.0013 & 0.070 & 0.323 & 0.0011 & 0.096 \\
\hline & & 1.6 & 0.441 & 0.0022 & 0.070 & 0.162 & 0.0008 & 0.079 & 0.244 & 0.0008 & 0.096 \\
\hline & & 1.4 & 0.421 & 0.0021 & 0.070 & 0.227 & 0.0011 & 0.070 & 0.223 & 0.0007 & 0.078 \\
\hline & & 1.2 & 0.346 & 0.0017 & 0.060 & 0.198 & 0.0010 & 0.081 & 0.193 & 0.0006 & 0.080 \\
\hline & & 1.0 & 0.295 & 0.0015 & 0.044 & 0.198 & 0.0010 & 0.086 & 0.052 & 0.0002 & 0.100 \\
\hline & \multirow[t]{6}{*}{0.2} & 2.0 & 0.306 & 0.0015 & 0.043 & 0.471 & 0.0023 & 0.063 & 0.290 & 0.0010 & 0.100 \\
\hline & & 1.8 & 0.291 & 0.0015 & 0.039 & 0.494 & 0.0024 & 0.046 & 0.304 & 0.0010 & 0.091 \\
\hline & & 1.6 & 0.359 & 0.0018 & 0.038 & 0.405 & 0.0020 & 0.043 & 0.288 & 0.0010 & 0.093 \\
\hline & & 1.4 & 0.341 & 0.0017 & 0.038 & 0.458 & 0.0023 & 0.035 & 0.287 & 0.0009 & 0.066 \\
\hline & & 1.2 & 0.281 & 0.0014 & 0.035 & 0.422 & 0.0021 & 0.045 & 0.199 & 0.0007 & 0.070 \\
\hline & & 1.0 & 0.233 & 0.0012 & 0.035 & 0.403 & 0.0020 & 0.057 & 0.154 & 0.0005 & 0.081 \\
\hline
\end{tabular}

\begin{tabular}{|c|c|c|c|c|c|c|c|c|c|c|c|}
\hline & & & \multicolumn{3}{|c|}{ Sub-period 1} & \multicolumn{3}{|c|}{ Sub-period 2} & \multicolumn{3}{|c|}{ Sub-period 3} \\
\hline Thr. & $\mathrm{SL}$ & TP & TR & $\mathrm{AR}$ & $\mathrm{MD}$ & TR & $\mathrm{AR}$ & $\mathrm{MD}$ & TR & $\mathrm{AR}$ & $\mathrm{MD}$ \\
\hline \multirow[t]{24}{*}{3} & \multirow[t]{6}{*}{0.8} & 2.0 & 0.181 & 0.0006 & 0.207 & 0.351 & 0.0012 & 0.252 & 0.124 & 0.0003 & 0.277 \\
\hline & & 1.8 & 0.184 & 0.0006 & 0.200 & 0.305 & 0.0010 & 0.237 & 0.145 & 0.0004 & 0.238 \\
\hline & & 1.6 & 0.373 & 0.0013 & 0.114 & 0.340 & 0.0011 & 0.248 & 0.051 & 0.0001 & 0.235 \\
\hline & & 1.4 & 0.428 & 0.0015 & 0.089 & 0.489 & 0.0016 & 0.216 & -0.082 & -0.0002 & 0.284 \\
\hline & & 1.2 & 0.295 & 0.0010 & 0.108 & 0.472 & 0.0016 & 0.235 & -0.021 & -0.0001 & 0.167 \\
\hline & & 1.0 & 0.189 & 0.0007 & 0.116 & 0.342 & 0.0011 & 0.193 & -0.224 & -0.0006 & 0.305 \\
\hline & \multirow[t]{6}{*}{0.6} & 2.0 & 0.387 & 0.0014 & 0.166 & 0.357 & 0.0012 & 0.175 & 0.266 & 0.0007 & 0.173 \\
\hline & & 1.8 & 0.297 & 0.0010 & 0.181 & 0.435 & 0.0015 & 0.159 & 0.279 & 0.0007 & 0.164 \\
\hline & & 1.6 & 0.375 & 0.0013 & 0.159 & 0.472 & 0.0016 & 0.167 & 0.186 & 0.0005 & 0.168 \\
\hline & & 1.4 & 0.440 & 0.0015 & 0.129 & 0.589 & 0.0020 & 0.138 & 0.079 & 0.0002 & 0.172 \\
\hline & & 1.2 & 0.338 & 0.0012 & 0.097 & 0.559 & 0.0019 & 0.162 & 0.118 & 0.0003 & 0.109 \\
\hline & & 1.0 & 0.209 & 0.0007 & 0.104 & 0.459 & 0.0015 & 0.129 & -0.021 & -0.0001 & 0.150 \\
\hline & \multirow[t]{6}{*}{0.4} & 2.0 & 0.413 & 0.0014 & 0.117 & 0.308 & 0.0010 & 0.185 & 0.370 & 0.0010 & 0.156 \\
\hline & & \begin{tabular}{|l|}
1.8 \\
\end{tabular} & 0.331 & 0.0012 & 0.114 & 0.341 & 0.0011 & 0.151 & 0.398 & 0.0010 & 0.145 \\
\hline & & 1.6 & 0.382 & 0.0013 & 0.106 & 0.299 & 0.0010 & 0.142 & 0.304 & 0.0008 & 0.145 \\
\hline & & 1.4 & 0.448 & 0.0016 & 0.094 & 0.344 & 0.0011 & 0.149 & 0.276 & 0.0007 & 0.108 \\
\hline & & 1.2 & 0.341 & 0.0012 & 0.063 & 0.269 & 0.0009 & 0.101 & 0.293 & 0.0008 & 0.093 \\
\hline & & \begin{tabular}{|l|}
1.0 \\
\end{tabular} & 0.247 & 0.0009 & 0.069 & 0.291 & 0.0010 & 0.098 & 0.107 & 0.0003 & 0.115 \\
\hline & \multirow[t]{6}{*}{0.2} & 2.0 & 0.318 & 0.0011 & 0.070 & 0.711 & 0.0024 & 0.093 & 0.293 & 0.0008 & 0.073 \\
\hline & & \begin{tabular}{|l|}
1.8 \\
\end{tabular} & 0.286 & 0.0010 & 0.074 & 0.693 & 0.0023 & 0.073 & 0.288 & 0.0007 & 0.073 \\
\hline & & 1.6 & 0.382 & 0.0013 & 0.066 & 0.656 & 0.0022 & 0.065 & 0.258 & 0.0007 & 0.073 \\
\hline & & 1.4 & 0.429 & 0.0015 & 0.047 & 0.679 & 0.0023 & 0.065 & 0.271 & 0.0007 & 0.060 \\
\hline & & 1.2 & 0.342 & 0.0012 & 0.042 & 0.599 & 0.0020 & 0.042 & 0.224 & 0.0006 & 0.067 \\
\hline & & 1.0 & 0.243 & 0.0008 & 0.042 & 0.577 & 0.0019 & 0.045 & 0.153 & 0.0004 & 0.088 \\
\hline
\end{tabular}




\begin{tabular}{|c|c|c|c|c|c|c|c|c|c|c|c|}
\hline & & & \multicolumn{3}{|c|}{ Sub-period 1} & \multicolumn{3}{|c|}{ Sub-period 2} & \multicolumn{3}{|c|}{ Sub-period 3} \\
\hline Thr. & SL & $\mathrm{TP}$ & TR & $\mathrm{AR}$ & $\mathrm{MD}$ & TR & $\mathrm{AR}$ & $\mathrm{MD}$ & TR & $\mathrm{AR}$ & $\mathrm{MD}$ \\
\hline \multirow[t]{24}{*}{2} & \multirow[t]{6}{*}{0.8} & 2.0 & 0.218 & 0.0006 & 0.332 & 0.431 & 0.0012 & 0.274 & 0.116 & 0.0003 & 0.270 \\
\hline & & 1.8 & 0.274 & 0.0007 & 0.321 & 0.375 & 0.0010 & 0.249 & 0.084 & 0.0002 & 0.267 \\
\hline & & 1.6 & 0.417 & 0.0011 & 0.243 & 0.311 & 0.0009 & 0.256 & -0.013 & 0.0000 & 0.303 \\
\hline & & 1.4 & 0.502 & 0.0014 & 0.194 & 0.528 & 0.0015 & 0.260 & -0.174 & -0.0004 & 0.365 \\
\hline & & 1.2 & 0.301 & 0.0008 & 0.158 & 0.665 & 0.0019 & 0.275 & -0.137 & -0.0003 & 0.294 \\
\hline & & 1.0 & 0.147 & 0.0004 & 0.153 & 0.512 & 0.0014 & 0.222 & -0.284 & -0.0006 & 0.347 \\
\hline & \multirow[t]{6}{*}{0.6} & 2.0 & 0.435 & 0.0012 & 0.279 & 0.387 & 0.0011 & 0.168 & 0.311 & 0.0007 & 0.138 \\
\hline & & 1.8 & 0.337 & 0.0009 & 0.293 & 0.447 & 0.0012 & 0.159 & 0.275 & 0.0006 & 0.139 \\
\hline & & 1.6 & 0.383 & 0.0010 & 0.266 & 0.401 & 0.0011 & 0.161 & 0.179 & 0.0004 & 0.167 \\
\hline & & 1.4 & 0.482 & 0.0013 & 0.213 & 0.589 & 0.0016 & 0.136 & 0.045 & 0.0001 & 0.197 \\
\hline & & 1.2 & 0.325 & 0.0009 & 0.171 & 0.735 & 0.0020 & 0.174 & 0.062 & 0.0001 & 0.134 \\
\hline & & 1.0 & 0.160 & 0.0004 & 0.170 & 0.599 & 0.0017 & 0.138 & -0.028 & -0.0001 & 0.148 \\
\hline & \multirow[t]{6}{*}{0.4} & 2.0 & 0.426 & 0.0011 & 0.185 & 0.486 & 0.0013 & 0.106 & 0.463 & 0.0010 & 0.102 \\
\hline & & 1.8 & 0.347 & 0.0009 & 0.189 & 0.495 & 0.0014 & 0.106 & 0.447 & 0.0010 & 0.119 \\
\hline & & 1.6 & 0.396 & 0.0011 & 0.176 & 0.462 & 0.0013 & 0.090 & 0.335 & 0.0007 & 0.136 \\
\hline & & 1.4 & 0.501 & 0.0014 & 0.145 & 0.554 & 0.0015 & 0.089 & 0.285 & 0.0006 & 0.132 \\
\hline & & 1.2 & 0.385 & 0.0010 & 0.110 & 0.617 & 0.0017 & 0.089 & 0.305 & 0.0007 & 0.105 \\
\hline & & 1.0 & 0.241 & 0.0006 & 0.122 & 0.587 & 0.0016 & 0.089 & 0.178 & 0.0004 & 0.120 \\
\hline & \multirow[t]{6}{*}{0.2} & 2.0 & 0.345 & 0.0009 & 0.108 & 0.949 & 0.0026 & 0.054 & 0.334 & 0.0007 & 0.063 \\
\hline & & 1.8 & 0.315 & 0.0008 & 0.112 & 0.899 & 0.0025 & 0.053 & 0.324 & 0.0007 & 0.060 \\
\hline & & 1.6 & 0.365 & 0.0010 & 0.087 & 0.870 & 0.0024 & 0.045 & 0.289 & 0.0006 & 0.067 \\
\hline & & 1.4 & 0.436 & 0.0012 & 0.065 & 0.829 & 0.0023 & 0.045 & 0.289 & 0.0006 & 0.075 \\
\hline & & 1.2 & 0.332 & 0.0009 & 0.068 & 0.745 & 0.0021 & 0.041 & 0.252 & 0.0005 & 0.076 \\
\hline & & 1.0 & 0.209 & 0.0006 & 0.067 & 0.695 & 0.0019 & 0.045 & 0.180 & 0.0004 & 0.085 \\
\hline
\end{tabular}




\subsubsection{Spain (IBEX)}

This section deals with the implementation of the method introduced on intraday data of the Spanish Ibex-35. The Ibex-35 (Iberia Index 35) is the Spanish benchmark index and the stock market barometer of the Stock Exchange in Madrid. Published for the first time on January 14, 1992, the index was recalculated making data available from December 31, 1986. In contrast to the DAX, the Ibex-35 is a price index. Thus, the index value represents the average price of the shares included in it. The index is not adjusted for dividend payments, therefore usual markdowns reasoned in dividend payments are reflected. In the Ibex-35 the 35 largest Spanish companies are listed, especially the financial, telecommunication and energy sectors. The five largest companies in these sectors are Telefònica, Banco Santander, Banco Bilbao Vizcaya Argentaria, Iberdrola and Repsol YPF. These companies make more than $60 \%$ of the capitalization of the Ibex-35 (finanzen.net GmbH, 2015c).

The following table 4.11 gives an overview of the Ibex-35's development within the last 15 years (finanzen.net GmbH, 2015c):

TABLE 4.11: Historic lows and highs for the Ibex-35, 2000-2015

\begin{tabular}{rrrrrr} 
Year & Annual start & Annual end & Annual low & Annual high & $\%$ \\
\hline 2015 & $10,350.8$ & - & $9,719.0$ & $11,866.4$ & 11.20 \\
2014 & $9,760.3$ & $10,279.5$ & $9,669.7$ & $11,187.8$ & 5.32 \\
2013 & $8,447.6$ & $9,916.7$ & $7,553.2$ & $10,037.8$ & 17.39 \\
2012 & $8,723.8$ & $8,167.5$ & $5,956.3$ & $8,902.1$ & -6.38 \\
2011 & $9,888.3$ & $8,566.3$ & $7,640.7$ & $11,113.0$ & -13.37 \\
2010 & $11,986.5$ & $9,859.1$ & $8,725.9$ & $12,218.0$ & -17.75 \\
2009 & $9,486.3$ & $12,018.4$ & $6,817.4$ & $12,034.7$ & 26.69 \\
2008 & $15,002.5$ & $9,195.8$ & $7,905.4$ & $15,002.5$ & -38.70 \\
2007 & $14,364.4$ & $15,182.3$ & $13,602.4$ & $15,945.7$ & 5.69 \\
2006 & $10,786.7$ & $14,146.5$ & $10,665.6$ & $14,387.6$ & 31.15 \\
2005 & $9,124.1$ & $10,733.9$ & $8,945.7$ & $10,919.2$ & 17.64 \\
2004 & $7,879.2$ & $9,080.8$ & $7,578.3$ & $9,100.7$ & 15.25 \\
2003 & $6,284.0$ & $7,737.2$ & $5,452.4$ & $7,760.4$ & 23.13 \\
2002 & $8,377.1$ & $6,036.9$ & $5,364.5$ & $8,554.7$ & -27.94 \\
2001 & $9,080.2$ & $8,397.6$ & $6,498.4$ & $10,132.0$ & -7.52 \\
2000 & $11,610.0$ & $9,109.8$ & $8,864.3$ & $12,816.8$ & -21.53 \\
\hline
\end{tabular}

It can be observed in table 4.11 that the Spanish Ibex-35 is very volatile. In 2008/2009 a strong negative growth of $-38.70 \%$ was recorded. Nevertheless the current high does not represent any low or high of the last 15 years. It is more a mean value located in the middle range. To understand this development in detail, a closer look at the economic activities is required. 
In the operation of figure 4.15 a price range of $\mathrm{R}=92$ points with a take profit level of $\mathrm{TP}=8,576+1 * 92=8,668$ and a stop loss level of $\mathrm{SL}=8,576-0,5^{*} 92=8,530$ can be observed:

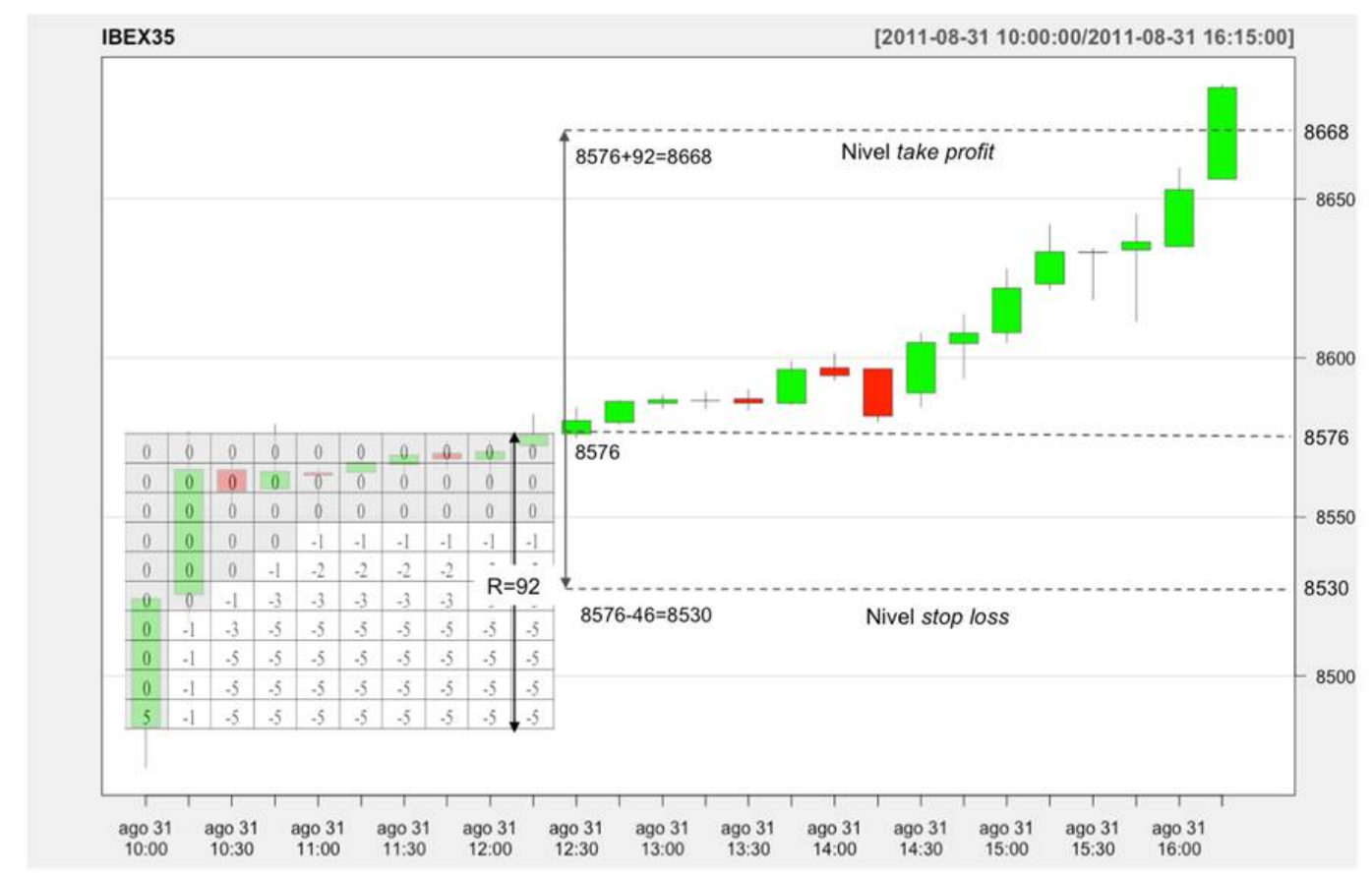

Figure 4.15: Candlestick Chart of the Spanish Ibex-35, from 10:00 a.m. on August 31, 2011 until 4:15 p.m. on the same day at time intervals of 15 minutes

Identification of a bull flag which corresponds to the ten first candlesticks of the period, and whose fit value $=5$. The price range for the flag is $\mathrm{R}=92$ points. The

purchase is made at the level of 8,576 . The SL is calculated, in this case, as the opening price of the candle No. $11(8,576)$ minus 0.5 times $\mathrm{R}\left(8,576-0,5^{*} 92=8,530\right)$, and the $\mathrm{TP}$ as the opening price plus one time $\mathrm{R}(8,576+1 * 92=8,668)$. The operation closes at 4:15 p.m. when the price reaches the TP level.

Therefore, the expected benefit of the operation is twice the maximum loss an investor is willing to assume. Obviously, the relationship between SL and TP may vary, as illustrated perfectly in figure 4.15. In this section a wide range of values for these parameters will be used in order to obtain more robust results for the investment strategy.

The investment strategy based on the flag pattern has been applied to intraday data of the main Spanish stock market index, the Ibex-35. The use of intraday data allows for the significant expansion of the sample size in the case of the daily data. Moreover, by expanding the sample size it is no longer necessary to consider long, overdue historical data in time to have a minimally significant sample size. The use of very old historical data may involve a significant limitation specified in the literature: validate a strategy based on a technology that was not available to investors at the investment time (Sullivan et al., 1999; Timmermann and Granger, 2004). This is the case, for example, in those 
works that employ artificial neural networks to validate strategies in instants of time in which that technique simply had not yet been invented.

Two databases were composed, one on 15-minutes candles and another one on 1 hour candles; and in both cases the period runs from May 15, 2000 to October 4, 2013. The sample consists of 127,480 candlesticks in the case of the data at time intervals of 15 minutes, involving the largest sample size ever used for analysis of an investment strategy. Consequently, in the case of hourly data that number is reduced to a quarter.

As noted at the end of the previous section and in order to improve the robustness of the results the following is parametrized:

1. the $\mathrm{SL}$ value is indexed to the price range $\mathrm{R}$,

2. the TP value is referenced to the price range $R$, and

3. the threshold of the fit function that identifies the flag pattern.

The investment strategy has been implemented on the following combinations of values:

$$
\begin{gathered}
\text { Threshold fitting value } \in\{1,2,3,4,5\} \\
S L \in\{0.2,0.4,0.6,0.8\} \\
T P \in\{1.0,1.2,1.4,1.6,1.8,2.0\}
\end{gathered}
$$

where the values of SL and TP are defined as multiples of the range R.

The combination of these three parameters allows a total of 120 different configurations. For each of them the total number of operations performed by the investment strategy, the overall profitability of the strategy and the maximum drawdown were calculated.

The maximum drawdown was used to measure the risk of the investment strategy, since the returns of these strategies do not follow a normal distribution and it is impossible to use the t-statistic (Leigh et al., 2004).

Table 4.12 shows the results after applying the trading rule on 120 configurations analysed, with all settings recording a positive return. Considering the risk, in 117 configurations $(97.5 \%)$ the profitability exceeds the maximum drawdown; therefore, in all these cases the investor would have obtained a favourable risk-adjusted return since the final return is greater than the maximum loss sustained throughout the period.

However, applying the same investment strategy on hourly data obtains very different results. In table 4.13 the performance of the strategy on this data is summarized. As it 
can be seen, in only 48 of the 120 configurations the return on the investment strategy is positive, representing a success rate of $40 \%$. Similarly, the assumed risk for most cases is also higher than the return obtained.

Therefore, there is a significant difference between 15 minute and hourly data; while in the first case the strategy obtains a positive risk-adjusted return, in the second, the profitability is mostly negative for wide casuistry of tested configurations. These results call into question one of the basic assumptions of technical analysis: fractality. As mentioned before, if eliminating any temporal reference graphics, it would not be possible to discern whether it is a weekly, daily or intraday chart (Elder, 2002).

Inline, Bollinger states that fractal patterns are very common, if reviewing a graph with a double bottom pattern in the long term, it can also be observed for the short term and the same pattern appears repeatedly, so that in the long term the double bottom could be found on a smaller scale in the short term (Bollinger, 2002).

However, having used the same technique for the graphical flag pattern recognition in the two databases, different results were archived when working with candles of 15 minutes and candles of an hourly frequency.

TABLE 4.12: Results of the investment strategy on data at time intervals of 15 minutes from the Spanish Ibex-35

Analysed period: from May 15, 2000 to October 4, 2013.

\begin{tabular}{|c|c|c|c|c|}
\hline SL & TP & TR & MD & TR>MD \\
\hline \multirow{5}{*}{0,8} & 2,0 & 1,104 & 0,283 & $\mathrm{Y}$ \\
\cline { 2 - 5 } & 1,8 & 0,892 & 0,303 & $\mathrm{Y}$ \\
\cline { 2 - 5 } & 1,6 & 0,683 & 0,265 & $\mathrm{Y}$ \\
\cline { 2 - 5 } & 1,4 & 0,571 & 0,279 & $\mathrm{Y}$ \\
\cline { 2 - 5 } & 1,2 & 0,308 & 0,380 & $\mathrm{~N}$ \\
\hline \multirow{5}{*}{0,6} & 1,0 & 0,069 & 0,431 & $\mathrm{~N}$ \\
\hline \multirow{5}{*}{} & 2,0 & 1,474 & 0,162 & $\mathrm{Y}$ \\
\cline { 2 - 5 } & 1,8 & 1,183 & 0,182 & $\mathrm{Y}$ \\
\cline { 2 - 5 } & 1,6 & 1,021 & 0,203 & $\mathrm{Y}$ \\
\cline { 2 - 5 } & 1,4 & 0,966 & 0,131 & $\mathrm{Y}$ \\
\cline { 2 - 5 } & 1,2 & 0,696 & 0,206 & $\mathrm{Y}$ \\
\cline { 2 - 5 } & 1,0 & 0,517 & 0,196 & $\mathrm{Y}$ \\
\hline
\end{tabular}

\begin{tabular}{|c|c|c|c|c|}
\hline SL & TP & TR & MD & TR $>$ MD \\
\hline \multirow{5}{*}{0,4} & 2,0 & 1,484 & 0,203 & $\mathrm{Y}$ \\
\cline { 2 - 5 } & 1,8 & 1,276 & 0,204 & $\mathrm{Y}$ \\
\cline { 2 - 5 } & 1,6 & 1,170 & 0,132 & $\mathrm{Y}$ \\
\cline { 2 - 5 } & 1,4 & 1,077 & 0,132 & $\mathrm{Y}$ \\
\cline { 2 - 5 } & 1,2 & 0,909 & 0,149 & $\mathrm{Y}$ \\
\cline { 2 - 5 } & 1,0 & 0,702 & 0,135 & $\mathrm{Y}$ \\
\hline \multirow{5}{*}{0,2} & 2,0 & 1,123 & 0,147 & $\mathrm{Y}$ \\
\cline { 2 - 5 } & 1,8 & 0,970 & 0,143 & $\mathrm{Y}$ \\
\cline { 2 - 5 } & 1,6 & 0,860 & 0,140 & $\mathrm{Y}$ \\
\cline { 2 - 5 } & 1,4 & 0,823 & 0,108 & $\mathrm{Y}$ \\
\cline { 2 - 5 } & 1,2 & 0,910 & 0,089 & $\mathrm{Y}$ \\
\cline { 2 - 5 } & 1,0 & 0,774 & 0,082 & $\mathrm{Y}$ \\
\hline
\end{tabular}

Panel a) Threshold for the fit value $=5$, Number of operations $=594$ 


\begin{tabular}{|c|c|c|c|c|}
\hline SL & TP & TR & MD & TR>MD \\
\hline \multirow{5}{*}{0,8} & 2,0 & 2,187 & 0,403 & $\mathrm{Y}$ \\
\cline { 2 - 5 } & 1,8 & 1,738 & 0,426 & $\mathrm{Y}$ \\
\cline { 2 - 5 } & 1,6 & 1,491 & 0,384 & $\mathrm{Y}$ \\
\cline { 2 - 5 } & 1,4 & 1,406 & 0,443 & $\mathrm{Y}$ \\
\cline { 2 - 5 } & 1,2 & 0,771 & 0,552 & $\mathrm{Y}$ \\
\cline { 2 - 5 } & 1,0 & 0,460 & 0,546 & $\mathrm{~N}$ \\
\hline \multirow{5}{*}{0,6} & 2,0 & 2,662 & 0,245 & $\mathrm{Y}$ \\
\hline \multirow{4}{*}{1,8} & 2,173 & 0,268 & $\mathrm{Y}$ \\
\cline { 2 - 5 } & 1,6 & 1,954 & 0,292 & $\mathrm{Y}$ \\
\cline { 2 - 5 } & 1,4 & 1,940 & 0,264 & $\mathrm{Y}$ \\
\cline { 2 - 5 } & 1,2 & 1,335 & 0,359 & $\mathrm{Y}$ \\
\cline { 2 - 5 } & 1,0 & 1,013 & 0,390 & $\mathrm{Y}$ \\
\hline
\end{tabular}

\begin{tabular}{|c|c|c|c|c|}
\hline SL & TP & TR & MD & TR>MD \\
\hline \multirow{5}{*}{0,4} & 2,0 & 2,604 & 0,307 & $\mathrm{Y}$ \\
\cline { 2 - 5 } & 1,8 & 2,243 & 0,311 & $\mathrm{Y}$ \\
\cline { 2 - 5 } & 1,6 & 2,106 & 0,211 & $\mathrm{Y}$ \\
\cline { 2 - 5 } & 1,4 & 2,067 & 0,217 & $\mathrm{Y}$ \\
\cline { 2 - 5 } & 1,2 & 1,682 & 0,206 & $\mathrm{Y}$ \\
\cline { 2 - 5 } & 1,0 & 1,301 & 0,227 & $\mathrm{Y}$ \\
\hline \multirow{5}{*}{0,2} & 2,0 & 2,359 & 0,180 & $\mathrm{Y}$ \\
\cline { 2 - 5 } & 1,8 & 2,085 & 0,180 & $\mathrm{Y}$ \\
\cline { 2 - 5 } & 1,6 & 1,974 & 0,180 & $\mathrm{Y}$ \\
\cline { 2 - 5 } & 1,4 & 2,011 & 0,149 & $\mathrm{Y}$ \\
\cline { 2 - 5 } & 1,2 & 1,897 & 0,108 & $\mathrm{Y}$ \\
\cline { 2 - 5 } & 1,0 & 1,581 & 0,114 & $\mathrm{Y}$ \\
\hline
\end{tabular}

Panel b) Threshold for the fit value $=4$, Number of operations $=1,124$

\begin{tabular}{|c|c|c|c|c|}
\hline SL & TP & TR & MD & TR>MD \\
\hline \multirow{5}{*}{0,8} & 2,0 & 2,351 & 0,569 & $\mathrm{Y}$ \\
\cline { 2 - 5 } & 1,8 & 2,179 & 0,582 & $\mathrm{Y}$ \\
\cline { 2 - 5 } & 1,6 & 1,940 & 0,539 & $\mathrm{Y}$ \\
\cline { 2 - 5 } & 1,4 & 1,806 & 0,420 & $\mathrm{Y}$ \\
\cline { 2 - 5 } & 1,2 & 1,030 & 0,455 & $\mathrm{Y}$ \\
\cline { 2 - 5 } & 1,0 & 0,681 & 0,522 & $\mathrm{Y}$ \\
\hline \multirow{5}{*}{0,6} & 2,0 & 3,036 & 0,392 & $\mathrm{Y}$ \\
\cline { 2 - 5 } & 1,8 & 2,808 & 0,393 & $\mathrm{Y}$ \\
\cline { 2 - 5 } & 1,6 & 2,495 & 0,408 & $\mathrm{Y}$ \\
\cline { 2 - 5 } & 1,4 & 2,520 & 0,304 & $\mathrm{Y}$ \\
\cline { 2 - 5 } & 1,2 & 1,851 & 0,292 & $\mathrm{Y}$ \\
\cline { 2 - 5 } & 1,0 & 1,598 & 0,311 & $\mathrm{Y}$ \\
\hline
\end{tabular}

\begin{tabular}{|c|c|c|c|c|}
\hline SL & TP & TR & MD & TR>MD \\
\hline \multirow{5}{*}{0,4} & 2,0 & 3,373 & 0,281 & $\mathrm{Y}$ \\
\cline { 2 - 5 } & 1,8 & 3,210 & 0,287 & $\mathrm{Y}$ \\
\cline { 2 - 5 } & 1,6 & 2,966 & 0,269 & $\mathrm{Y}$ \\
\cline { 2 - 5 } & 1,4 & 2,871 & 0,275 & $\mathrm{Y}$ \\
\cline { 2 - 5 } & 1,2 & 2,420 & 0,176 & $\mathrm{Y}$ \\
\cline { 2 - 5 } & 1,0 & 2,080 & 0,173 & $\mathrm{Y}$ \\
\hline \multirow{5}{*}{0,2} & 2,0 & 2,938 & 0,246 & $\mathrm{Y}$ \\
\cline { 2 - 5 } & 1,8 & 2,734 & 0,249 & $\mathrm{Y}$ \\
\cline { 2 - 5 } & 1,6 & 2,631 & 0,253 & $\mathrm{Y}$ \\
\cline { 2 - 5 } & 1,4 & 2,643 & 0,162 & $\mathrm{Y}$ \\
\cline { 2 - 5 } & 1,2 & 2,508 & 0,135 & $\mathrm{Y}$ \\
\cline { 2 - 5 } & 1,0 & 2,152 & 0,137 & $\mathrm{Y}$ \\
\hline
\end{tabular}

Panel c) Threshold for the fit value $=3$, Number of operations $=1,734$

\begin{tabular}{|c|c|c|c|c|}
\hline SL & TP & TR & MD & TR>MD \\
\hline \multirow{5}{*}{0,8} & 2,0 & 3,003 & 0,752 & $\mathrm{Y}$ \\
\cline { 2 - 5 } & 1,8 & 2,923 & 0,658 & $\mathrm{Y}$ \\
\cline { 2 - 5 } & 1,6 & 2,731 & 0,573 & $\mathrm{Y}$ \\
\cline { 2 - 5 } & 1,4 & 2,391 & 0,401 & $\mathrm{Y}$ \\
\cline { 2 - 5 } & 1,2 & 1,522 & 0,423 & $\mathrm{Y}$ \\
\cline { 2 - 5 } & 1,0 & 1,127 & 0,521 & $\mathrm{Y}$ \\
\hline \multirow{5}{*}{0,6} & 2,0 & 3,668 & 0,467 & $\mathrm{Y}$ \\
\cline { 2 - 5 } & 1,8 & 3,443 & 0,503 & $\mathrm{Y}$ \\
\cline { 2 - 5 } & 1,6 & 3,103 & 0,509 & $\mathrm{Y}$ \\
\cline { 2 - 5 } & 1,4 & 2,953 & 0,299 & $\mathrm{Y}$ \\
\cline { 2 - 5 } & 1,2 & 2,208 & 0,310 & $\mathrm{Y}$ \\
\cline { 2 - 5 } & 1,0 & 1,942 & 0,335 & $\mathrm{Y}$ \\
\hline
\end{tabular}

\begin{tabular}{|c|c|c|c|c|}
\hline SL & TP & TR & MD & TR>MD \\
\hline \multirow{5}{*}{0,4} & 2,0 & 4,237 & 0,337 & $\mathrm{Y}$ \\
\cline { 2 - 5 } & 1,8 & 4,024 & 0,341 & $\mathrm{Y}$ \\
\cline { 2 - 5 } & 1,6 & 3,763 & 0,325 & $\mathrm{Y}$ \\
\cline { 2 - 5 } & 1,4 & 3,494 & 0,311 & $\mathrm{Y}$ \\
\cline { 2 - 5 } & 1,2 & 2,924 & 0,215 & $\mathrm{Y}$ \\
\cline { 2 - 5 } & 1,0 & 2,714 & 0,247 & $\mathrm{Y}$ \\
\hline \multirow{5}{*}{0,2} & 2,0 & 3,886 & 0,309 & $\mathrm{Y}$ \\
\cline { 2 - 5 } & 1,8 & 3,660 & 0,314 & $\mathrm{Y}$ \\
\cline { 2 - 5 } & 1,6 & 3,541 & 0,281 & $\mathrm{Y}$ \\
\cline { 2 - 5 } & 1,4 & 3,406 & 0,175 & $\mathrm{Y}$ \\
\cline { 2 - 5 } & 1,2 & 3,212 & 0,164 & $\mathrm{Y}$ \\
\cline { 2 - 5 } & 1,0 & 2,994 & 0,151 & $\mathrm{Y}$ \\
\hline
\end{tabular}

Panel d) Threshold for the fit value $=2$, Number of operations $=2,322$ 


\begin{tabular}{|c|c|c|c|c|}
\hline SL & TP & TR & MD & TR>MD \\
\hline \multirow{5}{*}{0,8} & 2,0 & 4,243 & 0,646 & $\mathrm{Y}$ \\
\cline { 2 - 5 } & 1,8 & 4,150 & 0,625 & $\mathrm{Y}$ \\
\cline { 2 - 5 } & 1,6 & 3,913 & 0,446 & $\mathrm{Y}$ \\
\cline { 2 - 5 } & 1,4 & 3,262 & 0,454 & $\mathrm{Y}$ \\
\cline { 2 - 5 } & 1,2 & 2,258 & 0,495 & $\mathrm{Y}$ \\
\cline { 2 - 5 } & 1,0 & 1,726 & 0,454 & $\mathrm{Y}$ \\
\hline \multirow{5}{*}{0,6} & 2,0 & 4,947 & 0,482 & $\mathrm{Y}$ \\
\hline \multirow{4}{*}{} & 1,8 & 4,782 & 0,498 & $\mathrm{Y}$ \\
\cline { 2 - 5 } & 1,6 & 4,375 & 0,446 & $\mathrm{Y}$ \\
\cline { 2 - 5 } & 1,4 & 3,963 & 0,310 & $\mathrm{Y}$ \\
\cline { 2 - 5 } & 1,2 & 3,093 & 0,333 & $\mathrm{Y}$ \\
\cline { 2 - 5 } & 1,0 & 2,689 & 0,295 & $\mathrm{Y}$ \\
\hline
\end{tabular}

\begin{tabular}{|c|c|c|c|c|}
\hline SL & TP & TR & MD & TR>MD \\
\hline \multirow{5}{*}{0,4} & 2,0 & 5,273 & 0,345 & $\mathrm{Y}$ \\
\cline { 2 - 5 } & 1,8 & 5,079 & 0,379 & $\mathrm{Y}$ \\
\cline { 2 - 5 } & 1,6 & 4,969 & 0,338 & $\mathrm{Y}$ \\
\cline { 2 - 5 } & 1,4 & 4,506 & 0,330 & $\mathrm{Y}$ \\
\cline { 2 - 5 } & 1,2 & 3,866 & 0,239 & $\mathrm{Y}$ \\
\cline { 2 - 5 } & 1,0 & 3,526 & 0,214 & $\mathrm{Y}$ \\
\hline \multirow{5}{*}{0,2} & 2,0 & 5,231 & 0,327 & $\mathrm{Y}$ \\
\cline { 2 - 5 } & 1,8 & 4,950 & 0,329 & $\mathrm{Y}$ \\
\cline { 2 - 5 } & 1,6 & 4,904 & 0,258 & $\mathrm{Y}$ \\
\cline { 2 - 5 } & 1,4 & 4,593 & 0,173 & $\mathrm{Y}$ \\
\cline { 2 - 5 } & 1,2 & 4,192 & 0,163 & $\mathrm{Y}$ \\
\cline { 2 - 5 } & 1,0 & 3,877 & 0,169 & $\mathrm{Y}$ \\
\hline
\end{tabular}

Panel e) Threshold for the fit value $=1$, Number of operations $=2,976$

TABLE 4.13: Results of the investment strategy on hourly data of the Spanish Ibex-35

The analysed period reaches from May 15, 2000 to October 4, 2013.

\begin{tabular}{|c|c|c|c|c|}
\hline SL & TP & TR & MD & TR>MD \\
\hline \multirow{5}{*}{0,8} & 2,0 & $-0,286$ & 0,516 & $\mathrm{~N}$ \\
\cline { 2 - 5 } & 1,8 & $-0,247$ & 0,423 & $\mathrm{~N}$ \\
\cline { 2 - 5 } & 1,6 & $-0,360$ & 0,459 & $\mathrm{~N}$ \\
\cline { 2 - 5 } & 1,4 & $-0,295$ & 0,392 & $\mathrm{~N}$ \\
\cline { 2 - 5 } & 1,2 & $-0,353$ & 0,417 & $\mathrm{~N}$ \\
\cline { 2 - 5 } & 1,0 & $-0,293$ & 0,356 & $\mathrm{~N}$ \\
\hline \multirow{5}{*}{0,6} & 2,0 & $-0,168$ & 0,326 & $\mathrm{~N}$ \\
\cline { 2 - 5 } & 1,8 & $-0,206$ & 0,330 & $\mathrm{~N}$ \\
\cline { 2 - 5 } & 1,6 & $-0,297$ & 0,379 & $\mathrm{~N}$ \\
\cline { 2 - 5 } & 1,4 & $-0,117$ & 0,254 & $\mathrm{~N}$ \\
\cline { 2 - 5 } & 1,2 & $-0,156$ & 0,253 & $\mathrm{~N}$ \\
\cline { 2 - 5 } & 1,0 & $-0,144$ & 0,269 & $\mathrm{~N}$ \\
\hline
\end{tabular}

\begin{tabular}{|c|c|c|c|c|}
\hline SL & TP & TR & MD & TR>MD \\
\hline \multirow{5}{*}{0,4} & 2,0 & $-0,237$ & 0,319 & $\mathrm{~N}$ \\
\cline { 2 - 5 } & 1,8 & $-0,245$ & 0,349 & $\mathrm{~N}$ \\
\cline { 2 - 5 } & 1,6 & $-0,302$ & 0,392 & $\mathrm{~N}$ \\
\cline { 2 - 5 } & 1,4 & $-0,127$ & 0,229 & $\mathrm{~N}$ \\
\cline { 2 - 5 } & 1,2 & $-0,209$ & 0,293 & $\mathrm{~N}$ \\
\cline { 2 - 5 } & 1,0 & $-0,182$ & 0,259 & $\mathrm{~N}$ \\
\hline \multirow{5}{*}{0,2} & 2,0 & $-0,024$ & 0,150 & $\mathrm{~N}$ \\
\cline { 2 - 5 } & 1,8 & $-0,021$ & 0,152 & $\mathrm{~N}$ \\
\cline { 2 - 5 } & 1,6 & $-0,062$ & 0,172 & $\mathrm{~N}$ \\
\cline { 2 - 5 } & 1,4 & 0,004 & 0,150 & $\mathrm{~N}$ \\
\cline { 2 - 5 } & 1,2 & $-0,051$ & 0,158 & $\mathrm{~N}$ \\
\cline { 2 - 5 } & 1,0 & $-0,012$ & 0,160 & $\mathrm{~N}$ \\
\hline
\end{tabular}

Panel a) Threshold for the fit value $=5$, Number of operations $=97$

\begin{tabular}{|c|c|c|c|c|}
\hline SL & TP & TR & MD & TR>MD \\
\hline \multirow{5}{*}{0,8} & 2,0 & $-0,191$ & 0,601 & $\mathrm{~N}$ \\
\cline { 2 - 5 } & 1,8 & $-0,105$ & 0,569 & $\mathrm{~N}$ \\
\cline { 2 - 5 } & 1,6 & $-0,196$ & 0,562 & $\mathrm{~N}$ \\
\cline { 2 - 5 } & 1,4 & 0,064 & 0,483 & $\mathrm{~N}$ \\
\cline { 2 - 5 } & 1,2 & 0,307 & 0,414 & $\mathrm{~N}$ \\
\cline { 2 - 5 } & 1,0 & 0,197 & 0,404 & $\mathrm{~N}$ \\
\hline \multirow{5}{*}{0,6} & 2,0 & $-0,012$ & 0,430 & $\mathrm{~N}$ \\
\cline { 2 - 5 } & 1,8 & 0,002 & 0,423 & $\mathrm{~N}$ \\
\cline { 2 - 5 } & 1,6 & $-0,140$ & 0,418 & $\mathrm{~N}$ \\
\cline { 2 - 5 } & 1,4 & 0,178 & 0,321 & $\mathrm{~N}$ \\
\cline { 2 - 5 } & 1,2 & 0,317 & 0,261 & $\mathrm{Y}$ \\
\cline { 2 - 5 } & 1,0 & 0,253 & 0,256 & $\mathrm{~N}$ \\
\hline
\end{tabular}

\begin{tabular}{|c|c|c|c|c|}
\hline SL & TP & TR & MD & TR>MD \\
\hline \multirow{5}{*}{0,4} & 2,0 & $-0,054$ & 0,450 & $\mathrm{~N}$ \\
\cline { 2 - 5 } & 1,8 & $-0,078$ & 0,409 & $\mathrm{~N}$ \\
\cline { 2 - 5 } & 1,6 & $-0,201$ & 0,424 & $\mathrm{~N}$ \\
\cline { 2 - 5 } & 1,4 & 0,060 & 0,304 & $\mathrm{~N}$ \\
\cline { 2 - 5 } & 1,2 & 0,103 & 0,319 & $\mathrm{~N}$ \\
\cline { 2 - 5 } & 1,0 & 0,039 & 0,302 & $\mathrm{~N}$ \\
\hline \multirow{5}{*}{0,2} & 2,0 & 0,221 & 0,214 & $\mathrm{Y}$ \\
\cline { 2 - 5 } & 1,8 & 0,197 & 0,212 & $\mathrm{~N}$ \\
\cline { 2 - 5 } & 1,6 & 0,086 & 0,220 & $\mathrm{~N}$ \\
\cline { 2 - 5 } & 1,4 & 0,250 & 0,173 & $\mathrm{Y}$ \\
\cline { 2 - 5 } & 1,2 & 0,290 & 0,180 & $\mathrm{Y}$ \\
\cline { 2 - 5 } & 1,0 & 0,239 & 0,188 & $\mathrm{Y}$ \\
\hline
\end{tabular}

Panel b) Threshold for the fit value $=4$, Number of operations $=203$ 


\begin{tabular}{|c|c|c|c|c|}
\hline SL & TP & TR & MD & TR>MD \\
\hline \multirow{5}{*}{0,8} & 2,0 & $-0,223$ & 0,794 & $\mathrm{~N}$ \\
\cline { 2 - 5 } & 1,8 & $-0,299$ & 0,821 & $\mathrm{~N}$ \\
\cline { 2 - 5 } & 1,6 & $-0,377$ & 0,829 & $\mathrm{~N}$ \\
\cline { 2 - 5 } & 1,4 & $-0,040$ & 0,549 & $\mathrm{~N}$ \\
\cline { 2 - 5 } & 1,2 & 0,291 & 0,486 & $\mathrm{~N}$ \\
\cline { 2 - 5 } & 1,0 & 0,087 & 0,482 & $\mathrm{~N}$ \\
\hline \multirow{5}{*}{0,6} & 2,0 & 0,005 & 0,507 & $\mathrm{~N}$ \\
\cline { 2 - 5 } & 1,8 & $-0,112$ & 0,549 & $\mathrm{~N}$ \\
\cline { 2 - 5 } & 1,6 & $-0,212$ & 0,569 & $\mathrm{~N}$ \\
\cline { 2 - 5 } & 1,4 & 0,187 & 0,374 & $\mathrm{~N}$ \\
\cline { 2 - 5 } & 1,2 & 0,387 & 0,319 & $\mathrm{Y}$ \\
\cline { 2 - 5 } & 1,0 & 0,261 & 0,325 & $\mathrm{~N}$ \\
\hline
\end{tabular}

\begin{tabular}{|c|c|c|c|c|}
\hline SL & TP & TR & MD & TR>MD \\
\hline \multirow{5}{*}{0,4} & 2,0 & 0,048 & 0,542 & $\mathrm{~N}$ \\
\cline { 2 - 5 } & 1,8 & $-0,097$ & 0,554 & $\mathrm{~N}$ \\
\cline { 2 - 5 } & 1,6 & $-0,244$ & 0,608 & $\mathrm{~N}$ \\
\cline { 2 - 5 } & 1,4 & 0,096 & 0,368 & $\mathrm{~N}$ \\
\cline { 2 - 5 } & 1,2 & 0,065 & 0,400 & $\mathrm{~N}$ \\
\cline { 2 - 5 } & 1,0 & 0,023 & 0,441 & $\mathrm{~N}$ \\
\hline \multirow{5}{*}{0,2} & 2,0 & 0,546 & 0,177 & $\mathrm{Y}$ \\
\cline { 2 - 5 } & 1,8 & 0,431 & 0,169 & $\mathrm{Y}$ \\
\cline { 2 - 5 } & 1,6 & 0,317 & 0,169 & $\mathrm{Y}$ \\
\cline { 2 - 5 } & 1,4 & 0,512 & 0,127 & $\mathrm{Y}$ \\
\cline { 2 - 5 } & 1,2 & 0,503 & 0,142 & $\mathrm{Y}$ \\
\cline { 2 - 5 } & 1,0 & 0,472 & 0,156 & $\mathrm{Y}$ \\
\hline
\end{tabular}

Panel c) Threshold for the fit value $=3$, Number of operations $=353$

\begin{tabular}{|c|c|c|c|c|}
\hline SL & TP & TR & MD & TR>MD \\
\hline \multirow{5}{*}{0,8} & 2,0 & $-0,472$ & 1,019 & $\mathrm{~N}$ \\
\cline { 2 - 5 } & 1,8 & $-0,532$ & 1,082 & $\mathrm{~N}$ \\
\cline { 2 - 5 } & 1,6 & $-0,571$ & 1,047 & $\mathrm{~N}$ \\
\cline { 2 - 5 } & 1,4 & $-0,402$ & 0,871 & $\mathrm{~N}$ \\
\cline { 2 - 5 } & 1,2 & $-0,100$ & 0,544 & $\mathrm{~N}$ \\
\cline { 2 - 5 } & 1,0 & $-0,346$ & 0,691 & $\mathrm{~N}$ \\
\hline \multirow{5}{*}{0,6} & 2,0 & $-0,027$ & 0,607 & $\mathrm{~N}$ \\
\hline & 1,8 & $-0,123$ & 0,621 & $\mathrm{~N}$ \\
\cline { 2 - 5 } & 1,6 & $-0,184$ & 0,715 & $\mathrm{~N}$ \\
\cline { 2 - 5 } & 1,4 & 0,063 & 0,524 & $\mathrm{~N}$ \\
\cline { 2 - 5 } & 1,2 & 0,236 & 0,378 & $\mathrm{~N}$ \\
\cline { 2 - 5 } & 1,0 & 0,114 & 0,424 & $\mathrm{~N}$ \\
\hline
\end{tabular}

\begin{tabular}{|c|c|c|c|c|}
\hline SL & TP & TR & MD & TR>MD \\
\hline \multirow{5}{*}{0,4} & 2,0 & $-0,057$ & 0,674 & $\mathrm{~N}$ \\
\cline { 2 - 5 } & 1,8 & $-0,206$ & 0,709 & $\mathrm{~N}$ \\
\cline { 2 - 5 } & 1,6 & $-0,281$ & 0,598 & $\mathrm{~N}$ \\
\cline { 2 - 5 } & 1,4 & $-0,045$ & 0,388 & $\mathrm{~N}$ \\
\cline { 2 - 5 } & 1,2 & $-0,173$ & 0,482 & $\mathrm{~N}$ \\
\cline { 2 - 5 } & 1,0 & $-0,131$ & 0,570 & $\mathrm{~N}$ \\
\hline \multirow{5}{*}{0,2} & 2,0 & 0,598 & 0,302 & $\mathrm{Y}$ \\
\cline { 2 - 5 } & 1,8 & 0,442 & 0,282 & $\mathrm{Y}$ \\
\cline { 2 - 5 } & 1,6 & 0,357 & 0,285 & $\mathrm{Y}$ \\
\cline { 2 - 5 } & 1,4 & 0,481 & 0,182 & $\mathrm{Y}$ \\
\cline { 2 - 5 } & 1,2 & 0,419 & 0,184 & $\mathrm{Y}$ \\
\cline { 2 - 5 } & 1,0 & 0,383 & 0,187 & $\mathrm{Y}$ \\
\hline
\end{tabular}

Panel d) Threshold for the fit value $=2$, Number of operations $=495$

\begin{tabular}{|c|c|c|c|c|}
\hline SL & TP & TR & MD & TR $>$ MD \\
\hline \multirow{5}{*}{0,8} & 2,0 & $-0,749$ & 1,283 & $\mathrm{~N}$ \\
\cline { 2 - 5 } & 1,8 & $-0,816$ & 1,324 & $\mathrm{~N}$ \\
\cline { 2 - 5 } & 1,6 & $-0,780$ & 1,162 & $\mathrm{~N}$ \\
\cline { 2 - 5 } & 1,4 & $-0,611$ & 1,042 & $\mathrm{~N}$ \\
\cline { 2 - 5 } & 1,2 & $-0,418$ & 0,733 & $\mathrm{~N}$ \\
\cline { 2 - 5 } & 1,0 & $-0,701$ & 1,010 & $\mathrm{~N}$ \\
\hline \multirow{5}{*}{0,6} & 2,0 & $-0,307$ & 1,028 & $\mathrm{~N}$ \\
\hline & 1,8 & $-0,381$ & 0,925 & $\mathrm{~N}$ \\
\cline { 2 - 5 } & 1,6 & $-0,346$ & 0,944 & $\mathrm{~N}$ \\
\cline { 2 - 5 } & 1,4 & $-0,095$ & 0,833 & $\mathrm{~N}$ \\
\cline { 2 - 5 } & 1,2 & 0,000 & 0,652 & $\mathrm{~N}$ \\
\cline { 2 - 5 } & 1,0 & $-0,225$ & 0,671 & $\mathrm{~N}$ \\
\hline
\end{tabular}

\begin{tabular}{|c|c|c|c|c|}
\hline SL & TP & TR & MD & TR $>$ MD \\
\hline \multirow{5}{*}{0,4} & 2,0 & $-0,093$ & 0,592 & $\mathrm{~N}$ \\
\cline { 2 - 5 } & 1,8 & $-0,202$ & 0,612 & $\mathrm{~N}$ \\
\cline { 2 - 5 } & 1,6 & $-0,341$ & 0,676 & $\mathrm{~N}$ \\
\cline { 2 - 5 } & 1,4 & $-0,092$ & 0,558 & $\mathrm{~N}$ \\
\cline { 2 - 5 } & 1,2 & $-0,296$ & 0,625 & $\mathrm{~N}$ \\
\cline { 2 - 5 } & 1,0 & $-0,293$ & 0,663 & $\mathrm{~N}$ \\
\hline \multirow{5}{*}{0,2} & 2,0 & 0,764 & 0,374 & $\mathrm{Y}$ \\
\cline { 2 - 5 } & 1,8 & 0,627 & 0,356 & $\mathrm{Y}$ \\
\cline { 2 - 5 } & 1,6 & 0,574 & 0,311 & $\mathrm{Y}$ \\
\cline { 2 - 5 } & 1,4 & 0,709 & 0,198 & $\mathrm{Y}$ \\
\cline { 2 - 5 } & 1,2 & 0,553 & 0,207 & $\mathrm{Y}$ \\
\cline { 2 - 5 } & 1,0 & 0,438 & 0,230 & $\mathrm{Y}$ \\
\hline
\end{tabular}

Panel e) Threshold for the fit value $=1$, Number of operations $=683$ 


\subsection{Analysis results}

\subsubsection{Germany (DAX)}

This section continues the researches over one of the chart patterns that has aroused considerable interest in the academic field: the flag pattern. Furthermore, it analyses how it can be used in order to define trading rules with positive risk-adjusted returns.

In order to improve the robustness of the conclusions reached by other researchers, the work presents some relevant changes. First, the breakout and consolidation flag pattern version was used as opposed to the consolidation and breakout version which has already been explored in previous literature. A new definition of the grid of weights relates the recognition of this kind of patterns with the logic IF-THEN rule, which is closer to the decision making of stock markets investors. The second relevant change deals with the use of intraday data, which has increased the sample size to more than 127,000 Japanese candlesticks of the DAX Index. As stated, this seems to be the largest sample used to design a trading rule in this academic area. The third relevant change consisted of introducing a dynamic approach in the trading rule specification, by closing the operations when the price reached the level marked by the stop loss or by the take profit. The definition of these two parameters jointly with the threshold, which evaluates the matching of the price series to the flag pattern, considers 220 different configurations. Lastly, together with the return the maximum drawdown as a measure of the risk was also considered; all these aspects have allowed for the evaluation of the trading rule from the double perspective of the risk-adjusted return.

In general, the obtained results confirm the risk-adjusted return of the trading rule based on the flag pattern, especially in the cases in which the SL is extremely adjusted. Comparing it with the return obtained by the DAX index, it can be concluded that this last one provided a very poor return in comparison to the average return of the tested configurations, especially if not only considering the return, but also the risk measured by the maximum drawdown.

The investor should be aware of the transaction costs; they should choose a broker whose associated costs will allow obtaining a positive net return. Currently, the financial transaction costs are very small, especially when working with the market of futures; therefore, these conclusions will not be altered by the inclusion of these transaction costs. 


\subsubsection{USA (DJIA)}

The analysis results for the DJIA confirm the positive performance of the flag pattern over the intraday data of the DJIA for a time horizon of more than 13 years. This is opposite to Marshall et al. who did not find any positive empirical evidence for the U.S. equity market during a period of only two years (Marshall et al., 2008).

This study confirms the positive results obtained by other researchers about the trading rule based on bull flag pattern, by adding some relevant changes. As done in the analysis of the German stock market, the American stock market's analysis is also based on using the breakout and consolidation bull flag pattern version. Using intraday data allowed the use of historical data series of more than 90,000 observations. The second one introduces a dynamical approach when specifying the trading strategy, by closing the operations when the price level reached the SL or TP. The definition of these two parameters, together with the threshold which limits the fitting of the price series to the flag pattern, allowed 96 different configurations to be considered. The third topic was to validate the trading rule over three non-overlapping sub-periods.

It is confirmed that the trading rule provided positive results for all the configurations, with a generally positive performance for the three sub-periods. Results gathered from the whole sample confirm that the trading rule provides a positive return, even after considering the risk. Moreover, it beats the benchmark in the mean variance sense. The only negative consideration that an investor should contemplate would be to avoid transaction costs exceeding the average of returns obtained with the strategy.

The best results have been obtained when considering adjusted levels of SL, between 0.2 and 0.4 times the price range; and also for the high values of TP with respect to the given SL. The explanation of those SL levels can be found when defining the grid of weights which identifies the flag pattern. The proposed weights clearly limit one consolidation area which the price should not pass through. This area is located over the $30 \%$ limit (three first rows of the figure). In fact, this level corresponds to a stop loss of $0.2 / 0.4$, where the strategy gets it's best results. This result indicates that this level is acting in "support" of those operations. Thus, when the price passes through this level, it will quite likely finish the operation with losses, whereas when the price stays out of this level, it will very likely succeed in the operation. 


\subsubsection{Spain (IBEX)}

The analysis of the Spanish Ibex-35 applies the the flag pattern, and analyses how it can be used to define and validate market investment strategies.

In order to improve the robustness of the conclusions reached by other researchers, the same developments as in case of both previously analysed indices were applied.

The analysis uses intraday price data with 15-minutes time frames and hourly data. For the first case the sample size exceeds 127,000 candlesticks which seems to be the largest sample size ever used in academic work. All these aspects took into consideration 120 different configurations.

The results achieved on data from the main Spanish stock market index, Ibex-35, are mixed: In the case of 15 minutes data the investment strategy has reported positive returns for 120 configurations analysed, so that $97.5 \%$ of cases the return exceeded the risk assumed measured by the maximum drawdown; however, with hourly data investment strategy was profitable only in $40 \%$ of tested configurations, challenging the theory assumed that the behaviour of stock markets is fractal. These mixed results are in line with those reported in recent studies, such as Wang and Chan, which indicated different behaviour of the strategy according to the market on which it is applied. In the present case the performance is related to different data frequency (Wang and Chan, 2007). 


\section{Chapter 5}

\section{Conclusions}

Technical analysis as a prediction tool for future returns is based on historical data and gained popularity in the past in the academic literature and in the financial business world. Technical trading rules define when to buy, sell or hold an asset. Therefore they are the heart of any trading system since they give advice for the right timing of any investment decision. Even though technical analysis has not always enjoyed a positive reputation, nowadays practitioners often include technical analysis into their investment decisions which illustrates the importance of technical trading.

In the first step of the thesis, the statement that technical analysis not always enjoyed a positive reputation was analysed in depth. Therefore 23 studies in the field of technical analysis were examined by markets analysed (stocks, interest, commodities, etc.), the period tested and, of course, the approach applied (technical analysis studies). The clustering of different approaches offered by technical analysis occurred by pattern recognition studies and other studies. Further, 15 studies dealing with market anomalies were considered (market anomaly studies).

From nine analysed pattern recognition studies all gained profitable results, except of one. The remaining 15 technical analysis studies were grouped further. The conclusion is that the examined four standard studies showed mixed results, non-linear studies gained positive results in three cases and only one was mixed. Model-based bootstrap studies' results were negative in two of three studies, one was positive. It is very positive that especially the flag pattern studies all resulted in the statement that the approach using the flag template is profitable. This contributes to answer the research question and to prove the inefficiency of the analysed international stock markets.

This statement could be supported by market anomaly studies likewise since eight studies showed positive results. Only four studies contained negative and three studies mixed 
results. Thus, the literature review concludes that based on the statistical mass selected, technical analysis is a profitable forecasting technique with very little exceptions. Nevertheless, the approach using the flag pattern shows positive results without exceptions when looking at previous research. Therefore, in scope of the theoretical part of the thesis, the profitability of technical analysis, or, especially the flag pattern, concluding that the markets are not efficient, can be confirmed.

To prove this statement in terms of practical analysis, the corresponding indices - representing German, American and Spanish stock markets - were chosen and the application of the flag template concluded for the years between 2000 and 2013. Several changes with respect to previous research lines were implemented to increase the robustness of results. These include the application of the breakout and consolidation flag pattern version and relating the recognition of patterns with the IF-THEN logic rule. Further, intraday data was used for the analysis to increase the sample size. This resulted in working with the largest sample so far to design a trading rule in this academic area since previous researchers applied closing prices only. To realize a dynamic approach in the trading rule specification, SL or TP thresholds were implemented which is closer to investor's behaviour. In a last step the risk component was incorporated via the maximum drawdown.

In case of the analysis for Germany, the DAX was analysed in depth considering 15minutes time intervals from May 15, 2000 to October 4, 2013. The sample size comprised a total of 127,480 Japanese candlesticks. The combination of fit value, SL and TP thresholds led to 220 configurations of the trading rule which were tested. The overall results confirm that the trading rule beats the buy-and-hold strategy which serves as benchmark.

The analysis of the American DJIA covers a comparable long period, namely from May 22, 2000 to November 29, 2013. The amount of analysed candlesticks equals to 91,307 and the total number of configurations amounts to 96 . The results were positive when analysing the whole period. A modification of the analysis included dividing the sample period into three non-overlapping sub-periods. The first sub-period lasts from May 22, 2000 to November 26, 2004, the second one from November 26, 2004 to February 27, 2007 and the third one from February 27, 2007 to November 29, 2013. For this purpose the 96 configurations were applied again. All of the sub-periods are of the same size with nearly 31,500 candlesticks in 15-minutes intervals. The overall results -for the whole period and for each one of the sub-periods- are positive and beat the benchmark.

When analysing the Spanish Ibex-35 the sample period covered the time from May 15, 2000 to October 4, 2013. Two databases were composed. The analysis of 15-minutes intervals contained 127,480 candlesticks. For hourly data this number was reduced 
consequently to a quarter. In total, 120 configurations were tested. While the analysis of 15-minutes intervals obtained positive results, the hourly candles showed mixed results. This calls into question one of the basic assumptions of technical analysis: fractality. Fractality describes the assumption if eliminating any temporal reference graphics, it would not be possible to discern whether it is a weekly, daily or intraday chart.

To summarize, the analysis gained positive results for each analysed country, especially when considering 15-minutes intervals of data. Therefore, the statement that technical analysis is not a profitable forecasting technique can be negated also within the scope of the practical part of the thesis. Further, these practical analyses prove that the markets are not efficient and contradict the EMH.

Both, the theoretical and the practical part of the thesis, support the statement that technical analysis, or especially, the flag pattern, represent a profitable forecasting technique for international stock markets. The present work provides empirical evidence which confronts the EMH by introducing a new definition of the flag pattern. The results show that the trading rule can beat the market and illustrate that the European market is more inefficient than the U.S. market.

As a future research line it could be interesting considering the flag pattern in combination with volume information as earlier studies already underlined the informational role of volume and its applicability for technical analysis (Blume et al., 1994). The present doctoral thesis identifies the flag pattern with the matrix information, but also considering that the first part of the matrix should register high volume, and the consolidation part should register lower volumes. It could be also interesting to "filter" the flags. An analysis could be implemented anserwing the question if some technical indicators like SMA o RSI improve the strategy by filtering when to open a position. Maybe neural nets or support vector machines could help.

Further, the possibility of applying the investment strategy on other stock indices than the ones considered within the present research exists. It would also be interesting to analyse other financial assets such as stocks, currencies, commodities, etc. with the method proposed.

Likewise, it is also considered to test new configurations of the weight matrix, both, the values of their cells and the dimension of the matrix, to validate the investment strategy for the frequencies of data analysed and others to be analysed yet. Especially the analysis of hourly data has shown that here is more potential for analysis. Further, the application of White's reality check or the Hansen SPA in order to even more limit the data snooping effect show potential for future research. 
Another interesting aspect for future research would be including the examination of seasonal calendar effects, as the Monday effect or the January effect, into the analysis. Further, a link between the empirical analysis and the historical and economical information could be stronger focused. 
Appendix A

Technical analysis studies divided by categories 


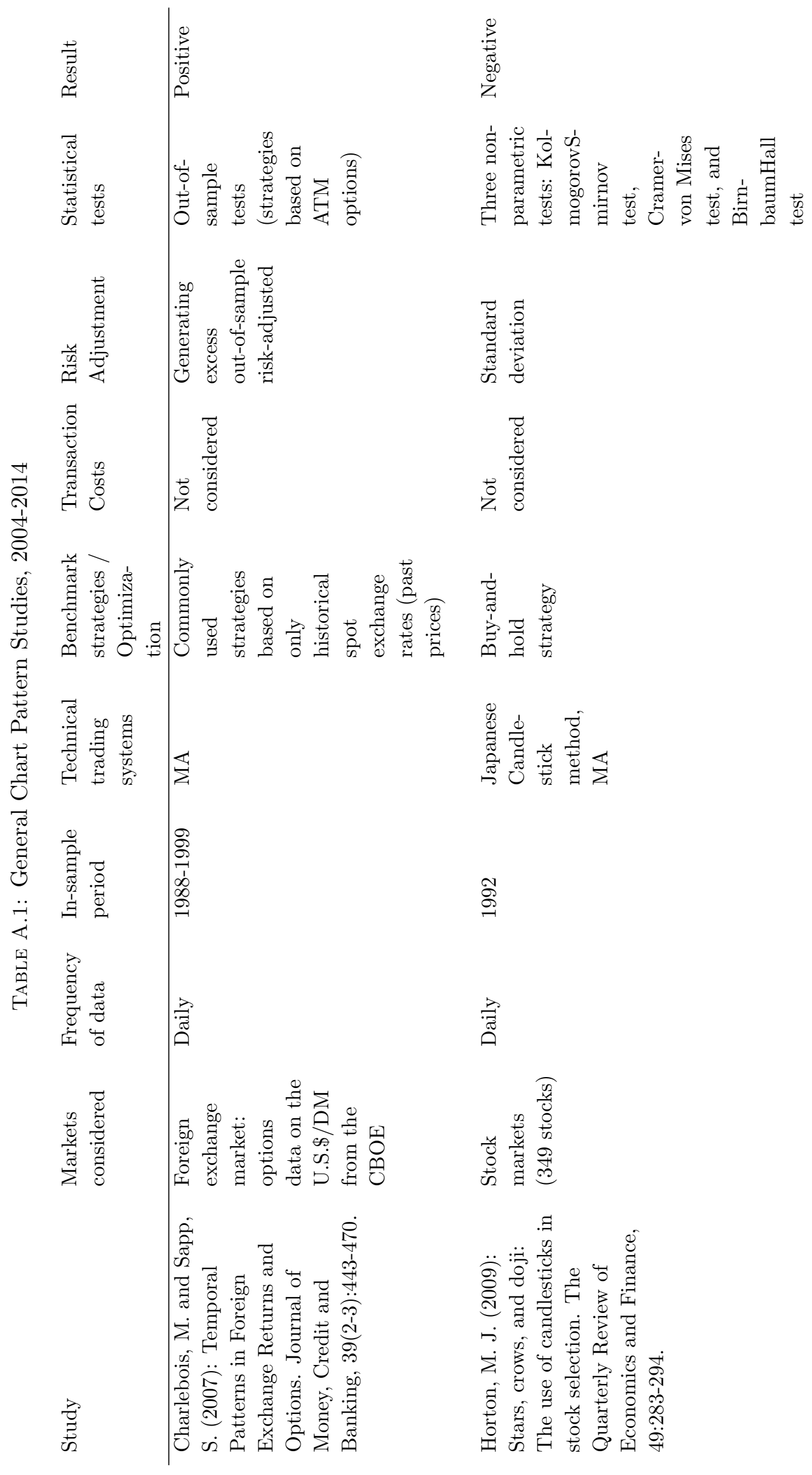




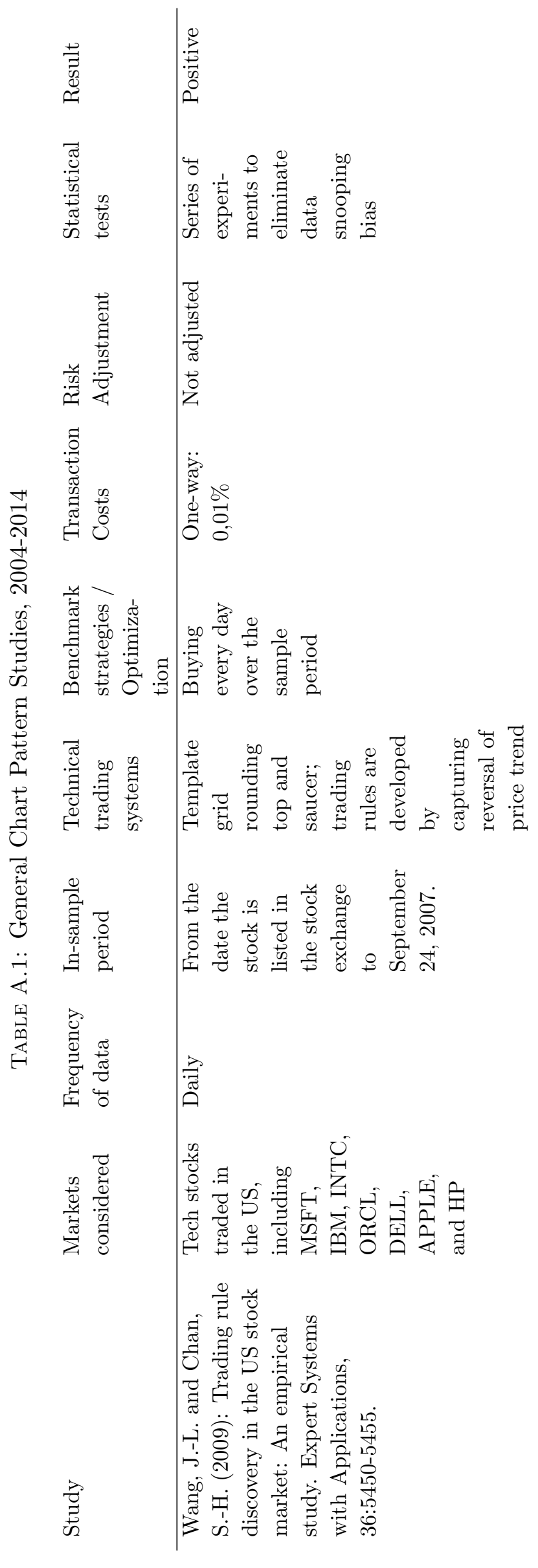




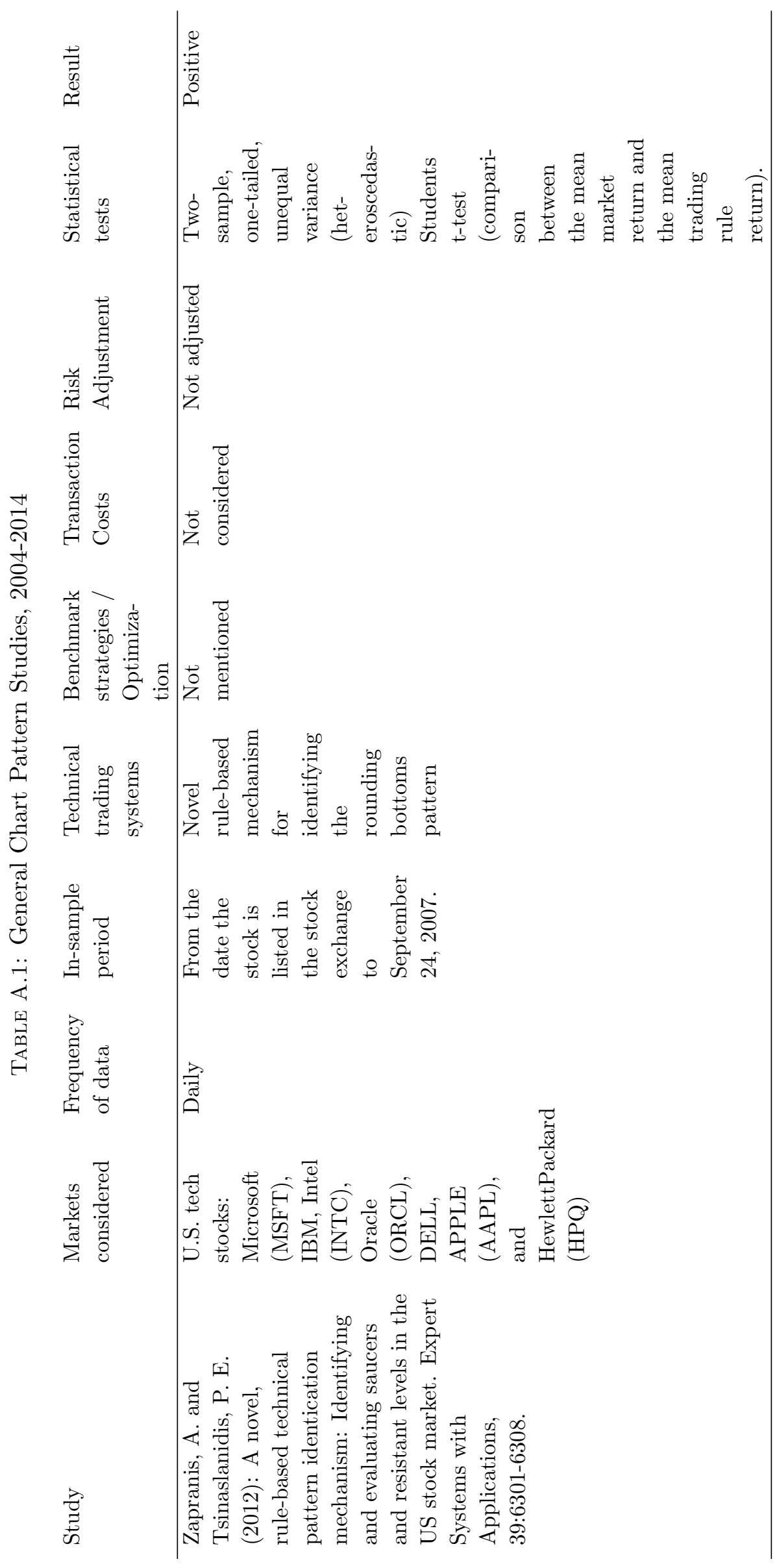




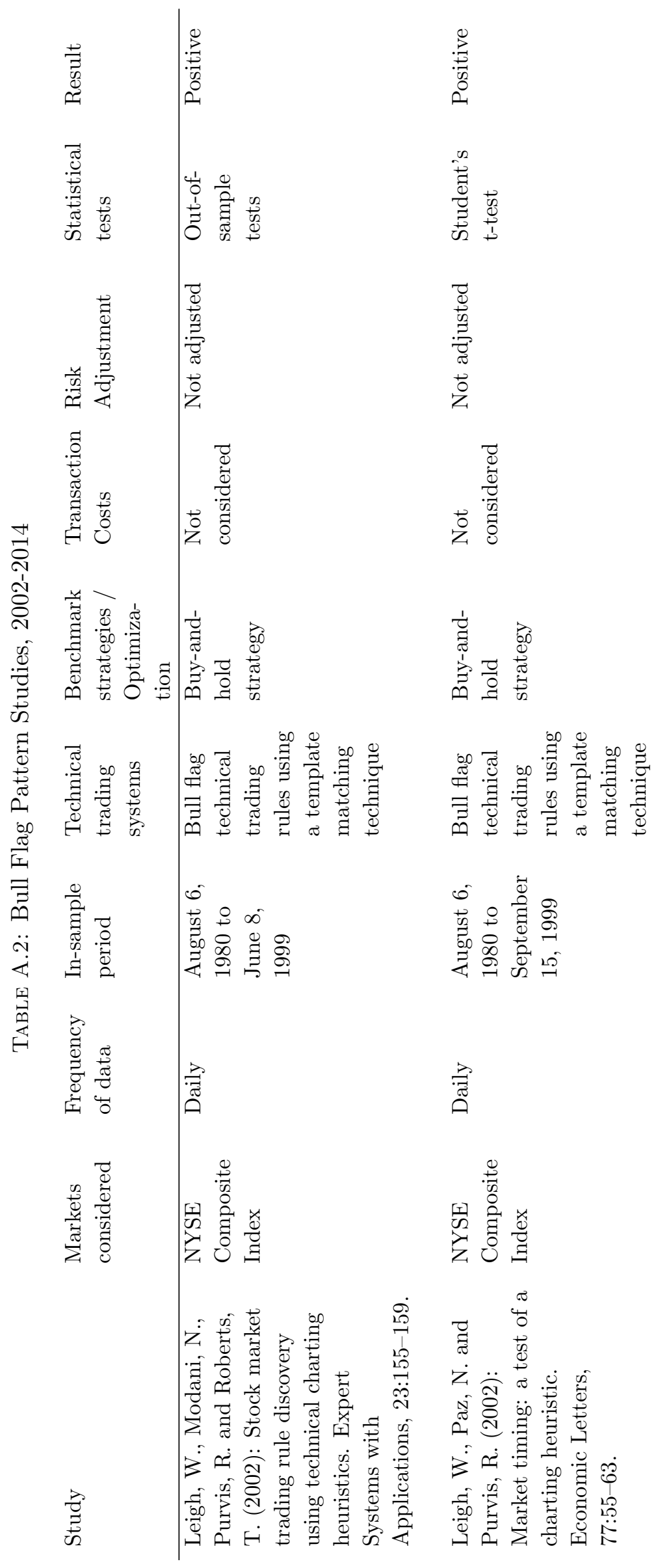




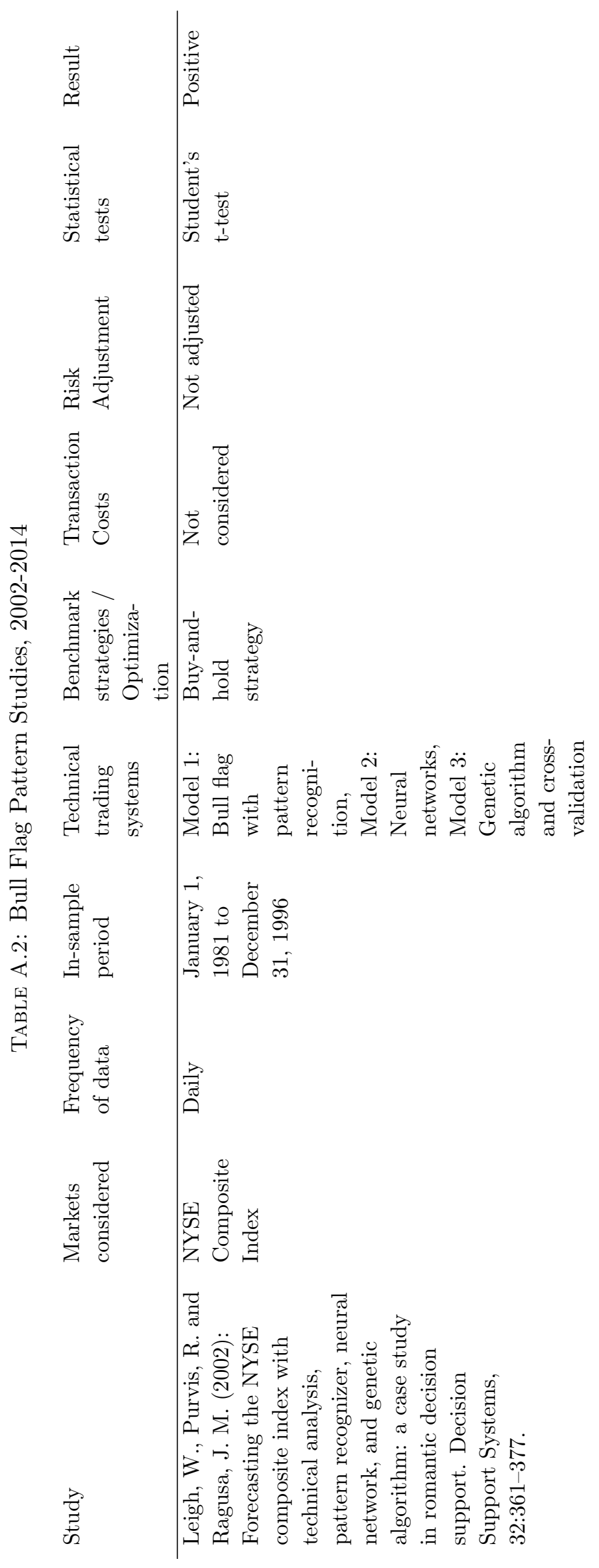




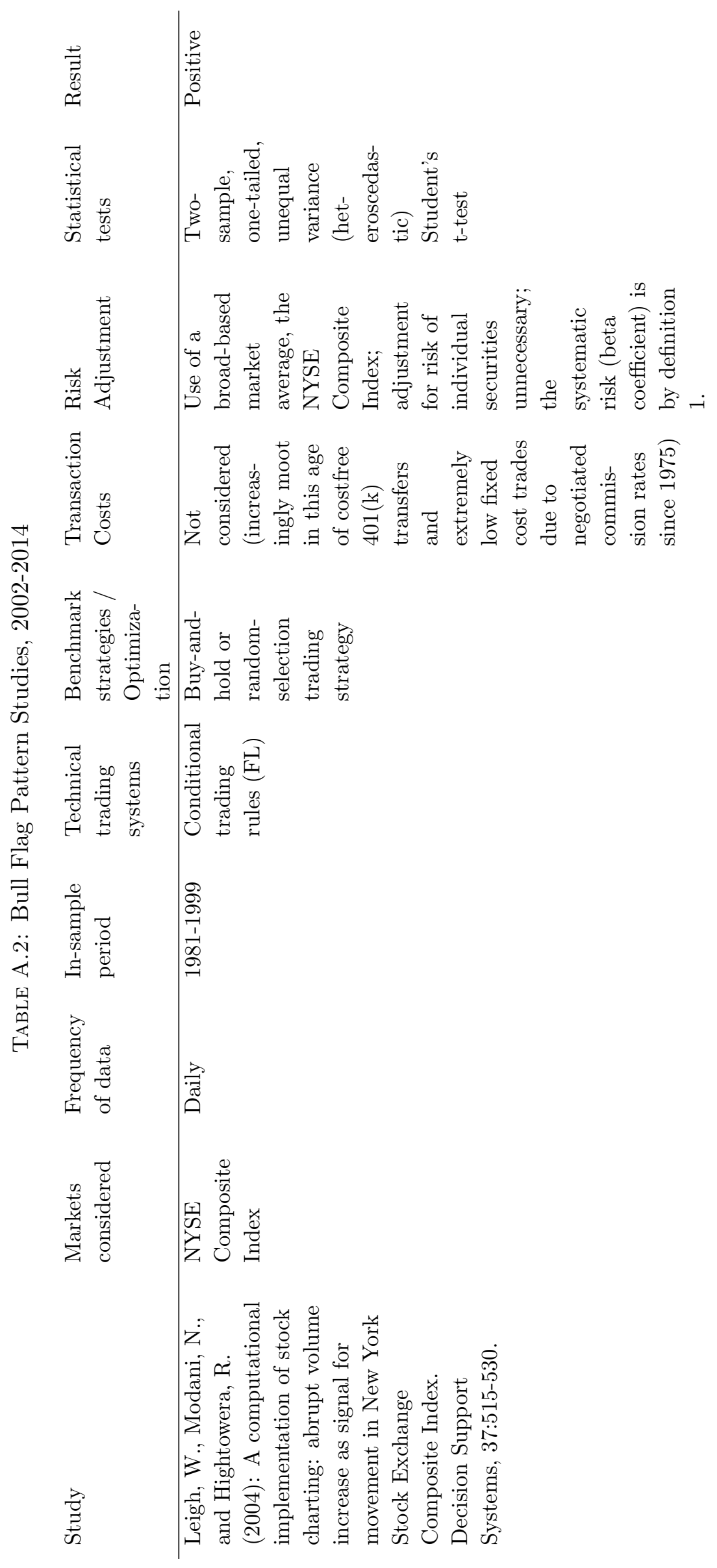




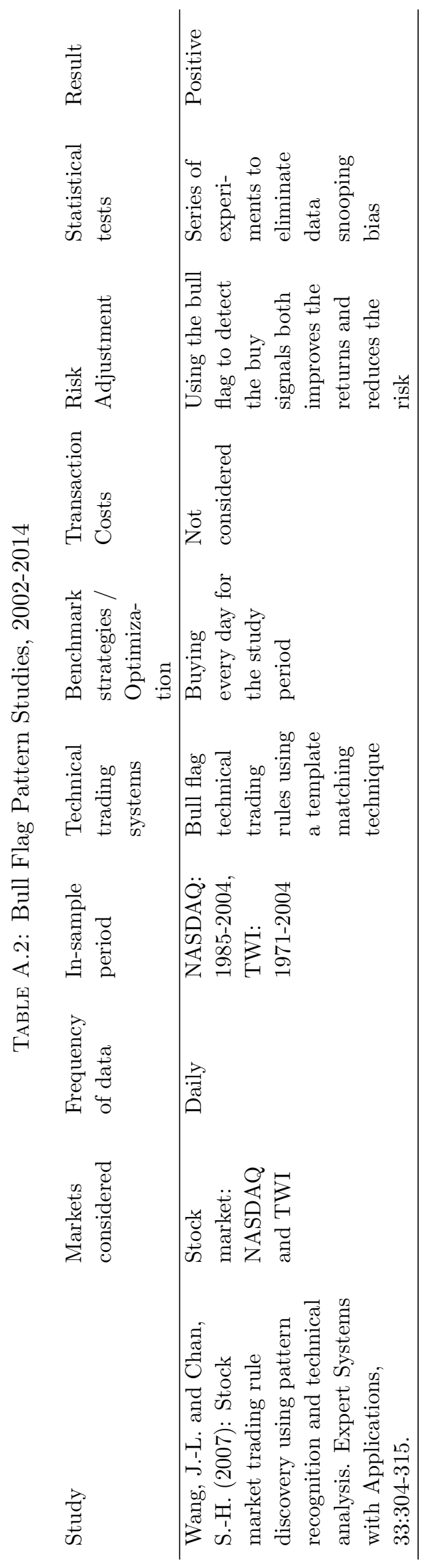




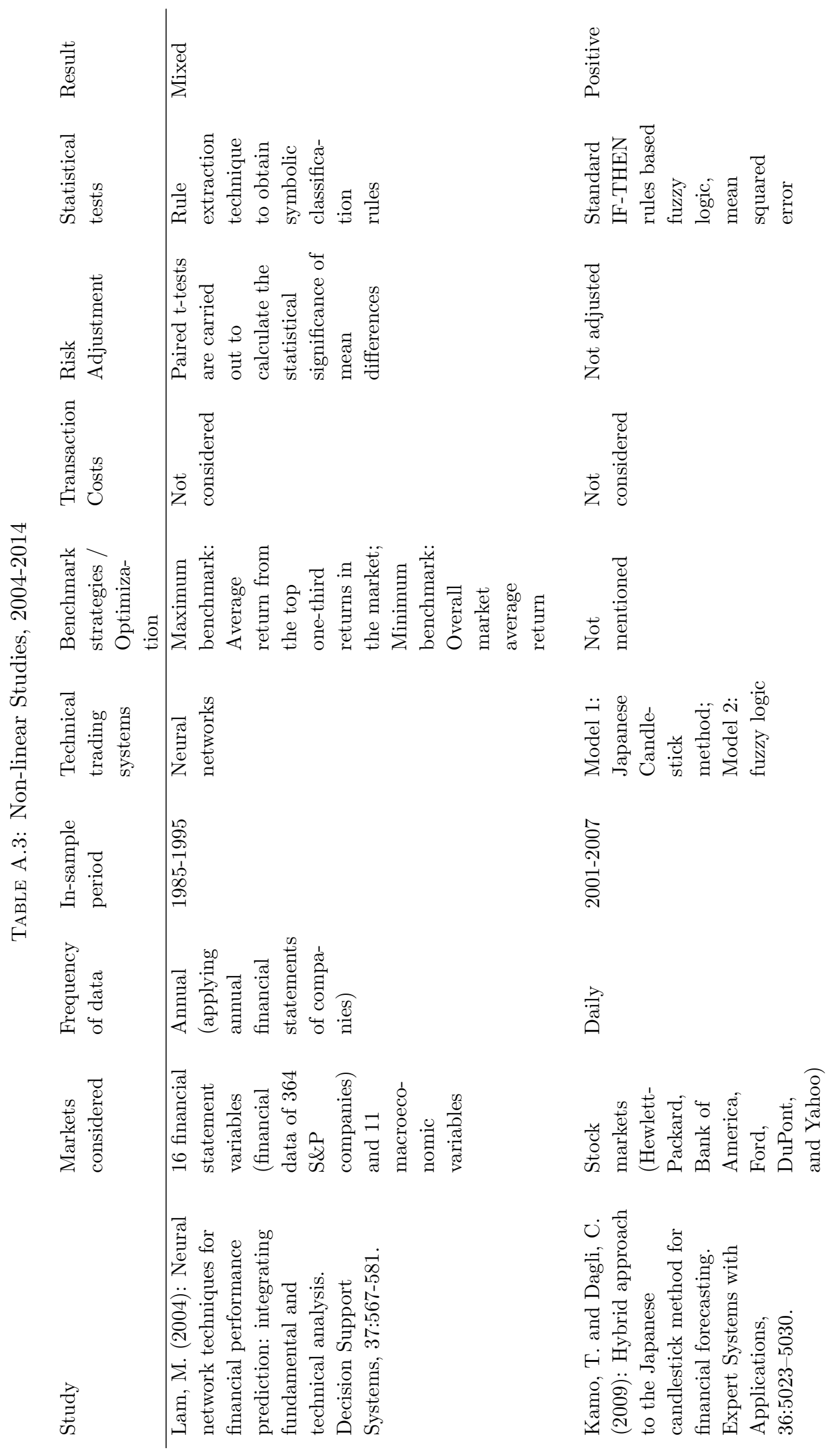




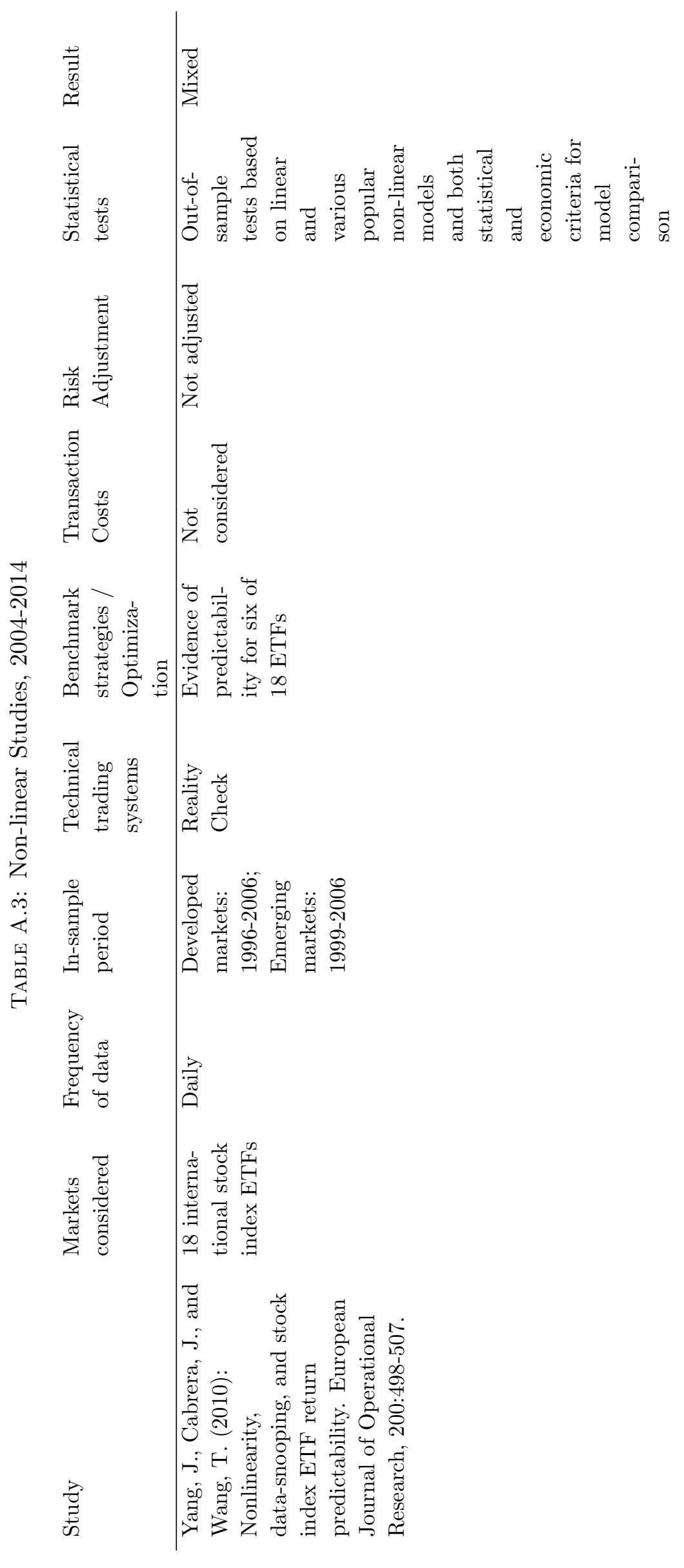



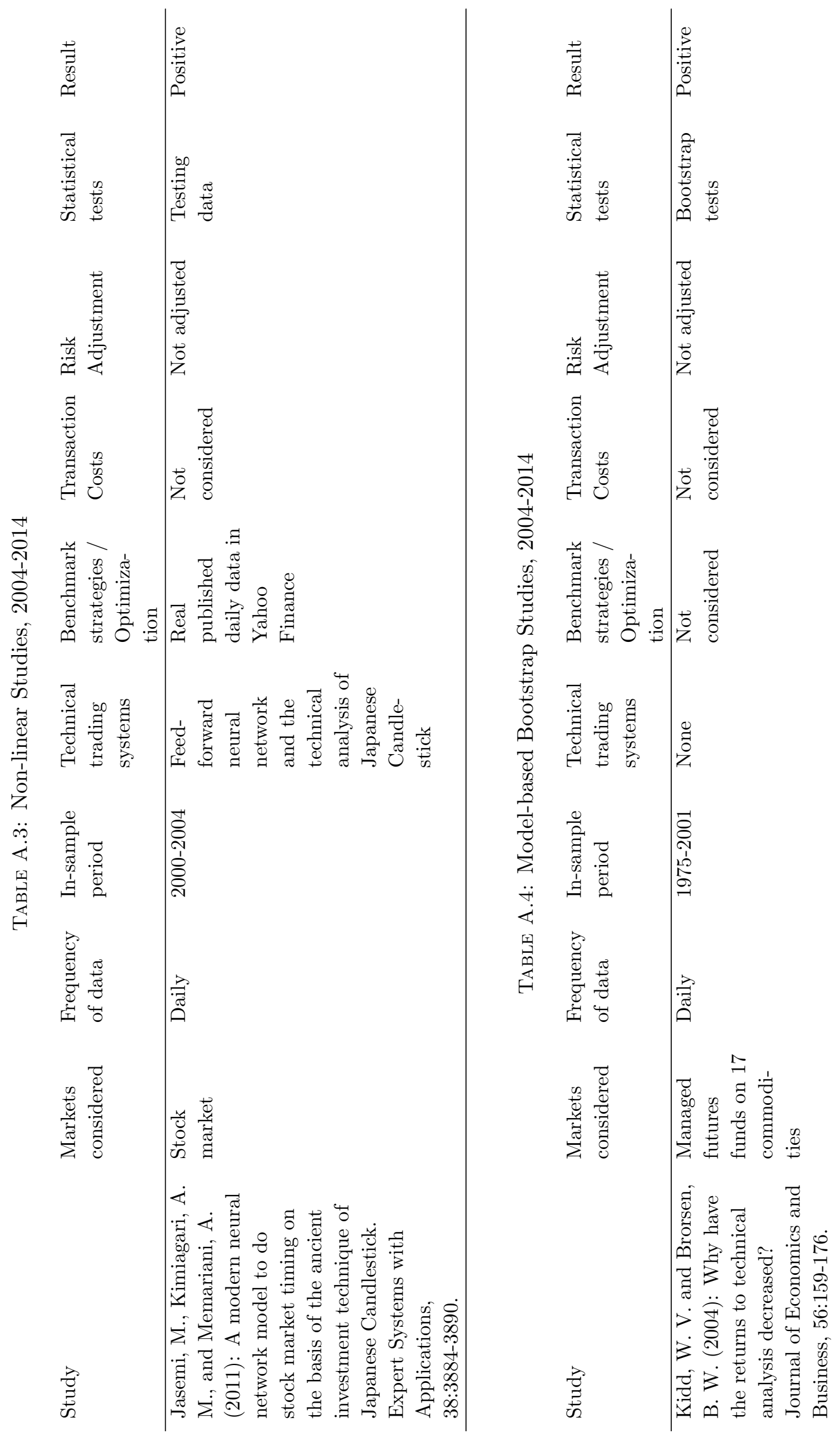


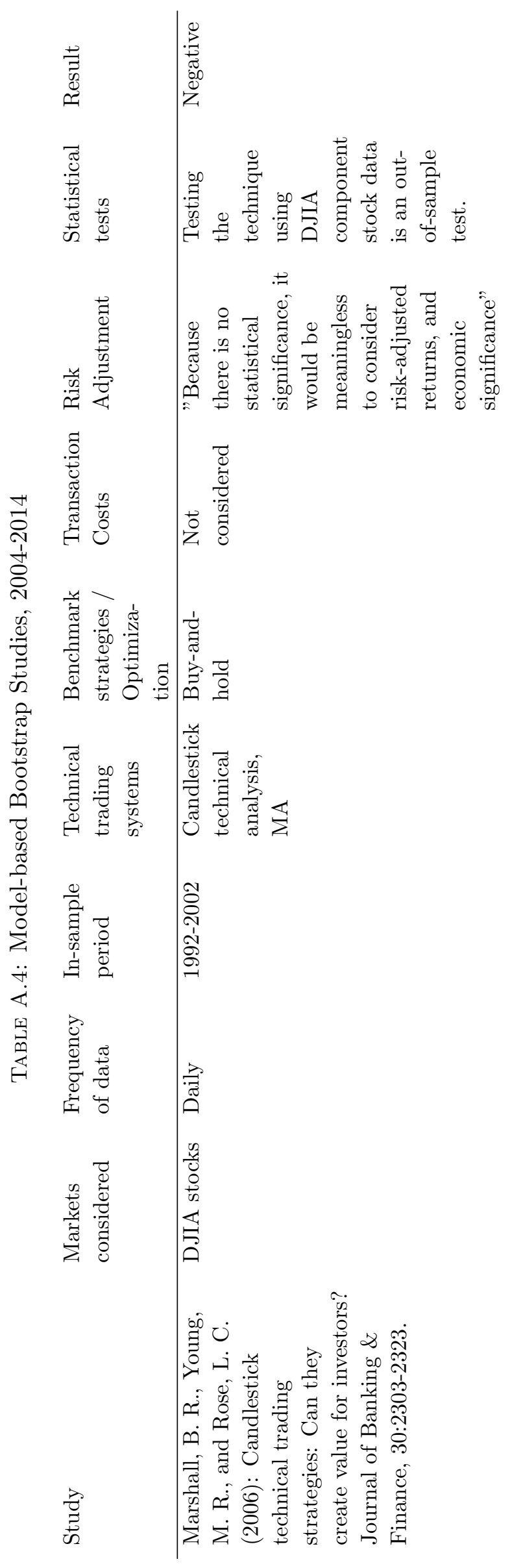




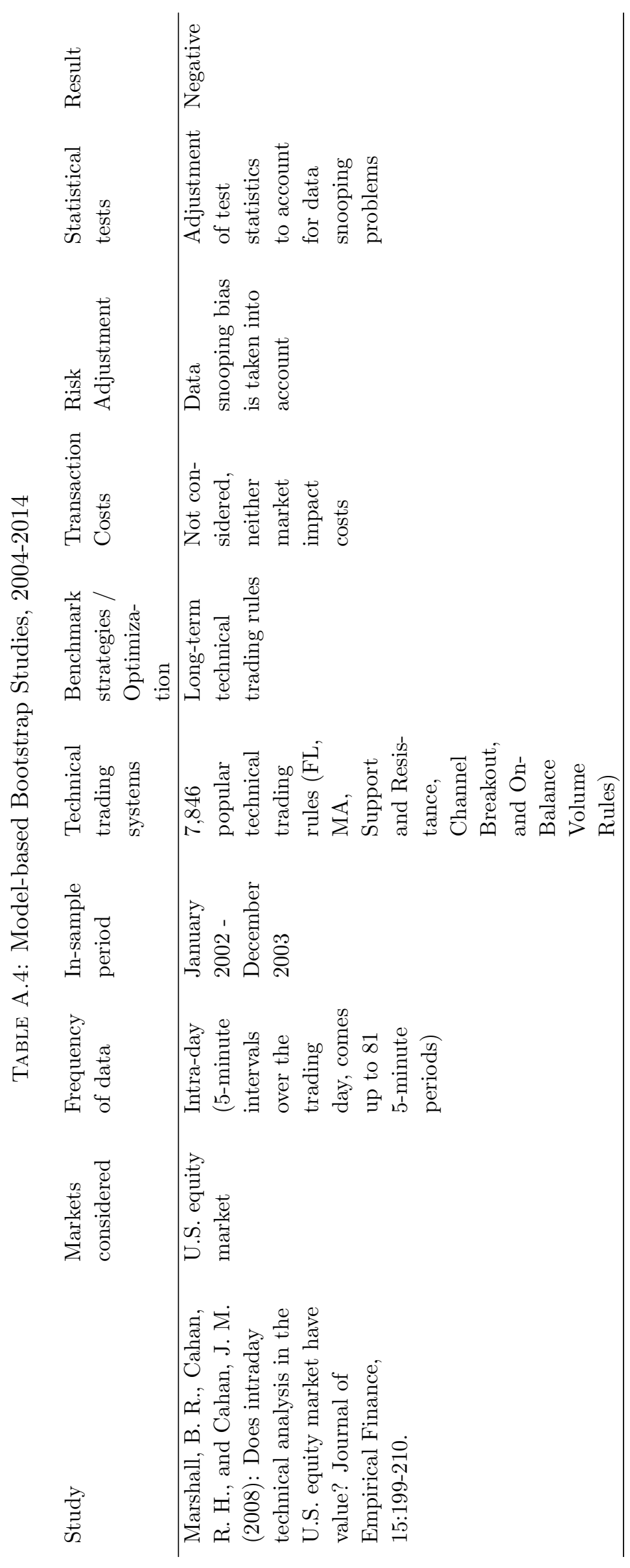




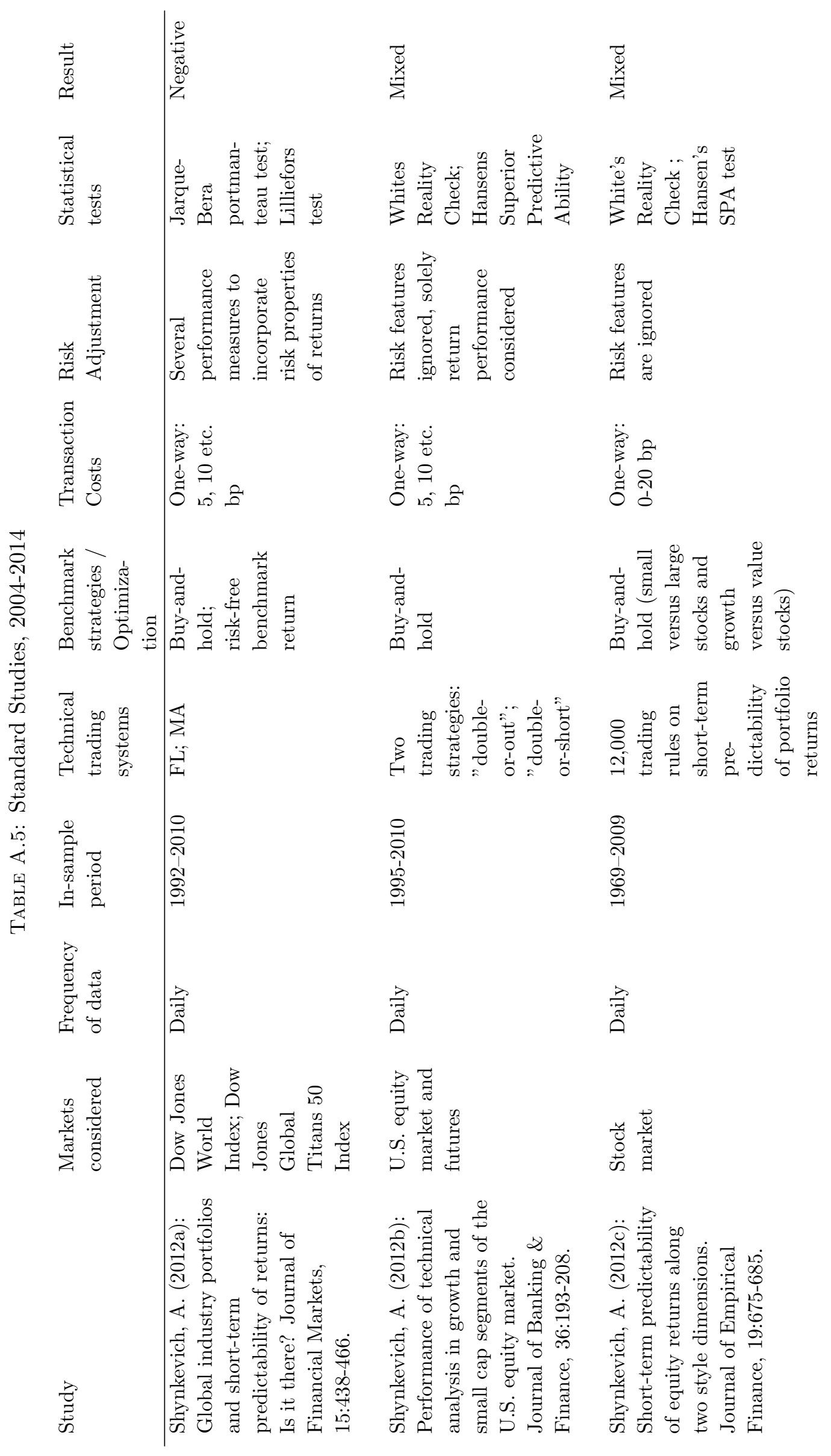




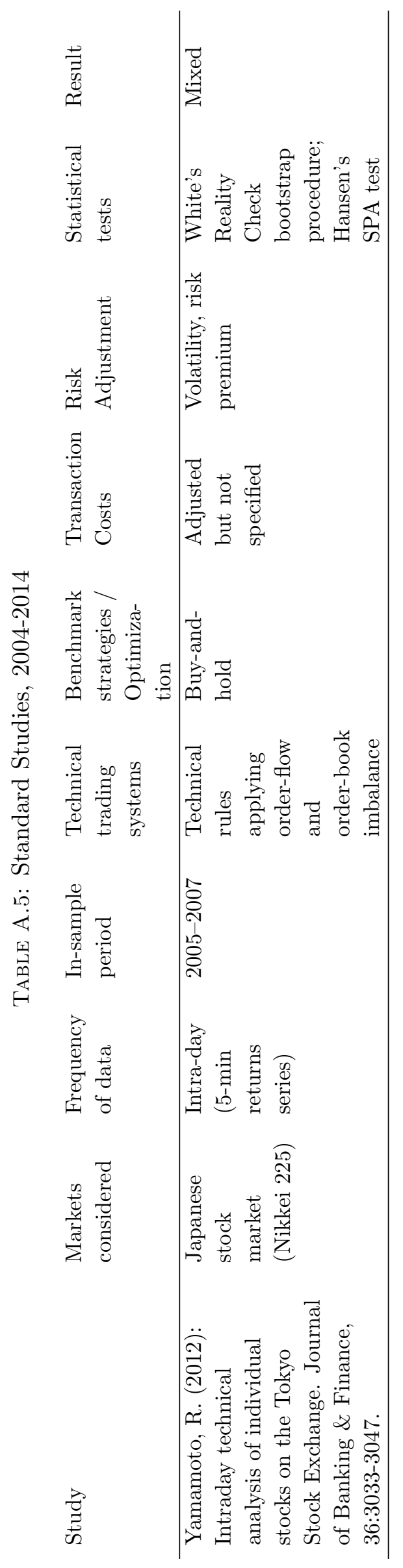




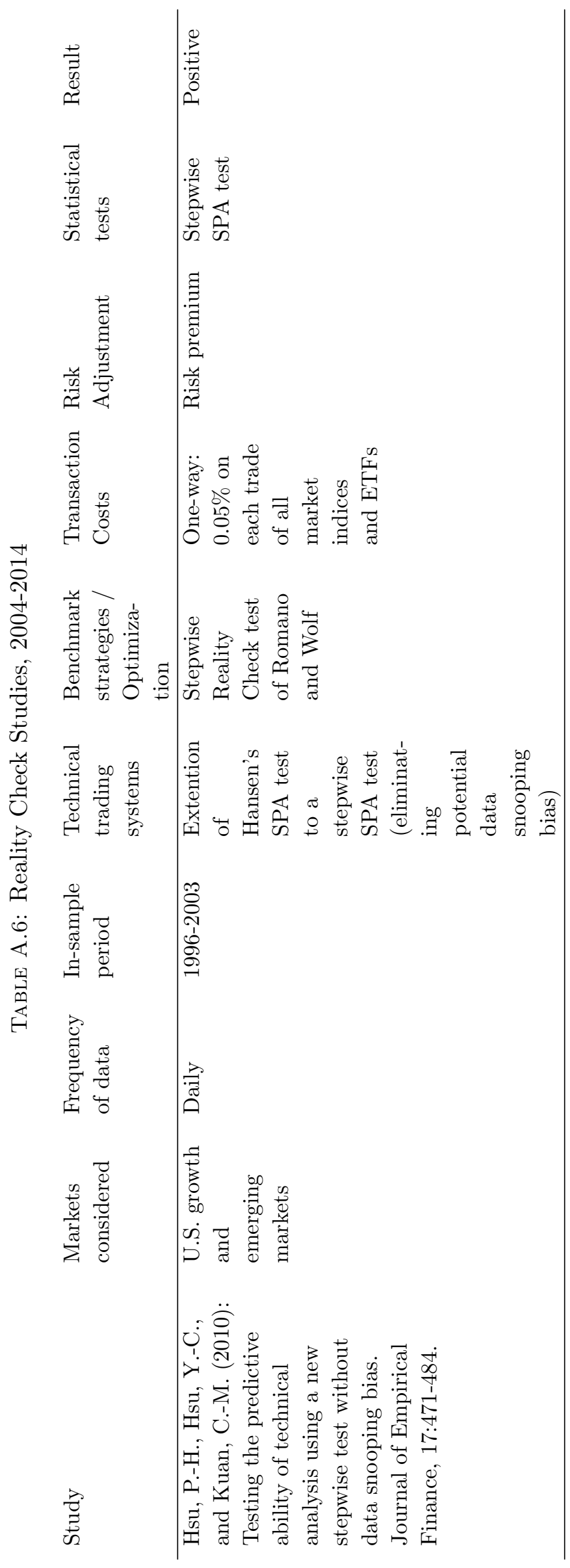




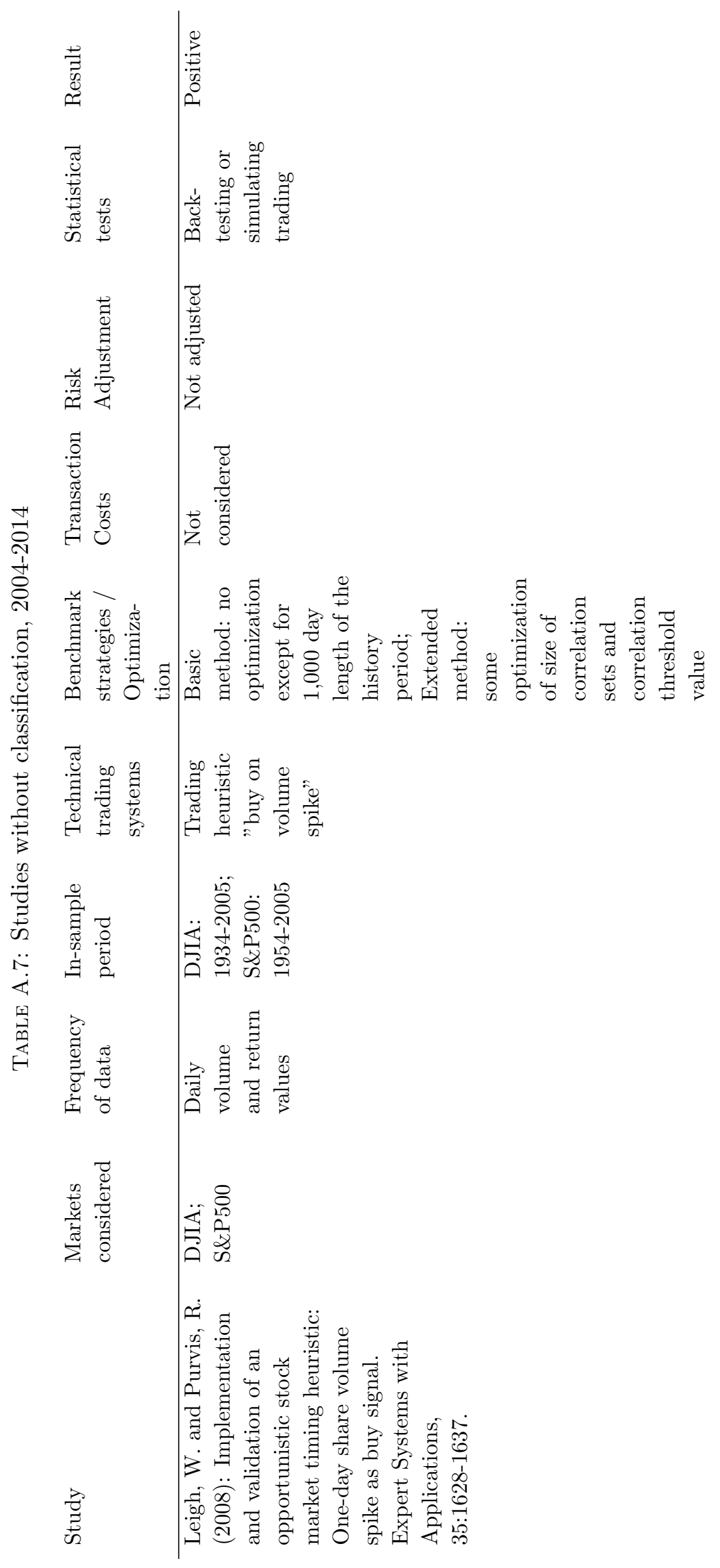




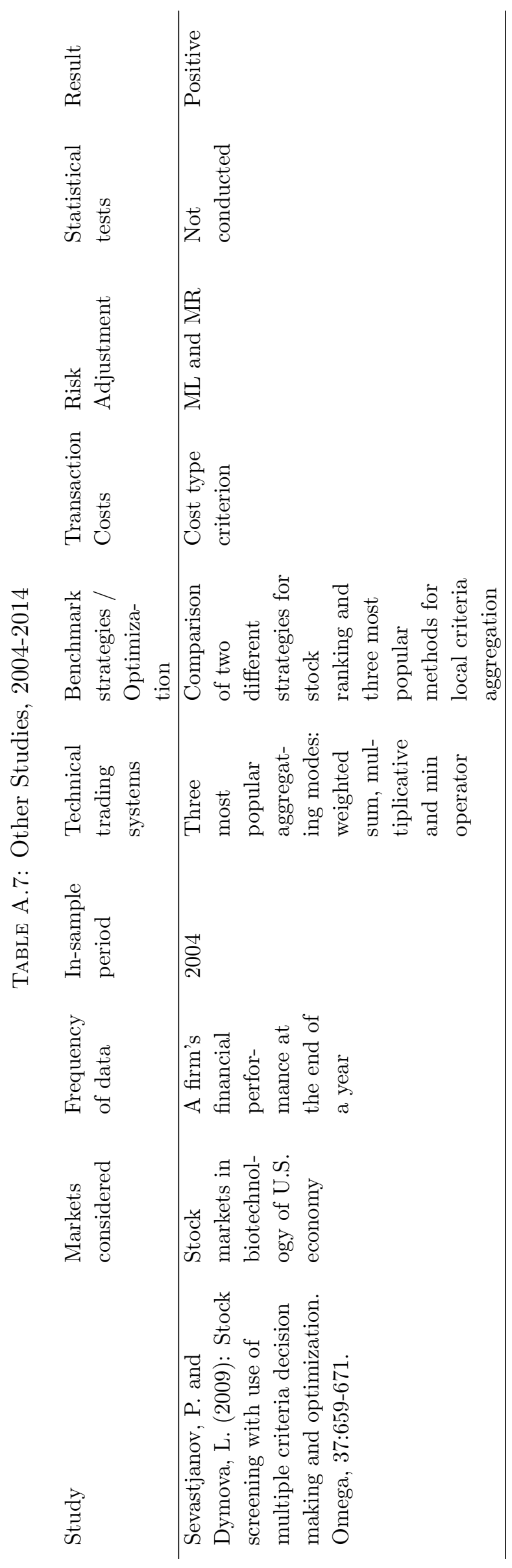


Appendix B

Market anomaly studies 


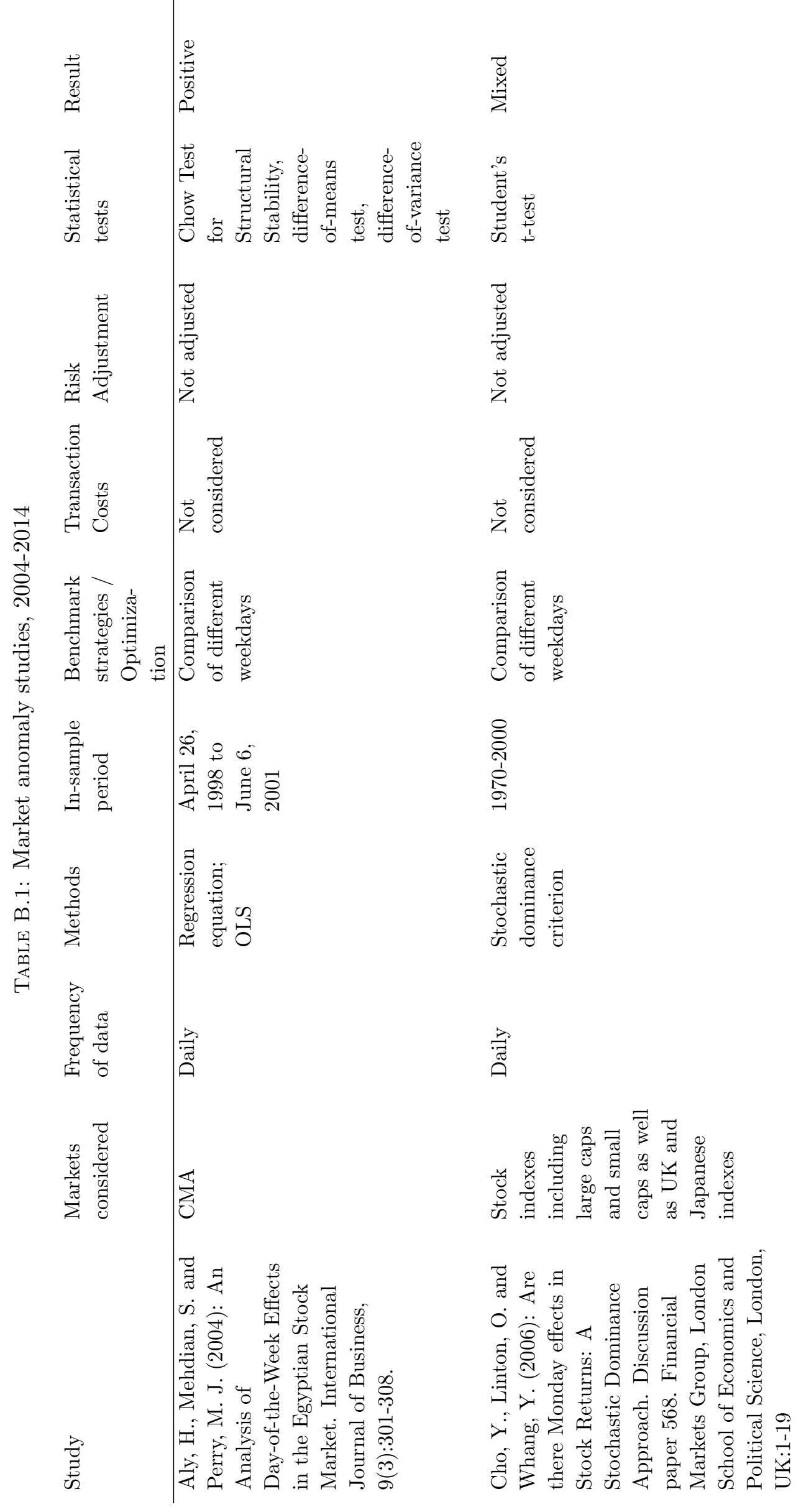




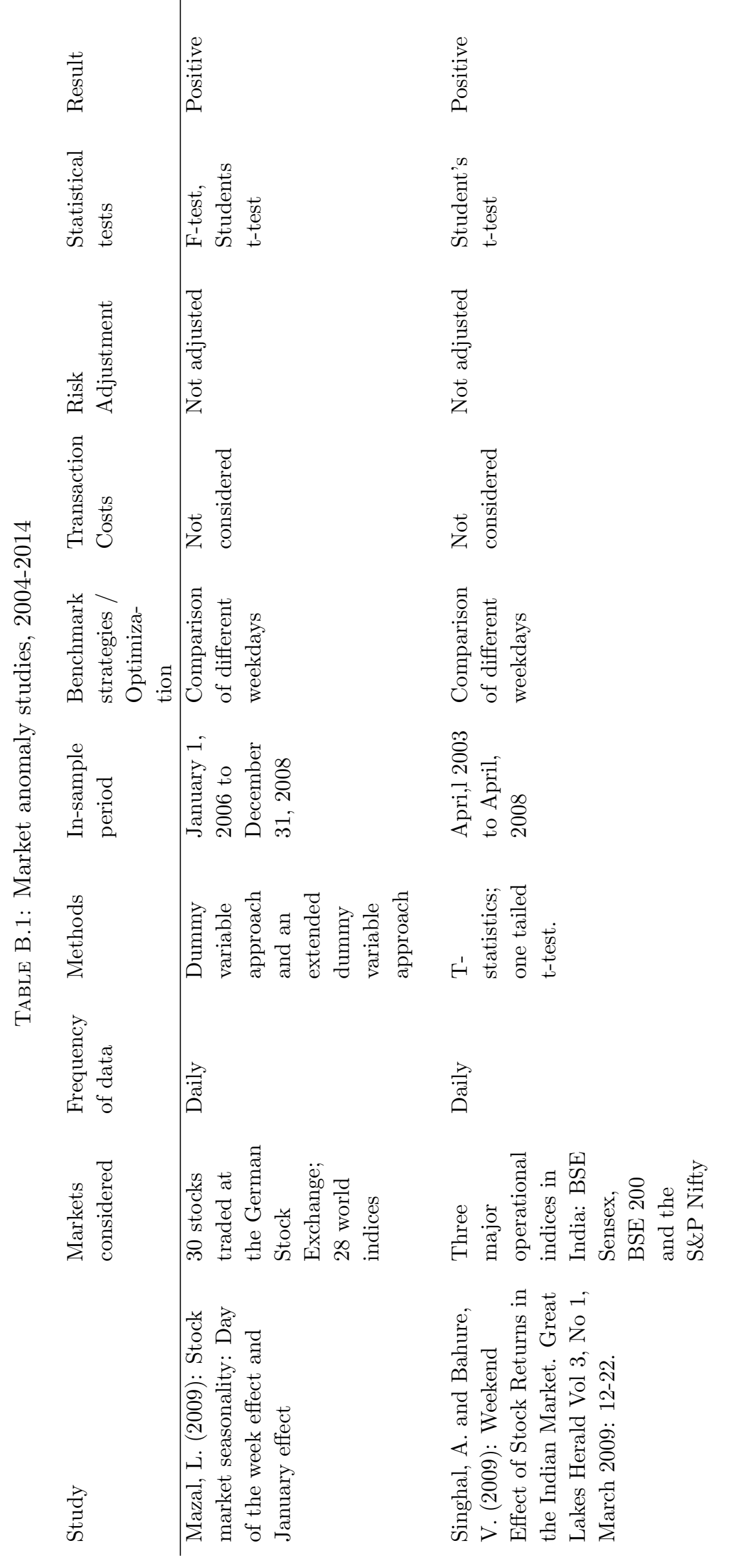




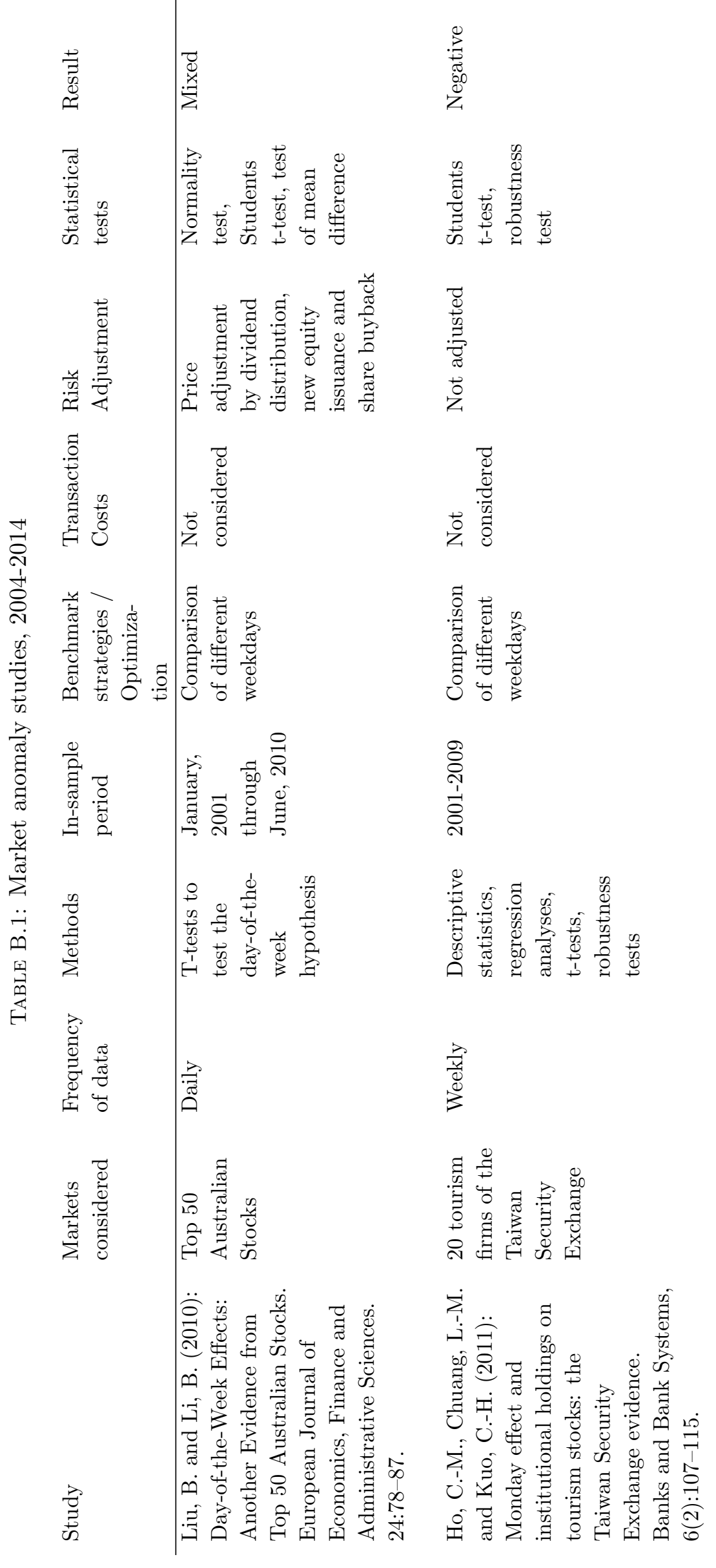




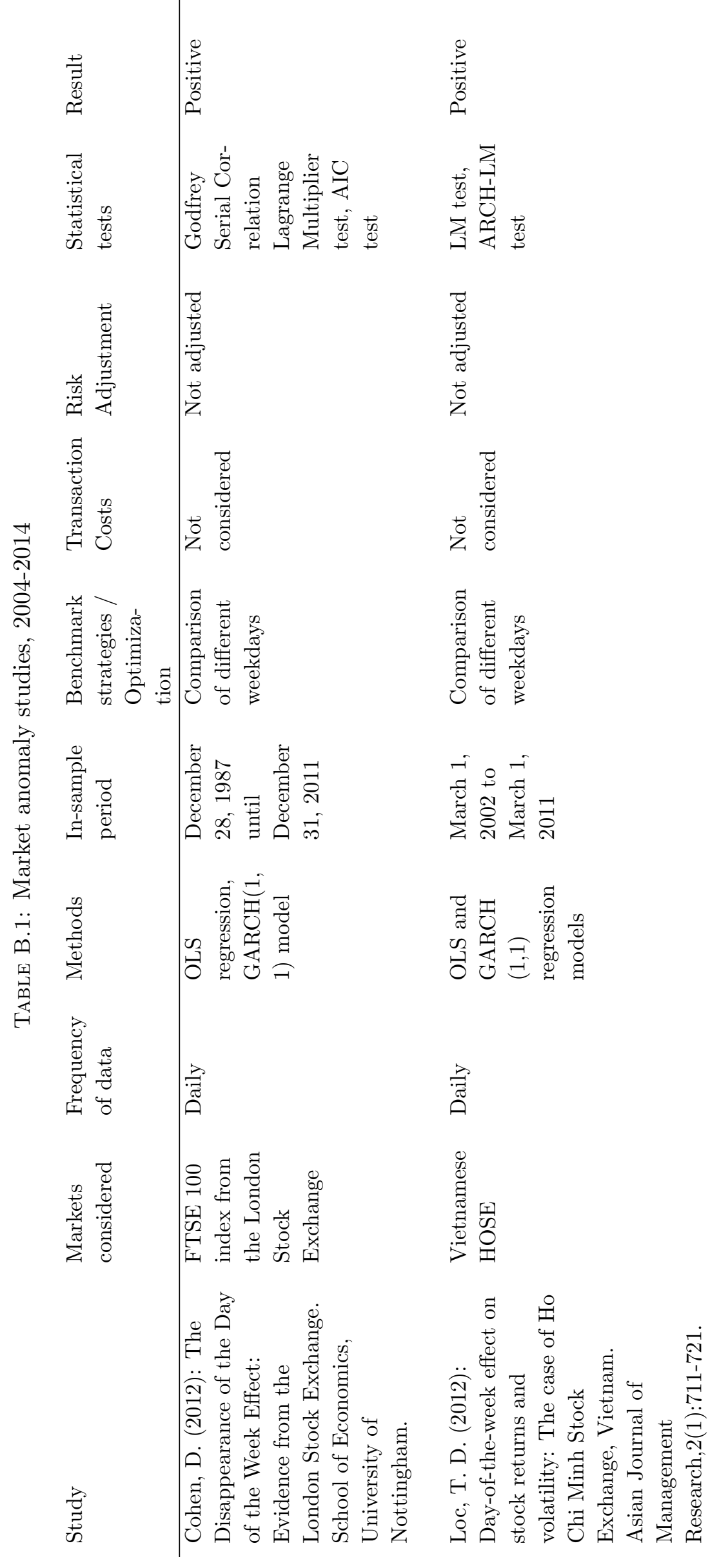




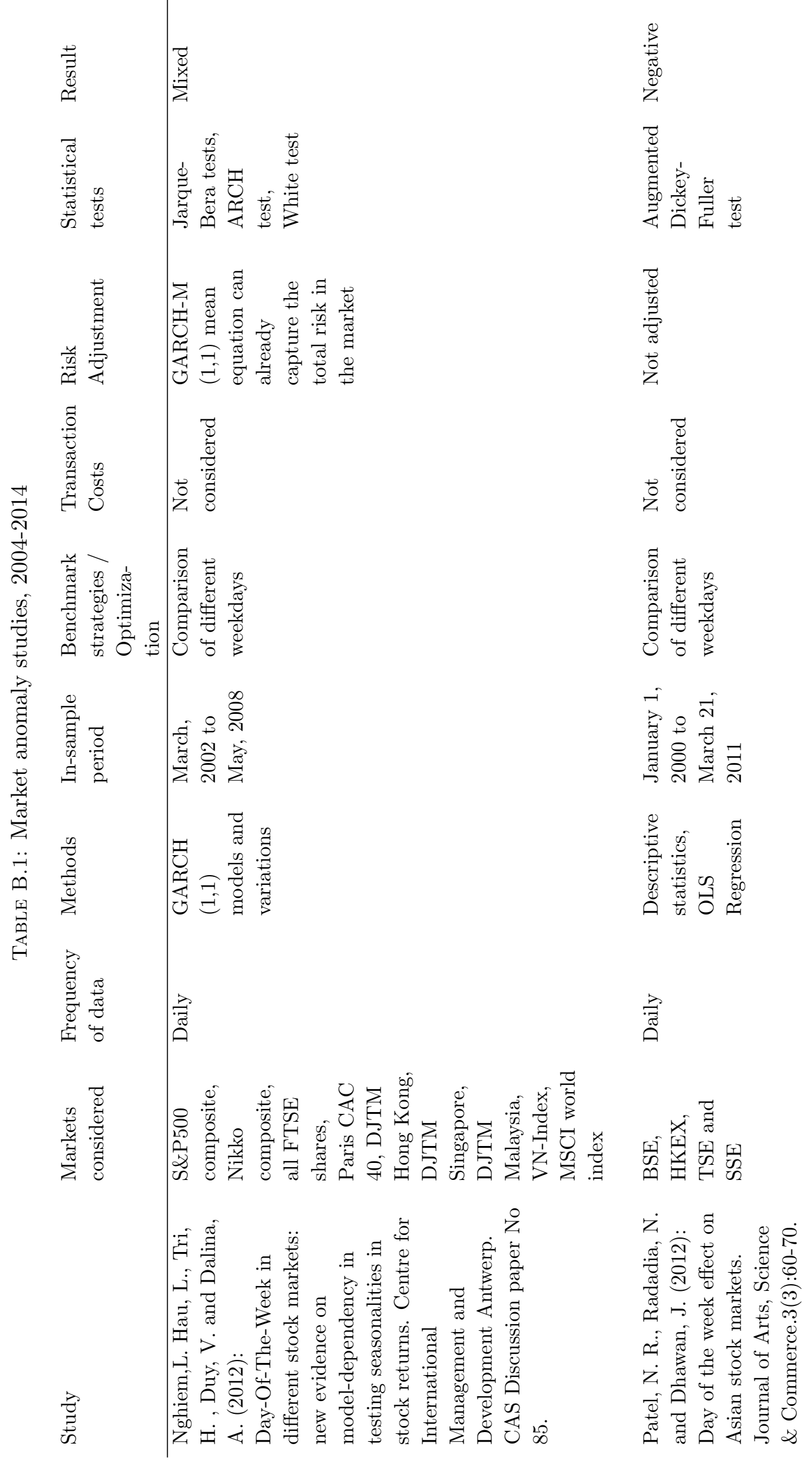




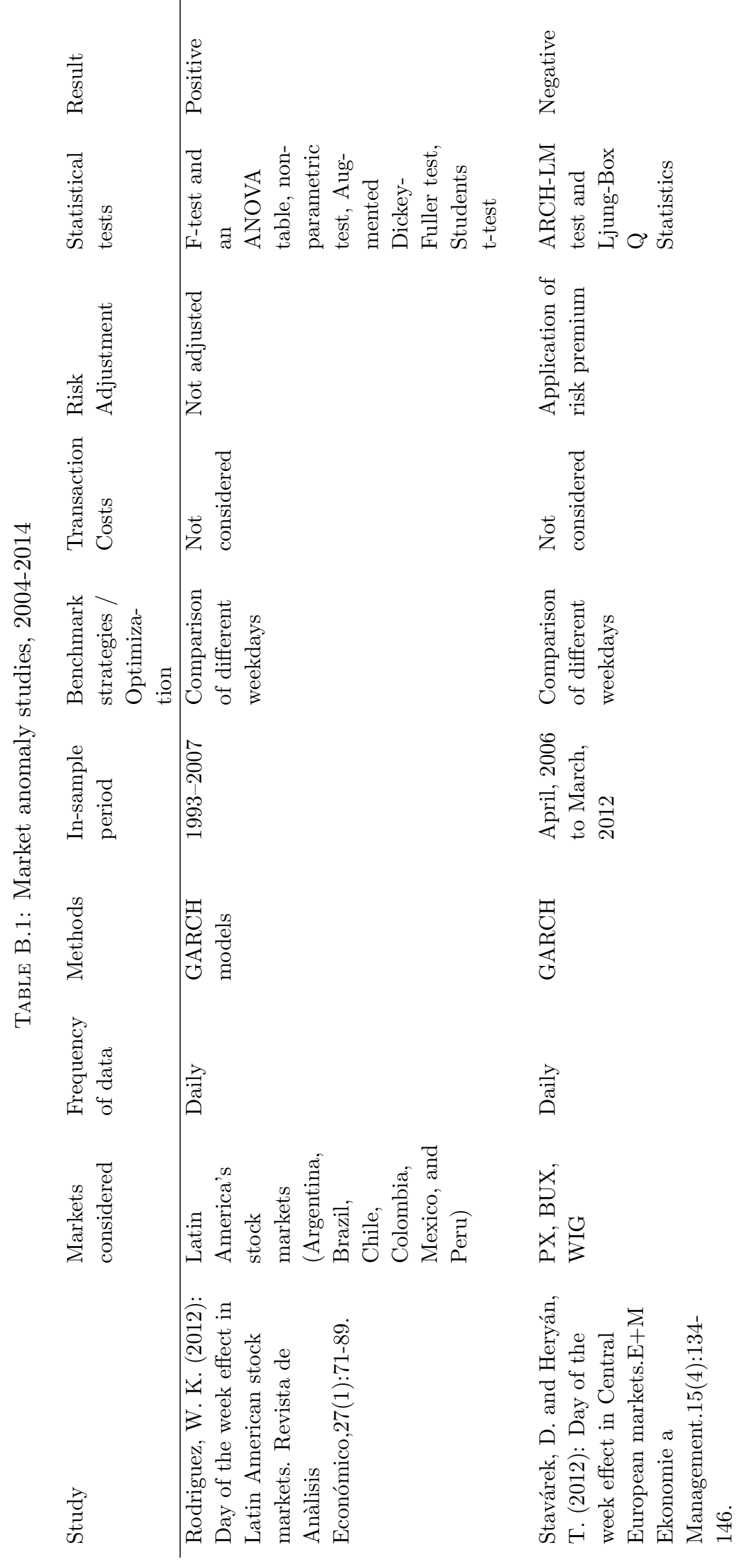




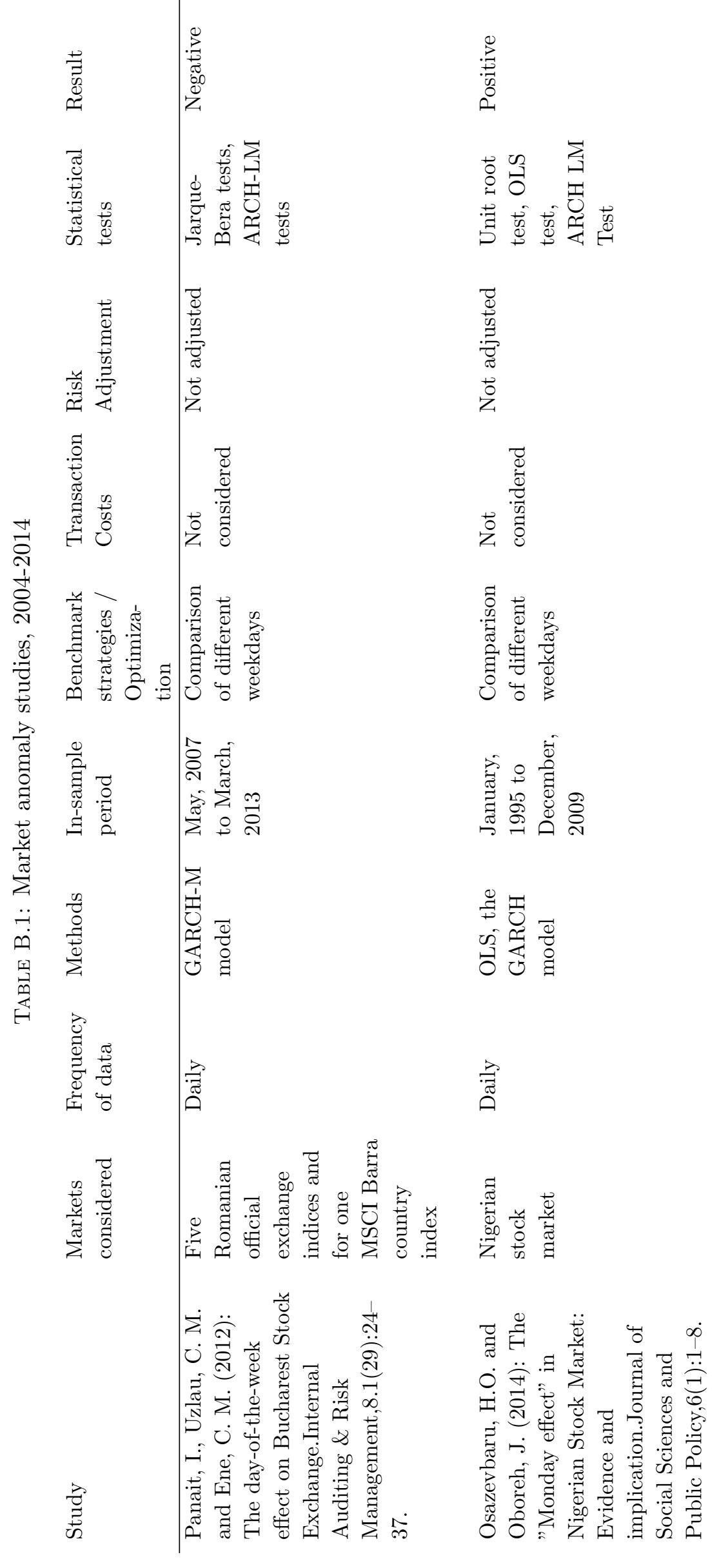




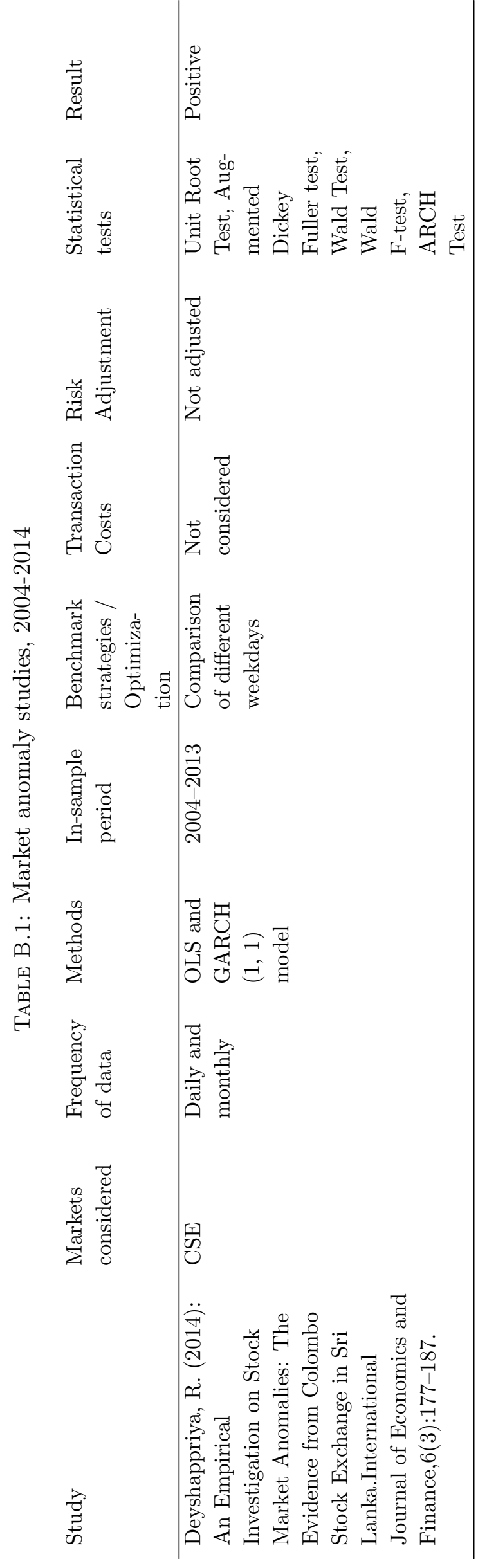




\section{Bibliography}

\section{Literature}

Acar, E. and Satchell, S. (2002). Advanced Trading Rules. Elsevier Science, 2 edition. Alexander, S. (1964). Price movements in speculative markets: Trends or random walks. Industrial Management Review, 2(5):7-26.

Aly, H., Mehdian, S., and Perry, M. J. (2004). An Analysis of Day-of-the-Week Effects in the Egyptian Stock Market. International Journal of Business, 3(9):301-308.

Ang, A., Goetzmann, W. N., and Schaefer, S. M. (2011). The Efficient Market Theory and Evidence: Implications for Active Investment Management. now.

Bachelier, L. (1990). Théorie de la spéculation. Annales scientifiques de l.N.S., $3(17): 21-86$.

Bajgrowicz, P. and Scaillet, O. (2012). Technical trading revisited: False discoveries, persistence tests, and transaction costs. Journal of Financial Economics, 106(3):473491.

Baker, H. K. and Ricciardi, V. (2014). Investor Behavior: The Psychology of Financial Planning and Investing. John Wiley \& Sons.

Barak, S., Dahooie, J. H., and Tichý, T. (2015). Wrapper ANFIS-ICA method to do stock market timing and feature selection on the basis of Japanese Candlestick. Expert Systems with Applications, 42(23):9221-9235.

Blume, L., Easley, D., and O'Hara, M. (1994). Market Statistics and Technical Analysis: The Role of Volume. Journal of Finance, 49(1):153-181.

Bollinger, J. (2002). Bollinger on Bollinger Bands. New York: McGraw Hill. 
Brock, W., Lakonishok, J., and LeBaron, B. (1992). Technical Trading Rules and the Stochastic Properties of Stock Returns. Journal of Finance, 47(5):1731-1764.

Bulkowski, T. N. (2011). Encyclopedia of Chart Patterns. John Wiley \& Sons, 2 edition.

Bulkowski, T. N. (2013). Fundamental Analysis and Position Trading: Evolution of a Trader. John Wiley \& Sons.

Bulkowski, T. N. (2014). Getting Started in Chart Patterns. John Wiley \& Sons.

Caginalp, G. and Laurent, H. (1998). The Predictive Power of Price Patterns. Applied Mathematical Finance, 5:181-206.

Carver, R. (2015). Systematic Trading: A unique new method for designing trading and investing systems. Harriman House Limited.

Chandra, P. (2008). Investment Analysis and Portfolio Management. Tata McGrawHill, 3 edition.

Chang, K. and Osler, C. (1999). Methodical madness: Technical analysis and the irrationality of exchange-rate forecasts. The Economic Journal, 109:636-661.

Charlebois, M. and Sapp, S. (2007). Temporal Patterns in Foreign Exchange Returns and Options. Journal of Money, Credit and Banking, 39(2-3):443-470.

Cheung, Y.-W. and Chinn, M. D. (2001). Currency Traders and Exchange Rate Dynamics: A Survey of the US Market. Journal of International Money and Finance, 20:439-471.

Cho, Y.-H., Linton, O., and Whang, Y.-J. (2006). Are there Monday effects in Stock Returns: A Stochastic Dominance Approach. Discussion paper. Financial Markets Group, London School of Economics and Political Science, London, UK., (568):1-19.

Chourmouziadis, K. and Chatzoglou, P. D. (2016). An intelligent short term stock trading fuzzy system for assisting investors in portfolio management. Expert Systems with Applications, 43:298-311.

Cohen, D. (2012). The Disappearance of the Day of the Week Effect: Evidence from the London Stock Exchange. Master's thesis, School of Economics, University of Nottingham.

Cohen, J. (1988). Statistical Power Analysis for the Behavioral Sciences. Lawrence Erlbaum Associates. 
Copur, Z. (2015). Handbook of Research on Behavioral Finance and Investment Strategies: Decision Making in the Financial Industry. IGI Global.

Daeubner, P. M. (2005). Alles was Sie über Technische Analyse wissen müssen. FinanzBuch Verlag.

Davidson, A. (2011). How to Win as a Stock Market Speculator. Kogan Page Publishers.

Deyshappriya, R. (2014). An Empirical Investigation on Stock Market Anomalies: The Evidence from Colombo Stock Exchange in Sri Lanka. International Journal of Economics and Finance, 6(3):177-187.

Dooley, M. P. and Shafer, J. R. (1983). Analysis of Short-Run Exchange Rate Behavior: March 1973 to November 1981. In Exchange Rate and Trade Instability: Causes, Consequences, and Remedies. Edited by D. Bigman and T. Taya. Cambridge, MA: Ballinger., pages 43-72.

Dormeier, B. (2011). The History of Technical Analysis. Pearson Education.

Downes, J. and Goodman, J. (1998). Dictionary of finance and investment terms. New York: Barrons Educational Series, Inc., 5.

Drake, P. P. and Fabozzi, F. J. (2012). Analysis of Financial Statements. John Wiley \& Sons.

Edwards, R. D., Magee, J., and Bassetti, W. (2012). Technical Analysis of Stock Trends. CRC Press, 10 edition.

Elder, A. (2002). Come Into My Trading Room: A Complete Guide to Trading. New York: John Wiley \& Sons Inc.

Esmalifalak, H., Ajirlou, A. I., Behrouz, S. P., and Esmalifalak, M. (2015). (Dis)integration levels across global stock markets: A multidimensional scaling and cluster analysis. Expert Systems with Applications, 42(22).

Fama, E. (1970). Efficient capital markets: a review of theory and empirical work. Journal of Finance, 25:383-417.

Fama, E. F. and Blume, M. E. (1966). Filter rules and stock market trading. Journal of Business, 39:226-241.

Fischer, R. and Fischer, J. (2003). Candlesticks, Fibonacci, and Chart Pattern Trading Tools: A Synergistic Strategy to Enhance Profits and Reduce Risk. John Wiley \& Sons. 
Fontanills, G. A. and Gentile, T. (2002). The Stock Market Course. John Wiley \& Sons.

Furgang, K. (2010). How the Stock Market Works. The Rosen Publishing Group.

Gandrud, C. (2015). Reproducible Research with $R$ and $R$ Studio. CRC Press, 2 edition.

Genay, R. (1998). The predictability of security returns with simple technical trading rules. Journal of Empirical Finance, 5:347-359.

Goodmann, S. (1979). Foreign exchange rate forecasting techniques: implications for business and policy. Journal of Finance, 34(2):415-427.

Groffig, T. (2001). Technische Analyse und ihre Auswirkungen auf Aktienkurse. Diplomica Verlag.

Hafer, R. W. and Hein, S. E. (2007). The Stock Market. Greenwood Publishing Group. Hansen, P. R. (2005). A test for superior predictive ability. Journal of Business and Economic Statistics, 23:365-380.

Harding, G. (2014). Efficient Market Hypothesis 35 Success Secrets - 35 Most Asked Questions On Efficient Market Hypothesis - What You Need To Know. Emereo Publishing.

Heese, V. and Riedel, C. (2015). Fundamentalanalyse versus Chartanalyse: Methoden der Aktienbewertung im Vergleich. Springer-Verlag.

Ho, C.-M., Chuang, L.-M., and Kuo, C.-H. (2011). Monday effect and institutional holdings on tourism stocks: the Taiwan Security Exchange evidence. Banks and Bank Systems, 6(2):107-115.

Holtfort, T. (2013). Moderne Finanzanalyse: Von der Fundamentalanalyse zur Biofinance. BoD Books on Demand.

Horton, M. J. (2009). Stars, crows, and doji: The use of candlesticks in stock selection. The Quarterly Review of Economics and Finance, 49:283-294.

Hsu, P.-H., Hsu, Y.-C., and Kuan, C.-M. (2010). Testing the predictive ability of technical analysis using a new stepwise test without data snooping bias. Journal of Empirical Finance, 17:471-484.

Jain, A. K., Duin, R. P., and Mao, J. (2000). Statistical Pattern Recognition: A Review. IEEE Transactions on pattern analysis and machine intelligence, 22(1):4-37. 
Jain, S., Munos, R., Stephan, F., and Zeugmann, T., editors (2013). Algorithmic Learning Theory, number 24th International Conference, Singapore. Springer-Verlag Berlin Heidelberg.

Jankovsky, J. A. (2011). Trading Rules that Work. John Wiley \& Sons.

Jasemi, M., Kimiagari, A. M., and Memariani, A. (2011). A modern neural network model to do stock market timing on the basis of the ancient investment technique of Japanese Candlestick. Expert Systems with Applications, 38:3884-3890.

Jensen, M. (1978). Some anomalous evidence regarding market efficiency. Journal of Financial Economics, 6:95-101.

Jensen, M. C. (1967). Random Walks: Reality or Myth - Comment. Financial Analysts Journal, 23:77-85.

Jiler, W. L. (2003). How Charts Can Help You in the Stock Market. McGraw Hill Professional.

Jobmann, D. (2008). Die ganze Welt der Technischen Analyse: Erfolgreich mit Indikatoren, Charts $\&$ Co. FinanzBuch Verlag.

Kamich, B. M. (2009). Chart Patterns. Bloomberg Press New York, 1 edition.

Kamo, T. and Dagli, C. (2009). Hybrid approach to the Japanese candlestick method for financial forecasting. Expert Systems with Applications, 36:5023-5030.

Kaufman, P. J. (2013). Trading Systems and Methods. John Wiley \& Sons.

Kendall, M. G. and Hill, A. B. (1953). The Analysis of Economic Time-Series-Part I: Prices. Journal of the Royal Statistical Society, 116(1):11-34.

Kidd, W. V. and Brorsen, B. W. (2004). Why have the returns to technical analysis decreased? Journal of Economics and Business, 56:159-176.

Kim, K. and Han, I. (2001). The extraction of trading rules from stock market data using rough sets. Expert Systems, 18(4):194-202.

Knight, T. (2011). High-Probability Trade Setups: A Chartist's Guide to Real-Time Trading. John Wiley \& Sons.

Koza, J. R. (1992). Genetic Programming: On the Programming of Computers by Means of Natural Selection. Cambridge, MA: MIT Press.

Kurth, S. (2011). Critical Review about Implications of the Efficient Market Hypothesis. GRIN Verlag, 1 edition. 
Lam, M. (2004). Neural network techniques for financial performance prediction: integrating fundamental and technical analysis. Decision Support Systems, 37:567581.

Lawrence, R. (1997). Using Neural Networks to Forecast Stock Market Prices. Technical report, Department of Computer Science, University of Manitoba, Manitoba, Canada.

Lee, A. C., Lee, J. C., and Lee, C. F. (2009). Financial Analysis, Planning \& Forecasting: Theory and Application. John Wiley \& Sons, 2 edition.

Lee, K. and Jo, G. (1999). Expert system for predicting stock market timing using a candlestick chart. Expert Systems with Applications, 16:357-364.

Lee, S. J., Oh, K. J., and Kim, T. Y. (2012). How many reference patterns can improve profitability for real-time trading in futures market? Expert Systems with Applications, 39:7458-7470.

Leigh, W., Frohlich, C. J., Hornik, S., Purvis, R. L., and Roberts, T. L. (2008). Trading With a Stock Chart Heuristic. IEEE transactions on systems, man, and cybernetics Part A: Systems and humans, 38:93-104.

Leigh, W., Modani, N., and Hightowera, R. (2004). A computational implementation of stock charting: abrupt volume increase as signal for movement in New York Stock Exchange Composite Index. Decision Support Systems, 37:515-530.

Leigh, W., Modani, N., Purvis, R., and Roberts, T. (2002a). Stock market trading rule discovery using technical charting heuristics. Expert Systems with Applications, $23: 155-159$.

Leigh, W., Paz, N., and Purvis, R. (2002b). Market timing: a test of a charting heuristic. Economic Letters, 77:55-63.

Leigh, W. and Purvis, R. (2008). Implementation and validation of an opportunistic stock market timing heuristic: One-day share volume spike as buy signal. Expert Systems with Applications, 35:1628-1637.

Leigh, W., Purvis, R., and Ragusa, J. M. (2002c). Forecasting the NYSE composite index with technical analysis, pattern recognizer, neural network, and genetic algorithm: a case study in romantic decision support. Decision Support Systems, 32:361-377.

Levy, R. A. (1971). The predictive significance of five-point chart patterns. Journal of Business, 44:316-323. 
Liu, B. and Li, B. (2010). Day-of-the-Week Effects: Another Evidence from Top 50 Australian Stocks. European Journal of Economics, Finance and Administrative Sciences, (24):78-87.

Lo, A. W., Mamaysky, H., and Wang, J. (2000). Foundations of Technical Analysis: Computational Algorithms, Statistical Inference, and Empirical Implementation. Journal of Finance, LV(4):1705-1765.

Loc, T. D. (2012). Day-of-the-week effect on stock returns and volatility: The case of Ho Chi Minh Stock Exchange, Vietnam. Asian Journal of Management Research, $2(1): 711$.

Lu, C.-J., Lee, T.-S., and Chiu, C.-C. (2009). Financial time series forecasting using independent component analysis and support vector regression. Decision Support Systems, 47:115-125.

Lui, Y.-H. and Mole, D. (1998). The Use of Fundamental and Technical Analyses by Foreign Exchange Dealers: Hong Kong Evidence. Journal of International Money and Finance, 47:535-545.

Marshall, B. R., Cahan, R. H., and Cahan, J. M. (2008). Does intraday technical analysis in the U.S. equity market have value? Journal of Empirical Finance, 15:199210 .

Marshall, B. R., Young, M. R., and Rose, L. C. (2006). Candlestick technical trading strategies: Can they create value for investors? Journal of Banking $\mathcal{G}$ Finance, 30:2303-2323.

Martínez, F. G., Royo, R. E. C., and Michniuk, K. (2014). Estrategia de inversión bursátil y reconocimiento gráfico de patrones: aplicación sobre datos intradía del índice Dow Jones. Cuadernos de Administración, 27(48):119-152.

Martínez, F. G., Royo, R. E. C., and Michniuk, K. (2015). Stock market trading rule based on pattern recognition and technical analysis: Forecasting the DJIA index with intraday data. Expert Systems with Applications, 42(14):5963-5975.

Mazal, L. (2009). Stock market seasonality: Day of the week effect and January effect. Master's thesis, Universidad del Pas Vasco/Euskal Herriko Unibertsitatea.

McNeel, R. W. (2005). Beating the Stock Market. Cosimo Inc.

Menkhoff, L. and Schlumberger, M. (1995). Persisitent Profitability of Technical Analysis on Foreign Exchange markets. BNL Quarterly Review, 193:189-215. 
Miller, F. P., Vandome, A. F., and McBrewster, J. (2009). Efficient-Market Hypothesis. Alphascript Publishing.

Molzahn, W. (2012). Charttechnik - Die "Technische Analyse" für Otto - Normalaktionär. Verlag Wolfgang Molzahn e. K.

Murphy, J. J. (1999). Technische Analyse der Finanzmärkte: Grundlagen, Strategien, Methoden. FinanzBuchVerlag.

Nghiem, L. T., Hau, L. L., Tri, H. M., Duy, V. Q., and Dalina, A. (2012). Day-OfThe-Week in different stock markets: new evidence on model-dependency in testing seasonalities in stock returns. Centre for International Management and Development Antwerp, CAS Discussion paper No 85.

Nguyen, T. H., Shirai, K., and Velcin, J. (2015). Sentiment analysis on social media for stock movement prediction. Expert Systems with Applications, 42(24):9603-9611.

Nison, S. (1991). Japanese Candlestick Charting Techniques. New York Institute of Finance, New York.

Nison, S. (2015). Technische Analyse mit Candlesticks: Alle wichtigen Formationen und ihr Praxiseinsatz. FinanzBuch Verlag.

North, C. and Caes, C. J. (2011). The Stock Market. The Rosen Publishing Group.

Osazevbaru, H. and Oboreh, J. (2014). The "Monday effect" in Nigerian stock market: Evidence and implication. Journal of Social Sciences and Public Policy, 6(1):1-8.

Panait, I., Uzlau, C. M., and Ene, C. M. (2013). The day-of-the-week effect on Bucharest Stock Exchange. Internal Auditing \& Risk Management, 8(1(29)):24-37.

Park, C.-H. and Irwin, S. H. (2004). The Profitability of Technical Analysis: A Review. Technical report, AgMAS Project Research Report.

Park, C.-H. and Irwin, S. H. (2007). What do we know about the profitability of Technical Analysis? Journal of Economic Surveys, 21(4):786-826.

Patel, N. R., Radadia, N., and Dhawan, J. (2012). Day of the week effect on Asian stock markets. Journal of Arts, Science \& Commerce, 3(3):60-70.

Peters, E. E. (1994). Fractal Market Analysis: Applying Chaos Theory to Investment and Economics. John Wiley \& Sons, 3 edition.

Priermeier, T. (2006). Fundamentale Analyse in der Praxis: Kennzahlen, Strategien, Praxisbeispiele. FinanzBuch Verlag. 
Pring, M. J. (2002). Technical Analysis Explained. New York: McGraw-Hill.

Productive Publications, editor (2012). Stock Market Investing for Beginners: How to Increase Your Wealth in Uncertain Times.

Rehkugler, H. and Poddig, T. (1994). Kurzfristige Wechselkursprognosen mit knstlichen Neuronalen Netzwerken. In Finanzmarktanwendungen neuronaler Netze und konometrischer Verfahren, pages 1-24.

Reilly, F. and Brown, K. (2011). Investment Analysis and Portfolio Management. Cengage Learning.

Robbins, R. (2012). Tactical Trend Trading: Strategies for Surviving and Thriving in Turbulent Markets. Apress.

Rodriguez, W. K. (2012). Day of the week effect in Latin American stock markets. Revista de Anàlisis Económico, 27(1):71-89.

Romano, J. P. and Wolf, M. (2005). Stepwise multiple testing as formalized data snooping. Econometrica, 73:1237-1282.

Ruppert, D. (2013). Klassische Börsenstrategien im Test: Erfolg durch individuelle Anpassung. Diplomica Verlag.

Samuelson, P. (1965). Proof That Properly Anticipated Prices Fluctuate Randomly. Industrial Management Review, 6:41-49.

Schabacker, R. (2005). Technical Analysis and Stock Market Profits. Harriman House Limited.

Scholl, R. (2014). Point \& Figure: Traden mit der zeitlosen Charttechnik. FinanzBuch Verlag.

Schulmeister, S. (1987). An Essay on Exchange Rate Dynamics. Wissenschaftszentrum Berlin für Sozialforschung, Berlin., (IIM/LMP 87-8).

Schulz, L. (2013). Vergleich von Fundamentalanalyse und technischer Analyse im Rahmen der Aktienkursprognose. Diplomica Verlag.

Schwager, J. D. (2013). Schwager über Technische Analyse. FinanzBuch Verlag.

Sevastjanov, P. and Dymova, L. (2009). Stock screening with use of multiple criteria decision making and optimization. Omega, 37:659-671.

Shim, J. K. and Siegel, J. G. (2007). Handbook of Financial Analysis, Forecasting, and Modeling. CCH, 3 edition. 
Shynkevich, A. (2012a). Global industry portfolios and short-term predictability of returns: Is it there? Journal of Financial Markets, 15:438-466.

Shynkevich, A. (2012b). Performance of technical analysis in growth and small cap segments of the US equity market. Journal of Banking \& Finance, 36:193-208.

Shynkevich, A. (2012c). Short-term predictability of equity returns along two style dimensions. Journal of Empirical Finance, 19:675-685.

Singhal, A. and Bahure, V. (2009). Weekend Effect of Stock Returns in the Indian Market. Great Lakes Herald, 3(1):12-22.

Snezhko, Y. S. (2015). The use of technical analysis indicators in the Russian stock market. Russian Journal of Entrepreneurship, 16(16):2682-2696.

Stavárek, D. and Heryán, T. (2012). Day of the week effect in Central European markets. E+M Ekonomie a Management, 15(4):134-146.

Sullivan, R., Timmermann, A., and White, H. (1999). Data Snooping, Technical Trading Rule Performance and the Bootstrap. Journal of Finance, 54(5):1647-1691.

Sweeney, R. J. (1986). Beating the Foreign Exchange Market. Journal of Finance, 41(1):163-182.

Tarr, I. (2014). Stock Market Trading for Beginners. Author House.

Taylor, M. P. and Allen, H. L. (1992). The Use of Technical Analysis in the Foreign Exchange Market. Journal of International Money and Finance, 11:304-314.

Taylor, S. J. (1986). Modelling Financial Time Series. John Wiley \& Sons, Chichester, England.

Teixeira, L. and de Oliveira, A. (2010). A method for automatic stock trading combining technical analysis and nearest neighbor classification. Expert Systems with Applications, 37(10):6885-6890.

Timmermann, A. and Granger, C. (2004). Efficient market hypothesis and forecasting. International Journal of Forecasting, 20(1):15-27.

Wang, J.-L. and Chan, S.-H. (2007). Stock market trading rule discovery using pattern recognition and technical analysis. Expert Systems with Applications, 33:304-315.

Wang, J.-L. and Chan, S.-H. (2009). Trading rule discovery in the US stock market: An empirical study. Expert Systems with Applications, 36:5450-5455.

Yamamoto, R. (2012). Intraday technical analysis of individual stocks on the Tokyo Stock Exchange. Journal of Banking \& Finance, 36:3033-3047. 
Yang, J., Cabrera, J., and Wang, T. (2010). Nonlinearity, data-snooping, and stock index ETF return predictability. European Journal of Operational Research, 200:498507.

Zapranis, A. and Tsinaslanidis, P. E. (2012). A novel, rule-based technical pattern identification mechanism: Identifying and evaluating saucers and resistant levels in the US stock market. Expert Systems with Applications, 39:6301-6308.

Zuravicky, O. (2005). The Stock Market: Understanding and Applying Ratios, Decimals, Fractions, and Percentages. The Rosen Publishing Group.

\section{Internet}

Auswärtiges Amt (2015a). http://www.auswaertiges-amt.de/DE/Aussenpolitik/ Laender/Laenderinfos/01-Laender/Spanien.html.

Date of access: June 10, 2015.

Auswärtiges Amt (2015b). http://www. auswaertiges-amt.de/DE/Aussenpolitik/ Laender/Laenderinfos/01-Nodes_Uebersichtsseiten/Deutschland_node.html.

Date of access: June 10, 2015.

Auswärtiges Amt (2015c). http://www.auswaertiges-amt.de/DE/Aussenpolitik/ Laender/Laenderinfos/01-Nodes_Uebersichtsseiten/UsaVereinigteStaaten_node. html.

Date of access: June 10, 2015.

Börsenlexikon (2015). http://boersenlexikon.faz.net/fundamen.htm.

Date of access: July 13, 2015.

finanzen.net GmbH (2015a). http://www.finanzen.net/index/Dax.

Date of access: May 15, 2015.

finanzen.net GmbH (2015b). http://www.finanzen.net/index/Dow_Jones.

Date of access: May 15, 2015.

finanzen.net GmbH (2015c). http://www.finanzen.net/index/IBEX_35.

Date of access: May 15, 2015.

Lexas Information Network (2015a). http://www.lexas.de/europa/deutschland/ index. aspx.

Date of access: June 9, 2015. 
Lexas Information Network (2015b). http://www. lexas.de/europa/spanien/.

Date of access: June 13, 2015.

Lexas Information Network (2015c). http://www. lexas.de/nordamerika/usa/index . aspx.

Date of access: June 13, 2015.

Statistisches Bundesamt (2015a). https://www.destatis.de/DE/Publikationen/ Thematisch/Internationales/Laenderprofile/USA2015.pdf.

Date of access: June 13, 2015.

Statistisches Bundesamt (2015b). https://www.destatis.de/Europa/DE/Staat/EU Staaten/Spanien.html.

Date of access: June 13, 2015.

Welt-in-Zahlen.de (2015a). http://www.welt-in-zahlen.de/laenderinformation . phtml? country=228.

Date of access: June 9, 2015.

Welt-in-Zahlen.de (2015b). http://www.welt-in-zahlen.de/laenderinformation . phtml? country $=44$.

Date of access: June 9, 2015. 